\title{
Apoptosis and inflammation in experimental ischemia- reperfusion : matters of life and cell death
}

Citation for published version (APA):

Daemen, M. A. R. C. (2001). Apoptosis and inflammation in experimental ischemia-reperfusion : matters of life and cell death. [Doctoral Thesis, Maastricht University]. Universiteit Maastricht. https://doi.org/10.26481/dis.20010511md

Document status and date:

Published: 01/01/2001

DOI:

10.26481/dis.20010511md

Document Version:

Publisher's PDF, also known as Version of record

\section{Please check the document version of this publication:}

- A submitted manuscript is the version of the article upon submission and before peer-review. There can be important differences between the submitted version and the official published version of record.

People interested in the research are advised to contact the author for the final version of the publication, or visit the DOI to the publisher's website.

- The final author version and the galley proof are versions of the publication after peer review.

- The final published version features the final layout of the paper including the volume, issue and page numbers.

Link to publication

\footnotetext{
General rights rights.

- You may freely distribute the URL identifying the publication in the public portal. please follow below link for the End User Agreement:

www.umlib.nl/taverne-license

Take down policy

If you believe that this document breaches copyright please contact us at:

repository@maastrichtuniversity.nl

providing details and we will investigate your claim.
}

Copyright and moral rights for the publications made accessible in the public portal are retained by the authors and/or other copyright owners and it is a condition of accessing publications that users recognise and abide by the legal requirements associated with these

- Users may download and print one copy of any publication from the public portal for the purpose of private study or research.

- You may not further distribute the material or use it for any profit-making activity or commercial gain

If the publication is distributed under the terms of Article $25 \mathrm{fa}$ of the Dutch Copyright Act, indicated by the "Taverne" license above, 


\title{
Apoptosis and inflammation \\ in experimental ischemia-reperfusion
}

\author{
Matters of life and cell death
}





\title{
Apoptosis and inflammation in experimental ischemia-reperfusion
}

\author{
Matters of life and cell death
}

\author{
PROEFSCHRIFT \\ ter verkrijging van de graad van doctor \\ aan de Universiteit Maastricht, \\ op gezag van de Rector Magnificus, \\ Prof. Dr. A.C. Nieuwenhuijzen Kruseman \\ volgens het besluit van het College van Decanen, \\ in het openbaar te verdedigen \\ op 11 mei 2001 om 12.00 uur \\ door \\ Marc Alexander Remon Christian Daemen \\ geboren op 30 april 1973 \\ te Geleen
}




\section{Promotor}

Prof. Dr. W.A. Buurman

\section{Beoordelingscommissie}

Prof. Dr. R.A.M.G. Donckerwolcke (voorzitter)

Prof. Dr. J.W. Cohen Tervaert

Prof. Dr. T.M. van Gulik (Universiteit van Amsterdam)

Prof. Dr. J.P. van Hooff

Prof. Dr. P. Vandenabeele (Universiteit Gent, België)

ISBN: $90-9014763-2$

NUGI: 743

Lay-out: B-Point, Karin Scheele

Druk: FEBOdruk, Enschede

The study presented in this thesis was performed at the Nutrition and Toxicology Research Institute Maastricht (NUTRIM), which participates in the Graduate School VLAG-2 (Food Technology. Agrobiotechnology, Nutrition and Health Sciences).

The financial support for publication of this thesis and activities accessory to defending it from De Nederlandse Nier Stichting, Fujisawa BV, Baxter BV, Novartis BV, Roche BV, Wyeth-Lederle BV, de stichting Dr. Ir. Van der Laar, Carl Zeiss BV, IMTIX-Sangstat BV is gratefully acknowledged. 
Dit proefschrift is opgedragen aan mijn goede vriend Jahzus de Blinkende Morgenster

Een verstrooid iemand die zich op het bevel "Rechtsom!" naar links draait, en dan, terwijl hij naar zijn voorhoofd grijpt, zegt "Ach - Rechtsom" en naar rechts gaat.

Wat is hem ingevallen? Een interpretatie? L. Wittgenstein. Philosophische Untersuchungen, 506 



\section{Contents}

CHAPTER 1 Apoptosis and inflammation in renal reperfusion injury (general introduction)

CHAPTER 2 Involvement of endogenous interleukin-10 and tumor necrosis factor- $\alpha$ in renal ischemia-reperfusion injury

CHAPTER 3 Ischemia-reperfusion induced IFN- $\gamma$ upregulation: involvement of IL-12 and IL-18

CHAPTER 4 Inhibition of apoptosis induced by ischemia-reperfusion prevents inflammation

CHAPTER 5 Functional protection by the acute phase proteins $\alpha \mathrm{l}$-acid glycoprotein and $\alpha 1$-antitrypsin against ischemiareperfusion injury by preventing apoptosis and inflammation: acute phase proteins in ischemia reperfusion

ChAPTER 6 Activated caspase-1 is not a central mediator of inflammation after renal ischemia-reperfusion: role of caspase-1 in renal ischemia

ChaPTER 7 Chemokines are intermediates between apoptosis and inflammation after renal ischemia-reperfusion

CHAPTER 8 Release of heart fatty-acid binding protein from damaged renal cells of the rat: potential as an early marker for mild ischemia-reperfusion injury

CHAPTER 9 Caspase-7 activation and cFLIP depletion during renal ischemia: correlation with the extent of reperfusion injury 
Summary / Samenvatting

Dankwoord

Curriculum Vitae

Publications 


\section{Chapter 1}

Apoptosis and inflammation in renal reperfusion injury (general introduction)

Marc A.R.C. Daemen, Wim A. Buurman 


\section{INTRODUCTION}

Organ injury following ischemia is the result of a complex sequelae of events. Central organ systems including the brain, heart, gut, and kidney are particularly sensitive to ischemic injury, which underlies many clinical diseases. A majority of cardiovascular and cerebrovascular problems are associated with ischemic tissue damage, including myocardial infarction, thrombosis and embolism, angina pectoris, stroke, peripheral vascular disease, cardiac and vascular surgery and cerebral trauma. Ischemia followed by reperfusion $(\mathrm{I} / \mathrm{R})$ has additional cardinal implications in the pathogenesis of trauma, septic and hemorrhagic shock, necrotizing enterocolitis, inflammatory bowel disease as well as organ transplantation and rejection. The early reperfusion phase in most of these clinical conditions is characterized by (often partially reversible) dysfunction of the ischemic organ and general signs of inflammation such as fever, which reflects an inflammatory process at the level of the injured organ.

Various aspects of $\mathrm{I} / \mathrm{R}$ injury have been revealed by clinical studies. For instance, Bittar et al. in 1975 demonstrated the presence of necrosis, glycogen loss and mitochondrial damage in cardiac tissue that was successfully revascularized by coronary artery bypass graft surgery (1). This suggested that the sequence of ischemia followed by reperfusion elicts a response resulting in organ damage considerably in excess of that induced by ischemia alone. Thrombolytic therapy for treatment of acute myocardial infarction was shown to be associated with optimal survival and clinical outcome only if the ischemic period was limited and complete reperfusion was induced (2). Moreover, studies in the field of clinical transplantation revealed that prolonged exposure of donor kidneys to warm ischemia prior to organ procurement increased the incidence of delayed function upon transplantation $(3,4)$.

Despite significant progress based on clinical studies, crucial mechanistic aspects of I/R pathophysiology and innovative concepts for its treatment have arisen from a longstanding tradition of experimental work employing animal models. Already in 1881 Litten described the pathological changes that kidneys of rabbits and dogs undergo when subjected to I/R (5). In this well performed study it is demonstrated that the mode of cell death induced by ischemia alone significantly differs from cell death after ischemia followed by reperfusion. The latter is characterized, among others, by tubular dilatation, development of fibrin depositions and formation of intraluminal debris and necrotic casts. Interestingly, this study additionally outlines a form of $\mathrm{I} / \mathrm{R}$-induced cell death that is morphologically reminiscent of what could be defined as a consequence of apoptosis almost a century later: "While in most of these epithelial cells the nucleus had disappeared, adjacent epithelial cells contained not one nucleus, but smaller nuclear fragments that stained well with common techniques". Israel in 1891 showed that I/R-induced renal injury is accompanied by edema formation, inflammation, detachment of tubuli from their basement membranes and a distinct form of cell shrinkage that affects tubular 
epithelium (6) (Figure 1). Later it was established that renal $\mathrm{L} / \mathrm{R}$ additionally induces impairment of renal function (7), morphological alterations in tubular mitochondria and a decrease in cortical pH (8). More recently in 1981, based on studies employing a model of feline intestinal I/R, Granger et al. reported the involvement of oxygen free radicals (OFR) (9), which were later implicated in the induction of reperfusion-induced inflammation and apoptosis. In this context, there has been persistent interest in the role of the energy metabolism/adenylate homeostasis (10) since dephosphorylation of purine compounds due to ischemia has been shown to induce OFR generation upon reperfusion (11). Moreover, vasoconstrictive or anti-inflammatory properties of the purine metabolite adenosine may co-determine the outcome of an ischemic insult $(12,13)$. Finally, integrity of the energy metabolism is a prerequisite for repair as well as activation of distinct apoptotic pathways (14).
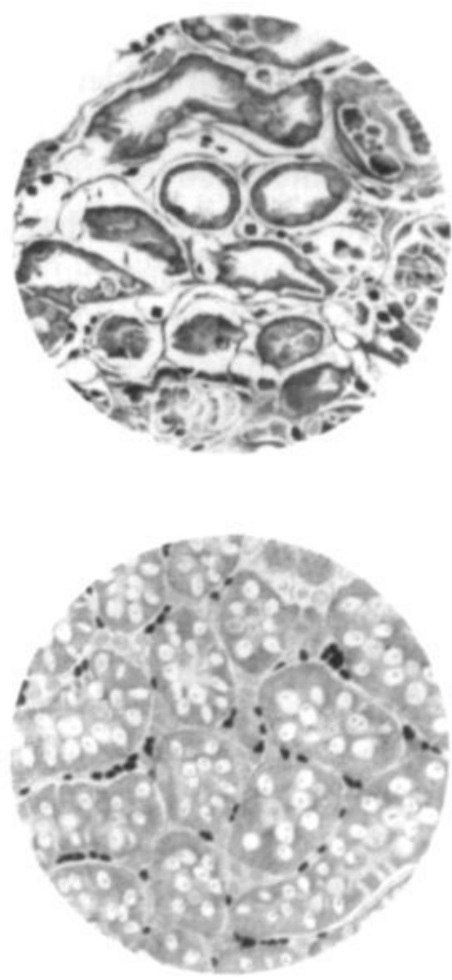

Figure 1. Israel in 1891 showed that I/R-induced renal injury in rabbits is accompanied by edema formation, inflammation, detachment of tubuli from their basement membranes and a distinct form of cell shrinkage that affects tubular epithelium (upper panel). The latter would now be considered characteristic for the apoptotic phenotype. Morphological changes were absent in control sections (lower panel). Lithographs reprinted from O. Israel, Virchows Archives 123, 1891. 
The deleterious role of the inflammatory response in I/R-induced organ damage was suggested in 1983 by Romson et al. who reported that dogs subjected to myocardial I/R and treated with neutrophil antiserum developed smaller infarcts as compared to non-treated controls (15). Subsequent studies showed that I/R enhanced local expression of adhesion molecules and other pro-inflammatory mediators were involved in the initiation of neutrophil chemotaxis and further development of inflammation in the reperfused organ (16, 17). In 1992 Schumer et al. in a rat model of renal $I / R$, studied the mode of cell death that was a consequence of reperfusion (18). They for the first time demonstrated apoptosis as opposed to the widespread necrotic form of cell death discernable after prolonged ischemia without reperfusion. These insights in the role of histopathological alterations, OFR formation, inflammation and apoptosis in $\mathrm{I} / \mathrm{R}$ pathophysiology lead to successful application of new therapies in various animal models $(16,19,20)$. Unfortunately however, the latter advances appeared only sufficient to permit very limited therapeutic testing and application in a clinical setting $(21,22)$.

Recent scientific progress with experimental models has contributed to recognition of a functional role for apoptosis, inflammation and the interplay between apoptosis and inflammation after I/R. It also lead to the discovery of new mediators that are potentially involved in clinical $I / R$ injury. These findings shed new light on issues in $I / R$ pathophysiology that thus far remained unresolved and put forth important opportunities to effectively treat clinical manifestations of I/R injury. Moreover, new diagnostic possibilities emerge from these advances. For instance, apoptotic alterations induced by ischemia may be employed to predict the amount of reperfusion damage upon clinical transplantation of organs subjected to prolonged periods of ischemia, so-called non-heart-beating (NHB) donors (3). This justifies the present chapter in which these proceedings will be debated against the background of the literature. Although many aspects of I/R are similar in various organ systems, we will mainly focus on renal $I / R$ injury keeping in mind that acute renal failure (ARF) is associated with an unacceptably high mortality, affects around $5 \%$ of hospitalized patients and has been reported to develop as a consequence of $\mathrm{I} / \mathrm{R}$ injury in $50 \%$ of cases (23). Our objective is to critically assess aspects of apoptosis and inflammation in terms of their involvement in the pathogenesis of renal $I / R$ injury. Moreover, the implications of recent experimental advances for treatment of renal $I / R$ injury in clinical practice will be discussed.

\section{APOPTOSIS AND ITS INVOLVEMENT IN RENAL REPERFUSION INJURY}

From a physiological point of view, the form of altruistic cell suicide that becomes manifest as the apoptotic phenotype, is an ingenious solution for removal of damaged and expended cells. An adequate stimulus can activate the machinery of individual cells in order to become apoptotic. From a classical point of view, such a cell will undergo morphological and biochemical changes and will ultimately be phagocytized by 
macrophages or adjacent cells without any evident inflammatory reaction. Apoptosis is abundant and essential for maintaining homeostasis in many physiological processes involving cell renewal including embryonic morphogenesis and hematopoesis. Apoptosis is also involved in various disease states, ranging from pathogenic infections, neurodegenerative syndromes to cancer.

Since the term apoptosis was first referred to in relation with renal $I / R(18)$, it has been implicated as an eminent symptom of $\mathrm{L} / \mathrm{R}$-induced organ damage. However, recent insights in the biochemistry of apoptosis redefine its involvement in $\mathrm{I} / \mathrm{R}$ injury towards a central and functional role in the development of organ damage. In particular the ambivalent involvement of caspases in the execution of apoptosis on one hand and on the other hand the requirement of caspases for activation of pro-inflammatory mediators, may have functional implications for apoptosis in the pathophysiology of $\mathrm{L} / \mathrm{R}$ injury. First, the more general aspects of apoptosis in renal $\mathrm{I} / \mathrm{R}$ injury will be discussed.

\section{MORPHOLOGICAL AND BIOCHEMICAL ASPECTS OF APOPTOSIS VERSUS NECROSIS}

Renal tubular apoptosis is an established attribute of $\mathrm{I} / \mathrm{R}$ injury in the kidney (24). Under apoptotic conditions a cell actively participates in its own demise. This has been described in isolated cells without the involvement of adjacent cells (25). Also, susceptibility to apoptosis as well as the apoptotic phenotype may differ among cell types. The intracellular biochemical cascade of apoptosis, among others, involves proteolytic (auto)activation of enzymes termed caspases (26). During apoptosis different activated caspases target various functional and structural intracellular proteins. This will ultimately result in cellular disassembly and the more or less characteristic morphological appearance of apoptotic cells (Figure 2).

First, cytoskeletal architecture is modified by proteolysis of substrates involved in regulation of cytoskeleton assembly such as fodrin, gelsolin and actin $(27,28)$. Related plasma membrane associated events include changes in membrane potential and expression of cell surface markers that facilitate phagocytic ingestion (29). These cell surface markers, including phosphatidylserine (PS) and phosphatidylethanolamine (PE) have been successfully employed in techniques aimed at identifying apoptotic cells in vitro and in vivo $(30,31)$. However, since necrosis can also induce cell surface expression of PS and PE the specificity of PS and PE externalization as a measure of apoptosis is still under debate $(32,33)$. In some cell types, the apoptotic response is associated with cytoplasmatic acidification and an increase in intracellular calcium. Apoptosis has been classically defined based on the ensuing characteristic changes in appearance, which include cell shrinkage, dense condensation of nuclear chromatin, nuclear fragmentation, dissolution of the nuclear membrane as well as plasma membrane blebbing $(34,35)$. During the final stages of apoptosis, the cytoplasmatic blebs will disengage to form membranebound cell remnants, or "apoptotic bodies". Under physiological conditions apoptotic 
bodies have been reported to be phagocytized without provoking an immune response. It has even been reported that apoptotic cells can actively suppress development of inflammation (36). However, recent experimental evidence indicates that under certain conditions such as during renal I/R injury (37), development (38) as well as other experimental conditions $(39,40)$ apoptotic cells can instigate inflammation.

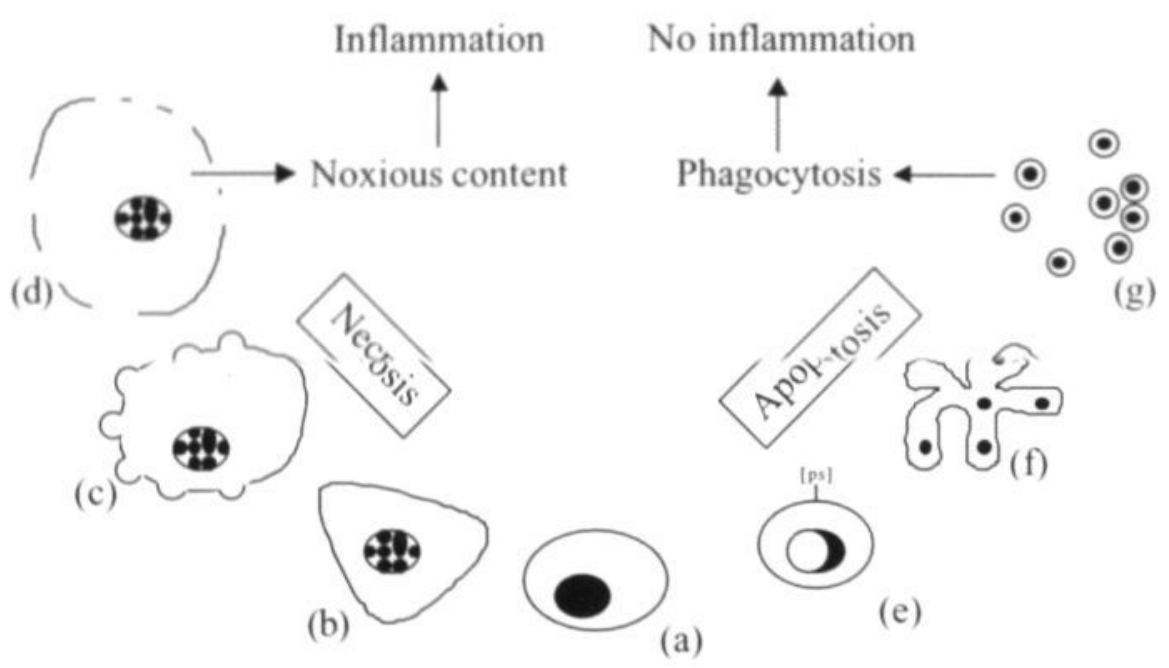

Figure 2. Paradigmatic view on stages of apoptosis and necrosis. Epithelial or endothelial cells (a) exposed to abrupt metabolic failure will undergo necrosis. In these cells, swelling of cytoplasmatic organelles and chromatine clumping will take place (b). Subsequently, cells will start to swell and cytoplasmatic blebs may appear (c). Finally, cells will disintegrate and will release intracytoplasmatic content (d) to induce an inflammatory response. Cells undergoing apoptosis initially exhibit condensed nuclear chromatin (often collapsed against the nuclear membrane), will start to shrink and will externalize phosphaditylserine (ps)(e). During the final stages, membrane blebbing takes place ( $f$ ) and "apoptotic bodies" will form that are classically ingested without provoking an inflammatory response $(\mathbf{g})$.

In contrast to apoptosis, necrosis is believed to mainly represent a passive consequence of gross injury to the cell and is associated with abrupt metabolic failure (Figure 2). The cellular biochemistry as well as morphological and physiological consequences of necrosis are also considered to be different from apoptosis. Various central steps in the apoptotic pathway essentially require ATP, including translocation of activated caspases to the nucleus (14) and Apaf-1/cytochrome-c induced caspase-9 activation (41). Enzymatic activation of caspases or as well as caspase substrates called "calpains" may also be functionally involved in necrosis. To this end, Edelstein et al. have demonstrated that hypox- 
ia-induced necrosis of rat renal proximal tubules can be prevented by caspase inhibition (42). However, necrosis but not apoptosis has been shown to occur under various rigorous ATP-depleted conditions $(43,44)$. Characteristic for necrosis is early swelling of cytoplasmatic organelles and chromatine clumping (Figure 2). On the surface of necrotic cells blebs may appear as well, but under these conditions membrane discontinuities rapidly develop causing water influx and ion redistribution. In turn, necrotic cells become hydrated and will start to swell and disintegrate. Release of intracellular proteolytic enzymes and other cytosolic material consequently are believed to induce an inflammatory response.

Recently intermediate types of cell death, chimerically termed "aponecrosis" and "oncosis" have been introduced $(44,45)$. This attempts to reflect that apoptosis and necrosis represent only two extremes of a continuum of intermediate forms of cell demise. For instance, oncosis is characterized by cytoplasmatic blebbing, dilatation of the endoplasmic reticulum, swelling of the cytosol, presence of normal or condensed mitochondria, and chromatin clumping in the nucleus (45). Whether the introduction of new nomenclature either clarifies the perception of cell death or merely adds to the confusion remains to be seen.

\section{DIFFICULTIES IN DISCRIMINATING APOPTOSIS FROM NECROSIS}

The morphological and biochemical features that distinguish apoptosis from necrosis seem distinct and well defined. However, in practice and from a functional point of view, both forms of cell death may be indistinguishable. For instance, it is thus far not known whether the apoptotic process and the necrotic process can elapse simultaneously and whether extrapolation of conclusions achieved under controlled in vitro conditions (simple systems) to in vivo conditions (complex systems) is appropriate (46). These considerations imply that techniques to discriminate apoptosis from necrosis, in particular under in vivo conditions, seldom yield conclusive results. Nevertheless, due to a lack of better alternatives such techniques are widely used.

Since caspases are considered to be the central enzymatic executioners of most forms of apoptotic cell death (as will be discussed below), caspase activation has been employed as a characteristic feature indicative of apoptosis. In vivo activation of various caspases has been demonstrated with specific fluorogenic substrates and with immunoblot methods. However, caspase activation has been associated with necrosis and inflammation under non-injurious conditions as well $(38,42)$. Similarly, PS translocation to the outer layer of the plasma membrane typical for an apoptotic cell (47) has been shown to also occur in necrotic cells $(32,33)$. In addition, internucleosomal DNA cleavage has been reported to occur during necrosis indistinguishable from that seen during apoptosis $(48,49)$. Moreover, both apoptosis and necrosis can elict immune responses during which secondary mediators such as TNF- $\alpha$ induce additional apoptosis as well as 
necrosis (50). Finally, it has to be taken into account that the nature of changes conferred by either necrosis or apoptosis varies extensively between types of cells and initiating stimuli.

Taken together, these considerations illustrate that both forms of cell death may be present at the same time, may exhibit overlap with respect to appearance and consequences and may mutually interact. It has even been proposed to expand the concept of cell death beyond manifestation of either necrosis or apoptosis to a wider phenomenological spectrum that is not limited by theoretical definitions (51). Hence, when studying phenomena such as I/R injury, rather than to create paradigmatical distinctions, the intricate relationship between apoptosis and necrosis and its consequences should be carefully taken into account. As suggested by Hengartner in a recent review on caspase biochemistry, ideally, our final classification will be determined not by morphology, but by which molecular pathways are activated in the dying cell (52).

\section{INDUCTION AND EXECUTION OF APOPTOSIS AFTER RENAL I/R}

To date, two pathways of apoptosis induction have been identified and both are implicated in I/R-induced apoptosis: Death-receptor dependent and death-receptor independent apoptosis (35). Considering the relative contribution of various pro-apoptotic stimuli, it is important to keep in mind the timeframe in which apoptosis and inflammation occur during reperfusion. For instance, the execution of apoptosis as a result of OFR liberation or ATP depletion is most likely initiated directly upon reperfusion as OFR are liberated and ATP is repleted. Conversely, release of pro-apoptotic factors that contribute to I/Rinduced apoptosis such as TNF- $\alpha$ and Fas-ligand can be observed at the time of development of inflammation, which ranges from several hours to days after ischemia $(50,53)$. Hence, various mechanisms contribute to I/R-induced apoptosis at different time points after the initial ischemic insult and early primary apoptosis may be caused by mechanisms that potentially differ from those responsible for delayed secondary apoptosis.

\section{DEATH-RECEPTOR MEDIATED APOPTOSIS}

The first pathway is mediated by ligation of so-called "death-receptors". This welldescribed extrinsic pathway allows apoptosis to be initiated by extracellular factors, including TNF- $\alpha$, the TNF- $\alpha$-Related Apoptosis Inducing Ligand (TRAIL) and Fas-ligand, that can bind to the $55 \mathrm{kDa}$ TNF-receptor, the TRAIL-receptors and Fas, respectively (Figure 3). After aggregation of death-receptors with their ligands, receptor oligomerization is achieved and the intracellular portions of death-receptors self-associate to form a death-domain (DD). From the cytoplasma, the receptor-coupled DD will recruit an adapter protein called FADD (Fas-associated death domain) or TRADD (TNFreceptor-associated death domain), which both contain a so-called "death effector 
domain" (DED) . Through the DED, which is also present on the pro-enzyme of caspase8/FLICE, pro-caspase- 8 accumulates to form a death-induced signaling complex (DISC). In the DISC the accumulated caspase- 8 polypeptides can activate each other, resulting in liberation of active caspase-8, which in turn can activate downstream effector caspases such as caspase- 3 .

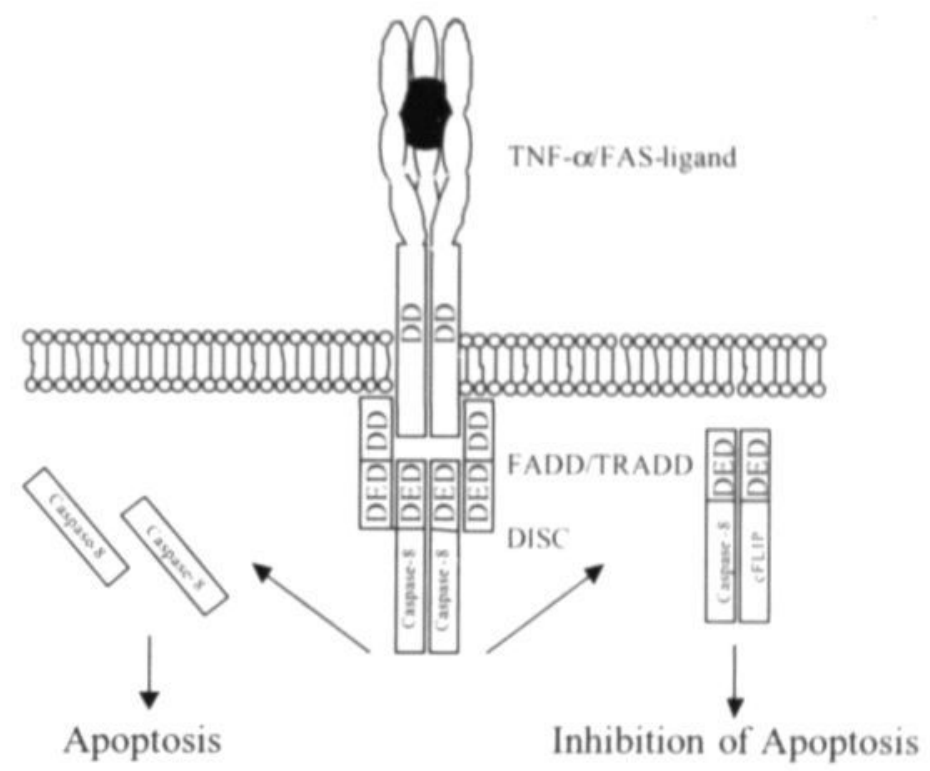

Figure 3. Schematic representation of death-receptor dependent or extrinsic apoptosis. The trimeric $55 \mathrm{kDa}$ TNF receptor or Fas-receptor binds TNF $-\alpha$ or Fas-ligand, which will induce recruitment of the FAD/TRAD adapter protein to the receptor through mutual binding of the "death domain" (DD). Next, pro-caspase- 8 will be recruited to FAD/TRAD by the "death-effector domain" (DED) to form the "death-inducing signaling complex" (DISC). Multiple recruit ed pro-caspase- 8 molecules will then auto-activate each other, which will lead to liberation of active caspase- 8 and apoptosis. In the presence of high levels of cFLIP, pro-caspase- 8 recruitment to FAD/TRAD is prevented by cFLIP. Therefore, in this case, caspase -8 activation will not take place and transition to the apoptotic phenotype is aborted.

Death-receptor ligation also activates pathways through phosphorylation of, among others, mitogen-activated protein kinase (MAPK) and c-Jun NH(2)-terminal kinase (JNK), by either caspase-dependent or -independent mechanisms (54). Furthermore, phosphorylation of $1-\kappa \beta$, leading to activation of NF- $\kappa \beta$ takes place. Consequently, autocrine production of death-ligands will promote the spread of death-receptor dependent apoptosis to adjacent cells. On the other hand, an anti-apoptotic role for activated NF- $\kappa \beta$ has recently been suggested $(55,56)$. Thus, an intricate network of phosphorylation-based 
signaling serves as a potent modifier of death-receptor responses.

The involvement of Fas in I/R-induced renal tubular apoptosis was elegantly demonstrated by Nogae et al. who showed marked intrarenal Fas up-regulation after $30 \mathrm{~min}$ of renal ischemia followed by $24 \mathrm{~h}$ of reperfusion in a murine model (53). This study additionally revealed that the extent of $\mathrm{I} / \mathrm{R}$-induced tubular apoptosis is significantly decreased after $24 \mathrm{~h}$ of reperfusion in $/ p r / p r$ B6 mice, which express only low levels of Fas. TNF- $\alpha$ is also considered to be centrally involved in the development of $\mathrm{I} / \mathrm{R}$-induced inflammation (57). TNF- $\alpha$ produced by mesangial cells and even tubular epithelial cells in response to $\mathrm{I} / \mathrm{R}$ has been demonstrated to contribute to functional renal damage by among others liberating OFR, reducing glomerular blood flow and causing fibrin depositions. In addition, since anti-TNF- $\alpha$ antibodies were shown to attenuate apoptosis after ischemia followed by $24 \mathrm{~h}$ of reperfusion in a murine model of renal I/R, TNF- $\alpha$ is also implicated as an initiator of $\mathrm{I} / \mathrm{R}$-induced apoptosis (50) (Chapter 2 ). TRAIL has not been associated with $\mathrm{I} / \mathrm{R}$ yet.

Another aspect of death-receptor mediated apoptosis is the role of the constitutively present cytoplasmatic protein cellular FLICE inhibitory protein (cFLIP). Like pro-caspase-8, this anti-apoptotic protein contains a DED. However, cFLIP lacks essential residues necessary to become proteolytically activated, which defines it as a constitutive competitive inhibitor of caspase- 8 activation. It was recently shown that cFLIP is depleted from cardiac tissue after $3 \mathrm{~h}$ of reperfusion (58). Data from our laboratory show a similar cFLIP depletion in renal tissue during ischemia and after $2 \mathrm{~h}$ of reperfusion (Chapter 9). Considering the endogenous anti-apoptotic role of cFLIP, this suggests increased vulnerability of cells to Fas-ligand and TNF- $\alpha$ mediated apoptosis following I/R. Fas-ligand mediated apoptosis and renal Fas mRNA up-regulation have been demonstrated in a model of renal I/R at $24 \mathrm{~h}$ of reperfusion (53). Similarly, TNF- $\alpha$ mediated apoptosis and peak renal TNF- $\alpha$ mRNA levels were seen at $24 \mathrm{~h}$ of reperfusion, but not during the first few hours of reperfusion (50). This delay in onset of death-receptor mediated apoptosis most likely occurs because antecedent de novo synthesis of death-ligands is required. Taken together, the evident participation of Fas-ligand and TNF- $\alpha$ suggest that deathreceptor mediated apoptosis is an important contributor to I/R-induced apoptotic cell death in a later phase of reperfusion. Moreover, I/R-induced cFLIP depletion, which has been demonstrated in heart and kidneys during ischemia and during the first few hours of reperfusion, respectively, may facilitate death-receptor mediated apoptosis in an advanced phase of reperfusion. Which specific events trigger accumulation, expression or release of Fas-ligand and TNF- $\alpha$ or depletion of cFLIP as a consequence of I/R, remains to be established. 


\section{DEATH-RECEPTOR INDEPENDENT APOPTOSIS}

The second pathway allows apoptosis to be initiated by factors that can access the cytosol and is essentially independent from death-receptor signaling (Figure 4). This intrinsic pathway involves release of mitochondrial cytochrome-c followed by activation of initiator caspase-9 (59). Also, a protein termed Apoptosis Inducing Factor (AIF) may be released from mitochondria to directly activate effector caspase-3 (60). Several mechanisms may explain increased mitochondrial permeability as a result of $1 / R$ and consequent release cytochrome-c and AIF. First, in vitro experiments established that hypoxia-induced ATP depletion is associated with a rise in intracellular calcium levels, which will induce non-specific hyperpermeability of the inner mitochondrial membrane (61). Second, ATP depletion in cultured renal proximal tubules induces translocation of the pro-apoptotic protein Bax from the cytosol to the mitochondrium, where it in turn causes release of cytochrome-c and AIF to the cytosol. Conversely, the anti-apoptotic protein $\mathrm{Bcl}-2$ prevents release of cytochrome-c and AIF from mitochondria (62). In vivo evidence for increased expression of both Bcl-2 and Bax during reperfusion of kidneys subjected to $\mathrm{I} / \mathrm{R}$ has been provided (63). In this context, Basile et al. showed up-regulation of renal mRNA as well as protein levels of anti-apoptotic Bcl-2 and pro-apoptotic Bax in an experimental model after $24 \mathrm{~h}$ of reperfusion (64). Moreover, mice overexpressing Bcl-2 are protected against cerebral (65) and intestinal (66) I/R injury, while mice with a disrupted $\mathrm{Bcl}-2$ gene exhibit exacerbated cerebral $\mathrm{I} / \mathrm{R}$ injury (67). A third cause of increased mitochondrial permeability after $\mathrm{I} / \mathrm{R}$ are OFR, which are liberated during early reperfusion and damage the mitochondrial membrane. However, since in vitro data show that apoptosis can also be induced by hypoxia/reoxygenation without the involvement of OFR in rat tubular cells (68), other factors may be more important. Finally, also deathreceptor mediated apoptosis may lead to activated caspase-8-induced mitochondrial damage (69) and ongoing caspase-activation in the course of apoptosis will ultimately inflict additional mitochondrial damage in a self-amplifying loop in which death-receptor dependent and death-receptor independent cell death are connected (70).

The released cytochrome-c can induce a conformational change of an extra-mitochondrial protein termed Apoptosis Protease Activating Factor-1 (Apaf-1), leading to uncovering of a caspase recruitment domain (CARD). This process is dependent on ATP (71) and is consequently inhibited under ATP-depleted conditions like prolonged ischemia. Similar to the DISC in death-receptor mediated apoptosis, the CARD of Apaf-1 can now recruit multiple pro-caspase- 9 molecules, which will ultimately lead to the formation of the Apaf-1/caspase-9 apoptosome complex and consequent caspase- 9 activation. In turn, activated caspase- 9 activates other caspases including caspase- 3 for execution of apoptosis to proceed. Despite evidence for similar regulation of apoptosis after $\mathrm{I} / \mathrm{R}$ in vivo (65, 66 ), it has to be taken into consideration that many aspects of death-receptor independent apoptosis have been established in in vitro systems. Therefore, considering presence of 
cell-cell interactions as well as different homeostatic regulation in vivo, the mechanisms of death-receptor independent apoptosis in vitro may differ from those in vivo. However, the evident involvement of OFR and ATP depletion in the course of in vivo I/R-injury as well as the observation that $\mathrm{Bcl}-2$ can modulate the extent of in vivo I/R-injury suggest that death-receptor independent apoptosis is prominently involved in I/R pathophysiology.

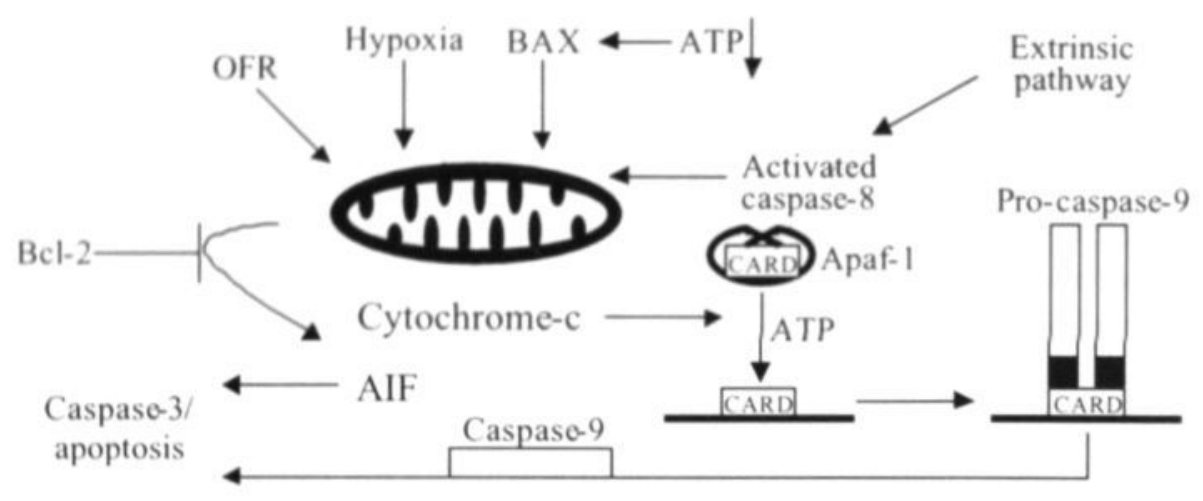

Figure 4. Schematic representation of death-receptor independent or intrinsic apoptosis. Extrinsic factors such as OFR and hypoxia permeabilize mitochondria for cytochrome-c and Apoptosis Inducing Factor (AIF). Similarly, ATP depletion will lead to BAX-dependent mitochondria permeabilization for cytochrome-c and AIF. Cytochrome-c induces a conformational change of Apoptosis Protease Activating Factor-1 (Apaf-1), leading to uncovering of the "caspase recruitment domain" (CARD). The latter will induce recruitment of caspase- 9 to form the apoptosome. Next, caspase- 9 will be activated, which will ultimately lead to transition to the apoptotic phenotype.

\section{OTHER FACTORS CONTRIBUTING TO I/R-INDUCED APOPTOSIS}

All initial events that lead to apoptosis ultimately converge to either death-receptordependent or death-receptor independent apoptosis, caspase activation and cellular demise. Following renal I/R, several of these initial events have been identified as important contributors to the development of apoptosis. Hydrolyzation of the plasma membrane component sphingosine and consequent liberation of ceramide has been reported to initiate apoptosis after as early as $30 \mathrm{~min}$ of renal reperfusion (72). In addition, the tumor suppressor gene $\mathrm{p} 53$, which is up-regulated after reperfusion and promotes cell differentiation, maturation and apoptosis has been suggested to be of pivotal importance (73), but this is still under debate (74). Another mechanism implicated to be involved in I/R-induced apoptosis is a sudden lack of "survival" signals that normally oppose pro- 
apoptotic stimuli (75). The survival signals referred to, comprise circulating levels and local expression of soluble growth hormones and also functionally important cell-cell and cell-matrix interactions (which are often disrupted during $1 / R)(76)$. Although no direct evidence for a cause-and-effect relationship exists between survival factor deficiency and I/R-induced apoptosis in the kidney, exogenous administration of survival factors such as Insulin-like Growth Factor-1 (IGF-1)(77), Epidermal Growth Factor $(\mathrm{EGF})(78)$ and Hepatocyte Growth Factor $(\mathrm{HGF})(79)$ has been proven to promote recovery from I/R injury. Surprisingly, these reports all focus on growth factor-induced accelerated growth and recovery in the reperfusion phase. We recently demonstrated that specifically suppressing the anti-apoptotic signal of IGF-1 by co-administrating a PI3kinase inhibitor, abrogates its therapeutic effect on renal $I / R$ injury (37). Therefore, it is likely that also anti-apoptotic signaling contributes to the observed beneficial effects. Additional work in this field is required to fully elucidate the contribution of various proapoptotic triggers in the course of $\mathrm{I} / \mathrm{R}$.

\section{CASPASES AND THEIR ROLE AS EXECUTIONERS OF I/R-INDUCED APOPTOSIS}

The discovery of caspases as the executioners of the apoptotic response lead to significant advancements in the understanding of the biochemistry of apoptosis (26). The caspase family is defined by sequence homology with the Interleukin- $1 \beta$ Converting Enzyme (ICE), now renamed caspase-1. Caspase-1 as a potential mediator of apoptosis emanated from the uncovering of sequence homology between mammalian caspase- 1 and a cell death inducing gene in the nematode Caenorhabditis elegans termed CED-3 (80). Other experiments later confirmed that activation of caspase- 1 is essential to the development of apoptosis in various cell types. Subsequently, new caspases were identified that were involved in various types of regulation in different organisms and organ systems, resulting in a diversity of names for the same individual protein. The name "caspase" was introduced in 1996 to avoid confusion and reflects the main biocatalytic attributes of the enzymes. The "c" makes reference to the fact that they are cysteine proteases, whereas "aspase" refers to their ability to proteolyse substrates behind specific aspartic residues. The caspase numbers correspond to the chronological order of their publication. Thus far, 14 murine and 14 human caspase homologues have been identified and about two-thirds of these have been suggested to have a role in the execution of apoptosis (26).

The morphological alterations that apoptotic cells undergo are, among others, carried out by activated caspases. All caspases are expressed as inactive pro-enzymes with a molecular weight of 30 to $50 \mathrm{kDa}$. Following an initial pro-apoptotic stimulus caspaseprecursors of so-called initiator caspases (e.g. caspase- 8 after death-receptor dependent apoptosis and caspase- 9 after death-receptor independent apoptosis) are activated as a result of proteolytic processing. Once activated, initiator caspases can activate other caspases in a cascade sequence leading to activation of effector caspases (among others cas- 
pase-3 and -7). Subsequently, effector caspases are believed to be able to degrade a variety of proteins essential to cell survival. These substrates, of which many remain to be discovered, include $\operatorname{KAD}(81)$. The latter is an inhibitor of Caspase-Activated DNAse (CAD), a nuclease capable of internucleosomal DNA cleavage as well as cleavage of anti-apoptotic Bcl-2. In addition, activated caspases can specifically activate proteins such as calpain, EMAP-II and pro-IL-1 13 by removing a negative regulatory domain or by inactivating a regulatory protein subunit.

In the field of neurology, it is established that caspase inhibition attenuates brain injury after middle cerebral artery occlusion followed by reperfusion (82). In line, broad-spectrum caspase inhibition with the peptide inhibitor $\mathrm{zVAD}$-fmk was shown to protect against cardiac I/R (20). Edelstein et al. reported that hypoxia increases caspase-1 and caspase-3 activity in an in vitro model of proximal tubular necrosis (42). In addition, Kaushal et al. showed up-regulation of caspase- 1 and caspase- 3 mRNA and protein after 4 to $16 \mathrm{~h}$ of reperfusion in a rat model of renal $\mathrm{I} / \mathrm{R}(83)$. Data from our laboratory confirmed these results by demonstrating renal caspase- 1 and caspase- 3 activation after 45 min of renal ischemia followed by either 2 or $24 \mathrm{~h}$ of reperfusion in a murine model (37) (Chapter 4). Also in this model, I/R-induced renal apoptosis was effectively prevented by pretreatment with the broad spectrum caspase inhibitor zVAD-fmk. Interestingly, this inhibition of activated caspases in the course of early reperfusion additionally prevented subsequent inflammation and impairment of renal function, indicating a functional contribution of the caspase activation cascade to the development of renal $I / R$ injury.

\section{INFLAMMATION IN THE COURSE OF RENAL REPERFUSION INJURY}

Inflammation is a crucial event in the development of organ damage and dysfunction due to I/R. Employment of specific anti-inflammatory interventions revealed the importance of inflammation to subsequent development of tissue injury and dysfunction. This strategy enabled the identification and relative contributions of various cells and mediators to $\mathrm{I} / \mathrm{R}$-induced inflammation. Despite an extensive number of publications addressing the involvement of inflammatory mediators in the course of $I / R$, the etiology of $I / R$-induced inflammation remains largely obscure.

\section{ROLE OF OXYGEN RADICAL MEDIATED REPERFUSION INJURY}

The organ condition that accompanies $I / R$ injury is generally associated with aspecific tissue damage inflicted by endogenously produced OFR immediately upon reperfusion (Figure 5)(9). Ischemia-induced dephosphorylation of adenosine 5 '-triphosphate (ATP) causes a local rise of hypoxanthine levels, while xanthine dehydrogenase is converted to xanthine oxidase. The latter has been suggested to occur as a result of proteolysis in the ischemic phase (84). After reoxygenation (reperfusion) xanthine oxidase converts 
hypoxanthine to xanthine, which results in extensive formation of the superoxide anion $\left(\mathrm{O}_{2}{ }^{*}\right)$. Since xanthine oxidase is mainly localized in the endothelial cell, reperfused vascular endothelium is considered to play a central role in OFR production after ischemia. However, it has to be taken into account that the presence of the enzyme xanthine oxidase is species dependent. Other processes that will ultimately result in production of OFR during reperfusion include the reduction of ferric iron leading to dismutation of hydrogen peroxide and plasma membrane phospholipase A2 activation leading to prostanoid production. Paller et al. in 1984 in a rat model of renal $\mathrm{I} / \mathrm{R}$ demonstrated beneficial effects of the radical scavengers superoxide dismutase and dimethylthiourea as well as the xanthine oxidase inhibitor allopurinol on renal function, lipid peroxidation and tubular injury (85). This underlines the functional importance of OFR liberation in the pathophysiology of renal I/R injury.

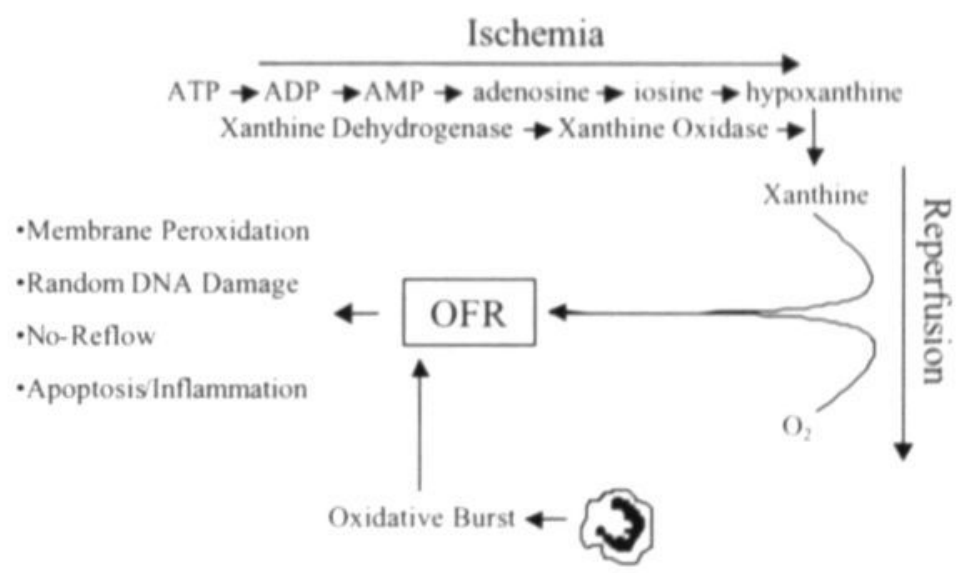

Figure 5. Mechanisms of oxygen free radical (OFR) synthesis in the course of I/R. Ischemia will lead to simultaneous degradation of purine nucleotides and conversion of xanthine dehydrogenase to xanthine oxidase. Upon reperfusion, accumulated xanthine will react with $\mathrm{O}_{2}$ to form OFR. Moreover, activated neutrophils will contribute to OFR synthesis by means of the oxidative burst activity. Liberated OFR in turn may contribute to tissue injury by mediating membrane peroxidation, random DNA cleavage, no-reflow and apoptosis as well as inflammation.

The highly reactive OFR liberated during reperfusion may induce lipid membrane peroxidation (85). Besides, they can denature functional intracellular proteins and directly mediate acute microcirculatory obstruction (no-reflow phenomenon)(86). Employing cultured tubular epithelial cells that were rendered chemically hypoxic with antimycin A, Hagar et al. showed a role for OFR in endonuclease activation and consequent induction of DNA strand breaks, generally associated with apoptosis (87). Moreover, OFR have 
been shown to be able to induce apoptosis in various cell types $(88,89)$. In addition, exposure of endothelial cells to OFR induces the prolonged expression of P-selectin on the cell surface, which results in enhanced PMN adherence (90). During this inflammatory response, granular enzymes such as elastase are released by infiltrating inflammatory cells and additional OFR are produced by the initiated respiratory burst.

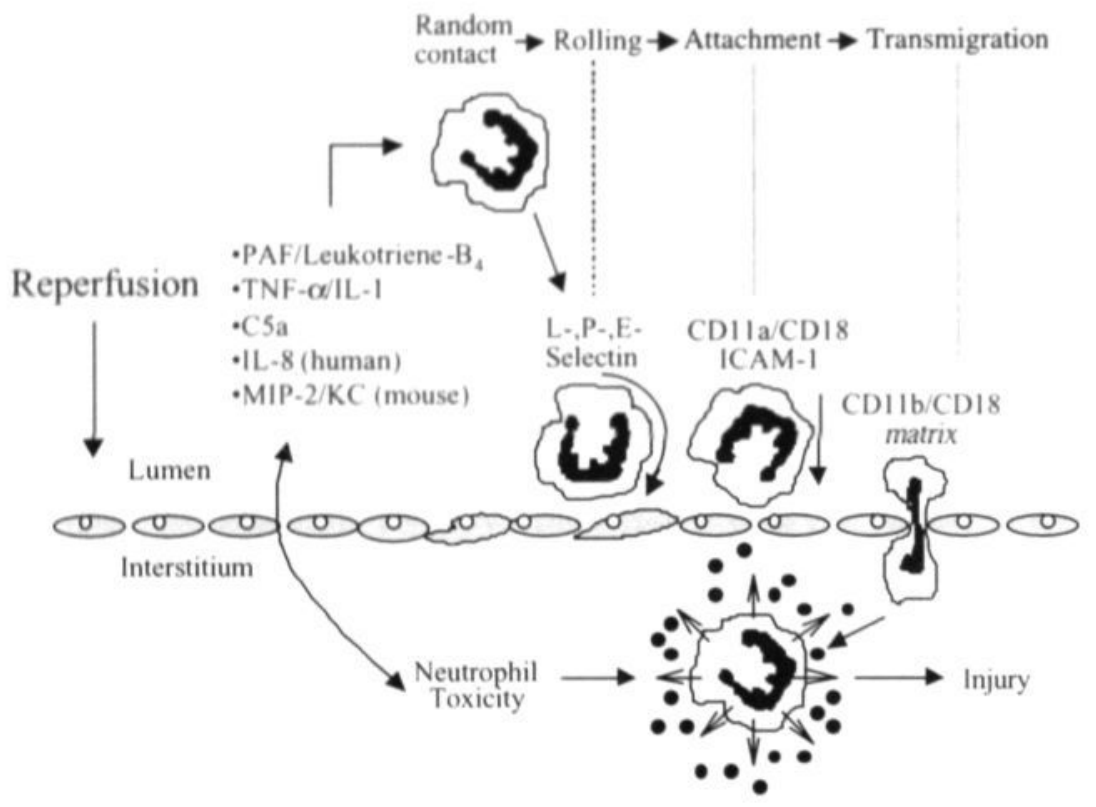

Figure 6. Schematic representation of neutrophil recruitment to the site of I/R-injury. Proinflammatory mediators are liberated during reperfusion by mechanisms that remain largely obscure. These mediators have chemotactic properties and can promote leukocyte rolling by enhancing selectin expression on neutrophils and on the endothelium. Subsequently, the $\beta$-integrins CDII and CD18 as well as ICAM-I and matrix components mediate attachment and transmigration of the neutrophil to and through the endothelium. Largely the same mediators that are chemotactic, also act as neutrophil agonists and activate neutrophils migrated to the interstitium. Finally, neutrophil respiratory burst activity accounts for additional tissue injury in the reperfused organ.

\section{SEQUESTRATION AND INFLUX OF POLYMORPHONUCLEAR NEUTROPHILS}

Although the contribution of neutrophils to I/R-induced kidney damage varies between models employed, many studies suggest that neutrophil recruitment to the site of injury (Figure 6) is a central event in the pathogenesis of $I / R$ injury in the kidney as wel as in other organs (91). For instance, rats that were neutrophil depleted and subjected to renal 
I/R showed improved kidney function and reduced acute tubular necrosis (92). As mentioned above, OFR have been implicated in neutrophil chemotaxis during early reperfir sion. ORF-induced lipid membrane peroxidation and consequent phospholipase A2 activation leads to formation of arachidonic acid and lysophospholipids (93). The latter two products can be metabolized to leukotriene B4 and platelet activating factor (PAF), both well-established chemoattractants that are both functional mediators of renal $1 / R$ injury $(94,95)$. Other mechanisms that have been suggested to contribute to neutrophil influx include ischemia-induced activation of the classical as well as the alternative complement cascade (96) and hypoxia-induced production of interleukin-8 (IL-8) and the IL-8 inducing cytokines IL- 1 and tumor necrosis factor- $\alpha$ (TNF- $\alpha$ ). Which specific events trigger the release of these mediators in the course of $\mathrm{I} / \mathrm{R}$ is largely unknown.

Additional to chemoattraction of neutrophils to the site of injury, transmigration through the endothelial barrier is required (97). Under normal conditions random contact exists between neutrophils and the endothelium. However, inflammatory mediators released during early reperfusion induce endothelial E-selectin and P-selectin expression. The latter two adhesion molecules mediate tethering and rolling interactions between the neutrophil and the endothelium. Singbartl et al. showed that E-selectin deficient mice as well as mice treated with antibodies directed against E-selectin are protected against renal $\mathrm{I} / \mathrm{R}$ injury, as a consequence of reduced renal neutrophil infiltration (98). As inflammation proceeds, neutrophils come to a sudden stop by attaching strongly to the endothelium via $\beta$-integrin (CD11/CD18) dependent mechanisms. Subsequent migration pass the endothelium is also regulated by the interaction between neutrophil integrins and endothelial ICAM-1. Dragun et al. have shown in rat model of $\mathrm{I} / \mathrm{R}$ and syngenic kidney transplantation that donor pretreatment with antisense oligodesoxynucleotides for ICAM-1 significantly improved graft function and survival (99). In line, Haug et al, in a clinical trial showed that immunosuppression with anti-ICAM-1 antibodies to recipients of cadaver donor renal allografts limited I/R-injury (100). This indicates a central role for the neutrophil in experimental as well as clinical $\mathrm{I} / \mathrm{R}$ injury.

Following transmigration, when the neutrophil has emerged between endothelial cells, the switch to neutrophil toxicity takes place. This effector function of neutrophils (neutrophil toxicity) in the postischemic kidney consists of indiscriminate triggering, resulting in local formation of OFR (respiratory burst) and liberation of proteolytic enzymes such as elastase, gelatinase and collagenase. OFR and proteolytic enzymes are generally released in parallel, and cooperate in destroying cells and dissolving connective tissues (101). Moreover, a number of pro-inflammatory signaling molecules implicated in the course of reperfusion may add to neutrophil toxicity by means of inducing and prolonging respiratory burst activity. These so-called neutrophil agonists, of which several are also responsible for neutrophil chemotaxis such as IL-8 and complement factor C5a, include among others damaged mitochondria (102), PAF (103), TNF- $\alpha$ and IL-1 (104). 


\section{LATE INFLAMMATION INDUCED BY RENAL ISCHEMIA REPERFUSION}

The sequelae of events following renal $\mathrm{I} / \mathrm{R}$ involves signs of not only an early but also a late inflammatory response. The latter phenomenon has been extensively investigated by Hallorans' group and is characterized by enhanced expression of MHC class I and II antigens as a consequence of increased IFN- $\gamma$ expression following I/R (105). In various experimental models, the onset of delayed inflammation was observed between 3 and 5 days of renal reperfusion and lasted during subsequent weeks $(106,107)$. Since enhanced tissue expression of MHC class I and II antigens is likely to predispose grafted kidneys to the development of rejection, delayed I/R-induced inflammation is particularly relevant in the field of transplantation.

Late inflammation after $\mathrm{I} / \mathrm{R}$ is a consequence of the potent $\mathrm{MHC}$ inducing capacities of IFN- $\gamma$ (108). The combined effects of, and complex interactions between IL-12 and IL18 ultimately enhance IFN- $\gamma$ production in the course of reperfusion (109). Interestingly, such regulation appears to be similar in host defence against pathogens such as Yersinia enterocolitica (110)(Figure 7). Like IL-1, production of biologically active IL-18 is dependent on caspase- 1 activation. We showed that treatment with anti-IFN- $\gamma$ antibodies abrogated delayed inflammation but not acute inflammation in an experimental model of renal I/R (109)(Chapter 3). Conversely, no evidence has been put forth showing effective prevention of early inflammation without affecting delayed inflammation. This suggests a relation between acute inflammation or tissue damage and the delayed inflammatory response to $\mathrm{I} / \mathrm{R}$.

The similarities observed between mechanisms of IFN- $\gamma$ induction during bacterial infections and non-microbial lesions such as renal $\mathrm{I} / \mathrm{R}$ injury raise the hypothesis that aspecific tissue damage contributes extensively to local up-regulation of IFN- $\gamma$. This concept is in line with the "danger"-theory proposed by Matzinger who suggests activation of immunity by danger (I/R-injury) rather than by mechanisms that discriminate between self and non-self (111). As pointed out earlier, I/R-induced MHC up-regulation may increase the severity of allorejection in the case ischemically damaged donor organs are used for transplantation. Also, one could speculate that $\mathrm{MHC}$ antigen up-regulation as a consequence of $\mathrm{I} / \mathrm{R}$ provides beneficial physiological protection by facilitating $\mathrm{T}$-cell responses to invading pathogens in damaged tissues. Besides altered MHC expression, other immune modulating molecules that are implicated in the pathophysiology of $I / R$ such as Toll-like receptors (112) and locally produced acute phase proteins (113) may be involved in such host defence processes. Further experimentation might allow these issues to be resolved. 


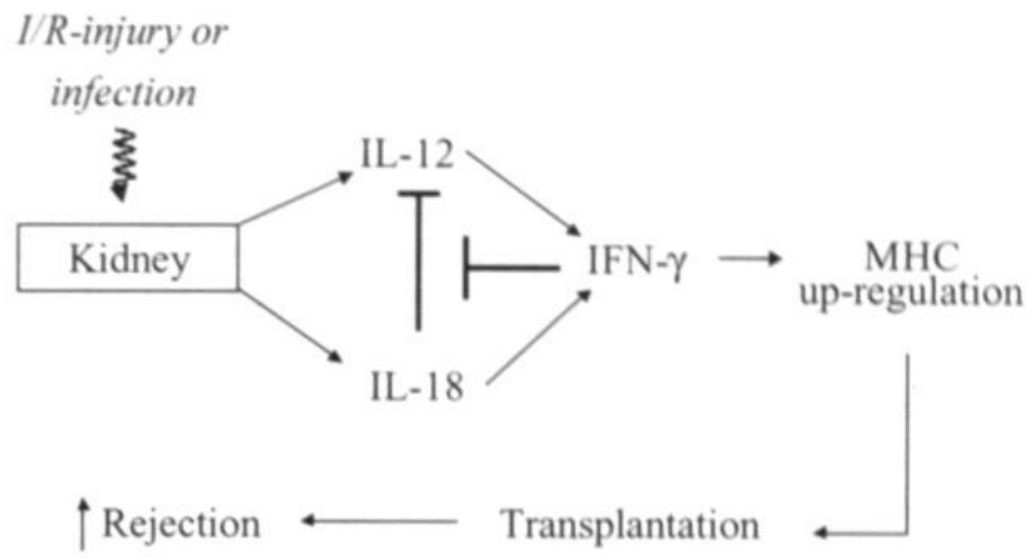

Figure 7. Schematic representation of the interactions between IL-12, IL-I 8 and IFN- $\gamma$ and subsequent induction of $\mathrm{MHC}$ class I and II antigens in the course of bacterial infections with Yersinia enterocolitica (ref. 110) as well as renal I/R injury ( $\mathrm{ref} .109$ ). I/R-induced enhanced MHC class I and II antigen expression may contribute to the higher incidence of delayed rejection associated with the use of NHB-donor kidneys.

\section{INTERPLAY BETWEEN APOPTOSIS AND INFLAMMATION IN THE COURSE OF I/R}

Although apoptosis, necrosis, elaboration of OFR as well as acute and delayed inflammation may appear as distinct entities during reperfusion, it has become evident that these aspects of $I / R$ injury are extensively interdependent. The redundancy and complexity of interactions inherent to development of $\mathrm{I} / \mathrm{R}$ injury have complicated the identification of central causative events. Recent insights in the functional role of apoptosis in $\mathrm{I} / \mathrm{R}$ injury benefited from the discovery and classification of caspases. Additional advances have been made after effective means to measure caspase activity and new pharmacological tools to inhibit caspase activity in vivo and in vitro became available. This has not only increased our knowledge of $\mathrm{I} / \mathrm{R}$ pathophysiology, but also led to the identification of endogenous protective mechanisms that co-determine how $I / R$ injury evolves.

\section{CASPASE AND CALPAINE ACTIVATION DURING INFLAMMATION}

Activated caspases participate not only in the promotion of apoptotic cell death, they also play a role in the processing of pro-inflammatory cytokines. Caspase-1 was initially termed interleukin-1B-converting enzyme (ICE) based on its central role in the maturation of pro-IL-1B (114). Also the maturation of the IFN- $\gamma$ inducing cytokine IL-18 is dependent on caspase-1 activation (115). Interestingly, both caspase-1 activation and pro- 
duction of IL-1B as well as IL-18 have been implicated in the pathogenesis of renal I/R injury $(109,116)$. These findings suggest that apoptosis contributes to inflammation through caspase activation. Indeed, selective inhibition of caspase-1 conferred protection against brain I/R-injury in various in vivo models (117). On the other hand, caspase-1 appears to be redundant in many forms of apoptosis and caspase-1 knockout mice are minimally protected against renal $\mathrm{L} / \mathrm{R}$ injury (Chapter 6)(118).

Caspase-7, an effector caspase with high structural and functional resemblance to caspase-3, has been recently demonstrated to be responsible for the processing of the chemokine endothelial monocyte-activating polypeptide II (EMAP-II)(119). Our experimental results show that active EMAP-II is produced in the early phase of renal I/R injury (37). Active EMAP-II is a potent attractor of neutrophils and data from our lab show caspase-7 activation even as early as during ischemia (Chapter 9). Taken together, caspase activation is not only responsible for $\mathrm{I} / \mathrm{R}$-induced apoptotic cell death, but additionally may function as an intermediate mechanism between apoptosis and subsequent inflammation (Chapter 7). As new caspase substrates are being identified, including precursors of thus far known and unknown pro-inflammatory mediators, the understanding of the functional role of caspase activation in the course of $I / R$ will grow.

Besides caspases, another group of cysteine proteases termed "calpaines" have recently been implicated in the pathogenesis of I/R injury in the kidney (120) and in other organs $(121,122)$. Shi et al. have demonstrated that activation of caspase- 3 as well as calpain occurs during early renal reperfusion (120). Since activated caspase- 3 can proteolyse calpastatin, an endogenous calpain inhibitor, caspase- 3 may mediate calpain activity during renal $\mathrm{I} / \mathrm{R}$ injury. Like active caspases, active calpains can cleave proteins important for structural cell integrity and cell function (123). Moreover, whereas caspase-1 mediates processing of IL-1 13 , calpain mediates processing of pro-IL- $1 \alpha$ to pro-inflammatory IL-1 $\alpha(124)$, a process that may contribute to apoptosis-induced inflammation in the course of renal $\mathrm{I} / \mathrm{R}$. Interestingly, activated calpaines have been shown to proteolyse the transcription factor NF- $\kappa \beta$ (125). NF- $\kappa \beta$ activation protects cells against apoptosis induced by chemotherapeutics, ionizing radiation as well as TNF- $\alpha$ (126). Thus, an I/Rinduced disbalance in calpain regulation may be of pivotal importance to the development of $\mathrm{I} / \mathrm{R}$ injury.

\section{ENDOGENOUS PROTECTION AGAINST I/R-INDUCED APOPTOSIS AND INFLAMMATION}

Throughout evolution, organisms have become equipped with various means of defense against threatening stimuli. It has become clear that homeostatic anticipation and adaptation can also confer protection against $\mathrm{I} / \mathrm{R}$ injury. Such endogenous protection applies to various aspects of $\mathrm{I} / \mathrm{R}$ pathophysiology, including apoptosis and inflammation. Indeed, apoptosis in general can be perceived as an altruistic form of cell suicide that encompasses a protective strategy. Moreover, I/R-induced inflammation involves the innate 
immune system that also covers the first line of defense against invading pathogens. It is conceivable that apoptosis as well as inflammation in the early course of $I / R$ primarily intend to efficiently clear away noxious debris at the site of injury. However, in the context of $\mathrm{I} / \mathrm{R}$ pathophysiology, the magnitude of the apoptotic as well as the inflammatory response is disproportional and consequently detrimental to the affected organ system.

Endogenous protection against reperfusion injury can be achieved by producing neutralizing mediators capable of blocking injurious cascades induced by $\mathrm{I} / \mathrm{R}$. For example, release of TNF- $\alpha$ has been shown to mediate I/R-induced apoptosis as well as inflammation. Other conditions that are associated with TNF- $\alpha$ production such as endotoxemia are characterized by the production of endogenous IL-10, a natural anti-inflammatory cytokine able to control excess production (127) as well as effects (128) of TNF- $\alpha$. Moreover, exogenous IL-10 is protective in models of septic shock as well as $1 / R$ injury $(127,129)$ and IL-10 has been shown to have anti-apoptotic properties (130). In line, we recently showed that renal $\mathrm{I} / \mathrm{R}$ induces local production of IL-10 and that IL-10 neutralization increases the amount of $\mathrm{L} / \mathrm{R}$-induced TNF- $\alpha$ production and organ damage (50).

Another mechanism by which an organism can protect itself against the consequences of $\mathrm{I} / \mathrm{R}$ is by a process called "ischemic preconditioning" in which single or multiple short periods of antecedent ischemia induce protection from $\mathrm{I} / \mathrm{R}$-induced injury in a biphasic pattern (131). Such protection lasts for $30 \mathrm{~min}$ to $2 \mathrm{~h}$ and is followed by a second window of protection appearing 12-24 h later. Ischemic preconditioning has been attributed to local protective mechanisms. Among others, heat shock proteins (HSP) have been reported to mediate the first window of protection conferred by ischemic preconditioning. It has been shown that ischemia leads to early up-regulation of HSP70 (132) and that overexpression of HSP protects against TNF- $\alpha$-induced apoptosis and confers protection to oxidative stress $(133,134)$.

We recently showed that renal $\mathrm{L} / \mathrm{R}$ induces a hepatic acute phase response and that mediators of this response ( $\alpha 1$-acid glycoprotein and $\alpha 1$-antitrypsin) protect against renal $\mathrm{I} / \mathrm{R}$ injury by attenuation of $\mathrm{I} / \mathrm{R}$-induced apoptosis as well as inflammation (113) (Chapter 5). Hence, the hepatic acute phase response, executed by the host in the aftermath of infection or injury, may contribute to preconditioning-induced late protection against $\mathrm{I} / \mathrm{R}$ injury. However, these and other protective mechanisms such as endogenous production of anti-apoptotic cytokines and growth factors, induction of Toll-like receptors, up-regulation of intracellular caspase inhibitors such as IAP's and cFLIP need to be studied more extensively to establish their functional role in $\mathrm{I} / \mathrm{R}$ pathogenesis.

\section{Clinical PERSPECTIVES}

Before the transition of experimental results to clinical application can be made, it is essential to be convinced of the necessity of such clinical application. Our understanding of the significance of reperfusion injury is restricted by the profuse literature in experi- 
mental models and limited literature in the clinical situation. Also, renal I/R injury is seldom presented as an isolated clinical problem and some clinicians may overlook the consequences of not treating $\mathrm{I} / \mathrm{R}$ injury as they focus on the underlying problem. Nevertheless, epidemiological figures support all efforts undertaken by clinicians as well as basic scientists to investigate new means to treat renal $\mathrm{I} / \mathrm{R}$ injury (23).

Experimental data that are currently available may justify clinical application of antiapoptotic agents in the treatment of $\mathrm{I} / \mathrm{R}$-injury in the kidney as well as in other organs. Moreover, new insights in the role of apoptosis in I/R-pathogenesis may yield diagnostic possibilities to predict the extent of reperfusion injury in ischemically injured transplant grafts (for instance NHB-kidneys) upon procurement.

\section{PhaRmaCOLOGICAL MODULATION OF APOPTOSIS}

It is now clear that apoptosis is abundantly involved in the pathogenesis of many diseases. Therefore, efficient and specific pharmacological modulation of apoptosis is likely to become an important tool to treat a variety of clinical conditions in the forseeable future. It is evident that not only transplantation medicine will benefit from these advances. The pharmacological anti-apoptotic approach may soon be employed to treat or prevent other prominent conditions and complications associated with I/R-injury, including brain and myocardial infarction followed by therapeutic in situ reperfusion. Furthermore, anti-apoptotic pharmacotherapy may be effective in treating or preventing renal, spinal and other complications resulting from extensive vascular or cardiopulmonary bypass surgery. Similarly, systemic syndromes such as septic and hemorrhagic shock as well as multi organ failure are potential future indications. Finally, prevention of immunosuppression by T-cel depleting chemotherapeutics, corticosteroids or stress through (co-)administration of specific inhibitors of T-cel apoptosis are interesting applications of anti-apoptotic pharmacotherapy.

A major problem concerning in vivo modulation of apoptosis is the complexity in signaling of the various pro- and anti-apoptotic pathways (135). For instance, pharmacological prevention of apoptosis in ischemically damaged kidney transplants could delay death of allogenic T-cells and promote transplant rejection (136). Also, pharmacological inhibition of apoptosis could favor development of necrosis (137) or induce long-term carcinogenic effects (138). In order to prevent such adverse effects it is necessary to develop very specific and short-acting pharmacotherapeutic strategies. In this context, reversible and irreversible caspase-specific inhibitors have been designed based on peptide sequence homology e.g. DEVD-X for caspase- 3 and IEVD-X for caspase-6. Also, non-peptide caspase inactivators with enhanced bioavailability and stability are under extensive investigation. The latter agents include thiol alkylating reagents such as $\mathrm{N}$ ethyl-maleimide and iodoacetate or substances in which homologous amino acids are replaced by pyridone moyeties (139). 
Another approach is employment of non-specific apoptosis inhibitors such as growth factors and acute phase proteins. The anti-apoptotic growth factor IGF-1 was successfully employed in various models of renal I/R-injury and has been administered to patients with primary IGF-1 deficiency (Laron dwarfism)(140) and chronic renal failure (141) without significant deleterious side-effects. Problems with toxicity or adverse effects related to therapeutical use of acute phase proteins are hardly to be expected, since phys iological concentrations of these proteins were shown to be able to attenuate experimental I/R injury.

Finally, death-receptor mediated apoptosis can be prevented by neutralization of deathligands such as TNF- $\alpha$ and Fas-ligand. In our laboratory we showed that treatment with anti-TNF- $\alpha$ antibodies could significantly reduce $\mathrm{I} / \mathrm{R}$-induced renal apoptosis in a murine model (50). Antibodies directed against human TNF- $\alpha$ have been clinically applied to treat various inflammatory conditions, such as sepsis (142) and inflammatory bowel disease (143), without obvious adverse effects. Whether neutralization of the Fas system is a clinical option remains to be established.

\section{DIAGNOSTIC POSSIBILITIES OF I/R-INDUCED APOPTOSIS}

No additional diagnostics are performed to assess ischemic damage in donor kidneys that were not evidently subjected to ischemia. However, when exposure to prolonged ischemia is evident or of uncertain time as in NHB donation, such diagnostics are of crut cial importance. NHB donation is associated with a high incidence of delayed graft function (3), rendering implementation of a NHB donor program still controversial. Methods that can establish whether ischemically damaged donor organs are suitable to be used for transplantation (viability testing) will minimize complications from the use of NHB grafts. Besides effective pharmacotherapy, reliable viability tests that estimate the extent of ischemic damage and predict post-transplant function will justify wider implementation of this donor pool.

Apoptosis is an active process and several crucial aspects of the apoptotic response require ATP, which is depleted during ischemia. Consequently, completion of apoptosis essentially requires reperfusion. In line, Burns et al. showed that significantly more apoptosis occurred in postreperfusion compared with prereperfusion biopsy specimens from cadaveric donor transplants (144). We and others demonstrated absence of morphological signs of apoptosis and also absence of internucleosomal DNA fragmentation after inducing ischemia without reperfusion in the kidney as well as in other organs $(37,145$, 146). Despite this low number of apoptotic cells in prereperfusion renal grafts, Oberbauwer et al. postulated that the number of apoptotic tubular epithelial cells in donor biopsies predicts early graft function (147). Indeed, in many studies the length of ischemia correlates with the extent of postreperfusion apoptosis. Also, it is evident that apoptosis is initiated by ischemia but that reperfusion is needed for completion of the 
apoptotic cascade. Thus, it is likey that during ischemia, cells conform to biochemical criteria that facilitate execution of apoptosis upon reperfusion.

Results from our laboratory show that caspase-7 activation and cFLIP depletion potentially initiate and/or amplify ischemia-induced apoptosis upon reperfusion, which is essential to consequent development of inflammation and organ damage (Chapter 9). Interestingly both caspase-7 activation and cFLIP depletion can be detected in kidneys subjected to ischemia without reperfusion. Hence, caspase-7 activation, cFLIP depletion and potentially other molecular events during (warm or cold) ischemia may be employed as a diagnostic tool to predict the amount of apoptosis, inflammation and organ function following transplantation of an ischemically damaged organ.

\section{Conclusion}

A cell exposed to an ischemic insult in the end will either die in an apoptotic or a necrotic fashion or will be repaired and survive. The observation that tissue damage inflicted by $\mathrm{I} / \mathrm{R}$ is often partially reversible indicates the involvement of active cell repair, regeneration and survival mechanisms. Curiously, seemingly viable cells that survive the initial injury choose to commit suicide by means of apoptosis. The latter may be part of a teleological solution to prevent survival of cells with damaged DNA. Alternatively and/or additionally, I/R-induced apoptosis represents an effort undertaken by the organism to prevent necrotic cell death in the long-term.

Paradigmatically, as opposed to apoptosis, regeneration is not possible in case of necrosis. In general, several stimuli including unconditional metabolic collapse and cell membrane disruption by OFR will result in the necrotic phenotype. Also, insufficient phagocytotic capacity of neighbouring cells will lead to a conversion from the apoptotic to the necrotic phenotype (secondary necrosis). The conditions that favour apoptosis, necrosis as well as cell survival are more or less all present in an organ subjected to I/R. An overall balance between these factors will ultimately determine the amount of reperfusion injury and residual function of the postischemic organ. Shifting of this balance constitutes the central pathophysiological mechanism leading to $\mathrm{I} / \mathrm{R}$-injury. The question remaining addresses the nature of this balance.

It is not likely that an organ system such as the kidney can discriminate between different causes of cellular injury, whether it for instance is $I / R$, intoxication or radiation. Also, it is not known what the consequences of cell survival by endogenous or exogenous inhibition of apoptosis are in the long-term. In spite of the capacity to effectively inhibit apoptosis, an organism paradoxically prefers apoptosis as a prominent form of cell death following I/R. Hypothetically, this is a consequence of insufficient evolutionary selection pressure with respect to prevalence of cell survival mechanisms. Obviously, cells that are genetically damaged by aspecific exogenous stimuli such as $\mathrm{I} / \mathrm{R}$, (nephro)toxic agents or radiation are potentially mutagenic. In spite of residual function, 
it is an advantage to permanently remove such cells. Whether we prove to be wiser than evolution and succeed in preventing the injurious effects of renal $\mathrm{I} / \mathrm{R}$ as well as the potential long-term consequences of its pharmacological antidotes, remains to be seen.

In its various clinical presentations I/R-injury forms a significant burden to modern healthcare. The study of $\mathrm{I} / \mathrm{R}$ pathophysiology in animal models as well as in the clinical situation is an essential prerequisite for the development of improved means of management. It is now clear that apoptosis can no longer be regarded as but an epiphenomenon of reperfusion injury. Recent observations in various organ systems indicate a functional role for apoptosis and biochemical pathways leading to apoptosis in the development of I/R injury. An important advantage is that the fate of cells that are bound to die by apoptosis can be changed by adequate pharmacotherapy. Even more important, the deleterious consequences of activation of the apoptotic cascade can be prevented pharmacologically. Serious studies are essential to elucidate short- as well as long-term beneficial and/or detrimental effects of such interventions. The implications of clinical application are potentially enormous, particularly in situations such as preservation and use of ischemically damaged donor organs, renal, brain and myocardial ischemia, vascular surgery, shock and many other conditions.

\section{REFERENCES}

1. Bittar N, Koke JR, Berkoff HA, Kahn DR. Histochemical and structural changes in human myocardial cells after cardiopulmonary bypass. Circulation 1975; 52 supp. 2: 116.

2. Anderson JL, Karagounis LA, Califf RM. Meta-analysis of five reported studies on the relation of early coronary patency grades with mortality and outcomes after acute myocardial infarction. Am J Cardiol 1996; 78: 1.

3. Wijnen RM, Booster MH, Stubenitsky BM, De Boer J, Heineman E, Kootstra G. Outcome of transplantation of non-heart-beating donor kidneys. Lancet 1995; 345: 1067.

4. Shoskes DA, Halloran PF. Delayed graft function in renal transplantation: etiology, management and long-term significance. $J$ Urol 1996; 155: 1831.

5. Litten M. Ueber pathologische Verkalkungen und Kalkmetastasen in den Nieren. Virchows Arch 1881; 83: 508 .

6. Israel O. Die anämische Nekrose der Nierepithelien. Experimentelle Untersuchung. Virchows Arch 1891; 123: 310 .

7. Scarff RW, Keele CA. The effects of temporary occlusion of the renal circulation in the rabbit. Br J Exp Pathol 1943; 24: 147.

8. Emmel VM. Mitochondrial and $\mathrm{pH}$ changes in the rat's kidney following interruption and restoration of the renal circulation. Anat Rec 1940; 78: 361 .

9. Granger DN, Rutili G, McCord JM. Superoxide radicals in feline intestinal ischemia. Gastroenterology 1981; 81: 22.

10. Hochachka PW. Defense strategies against hypoxia and hypothermia. Science 1986; $231: 234$.

11. McCord JM. Oxygen-derived free radicals in postischemic tissue injury. $N$ Engl J Med 1985; 312: 159. 
12. Le HM, Angielski S, Dubach UC. Properties of an ecto-5'-nucleotidase of the renal brush border. Ren Physiol 1985; 8: 321.

13. Bouma MG, Van den Wildenberg FAJM, Buurman WA. The anti-inflammatory potential of adenosine in ischemia-reperfusion injury: established and putative beneficial actions of a retaliatory metabolite. Shock 1997: 8: 313.

14. Melchior F, Gerace L. Mechanisms of nuclear protein import. Curr Opin Cell Biol 1995:7: 310.

15. Romson JL. Hook BG, Kunkel SL, Abrams GD, Schork MA, Lucchesi BR. Reduction of the extent of ischemic myocardial injury by neutrophil depletion in the dog. Circulation 1983; 67: 1016.

16. Vedder NB, Winn RK, Rice CL, Chi EY, Arfors KE, Harlan JM. Inhibition of leukocyte adherence by anti-CD 18 monoclonal antibody attenuates reperfusion injury in the rabbit ear. Proc Natl Acad. Sci U.S.A. 1990; 87: 2643.

17. Winn RK, Ramamoorthy C, Vedder NB, Sharar SR, Harlan JM. Leukocyte-endothelial cell interactions in ischemia-reperfusion injury. Ann N Y Acad Sci 1997: 832: 311.

18. Schumer M, Colombel MC, Sawczuk IS, et al. Morphologic, biochemical, and molecular evidence of apoptosis during the reperfusion phase after brief periods of renal ischemia. $A m J$ Pathol 1992; 140: 831.

19. Rabb H, Mendiola CC, Saba SR, et al. Antibodies to ICAM-I protect kidneys in severe ischemic reperfusion injury. Biochem Biophys Res Commun 1995; 211: 67.

20. Yaoita H. Ogawa K. Machara K. Maruyama Y. Attenuation of ischemia/reperfusion injury in rats by a caspase inhibitor. Circulation 1998; 97: 276.

21. Haug CE, Colvin RB, Delmonico FL, et al. A phase I trial of immunosuppression with antiICAM-I (CD54) mAb in renal allograft recipients. Transplantation 1993; 55: 766.

22. Mathew JP, Rinder CS. Tracey JB, et al. Acadesine inhibits neutrophil CDI Ib up-regulation in vitro and during in vivo cardiopulmonary bypass. J Thorac Cardiovasc Surg 1995; 109: 448.

23. Thadhani R, Pascual M, Bonventre JV. Acute renal failure. N Engl J Med 1996; 334: 1448.

24. Lieberthal W, Koh JS, Levine JS. Necrosis and apoptosis in acute renal failure. Semin Nephrol 1998; 18: 505 .

25. Staunton MJ, Gaffney EF. Apoptosis: basic concepts and potential significance in human cancer. Arch Pathol Lab Med 1998; 122: 310.

26. Thornberry NA, Lazebnik Y. Caspases: enemies within. Science 1998; 281: 1312.

27. Geng YJ, Azuma T, Tang JX, et al. Caspase-3-induced gelsolin fragmentation contributes to actin cytoskeletal collapse, nucleolysis, and apoptosis of vascular smooth muscle cells exposed to proinflammatory cytokines. Eur J Cell Biol 1998; 77: 294.

28. Waterhouse NJ. Finucane DM, Green DR, et al. Calpain activation is upstream of caspases in radiation-induced apoptosis. Cell Death Differ 1998; 5: 1051.

29. Fadok VA, Bratton DL, Rose DM, Pearson A, Ezekewitz RA, Henson PM. A receptor for phosphatidylserine-specific clearance of apoptotic cells. Nature 2000; $405: 85$.

30. Maulik N, Kagan VE, Tyurin VA, Das DK. Redistribution of phosphatidylethanolamine and phosphatidylserine precedes reperfusion-induced apoptosis. Am J Physiol 1998; 43: H242.

31. Hofstra L. Liem IH, Dumont EA, et al. Visualisation of cell death in vivo in patients with acute myocardial infarction. Lancet 2000; 356: 209.

32. Louagie H, Cornelissen M, Philippe J, Vral A, Thierens H, De RL. Flow cytometric scoring of apoptosis compared to electron microscopy in gamma irradiated lymphocytes. Cell Biol Int 1998; $22: 277$. 
33. Waring P, Lambert D, Sjaarda A, Hurne A, Beaver J. Increased cell surface exposure of phosphatidylserine on propidium iodide negative thymocytes undergoing death by necrosis. Cell Death Differ 1999; 6: 624

34. Kerr JF, Wyllie AH, Currie AR. Apoptosis: a basic biological phenomenon with wide-ranging implications in tissue kinetics. Br J Cancer 1972; 26: 239.

35. Tran TB, Miller RJ. Apoptosis: death and transfiguration. Science Med 2000; 6: 18.

36. Fadok VA, Bratton DL, Konowal A, Freed PW, Westcott JY, Henson PM. Macrophages that have ingested apoptotic cells in vitro inhibit proinflammatory cytokine production through autocrine/paracrine mechanisms involving TGF-beta, PGE2, and PAF. J Clin Invest 1998; 101: 890.

37. Daemen MARC, Van 't Veer C, Denecker G, et al. Inhibition of apoptosis induced by ischemiareperfusion prevents inflammation. J Clin Invest 1999; 104: 541.

38. Knies UE, Behrensdorf HA, Mitchell CA, et al. Regulation of endothelial monocyte-activating polypeptide II release by apoptosis. Proc Natl Acad Sci U.S.A. 1998; 95: 12322

39. Miwa K, Asano M, Horai R, Iwakura Y, Nagata S, Suda T. Caspase I-independant IL-Ibeta release and inflammation induced by the apoptosis inducer Fas ligand. Nature Med 1998: 4: 1287.

40. Wkasugi, K, Schimmel, P. Two distinct cytokines released from a human aminoacyl-tRNA synthetase. Science 1999; 284, 147.

41. Eguchi Y, Srinivasan A, Tomaselli KJ, Shimizu S, Tsujimoto Y. ATP-dependent steps in apoptotic signal transduction. Cancer Res 1999; $59: 2174$.

42. Edelstein CL, Shi Y, Schrier RW. Role of caspases in hypoxia-induced necrosis of rat renal proximal tubules. J Am Soc Nephrol 1999; 10: 1940.

43. Nicotera P, Leist M, Ferrando ME. Apoptosis and necrosis: different execution of the same death. Biochem Soc Symp 1999; 66: 69.

44. Formigli L, Papucci L, Tani A, et al. Aponecrosis: morphological and biochemical exploration of a syncretic process of cell death sharing apoptosis and necrosis. J Cell Physiol 2000:182: 41.

45. Trump BF, Berezesky IK, Chang SH, Phelps PC. The pathways of cell death: oncosis, apoptosis, and necrosis. Toxicol Pathol 1997; 25: 82 .

46. Columbano A. Cell death: current difficulties in discriminating apoptosis from necrosis in the context of pathological processes in vivo. J Cell Biochem 1995; 58: 181 .

47. Vermes I, Haanen C, Steffens NH, Reutelingsperger C. A novel assay for apoptosis. Flow cytometric detection of phosphatidylserine expression on early apoptotic cells using fluorescein labelled Annexin V. J Immunol Methods 1995; 184: 39.

48. Iwata M, Myerson D. Torok Storb B, Zager RA. An evaluation of renal tubular DNA laddering in response to oxygen deprivation and oxidant injury. $J$ Am Soc Nephrol 1994: 5: 1307.

49. Portera CC. Price DL, Martin LJ. Excitotoxic neuronal death in the immature brain is an apoptosis-necrosis morphological continuum. J Comp Neurol 1997; 378: 70.

50. Daemen MARC, Van de Ven WCM, Heineman E, Buurman WA. Pro- and anti-inflammatory mechanisms in renal reperfusion injury in mice. Modulation by endogenous tumor necrosis factor alpha and interleukin-10. Transplantation 1999; 67: 792.

51. Farber E. Programmed cell death: necrosis versus apoptosis. Mod Pathol 1994; $7: 605$.

52. Hengartner MO. The biochemistry of apoptosis. Nature 2000; 407: 770

53. Nogae S, Miyazaki M, Kobayashi N, et al. Induction of apoptosis in ischemia-reperfusion model of mouse kidney: Possible involvement of Fas. J Am Soc Nephrol 1998; 9: 620.

54. Herr I, Posovszky C, Di ML, Cifone MG, Boehler T, Debatin KM. Autoamplification of apoptosis following ligation of CD95-L. TRAIL and TNF-alpha. Oncogene 2000; 19: 4255. 
55. Rivera WI, Cvijic ME, Xiao G, Sun SC. The NF-kappa B signaling pathway is not required for Fas ligand gene induction but mediates protection from activation-induced cell death. $J$ Biol Chem 2000; 275: 25222 .

56. Mustapha S, Kirshner A, De Moissac D, Kirshenbaum LA. A direct requirement of nuclear factor-kappa B for suppression of apoptosis in ventricular myocytes. Am J Physiol 2000; 279: H939.

57. Donnahoo KK, Shames BD, Harken AH, Meldrum DR. Review article: the role of tumor necrosis factor in renal ischemia-reperfusion injury. J Urol 1999; 162: 196.

58. Rasper DM, Vaillancourt JP, Hadano S, et al. Cell death attenuation by 'Usurpin', a mammalian DED-caspase homologue that precludes caspase- 8 recruitment and activation by the CD-95 (Fas, APO-1) receptor complex. Cell Death Differ 1998; 5: 271.

59. Li P, Nijhawan D, Budihardjo I, et al. Cytochrome c and dATP-dependent formation of ApafI/caspase-9 complex initiates an apoptotic protease cascade. Cell 1997; 91: 479.

60. Susin SA, Zamzami N, Castedo M, et al. Bcl-2 inhibits the mitochondrial release of an apoptogenic protease. J Exp Med 1996; 184: 1331.

61. Frade JM, Michaelidis TM. Origin of eukaryotic programmed cell death: a consequence of aerobic metabolism? Bioessays 1997; 19: 827.

62. Saikumar P, Dong Z, Patel Y, et al. Role of hypoxia-induced Bax translocation and cytochromec release in reoxygenation injury. Oncogene 1998; 17: 3401 .

63. Gobe G, Zhang XJ, Willgoss DA, Schoch E, Hogg NA, Endre ZH. Relationship between expression of Bcl-2 genes and growth factors in ischemic acute renal failure in the rat. $J$ Am Soc Nephrol 2000: 11: 454 .

64. Basile DP, Liapis H, Hammerman MR. Expression of $\mathrm{Bcl}-2$ and bax in regenerating rat renal tubules following ischemic injury. Am J Physiol 1997; 272: F640.

65. Martinou JC, Dubois DM, Staple JK, et al. Overexpression of Bcl-2 in transgenic mice protects neurons from naturally occurring cell death and experimental ischemia. Neuron 1994; 13: 1017.

66. Coopersmith CM, O’Donnell D, Gordon JI. Bcl-2 inhibits ischemia-reperfusion-induced apoptosis in the intestinal epithelium of transgenic mice. Am J Physiol 1999; 276: G677.

67. Hata R, Gillardon F, Michaelidis TM, Hossmann KA. Targeted disruption of the bcl-2 gene in mice exacerbates focal ischemic brain injury. Metab Brain. Dis 1999; 14: 117.

68. Saikumar P, Dong Z, Weinberg JM, Venkatachalam MA. Mechanisms of cell death in hypoxia/reoxygenation injury. Oncogene 1998; 17. 3341 .

69. Luo X, Budihardjo I, Zou H, Slaughter C, Wang X. Bid, a Bcl2 interacting protein, mediates cytochrome $\mathrm{c}$ release from mitochondria in response to activation of cell surface death receptors. Cell 1998; 94: 481.

70. Marzo I, Susin SA, Petit PX, et al. Caspases disrupt mitochondrial membrane barrier function. FEBS Lett 1998; 427: 198.

71. Hu Y, Benedict MA, Ding L, Nunez G. Role of cytochrome $\mathrm{c}$ and dATP/ATP hydrolysis in Apaf1-mediated caspase-9 activation and apoptosis. EMBO J 1999; 18: 3586.

72. Zager RA, Iwata M, Conrad DS, Burkhart KM, Igarashi Y. Altered ceramide and sphingosine expression during the induction phase of ischemic acute renal failure. Kidney Int 1997; 52: 60.

73. Raafat AM, Murray MT, McGuire T, et al. Calcium blockade reduces renal apoptosis during ischemia reperfusion. Shock 1997; 8: 186.

74. Webster KA, Discher DJ, Kaiser S, Hernandez O, Sato B, Bishopric NH. Hypoxia-activated apoptosis of cardiac myocytes requires reoxygenation or a $\mathrm{pH}$ shift and is independent of $53 . J$ Clin Invest 1999; 104: 239.

75. Harris RC. Growth factors and cytokines in acute renal failure. Adv Ren Replace Ther 1997; 4: 43. 
76. Hague A, Hicks DJ, Bracey TS, Paraskeva C. Cell-cell contact and specific cytokines inhibit apoptosis of colonic epithelial cells: growth factors protect against c-myc-independent apoptosis. Br J Cancer 1997; 75: 960.

77. Hirschberg R, Ding H. Mechanisms of insulin-like growth factor-1-induced accelerated recovery in experimental ischemic acute renal failure. Miner Electrolyte Metab 1998; 24:211.

78. Humes HD, Cieslinski DA, Coimbra TM, Messana JM, Galvao C. Epidermal growth factor enhances renal tubule cell regeneration and repair and accelerates the recovery of renal function in postischemic acute renal failure. J Clin Invest 1989; 84: 1757.

79. Miller SB, Martin DR, Kissane J, Hammerman MR. Hepatocyte growth factor accelerates recovery from acute ischemic renal injury in rats. Am J Physiol 1994; 266: F129.

80. Yuan J, Shaham S, Ledoux S, Ellis HM, Horvitz HR. The C. elegans cell death gene ced-3 encodes a protein similar to mammalian interleukin-1 beta-converting enzyme. Cell 1993; 75: 641.

81. Enari M, Sakahira H, Yokoyama H, Okawa K, Iwamatsu A, Nagata S. A caspase-activated DNase that degrades DNA during apoptosis, and its inhibitor ICAD. Nature 1998; $391: 43$.

82. Hara H, Fink K, Endres M, et al. Attenuation of transient focal cerebral ischemic injury in transgenic mice expressing a mutant ICE inhibitory protein. J Cereb Blood Flow Metab 1997; 17: 370.

83. Kaushal GP, Singh AB, Shah SV. Identification of gene family of caspases in rat kidney and altered expression in ischemia-reperfusion injury. Am J Physiol 1998; 274: F587.

84. Parks DA, Granger DN, Bulkley GB, Shah AK. Soybean trypsin inhibitor attenuates ischemic injury to the feline small intestine. Gastroenterology 1985; 89:6.

85. Paller MS, Hoidal JR, Ferris TF. Oxygen free radicals in ischemic acute renal failure in the rat. J Clin Invest 1984; 74: 1156.

86. Punch J, Rees R, Cashmer B, Wilkins E, Smith DJ, Till GO. Xanthine oxidase: its role in the noreflow phenomenon. Surgery 1992; 111: 169.

87. Hagar H, Ueda N, Shah SV. Role of reactive oxygen metabolites in DNA damage and cell death in chemical hypoxic injury to LLC-PKI cells. Am J Physiol 1996; 271: F209.

88. Von Harsdorf R, Li PF, Dietz R. Signaling pathways in reactive oxygen species-induced cardiomyocyte apoptosis. Circulation 1999; 99: 2934.

89. Teranishi M, Spodonik JH, Karbowski M, Kurono C, Soji T, Wakabayashi T. Swelling of freeradical-induced megamitochondria causes apoptosis. Exp Mol Pathol 2000; 68: 104.

90. Patel KD, Zimmerman GA, Prescott SM, Mcever RP, Mcintyre TM. Oxygen radicals induce human endothelial cells to express GMP-140 and bind neutrophils. J Cell Biol 1991; 112: 749.

91. De Greef KE, Ysebaert DK, Ghielli M, et al. Neutrophils and acute ischemia-reperfusion injury. $J$ Nephrol 1998; 11: 110.

92. Klausner JM, Paterson IS, Goldman G, et al. Postischemic renal injury is mediated by neutrophils and leukotrienes. Am J Physiol 1989; 256: F794.

93. Buschbeck M, Ghomashchi F, Gelb MH, Watson SP, Borsch HA. Stress stimuli increase calcium-induced arachidonic acid release through phosphorylation of cytosolic phospholipase A2. Biochem J 1999; 344: 359.

94. Lopez Farre A, Bernabeu F, Gomez Garre D, Ramon Braquet P, Lopez Novoa J. Platelet-activating factor antagonists treatment protects against postischemic acute renal failure in rats. $J$ Pharmacol Exp Ther 1990; 253: 328.

95. Torras J, Bordalba JR, Seron D, et al. Protective effect of the PAF antagonist BN 52021 in an experimental renal warm ischemia model. Transpl Int 1993; 6: 236.

96. Zhou W, Farrar CA, Abe K, et al. Predominant role for C5b-9 in renal ischemia/reperfusion injury. J Clin Invest 2000; 105: 1363. 
97. Ley K. Molecular mechanisms of leukocyte recruitment in the inflammatory process. Cardiovasc Res 1996: 32: 733 .

98. Singbartl K, Ley K. Protection from ischemia-reperfusion induced severe acute renal failure by blocking E-selectin. Crit Care Med 2000; 28: 2507.

99. Dragun D. Tullius SG, Park JK, et al. ICAM-I antisense oligodesoxynucleotides prevent reperfusion injury and enhance immediate graft function in renal transplantation. Kidney Int 1998; 54: 590.

100. Haug CE, Colvin RB, Delmonico FL, et al. A phase I trial of immunosuppression with antiICAM-I (CD54) mAb in renal allograft recipients. Transplantation 1993; 55: 766.

101. Weiss SJ. Tissue destruction by neutrophils. N Engl J Med 1989; 320: 365.

102. Carp H. Mitochondrial $\mathrm{N}$-formylmethionyl proteins as chemoattractants for neutrophils. $J$ Exp Med 1982; 155: 264

103. Lennon GM, Ryan PC, Fitzpatrick JM. Ischaemia-reperfusion injury in the rat kidney: effect of a single dose of sodium bicarbonate. Br J Surg 1993; 80: 112.

104. Dewald B. Baggiolini M. Activation of NADPH oxidase in human neutrophils. Synergism between fMLP and the neutrophil products PAF and LTB4. Biochem Biophys Res Commun 1985; 128: 297

105. Halloran PF, Homik J, Goes N, et al. The injury response: a concept linking nonspecific injury, acute rejection, and long term transplant outcomes. Transplant Proc 1997; 29: 79.

106. Shoskes DA, Parfrey NA, Halloran PF. Increased major histocompatibility complex antigen expression in unilateral ischemic acute tubular necrosis in the mouse. Transplantation 1990; 49: 201.

107. Goes N, Urmson J, Ramassar V, Halloran PF. Ischemic acute tubular necrosis induces an extensive local cytokine response. Evidence for induction of interferon-gamma, transforming growth factor-beta 1, granulocyte-macrophage colony- stimulating factor, interleukin-2, and interleukin10. Transplantation 1995; 59: 565.

108. Shoskes DA, Halloran PF. Ischemic injury induces altered MHC gene expression in kidney by an interferon-gamma-dependent pathway. Transplant Proc 1991; 23 : 599.

109. Daemen MARC, Van 't Veer C, Wolfs TGAM, Buurman WA. Ischemia-reperfusion induced IFN-gamma upregulation: Involvement of IL-12 and IL-18. J Immunol 1999; 162: 5506.

110. Bohn E, Sing A, Zumbihl R, et al. IL-18 (IFN-gamma-inducing factor) regulates early cytokine production in, and promotes resolution of, bacterial infection in mice. J Immunol 1998; 160: 299.

111. Matzinger P. An innate sense of danger. Semin Immunol 1998; 10: 399.

112. Frantz S, Kobzik L, Kim YD, et al. Toll4 (TLR4) expression in cardiac myocytes in normal and failing myocardium. J Clin Invest 1999: 104: 271.

113. Daemen MARC, Heemskerk VH, Van 't Veer C, et al. Functional protection by acute phase proteins alpha(1)-acid glycoprotein and alpha(1)-antitrypsin against ischemia/reperfusion injury by preventing apoptosis and inflammation. Circulation 2000; 102: 1420.

114. Howard AD, Kostura MJ. Thornberry N, et al. IL-1-converting enzyme requires aspartic acid residues for processing of the IL-1 beta precursor at two distinct sites and does not cleave 31kDa IL-I alpha. J Immunol 1991; 147: 2964.

115. Gu Y, Kuida K, Tsutsui H, et al. Activation of interferon-gamma inducing factor mediated by interleukin-I beta converting enzyme. Science 1997; 275: 206.

116. Haq M. Norman J. Saba SR. Ramirez G. Rabb H. Role of IL-1 in renal ischemic reperfusion injury. J Am Soc Nephrol 1998: 9:614. 
117. Friedlander RM, Gagliardini V, Hara H, et al. Expression of a dominant negative mutant of interleukin-1 beta converting enzyme in transgenic mice prevents neuronal cell death induced by trophic factor withdrawal and ischemic brain injury. $J$ Exp Med 1997; 185: 933.

118. Daemen MARC, Denecker G, Van 't Veer C, Wolfs TGAM, Vandenabeele P, Buurman WA. Activated caspase-1 is not a central mediator of inflammation in the course of schemia-reperfusion. Transplantation, in press.

119. Behrensdorf HA, Van de Craen M, Knies UE, Vandenabeele P, Clauss M. The endothelial monocyte-activating polypeptide II (EMAP II) is a substrate for caspase-7. FEBS Lett 2000; 466: 143.

120. Shi Y, Melnikov V, Schrier RW, Edelstein CL. Downregulation of the calpain inhibitor protein calpastatin by caspases during renal ischemia-reperfusion. Am J Physiol 2000; 279; F509.

121. Lee KS, Frank S, Vanderklish P, Arai A, Lynch G. Inhibition of proteolysis protects hippocampal neurons from ischemia. Proc Natl Acad Sci U.S.A. 1991; 88: 7233.

122. Kohli V, Madden JF, Bentley RC, Clavien PA. Calpain mediates ischemic injury of the liver through modulation of apoptosis and necrosis. Gastroenterology 1999; 116: 168.

123. David LL, Shearer TR, Shih M. Sequence analysis of lens beta-crystallins suggests involvement of calpain in cataract formation. J Biol Chem 1993; 268: 1937.

124. Carruth LM, Demczuk S, Mizel SB. Involvement of a calpain-like protease in the processing of the murine interleukin 1 alpha precursor. J Biol Chem 1991; 266: 12162.

125. Liu ZQ, Kunimatsu M, Yang JP, Ozaki Y, Sasaki M, Okamoto T. Proteolytic processing of nuclear factor kappa B by calpain in vitro. FEBS Lett 1996: 385: 109.

126. Wang CY, Mayo MW, Baldwin AS Jr. TNF- and cancer therapy-induced apoptosis: potentiation by inhibition of NF-kappaB. Science 1996; 274: 784.

127. Gerard C, Bruyns C, Marchant A, et al. Interleukin 10 reduces the release of tumor necrosis factor and prevents lethality in experimental endotoxemia. J Exp Med 1993; 177: 547.

128. Leeuwenberg JF, Jeunhomme TM, Buurman WA. Slow release of soluble TNF receptors by monocytes in vitro. $J$ Immunol 1994; 152: 4036.

129. Marchant A, Bruyns C, Vandenabeele P, et al. The protective role of interleukin-10 in endotoxin shock. Prog Clin Biol Res 1994; 388: 417.

130. Arai T, Hiromatsu K, Nishimura H, et al. Endogenous interleukin 10 prevents apoptosis in macrophages during Salmonella infection. Biochem Biophys Res Commun 1995; 213:600.

131. Meldrum DR, Cleveland JJ, Rowland RT, Banerjee A, Harken AH. Meng X. Early and delayed preconditioning: differential mechanisms and additive protection. Am J Physiol 1997; 273: H725.

132. Akcetin Z, Pregla R, Darmer D, et al. Differential expression of heat shock proteins 70-1 and 702 mRNA after ischemia-reperfusion injury of rat kidney. Urol Res 1999:27:306.

133. Mehlen P, Preville X, Chareyron P. Briolay J, Klemenz R. Arrigo AP. Constitutive expression of human hsp27. Drosophila hsp27, or human alpha B-crystallin confers resistance to TNF- and oxidative stress-induced cytotoxicity in stably transfected murine L929 fibroblasts. J Immunol $1995 ; 154: 363$

134. Ahn JH, Ko YG, Park WY. Kang YS, Chung HY, Seo JS. Suppression of ceramide-mediated apoptosis by HSP70. Mol Cells 1999; 9: 200.

135. Deigner HP. Kinscherf R. Modulating apoptosis: current applications and prospects for future drug development. Curr Med Chem 1999; 6: 399.

136. Zavazava N. Kabelitz D. Alloreactivity and apoptosis in graft rejection and transplantation tolerance. J Leukoc Biol 2000; 68: 167.

137. Vercammen D, Beyaert R. Denecker G, et al. Inhibition of caspases increases the sensitivity of L929 cells to necrosis mediated by tumor necrosis factor. J Exp Med 1998; 187: 1477. 
138. Foster JR. Cell death and cell proliferation in the control of normal and neoplastic tissue growth. Toxicol Pathol 2000; 28: 441.

139. Dolle RE, Prouty CP, Prasad CV, et al. First examples of peptidomimetic inhibitors of interleukin-1 beta converting enzyme. J Med Chem 1996; 39: 2438.

140. Laron Z. Clinical use of somatomedin-1: yes or no? Paediatr Drugs 1999; 1: 155.

141. Hirschberg R, Kopple J, Lipsett P, et al. Multicenter clinical trial of recombinant human insulinlike growth factor I in patients with acute renal failure. Kidney Int 1999; 55: 2423.

142. Fisher CJ, Opal SM, Dhainaut JF, et al. Influence of an anti-tumor necrosis factor monoclonal antibody on cytokine levels in patients with sepsis. The CB0006 Sepsis Syndrome Study Group. Crit Care Med 1993; 21: 318.

143. Sandborn WJ, Hanauer SB. Antitumor necrosis factor therapy for inflammatory bowel disease: a review of agents, pharmacology, clinical results, and safety. Inflamm. Bowel Dis 1999; 5: 119.

144. Burns AT, Davies DR, McLaren AJ, Cerundolo L, Morris PJ, Fuggle SV. Apoptosis in ischemia/reperfusion injury of human renal allografts. Transplantation 1998; 66: 872.

145. Kohli V, Selzner M, Madden JF, Bentley RC, Clavien PA. Endothelial cell and hepatocyte deaths occur by apoptosis after ischemia-reperfusion injury in the rat liver. Transplantation 1999; 67: 1099.

146. Freude B, Masters TN, Robicsek F, et al. Apoptosis is initiated by myocardial ischemia and executed during reperfusion. J Mol Cell Cardiol 2000; 32: 197.

147. Oberbauer R, Rohrmoser M, Regele H, Muhlbacher F, Mayer G. Apoptosis of tubular epithelial cells in donor kidney biopsies predicts early renal allograft function. $J$ Am Soc Nephrol 1999; 10: 2006. 


\section{CHAPTER 2}

\section{Involvement of endogenous interleukin-10 and}

tumor necrosis factor- $\alpha$ in renal ischemia-reperfusion injury

Marc A.R.C. Daemen, Monique W.C.M. van de Ven, Erik Heineman, Wim A. Buurman 


\section{ABSTRACT}

Ischemia followed by reperfusion is a common clinical event associated with a proinflammatory response leading to organ dysfunction. The aim of the present study is to evaluate the interplay between this pro-inflammatory response and apoptosis. We investigated the role of the pro-inflammatory mediator tumor necrosis factor- $\alpha$ (TNF- $\alpha$ ) and the anti-inflammatory mediator interleukin-10 (IL-10) in inflammation and apoptosis following renal ischemia reperfusion.

Male Swiss mice were subjected to $45 \mathrm{~min}$ of ischemia followed by reperfusion and subsequently administered neutralizing Abs against either TNF- $\alpha$ (TN3), IL-10 (JES52A5) or control.

After 1 day of reperfusion anti-TNF- $\alpha$ treatment reduced while anti-IL-10 treatment exacerbated postischemic renal injury, inflammation and, to a lesser extent, apoptosis as measured by changes in blood urea nitrogen content, immunohistologically detectable renal TNF- $\alpha$ protein and neutrophils, histological integrity of renal parenchyma and DNA-ladder formation. Furthermore, anti-IL-10 treatment enhanced major histocompatibility complex class I and II expression at day 7 as measured by enzyme immunoassay and immunohistology.

These data indicate that the extent of reperfusion-induced apoptosis is modulated by the inflammatory response during which locally produced TNF- $\alpha$ plays a significant role in the development of tissue injury. Subsequently, this pro-inflammatory reaction is followed by endogenous production of the anti-inflammatory cytokine IL-10 which serves as a physiological counterbalance to the effects of TNF- $\alpha$. These novel pathophysiologal insights may provide new basis for the development of tools for limiting ischemia and reperfusion injury.

\section{INTRODUCTION}

Renal insufficiency as a consequence of hypoperfusion/ischemia followed by reperfusion is of particular relevance to transplantation (1) but also to coronary bypass surgery (2), aortic cross-clamping (3) and shock (4). Many studies show that an inflammatory response induced by ischemia followed by reperfusion $(\mathrm{I} / \mathrm{R})$ is largely responsible for functional organ failure and tissue damage $(5,6)$. The acute inflammatory response initiated by $\mathrm{I} / \mathrm{R}$ is characterized among others by the induction of a pro-inflammatory cytokine cascade $(7,8)$, expression of adhesion molecules $(9)$ and cellular infiltration (10). Other signs of the inflammatory response are less acute and include local infiltration by T-cells and macrophages (5) as well as upregulation of major histocompatibility complex (MHC) antigens with respect to renal I/R $(11,12)$. Recent reports support the notion that beside inflammation, apoptotic cell death is triggered by $I / R(13,14)$. The execution of sublethally injured but viable cells normally capable of complete recovery 
set in motion by apoptosis may contribute to reperfusion injury. Apoptosis can be triggered among others by the pro-inflammatory cytokine tumor necrosis factor-a (TNF- $\alpha$ ) (15). The release of TNF- $\alpha$, which has been attributed a central role not only in apoptosis but also in inflammation, has been implied to be involved in I/R injury in the liver by Colletti et al. They demonstrated the presence of detectable TNF- $\alpha$ plasma levels and showed that histological damage and increased neutrophil sequestration in the liver as well as remote pulmonary injury were mediated by TNF- $\alpha(16,17)$. These findings are in line with the reported TNF- $\alpha$-induced expression of chemokines $(16,18)$ and adhesion molecules (19). TNF- $\alpha$ until now has not been established as a mediator of renal $1 / R$ injury but may be of importance considering the ability of renal cells to produce TNF- $\alpha$ (20).

Conditions associated with TNF- $\alpha$ release such as endotoxemia among others are characterized by the production of endogenous interleukin-10 (IL-10) (21), a natural antiinflammatory response controlling excess production (22), as well as effects (23) of TNF- $\alpha$. Besides, in a model of non-uremic renal I/R injury, enhanced IL-10 mRNA production has been demonstrated (12). These considerations prompted us to hypothesize that renal $\mathrm{I} / \mathrm{R}$ is attended by enhancement of pro-inflammatory next to anti-inflammatory mechanisms in an activated balance that regulates the extent of reperfusion-induced inflammation as well as apoptosis.

We evaluated the involvement of the pro-inflammatory cytokine TNF- $\alpha$ as well as the anti-inflammatory cytokine IL-10 in a murine model of renal I/R injury. To this end, mice were treated with the neutralizing anti-murine TNF- $\alpha$ monoclonal antibody (mAb) TN3 or the anti-murine IL-10 mAb JES5-2A5. Renal function, morphology, TNF- $\alpha$ expression and neutrophil infiltration in addition to MHC class I and II up-regulation, expression of TNF- $\alpha$ and IL-10 specific mRNA levels, and the extent of renal apoptosis were investigated.

\section{Materials and Methods}

\section{ANTIBODIES AND REAGENTS}

The following antibodies (Abs) were used: anti-murine TNF- $\alpha$ mAb TN3, a complementarity-determining regions grafted murine $\mathrm{IgG} 2 \mathrm{a}$ was a generous gift from Celltech (Slough, UK); anti-murine IL-10 mAb JES5-2A5, a Rat IgGl, was kindly provided by HBT (Uden, The Netherlands); anti-human TNF- $\alpha$ mAb 52 B83 $(24,25)$ cross-reactive with murine TNF- $\alpha$; mAb GL113 a control rat IgGl was kindly provided by Dr. Savelkoul (Erasmus University, Rotterdam, The Netherlands); mAb 5D7, a control murine IgG2a; anti-murine MHC class I $\mathrm{mAb} \mathrm{ml} / 42.3 .9 .8$ was purchased from the ATTC (Rockville, MD); anti-murine MHC class II mAb H82-168.10 was kindly provided by Dr. Pierres (CNRS INSERM, Marseille, France); anti-murine neutrophil mAb Gr-1 was 
purchased from Pharmingen (San Diego, CA). Other reagents used were: peroxidase conjugated goat anti-rat IgG and peroxidase conjugated goat anti-rabbit IgG purchased from Jackson (West Grove, PA); the digoxigenin-labeling compound digoxigenin-3-0-methylcarbonyl-e-aminocaproic-acid-N-hydroxy-succinimide ester, alkaline phosphatase-conjugated sheep anti-digoxigenin and alkaline phosphatase chromogen NBT/BCIP were purchased from Boehringer Mannheim (Mannheim, Germany); murine recombinant TNF- $\alpha$ was purchased from ICN (Costa Mesa, CA). All other reagents were purchased from Sigma Chemical (St. Louis, MO).

\section{RENAL ISCHEMIA/REPERFUSION INJURY MODEL}

Male Swiss mice weighing 20-25 g were obtained from Charles River Breeding Laboratories (Heidelberg, Germany). Animals were housed individually in standard laboratory cages and were allowed free access to food and water throughout the experiments. The studies were carried out under a protocol approved by the Institutional Animal Care Committee of the University of Maastricht. At the start of the experiments, mice were anesthetized with sodium pentobarbital $(50 \mathrm{mg} / \mathrm{kg}$ i.p.). A rectal probe (ColePalmer, Vernon Hills, IL) to monitor body temperature was inserted and body temperature was maintained at $39^{\circ} \mathrm{C}$ by a heating lamp until animals recovered from anesthesia. Under aseptic conditions a 1.0-cm-long midline abdominal incision was made and ischemia was induced by applying a non-traumatic vascular clamp to the left renal pedicle for $45 \mathrm{~min}$. After $3 \mathrm{~min}$ the kidney was inspected for signs of ischemia; subsequently, the wound was covered with cotton soaked in sterile phosphate-buffered saline (PBS). After removal of the clamp, the left kidney was inspected for restoration of blood flow and the contralateral kidney was removed and stored for further analysis. The wound was closed in two layers, and, subsequently, $0.25 \%$ bupivacaine was applied topically for postoperative pain management. Finally, to maintain fluid balance and volume status, mice were supplemented with $1 \mathrm{ml}$ prewarmed $\left(37^{\circ} \mathrm{C}\right)$ PBS subcutaneously. The animals were sacrificed at $6 \mathrm{~h}$ as well as $1,3,5$ and 7 days after reperfusion. At the time of sacrifice, blood was collected by orbital puncture and the left kidney was harvested for further analysis.

Mice were subjected to ischemia and treated with anti-TNF- $\alpha$ mAb TN3 $(n=28)$, control IgG2a mAb 5 D7 $(n=19)$, anti-IL-10 mAb JES5-2A5 $(n=28)$, control IgG1 mAb GL113 $(n=19)$ or PBS $(n=28)$. A sham-group $(n=14)$ underwent the same surgical procedure as animals subjected to ischemia except for clamping of the renal pedicle. These animals were treated with PBS and sacrificed at corresponding timepoints. All pharmacological interventions were carried out ten min before removal of the clamps. Mice were intraperitoneally administered either $1 \mathrm{mg}$ of mAbs dissolved in $0.5 \mathrm{ml}$ PBS or $0.5 \mathrm{ml}$ PBS. The doses of the treatments used have been shown to have in vivo neutralizing capacities $(26,27)$ and administration of these reagents to mice not subjected to renal I/R 
did not influence any of the investigated parameters (data not shown). When data obtained from the groups that received 5D7 or GL113 were compared to the ischemia/ PBS group, no significant differences were observed (data not shown) indicating that aspecific IgG does not affect any of the parameters evaluated.

\section{HISTOLOGY}

Specimens of harvested kidneys were either fixed in buffered formaline and paraffinembedded or immediately frozen and stored at $-70^{\circ} \mathrm{C}$. Paraffin sections $(5 \mu \mathrm{m})$ were stained with periodic acid Schiff (PAS). These sections were used to judge the extent of tissue damage by assessing tubular dilatation, presence of intratubular debris, vacuolization of tubular epithelium cells and, loss of brush border membrane integrity. We refrained from subjective tissue damage quantification because of the large variability involved with this method. In addition, immunostaining for TNF- $\alpha$ with digoxigeninlabeled $\mathrm{mAb} 52 \mathrm{~B} 83$ was performed on paraffin sections using alkaline phosphatase-conjugated sheep anti-digoxigenin as the secondary detection mAb and NBT/BCIP as a chromogen, followed by a methyl green counterstain. Frozen sections $(5 \mu \mathrm{m})$ were stained for neutrophils with mAb Gr-1 (28), for MHC class I with mAb ml/42.3.9.8 (29) and for MHC class II with mAb H82-168.10 using peroxidase-labeled goat anti-rat IgG as the secondary detection $\mathrm{mAb}$ and 3-amino-9-ethylcarbazole (AEC) as a chromogen, followed by a hematoxylin counterstain. To block aspecific peroxidase activity, sections were pretreated for $10 \mathrm{~min}$ with PBS containing $0.03 \% \mathrm{H}_{2} \mathrm{O}_{2}$. No significant staining was detected in slides incubated with control $\mathrm{mAb}$ instead of the primary detecting $\mathrm{mAb}$, indicating the absence of significant background staining.

\section{REVERSE TRANSCRIPTASE POLYMERASE CHAIN REACTION (RT-PCR)}

After nephrectomy, kidney specimens were immediately immersed in a freshly prepared conservation solution containing $4 \mathrm{M}$ guanidinium thiocyanate, $25 \mathrm{mM}$ sodium citrate, $0.5 \% \mathrm{~N}$-laurylsarcosine and $0.1 \mathrm{M} \beta$-mercaptoethanol. Samples were snap frozen in liquid nitrogen and stored at $-70^{\circ} \mathrm{C}$ until further analysis by RT-PCR as described previously (30). Briefly, total cellular RNA was isolated by homogenizing renal tissue in conservation solution, followed by extraction with phenol-chloroform-isoamyl alcohol. After alcohol precipitation the pellet was dissolved in diethyl pyrocarbonate-water and total RNA was determined by spectrophotometric analysis at 260 and $280 \mathrm{~nm}$ wavelength. $5 \mu \mathrm{g}$ of total RNA was reversed transcribed in a $20-\mu \mathrm{l}$ volume using oligo(dT) primer and Moloney murine leukemia virus reverse transcriptase (Life Technologies Gibco, Paisly, United Kingdom) according to the supplier's recommendations. 
Per sample, four 2 -fold serial dilutions of cDNA were amplified in a $25 \mu \mathrm{l}$ reaction mixture containing $100 \mu \mathrm{M}$ of each dNTP, $200 \mathrm{nM}$ primers and $0.5 \mathrm{U}$ Taq DNA polymerase (Perkin Elmer/Cetus, Emeryville, CA) during 30-40 cycles under the following conditions: $94^{\circ} \mathrm{C}$ for 15 seconds, $60^{\circ} \mathrm{C}$ for 20 seconds and, $72^{\circ} \mathrm{C}$ for 20 seconds. Primers used for murine TNF- $\alpha$ mRNA were sense primer 5'-GGCAGGTCTACTTTGGAGTCATTGC-3' and antisense primer ' 5'-ACATTCGAGGCTCCAGTGAATTCGG-3'; primers used for murine IL-10 mRNA were sense primer 5'-TGCCTTCAGTCAAGTGAAGACT-3' and antisense primer 5'-TGCCTTCAGTCAAGTGAAGACT-3'; $\beta$-actin specific primers were sense primer 5'-TAAAACGCAGCTCAGTAACAGTCCG-3' and antisense primer 5'-TGCAATCCTGTGGCATCCATGAAAC-3'. Synthetic genes containing nonhomologous DNA with binding sites for 5' and 3' cytokine-specific primers were used as control DNA fragments (31). All primers and synthetic genes were kindly provided by Prof. H. Volk, Humbold University, Berlin, Germany. The reaction product was analyzed on a $1.5 \%$ agarose gel containing ethidium bromide. In all experiments, a mock PCR (without cDNA) was included to exclude contamination. Band proportions were estimated by measuring the intensity of ethidium bromide fluorescence with a digital camera (Imagemaster VDS, Pharmacia, Uppsala, Sweden).

\section{ASSAYS FOR MYELOPEROXIDASE (MPO) AND BLOOD UREA NITROGEN (BUN)}

To quantify the extent of renal neutrophil accumulation, renal MPO content was determined (32). Snap-frozen samples were thawed, homogenized for 30 seconds using a tissue homogenizer (T25B, IKA GmbH, Staufen, Germany) at 20,000 rotations/min in $0.5 \%$ hexadecyltrimethylammonium bromide dissolved in $50 \mathrm{mM} \mathrm{PBS} \mathrm{pH}=6.0$ and made up to concentrations of $0.17 \mathrm{~g} / \mathrm{ml}$ renal tissue. After heat incubation $\left(2 \mathrm{~h}, 60^{\circ} \mathrm{C}\right)$ in a water bath to verify myeloperoxidase heat resistance (33), samples were frozen and thawed in order to release cellular MPO. Next, samples were spun at $11,000 \mathrm{~g}$ for $5 \mathrm{~min}$ and supernatants were collected. Enzymatic detection of myeloperoxidase was performed in a 96-well plate (Costar, Cambridge, MA). Assay mixtures consisted of $40 \mu \mathrm{l} \mathrm{H}_{2} \mathrm{O}_{2}$ (final concentration 0.3 $\mathrm{mM}$ ) in $80 \mathrm{mM}$ PBS pH=5.4 and $40 \mu \mathrm{l}$ in $0.5 \%$ hexadecyltrimethylammonium bromide, $50 \mathrm{mM}$ PBS $\mathrm{pH}=6.0$ containing diluted sample. The reaction was initiated by addition of $20 \mu \mathrm{l}$ tetramethylbenzidine (final concentration $1.6 \mathrm{mM}$ ) in dimethyl sulfoxide and stopped after $15 \mathrm{~min}$ by the addition of $50 \mu \mathrm{l} /$ well $1 \mathrm{M} \mathrm{H}_{2} \mathrm{SO}_{4}$. Subsequently, optical density (OD) was determined at $450 \mathrm{~nm}$. All samples were assayed in triplicate. MPO activity was calculated per mg renal tissue by comparing OD of sample wells with a titration curve of horseradish peroxidase. The obtained relative MPO activities were standardized with respect to wet/dry ratios of the assayed renal tissue and are presented relative to the amount of MPO present in the contralateral kidney harvested immediately after reperfusion. BUN was measured in serum obtained by orbital puncture at the time of sacrifice using a BUN unimate 5 kit in a Cobas Fara autoanalyzer (Roche, Basle, Switzerland). 


\section{WEHI TNF- $\alpha$ BIOASSAY}

Biological TNF- $\alpha$ activity was measured using the murine fibrosarcoma WEHI 164 cell line as described previously (34). The sensitivity of the assay was $10 \mathrm{pg} / \mathrm{ml}$.

\section{IMMUNOASSAYS}

Enzyme-linked immunosorbent assay (ELISA) for TNF- $\alpha$ was performed as described in detail previously (35). For the quantification of MHC class I and II antigens in the kidney, a non-radioactive enzyme immuno assay (EIA) was developed. Snap-frozen renal tissue was thawed, homogenized for 30 seconds using a tissue homogenizer at 20,000 rotations $/ \mathrm{min}$, made up to a concentration of $20 \mathrm{mg} / \mathrm{ml}$ in PBS containing $8 \mathrm{nM}$ deoxyribonuclease I, $0.4 \mathrm{mM}$ phenylmethylsulfonyl fluoride (PMSF) and subsequently spun at $11,000 \mathrm{~g}$. Pellets were resuspended in $100 \mu \mathrm{l}$ PBS, $0.1 \%$ bovine serum albumine (BSA) containing $\mathrm{mAb} \mathrm{ml} / 42.3 .9 .8$ or mAb H82-168.10 for detection of MHC class I or MHC class II, respectively. After $1 \mathrm{~h}$ incubation on ice, pellets were washed twice with ice-cold PBS $0.1 \%$ BSA.

Next, pellets were resuspended, incubated for $1 \mathrm{~h}$ with peroxidase conjugated goat antirat $\mathrm{IgG}$, washed twice and resuspended in $0.25 \mathrm{ml}$ PBS containing $0.1 \% \mathrm{BSA}, 8 \mathrm{nM}$ deoxyribonuclease I and $0.4 \mathrm{mM}$ PMSF and incubated for $15 \mathrm{~min}$ at room temperature. Next, suspensions were added in a 96-well sample plate (Costar), $30 \mu \mathrm{l}$ TMB substrate was added and after $15 \mathrm{~min}$ the reaction was stopped. Subsequently, OD was determined at $450 \mathrm{~nm}$. All samples were measured in triplicate. MHC class I and II content were calculated per milligram of renal tissue by comparing $\mathrm{OD}$ of sample wells with a titration curve of horseradish peroxidase. The obtained MHC class I/II contents are presented relative to the amount of $\mathrm{MHC}$ class $\mathrm{I} / \mathrm{II}$ in the contralateral kidney harvested immediately after reperfusion.

\section{DNA LADDER FORMATION}

The presence of nucleosomal laddering in kidneys was investigated with a commercially available ligase-mediated (LM)-PCR assay kit (Apoalert, Clontech, Palo Alto, CA) enabeling the semiquantitative measurement of the extent of apoptosis (36). In brief, DNA was isolated from tissue samples previously frozen at $-70^{\circ} \mathrm{C}$ employing a commercially available DNA purification kit (Wizard, Promega, Madison, WI) according to the manufacturers instructions. DNA purity and concentration were determined by electrophoresis through a $0.8 \%$ agarose gel containing ethidium bromide, followed by detection under ultraviolet illumination as well as by measuring absorbance at $260 / 280 \mathrm{~nm}$. Dephosphorylated adaptors were ligated to 5'-phosphorylated blunt ends with T4 DNA ligase (during $16 \mathrm{~h}$ at $16^{\circ} \mathrm{C}$ ) and served as primers in a LM-PCR under the following con- 
ditions: hotstart $\left(72^{\circ} \mathrm{C}\right.$ for $\left.8 \mathrm{~min}\right), 25$ cycles $\left(94^{\circ} \mathrm{C}\right.$ for 60 seconds and $72^{\circ} \mathrm{C}$ for $180 \mathrm{sec}$ onds), post-cycling $\left(72^{\circ} \mathrm{C}\right.$ for $\left.15 \mathrm{~min}\right)$. To confirm that equal amounts of DNA were used for the PCR, an internal control that consisted of DNA amplification using En-2 primer pairs was performed. Amplified DNA was subjected to gel electrophoresis on a $1.2 \%$ agarose gel containing ethidium bromide.

\section{STATISTICAL ANALYSIS}

Data are expressed as medians with interquartile ranges. Experimental data from animals subjected to $\mathrm{I} / \mathrm{R}$ were compared with sham-operated controls using the Mann-Whitney$\mathrm{U}$ test. When data were compared between ipsi- and contralateral kidneys, the Wilcoxon signed-rank test was used. $\mathrm{P}<0.05$ was taken to denote statistical significance.

\section{RESULTS}

INVOLVEMENT OF TNF- $\alpha$ IN RENAL FUNCTION AND INFLAMMATION AFTER ISCHEMIA/ REPERFUSION

First, we studied renal production of TNF- $\alpha$ following I/R. TNF- $\alpha$ protein was identified by immunohistology at day 1 after ischemia and was distributed in and along damaged tubular epithelium and in infiltrating leukocytes (Figure lb). Positive immunostaining was limited to the outer stripe of the outer medulla and not detectable in the superficial cortical or other medullar regions. Specific immunoreactivity decreased rapidly after day 1 following reperfusion. In addition, TNF- $\alpha$ could not be detected in kidneys obtained from animals subjected to the sham procedure or in contralateral control kidneys. To further establish that TNF- $\alpha$ was kidney derived, expression of mRNA for TNF- $\alpha$ was assessed by RT-PCR. Figure 2 demonstrates enhanced renal TNF- $\alpha$ mRNA expression after $\mathrm{I} / \mathrm{R}$ in representative samples, reaching peak levels at day 1 compared to baseline levels in kidneys obtained from sham-operated controls. We additionally investigated whether, as a consequence of increased local expression, TNF- $\alpha$ was detectable systemically in sera obtained from animals $1,3,5$ and 7 days after reperfusion. Plasma levels of TNF- $\alpha$ evaluated using both the WEHI 164 cytotoxicity and ELISA were below detection in all samples investigated (data not shown).

Next, to elucidate functional aspects of TNF- $\alpha$ in renal reperfusion injury we employed a neutralizing anti-TNF- $\alpha \mathrm{Ab}$ (TN3). At day 1 after renal ischemia, BUN content, reflecting renal function, was significantly higher when compared to sham-operated animals (Figure 3). Anti-TNF- $\alpha$ treatment resulted in a moderately but significantly decreased BUN content when compared to control treatment, indicating that endogenous TNF- $\alpha$ contributes to impairment of renal function. 


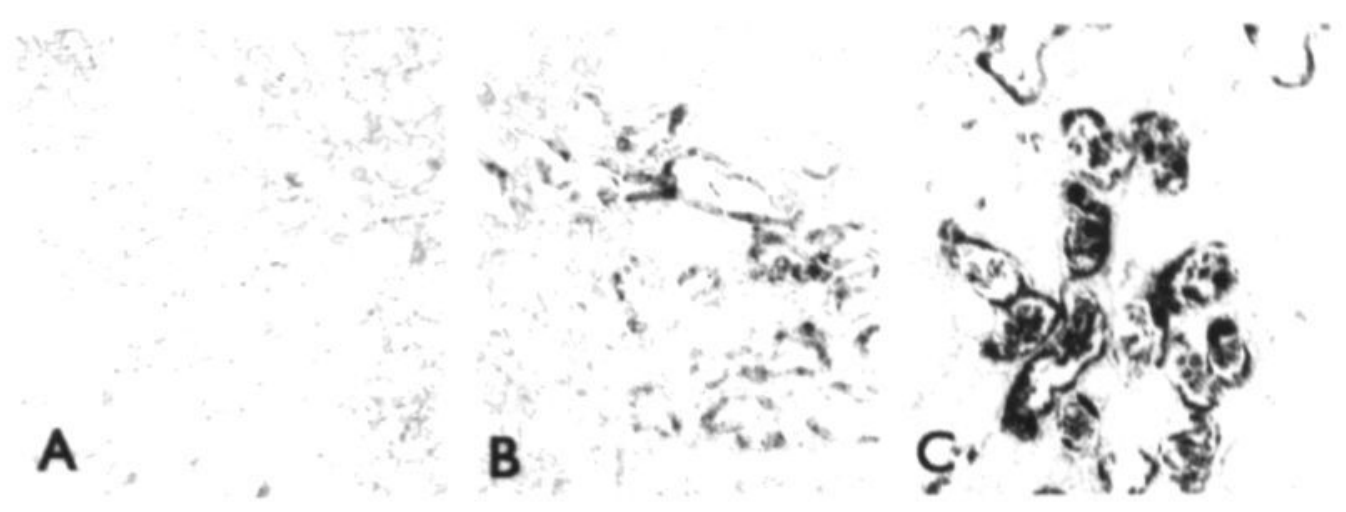

Figure 1. Immunostaining of TNF- $\alpha$ with $\mathrm{mAb} 52 \mathrm{~B} 83$ is confined to the outer stripe of the outer renal medulla after $24 \mathrm{~h}$ of reperfusion. Contralateral control kidney, lacking staining for TNF- $\alpha(\mathbf{A})$. Kidney subjected to I/R, showing significant medullar staining for TNF- $\alpha$ (B). Kidney from anti-IL-10-treated mouse subjected to I/R, strongly enhanced staining for TNF- $\alpha$ present in tubular epithelium and infiltrating cells $(\mathbf{C})$ (paraffin preserved section, magnification 200x).

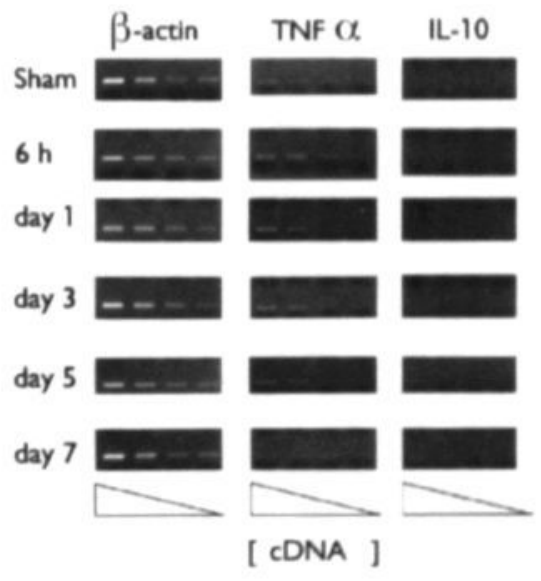

Figure 2. Peak renal TNF- $\alpha$ mRNA expression after 1 day of reperfusion as well as slightly enhanced IL-10 mRNA expression detectable from day 5 onwards when compared to baseline levels in kidneys obtained from sham-operated controls. Shown are representative samples of which cDNA was amplified in four 2 -fold serial dilutions and calibrated against identical levels of $\beta$-actin mRNA. 


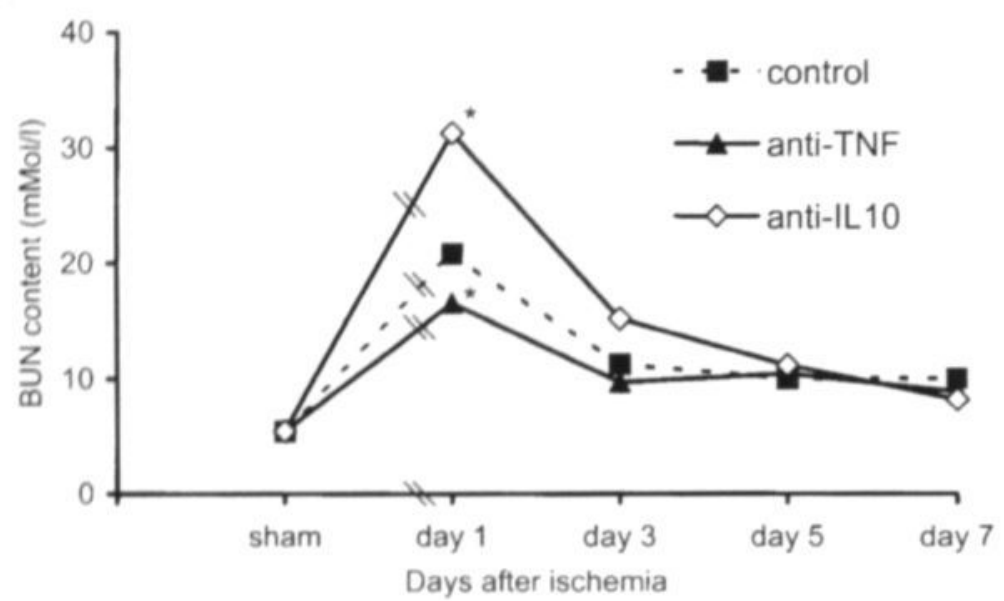

Figure 3. Anti-TNF- $\alpha$ treatment attenuates (median: $16.5 \mathrm{mMol} / \mathrm{L}$ and quartiles 14.7-19.3 $\mathrm{mMol} / \mathrm{L}$ ), whereas anti-IL-10 treatment enhances (median: $31.3 \mathrm{mMol} / \mathrm{L}$ and quartiles 18.6$31.4 \mathrm{mMol} / \mathrm{l}$ ) deterioration of kidney function when compared to control-treated mice (median: $20.8 \mathrm{mMol} / \mathrm{L}$ and quartiles $16.3-24.8 \mathrm{mMol} / \mathrm{l})$ as measured by determination of blood urea nitrogen (BUN), after I day of reperfusion. Statistical significance $\left({ }^{*}\right)$ was denoted at $\mathrm{P}<0.05$. The data shown are medians.
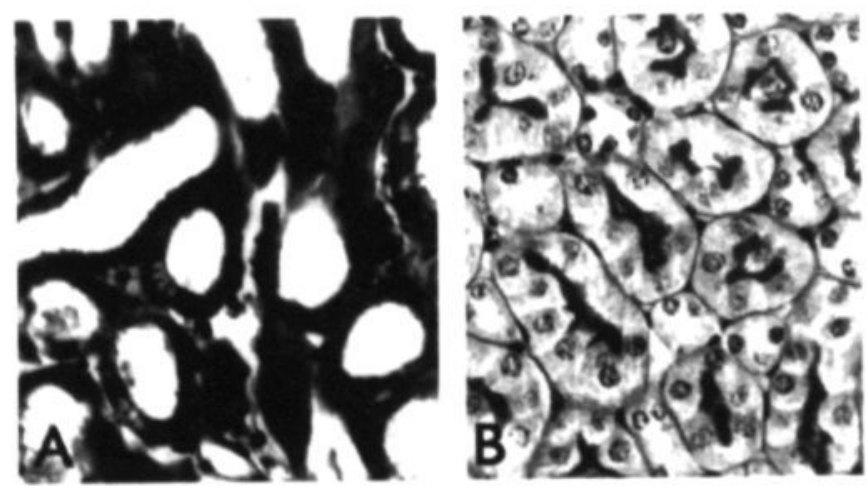

Figure 4. Renal I/R leads to extensive histological damage, characterized by tubular dilatation, luminal debris, tubular vacuolization, damaged brush border membranes and tubular necrosis at day 1 (A). Compare with kidney obtained from animal subjected to the sham-procedure (B) (PAS-stain of paraffin preserved section, magnification 200x). 


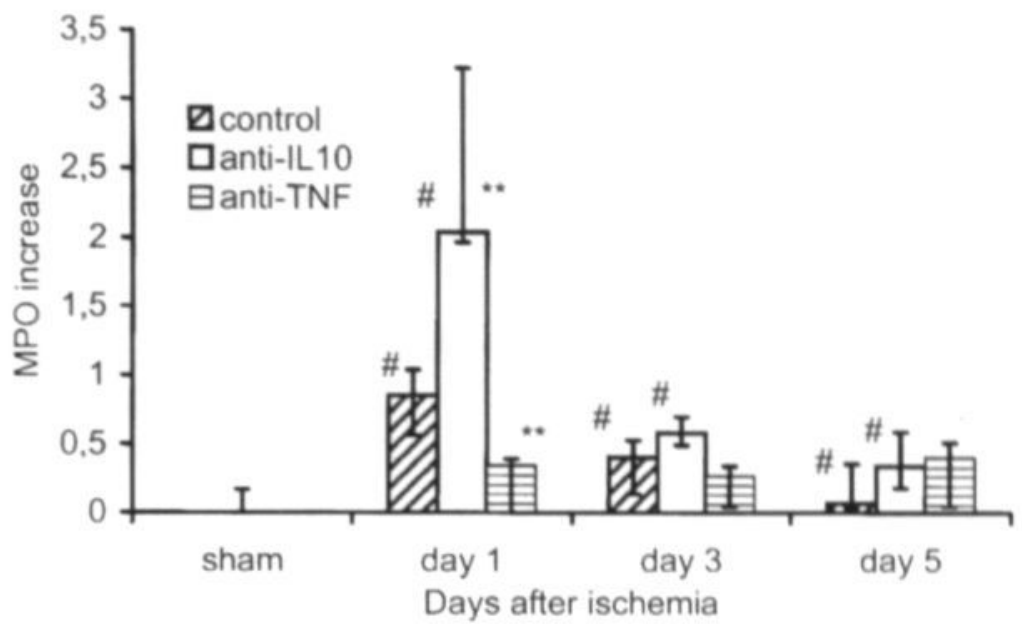

Figure 5. Neutrophil influx, assessed by MPO increase, is up-regulated by pro- (TNF- $\alpha$ ) and down-regulated by anti-inflammatory (IL-10) cytokines after I day of renal reperfusion. Note the reduced renal MPO increase in animals that received anti-TNF- $\alpha$ treatment and the increased renal MPO content in animals that received anti-IL-10 treatment. Statistical significance compared to control-treated animals (**) was denoted at $\mathrm{P}<0.01$ and compared to contralateral control kidneys $(\#)$ at $\mathrm{P}<0.05$. The data shown are medians with interquartile ranges.

After 1 day of reperfusion, histological injury was clearly present (Figure 4). Renal crosssections showed an overall dilatation of proximal convoluted tubuli, intraluminal tubular debris, loss of tubular brush border membrane integrity, patchy necrosis and detachment of tubular cells from supporting basement membranes. In parallel, immunohistology revealed an extensive influx of $\mathrm{Gr}-1$ positive cells (neutrophils) in the cortical areas (data not shown). This accumulation of neutrophils was quantified by assessment of renal MPO activity. As shown in Figure 5, MPO activity in control-treated animals was significantly increased after 1,3 , and 5 days of reperfusion when compared to contralateral controls. Anti-TNF- $\alpha$ treatment significantly reduced the MPO content at day 1 when compared to control-treated animals.

After 5 and 7 days of reperfusion, morphological changes became less pronounced. At these timepoints however, large fibrotic lesions became discernible. MHC class I and II expression, distinct late hallmarks of the inflammatory response, were strongly enhanced as shown by EIA (Figure 6). The differences in MHC expression less than zero imply increased constitutive levels in contralateral controls compared to kidneys subjected to $\mathrm{I} / \mathrm{R}$ as a consequence of natural variations. At day 5 , MHC class I in kidneys subjected to $\mathrm{I} / \mathrm{R}$ significantly increased as compared to contralateral control kidneys. Moreover, at day 7 , MHC class I as well as MHC class II significantly increased as compared to contralateral controls. These findings are supported by immunohistological data indicating 
MHC I and II upregulation at day 5 and 7 (Figure 7). After day 5, tubular epithelium and arterial endothelium stained intensely positive for MHC class I (Figure 7b), whereas MHC class II immunoreactivity was confined mainly to tubular epithelium (data not shown). The immunohistological data additionally showed that the contribution of infiltrating immune cells to I/R-induced $\mathrm{MHC}$ class I and II upregulation was insignificant and that MHC class I and II immunostaining was most prominent in the outer stripe of the outer medulla. These results were quantitatively confirmed employing an EIA, which demonstrated increased expression of MHC class I (Figure 6a) as well as MHC class II protein (Figure $6 \mathrm{~b}$ ) at day 5 and when compared to sham operated animals. Anti-TNF- $\alpha$ treatment affected neither MHC class I nor MHC class II expression.
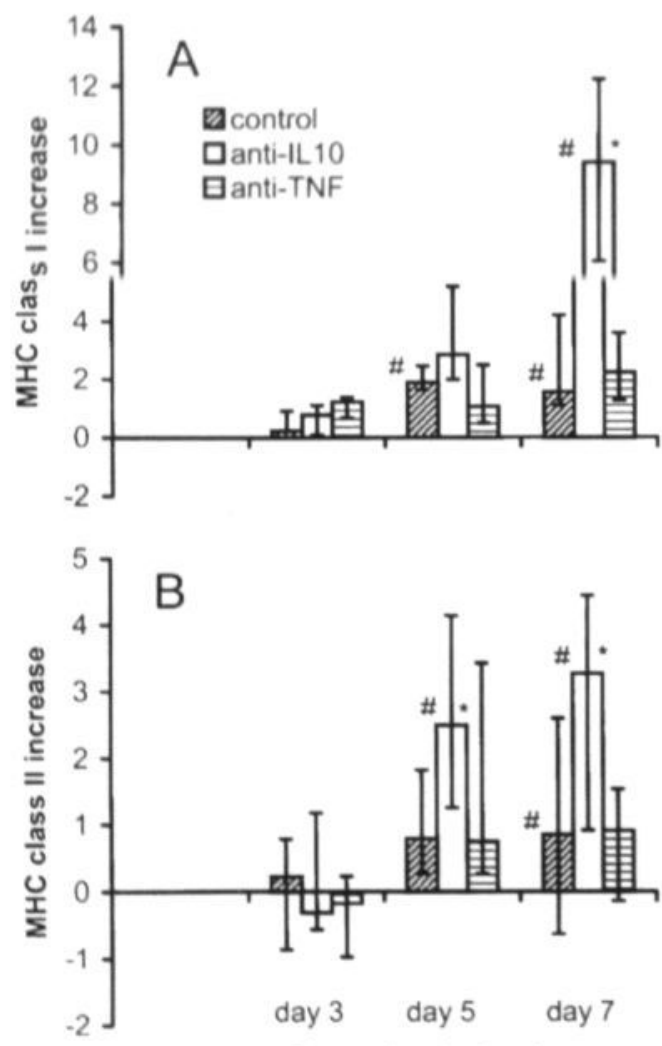

Days after ischemia

Figure 6. Anti-IL-10 treatment leads to strongly enhanced renal expression of MHC class I (A) and $\mathrm{MHC}$ class II (B) after I/R as assessed by enzyme immuno assay. Numbers on the $y$-axis indicate the relative difference in arbitrary units between kidneys subjected to $\mathrm{L} / \mathrm{R}$ and contralateral controls calibrated against a standard titration curve of HRP. Statistical significance compared to control-treated animals (*) or compared to contralateral control kidneys (\#) was denoted at $\mathrm{P}<0.05$. The data shown are medians with interquartile ranges. 

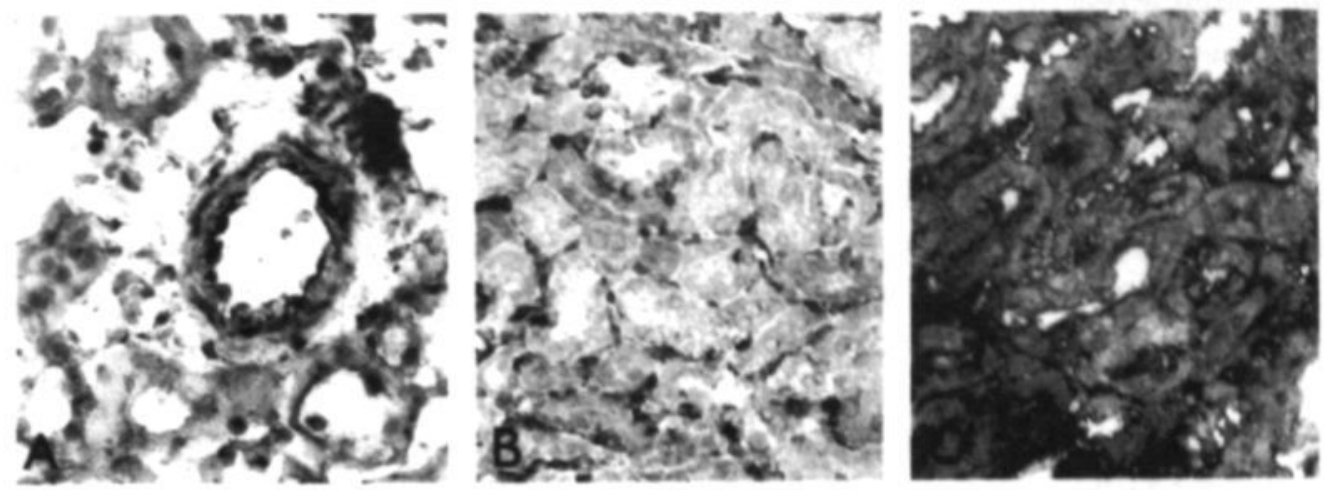

Figure 7. Minimal constitutive MHC class I expression detected by employing $\mathrm{mAb}$ $\mathrm{ml} / 42.3 .9 .8$ on arterial endothelium and tubular epithelium in contralateral control kidneys (A) whereas immunostaining of MHC class I antigens on tubular epithelium after 7 days of reperfusion is moderately enhanced in control-treated animals (B) and strongly enhanced in anti-IL10-treated animals (C). Immunostaining was most prominent in the outer stripe of the outer medulla and not present in negative controls (frozen sections, magnification 200x).

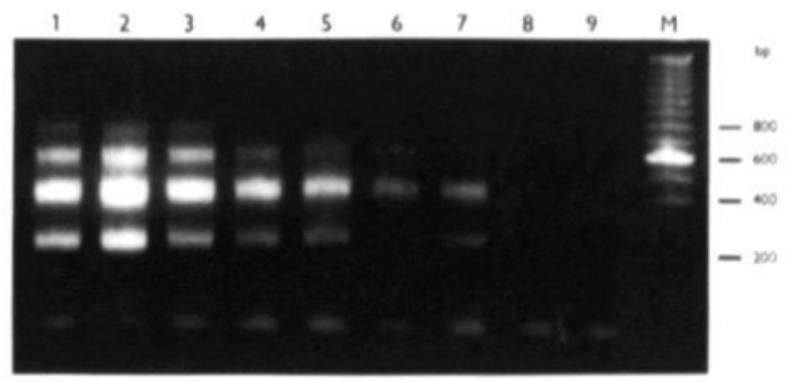

Figure 8. In kidneys obtained from anti-IL-I0-treated animals (lane 1-3) the extent of apoptosis as reflected by the amount of fragmented DNA amplified by LM-PCR and visualized on ethidium-bromide-stained gels was increased when compared to control-treated animals (lane 4-5) at 1 day after ischemia. To a lesser extent, apoptosis was present in kidneys obtained from anti-TNF- $\alpha$-treated animals (lane 6-7). Contralateral control kidneys (lane 8-9) exhibited almost no sign of apoptosis. M, molecular weight markers (range, 100 to 2000 base pairs).

\section{INVOLVEMENT OF ENDOGENOUS IL-10}

As stated above, endogenous production of IL-10 is an important aspect of the natural anti-inflammatory response. In order to assess whether this type of regulation also determines the outcome of renal $\mathrm{I} / \mathrm{R}$, we first investigated the presence of IL-10 $\mathrm{mRNA}$ in the postischemic kidney by means of RT-PCR (Figure 2). In line with previous reports (12), 
increased levels of renal IL-10 mRNA were detected in all animals subjected to I/R from day 5 onwards. These data prompted us to investigate the putative regulatory influence of endogenously produced IL-10 in the inflammatory process induced by $\mathrm{I} / \mathrm{R}$. To this end, mice were administered the anti-IL-10 mAb JES5-2A5. Immunohistology showed that IL-10 suppression enhanced renal TNF- $\alpha$ protein expression without altered distribution (Figures 1, b and c). Anti-IL-10 treatment significantly exacerbated renal function impairment after 1 day of reperfusion, as indicated by an increased BUN content when compared to control treatment (Figure 3). Kidneys taken from anti-IL-10-treated animals also revealed substantial histological damage. In these kidneys more neutrophils could be detected by immunohistology (data not shown). This was reflected by the significantly increased MPO activity after 1, 3 and 5 days of reperfusion when compared to the contralateral control kidney as well as when compared to control-treated animals after 1 day of reperfusion (Figure 5).

Further, the enhanced inflammation following anti-IL-10 treatment resulted in a strongly increased kidney MHC expression at day 7 after ischemia, as demonstrated by MHC class I (Figure 7c) and II (data not shown) specific immunostaining. In these mice, quantification of MHC class I and II expression by EIA revealed significantly increased levels of both MHC class I and II antigens at day 5 and 7 when compared to contralateral kidneys or to control-treated animals at corresponding timepoints after reperfusion (Figure 6).

INTERPLAY BETWEEN INFLAMMATION AND APOPTOSIS FOLLOWING ISCHEMIA/REPERFUSION

The characteristic fragmentation of DNA, which can serve as an identifying marker of apoptosis results from activation of specific DNA-degrading endonucleases causing the formation of 180-200 base pair fragments (37). We analyzed the degree of renal DNAfragmentation in mice treated with either anti-TNF- $\alpha$ or anti-IL-10 Abs to determine whether the I/R-induced pro-inflammatory response modulates apoptosis. All kidneys subjected to I/R clearly showed DNA laddering (Figure 8). Ladder band intensity decreased in anti-TNF- $\alpha$-treated animals suggesting that TNF- $\alpha$ is involved in apoptosis observed after reperfusion. Moreover, in kidneys from anti-IL-10-treated animals (which showed an increased inflammatory response), DNA-laddering was more apparent (Figure 8), indicating that in this model enhanced inflammation increases the extent of apoptosis.

\section{Discussion}

The present results demonstrate the presence of immunohistologically detectable TNF- $\alpha$ protein in the reperfused kidney as well as increased renal TNF- $\alpha$ mRNA levels as measured by RT-PCR. The finding that plasma levels of (bioactive) TNF- $\alpha$ after renal I/R 
remained undetectable, suggest that the involvement of TNF- $\alpha$ is restricted solely to the kidney. Anti-TNF- $\alpha$ treatment resulted in less histological damage and improved renal function. Hence, local TNF- $\alpha$ production, up-regulated following $\mathrm{I} / \mathrm{R}$, is involved in the process leading to the observed histological damage as well as to impaired organ function, which is supported by reports on local expression of TNF- $\alpha$ mRNA after I/R of the liver (16), the heart (8) and the brain (38). An attribute of TNF- $\alpha$ of particular relevance to its role in renal I/R is the ability of reducing glomerular function (39). Other activating and indirect neutrophil chemotactic properties of TNF- $\alpha$ include activation of polymorphunuclear neutrophils (PMN) (40), induction of adhesion molecules like ICAM-1 (41) and P- and E-selectin (42) as well as chemokines such as MCP-1 (43) and the murine IL-8 homologue $\mathrm{KC}(44)$, which all have been associated with I/R-induced inflammation $(5,9,45,46)$. These properties of TNF- $\alpha$ may account for our finding that kidney infiltration by neutrophils at day 1 was significantly reduced in anti-TNF- $\alpha$-treated animals. $\mathrm{I} / \mathrm{R}$ invariably induced renal apoptosis and TNF- $\alpha$ clearly contributes to its severity since DNA ladders are less apparent in anti-TNF- $\alpha$-treated mice. In contrast, a role for TNF- $\alpha$ in the upregulation of MHC antigens after 5 and 7 days of reperfusion is less evident considering our data, which show that expression of these antigens was not affected by antiTNF- $\alpha$ treatment. Taken together, these findings indicate that TNF- $\alpha$, produced in the kidney, functionally contributes to the pathophysiology of early renal I/R injury.

We hypothesized that production of endogenous IL-10 is part of a natural anti-inflammatory response that limits the deleterious effects of the pro-inflammatory cascade induced by $\mathrm{I} / \mathrm{R}$. In support of this hypothesis, our results show that kidneys from anti-IL10 -treated animals exhibited a pronounced positive immunostaining for TNF- $\alpha$ protein. In these animals, the absence of the broad range of anti-inflammatory properties exerted by IL-10, such as inhibition of TNF- $\alpha$, IL-1 (47), IL-6 (48), free radical production (49) and expression of adhesion molecules (50), apparently contributes to an enhanced proinflammatory response leading to the observed additional impairment of renal function and enhanced neutrophil influx. The observed lack of renal IL-10 mRNA after 1 and 3 days of reperfusion in control-treated mice could either imply that undetectable amounts of IL-10 mRNA are associated with early regulation of the observed pro-inflammatory response or that the IL-10 involved is not kidney derived. At day 5 and 7 however, when anti-IL-10-treated animals show increased renal MHC class I and II, which suggests that this response is normally limited by endogenous IL-10, the presence of renal IL-10 mRNA becomes evident.

The anti-inflammatory aspects of IL-10 have been extensively studied. IL-10 has been shown in vitro $(47,51)$ and in vivo $(21,22)$ to be capable among others to regulate TNF$\alpha$ production by neutrophils, macrophages and Thl-cells. Adenosine, an endogenous nucleoside released in conditions of metabolic stress such as ischemia has been reported to limit among others TNF- $\alpha$ production (52), a process suggested to be mediated by IL10 (51). The increased degree of renal apoptosis observed in mice that received anti-IL- 
$10 \mathrm{mAbs}$ most likely is the result of enhanced local TNF- $\alpha$ levels in these animals. However, also TNF- $\alpha$ independent anti-apoptotic effects attributed to IL-10 such as induction of $\mathrm{Bcl}-2$ expression, a potent apoptosis repressor mechanism (53), must be taken into consideration.

Renal IL-10 mRNA production has been reported in a model of non-uremic renal $\mathrm{I} / \mathrm{R}$ injury (12), to down-regulate IFN- $\gamma$ production by Thl cells (54) and to abrogate the production of the IFN- $\gamma$ inducing cytokine IL-12 by monocytes in vivo (55) and in vitro (56). Since up-regulation of MHC antigens is initiated in particular by IFN- $\gamma(57)$, these reports suggest that in our experiments the observed additional up-regulation of MHC antigens in anti-IL-10-treated mice is associated with direct or indirect IFN- $\gamma$ modulating properties of endogenously produced IL-10. Although not functional in our model, MHC class I and II up-regulation may render grafted tissue more susceptible to allograft rejection $(58,59)$.

These results indicate that the extent of postischemic tissue damage induced by inflammation and apoptosis is determined by an activated balance between pro- and antiinflammatory mediators. Similar to experimental septic shock (21), the observed protective anti-inflammatory response features regulation of endogenous IL-10. Hence, this may explain why supplementation with exogenous IL-10 is protective in experimental septic shock (22) as well as in experimental I/R $(60,61)$. The administration of exogenous IL-10 or IL-10-inducing drugs (as opposed to IL-10-suppressive drugs such as FK506 and cyclosporine) in the moderation of reperfusion injury may be a valuable clinical tool not only to reduce neutrophil mediated tissue damage and apoptotic cell damage but also to prevent increased graft immunogenicity provoked by enhanced MHC class I and II expression.

The present results reveal a role for local TNF- $\alpha$ as an important pro-inflammatory mediator of early (day 1) I/R-induced inflammation as well as an anti-inflammatory and regulatory role for endogenous IL-10 in both an early (day 1) and a late (day 7) phase of reperfusion injury. We show that the counter-regulatory properties of endogenously produced IL-10 offers physiological protection against inflammatory as well as apoptotic cascades that ultimately lead to tissue injury. Further studies should reveal the therapeutic potential of pharmacological IL-10 enhancement or supplementation.

\section{REFERENCES}

1. Wijnen RM, Booster MH, Stubenitsky BM, de Boer J, Heineman E, Kootstra G. Outcome of transplantation of non-heart-beating donor kidneys. Lancet 1995; 345: 1067.

2. Mangos GJ, Brown MA, Chan WY, Horton D, Trew P, Whitworth JA. Acute renal failure following cardiac surgery: incidence, outcomes and risk factors. Aust N Z J Med 1995; 25: 284.

3. Myers BD, Miller DC, Mehigan JT, et al. Nature of the renal injury following total renal ischemia in man. J Clin Invest 1984; 73: 329 . 
4. Groeneveld AB. Pathogenesis of acute renal failure during sepsis. Nephrol Dial Transplant 1994; 9 Suppl 4: 47.

5. Takada M, Nadeau KC, Shaw GD, Marquette KA, Tilney NLRA. The cytokine adhesion molecule cascade in ischemia/reperfusion injury of the rat kidney: inhibition by a soluble P selectin ligand. J Clin Invest 1997; 99: 2682.

6. Vedder NB, Winn RK, Rice CL, Chi EY, Arfors KE, Harlan JM. Inhibition of leukocyte adherence by anti-CD18 monoclonal antibody attenuates reperfusion injury in the rabbit ear. Proc Natl Acad Sci USA 1990; 87: 2643.

7. Halloran PF, Homik J, Goes N, et al. The injury response: a concept linking nonspecific injury, acute rejection, and long term transplant outcomes. Transplant Proc 1997; 29: 79.

8. Herskowitz A, Choi S, Ansari AA, Wesselingh S. Cytokine mRNA expression in postischemic/reperfused myocardium. Am J Pathol 1995; 146: 419.

9. Rabb H, Mendiola CC, Saba SR, et al. Antibodies to ICAM-1 protect kidneys in severe ischemic reperfusion injury. Biochem Biophys Res Comm 1995; 211: 67.

10. Linas SL, Whitenburg D, Parsons PE, Repine JE. Ischemia increases neutrophil retention and worsens acute renal failure - role of oxygen metabolites and ICAM 1. Kidney Int 1995; $48 ; 1584$.

11. Goes N, Hobart M, Ramassar V, Urmson J, Halloran PF. Many forms of renal injury induce a stereotyped response with increased expression of MHC, IFN gamma, and adhesion molecules. Transplant Proc 1997; 29: 1085.

12. Goes N, Urmson J, Vincent D, Ramassar V, Halloran PF. Induction of major histocompatibility complex markers and inflammatory cytokines after ischemic injury to the kidney: lessons from interferon-gamma gene knockout mice. Transplant Proc 1995; 27: 771.

13. Raafat AM, Murray MT, McGuire T, et al. Calcium blockade reduces renal apoptosis during ischemia reperfusion. Shock 1997; 8:186.

14. Shah KA, Shurey S, Green CJ. Apoptosis after intestinal ischemia-reperfusion injury - A morphological study. Transplantation 1997; 64: 1393.

15. Schulze OK, Bakker AC, Vanhaesebroeck B, Beyaert R, Jacob WA, Fiers W. Cytotoxic activity of tumor necrosis factor is mediated by early damage of mitochondrial functions. Evidence for the involvement of mitochondrial radical generation. J Biol Chem 1992; 267:5317.

16. Colletti LM, Kunkel SL, Walz A, et al. The role of cytokine networks in the local liver injury following hepatic ischemia/reperfusion in the rat. Hepatology 1996; 23: 506.

17. Colletti LM, Remick DG, Burtch GD, Kunkel SL, Strieter RM, Campbell DA, Jr. Role of tumor necrosis factor-alpha in the pathophysiologic alterations after hepatic ischemia/reperfusion injury in the rat. J Clin Invest 1990; 85: 1936.

18. Colletti LM, Kunkel SL, Walz A, et al. Chemokine expression during hepatic ischemia/reperfusion-induced lung injury in the rat. The role of epithelial neutrophil activating protein. J Clin Invest 1995; 95: 134 .

19. Ioculano M, Altavilla D, Squadrito F, et al. Tumour necrosis factor mediates E-selectin production and leukocyte accumulation in myocardial ischaemia-reperfusion injury. Pharmacol Res 1995; $31: 281$.

20. Affres H, Perez J, Hagege J, et al. Desferrioxamine regulates tumor necrosis factor release in mesangial cells. Kidney Int 1991: 39: 822 .

21. Marchant A, Bruyns C, Vandenabeele P, et al. Interleukin-10 controls interferon-gamma and tumor necrosis factor production during experimental endotoxemia. Eur $J$ Immunol 1994; 24 : 1167. 
22. Gerard C, Bruyns C, Marchant A, et al. Interleukin 10 reduces the release of tumor necrosis factor and prevents lethality in experimental endotoxemia. $J$ Exp Med 1993; 177: 547.

23. Leeuwenberg JF, Jeunhomme TM, Buurman WA. Slow release of soluble TNF receptors by monocytes in vitro. $J$ Immunol 1994; 152: 4036.

24. Bradding P, Mediwake R, Feather IH, et al. TNF alpha is localized to nasal mucosal mast cells and is released in acute allergic rhinitis. Clin Exp Allergy 1995; 25: 406.

25. Wilkinson LS, Edwards JC. Binding of antibodies raised against tumour necrosis factor alpha (TNF alpha) to blood vessels and macrophages in inflamed synovial tissue. Rheumatol Int 1991; I1: 19.

26. Howard M, Muchamuel T, Andrade S, Menon S. Interleukin 10 protects mice from lethal endotoxemia. J Exp Med 1993; 177: 1205.

27. Bemelmans MH, Gouma DJ, Greve JW, Buurman WA. Effect of antitumour necrosis factor treatment on circulating tumour necrosis factor levels and mortality after surgery in jaundiced mice. Br J Surg 1993; 80: 1055 .

28. Fleming TJ, Fleming ML, Malek TR. Selective expression of Ly-6G on myeloid lineage cells in mouse bone marrow. RB6-8C5 mAb to granulocyte-differentiation antigen (Gr-1) detects members of the Ly-6 family. J Immunol 1993; 151: 2399.

29. Thor G, Sepulveda H, Chada S, Dutton RW. Monoclonal antibody that distinguishes between a phosphorylated, beta 2-microglobulin-associated, and a free, nonphosphorylated, chain of $\mathrm{MHC}$ class I. J Immunol 1993; 151: 211.

30. Chomczynski P, Sacchi N. Single-step method of RNA isolation by acid guanidinium thiocyanate-phenol-chloroform extraction. Anal Biochem 1987; 162: 156.

31. Platzer C, Richter G, Uberla K, et al. Analysis of cytokine mRNA levels in interleukin-4-transgenic mice by quantitative polymerase chain reaction. Eur J Immunol 1992; 22: 1179.

32. Laight DW, Lad N, Woodward B, Waterfall JF. Assessment of myeloperoxidase activity in renal tissue after ischemia/reperfusion. Eur J Pharmacol 1994; 292: 81.

33. Schierwagen C, Bylund Fellenius AC, Lundberg C. Improved method for quantification of tissue PMN accumulation measured by myeloperoxidase activity. J Pharmacol Meth 1990; 23: 179.

34. Espevik T, Nissen Meyer J. A highly sensitive cell line, WEHI 164 clone 13, for measuring cytotoxic factor/tumor necrosis factor from human monocytes. J Immunol Meth 1986; 95 : 99.

35. Dentener MA, Greve JW, Maessen JG, Buurman WA. Role of tumour necrosis factor in the enhanced sensitivity of mice to endotoxin after exposure to lead. Immunopharmacol Immunotoxicol 1989; 11: 321 .

36. Staley K, Blaschke AJ, Chun J. Apoptotic DNA fragmentation is detected by a semiquantitative ligation-mediated PCR of blunt DNA ends. Cell Death Diff 1997; 4: 66.

37. Ueda N, Shah SV. Endonuclease-induced DNA damage and cell death in oxidant injury to renal tubular epithelial cells. J Clin Invest 1992; 90: 2593.

38. Wang X. Yue TL, Barone FC, White RF, Gagnon RC, Feuerstein GZ. Concomitant cortical expression of TNF-alpha and IL-I beta mRNAs follows early response gene expression in transient focal ischemia. Mol Chem Neuropathol 1994; 23: 103.

39. Bertani T, Abbate M, Zoja C, et al. Tumor necrosis factor induces glomerular damage in the rabbit. Am J Pathol 1989; 134: 419.

40. Dentener MA. Francot GJ, Hiemstra PS, et al. Bactericidal/permeability-increasing protein release in whole blood ex vivo: strong induction by lipopolysaccharide and tumor necrosis factor-alpha. J Infect Dis 1997: 175: 108. 
41. Ikuta S, Kirby JA, Shenton BK, Givan AL, Lennard TW. Human endothelial cells: effect of TNF-alpha on peripheral blood mononuclear cell adhesion. Immunology 1991; 73: 71 .

42. Weller A, Isenmann S, Vestweber D. Cloning of the mouse endothelial selectins. Expression of both E- and P-selectin is inducible by tumor necrosis factor alpha. J Biol Chem 1992; 267: 15176.

43. Satriano JA, Hora K, Shan Z, Stanley ER, Mori T, Schlondorff D. Regulation of monocyte chemoattractant protein-1 and macrophage colony-stimulating factor-1 by IFN-gamma, tumor necrosis factor- alpha, IgG aggregates, and cAMP in mouse mesangial cells. J Immunol 1993; 150: 1971 .

44. Ohmori Y, Wyner L, Narumi S, Armstrong D, Stoler M, Hamilton TA. Tumor necrosis factoralpha induces cell type and tissue- specific expression of chemoattractant cytokines in vivo. $\mathrm{Am}$ $J$ Pathol 1993; 142: 861.

45. Chiao H, Kohda Y, McLeroy P, Craig L, Housini I, Star RA. Alpha melanocyte stimulating hormone protects against renal injury after ischemia in mice and rats. J Clin Invest 1997; 99: 1165.

46. Kumar AG, Ballantyne CM, Michael LH, et al. Induction of monocyte chemoattractant protein-1 in the small veins of the ischemic and reperfused canine myocardium. Circulation 1997; 95: 693.

47. Cassatella MA, Meda L, Bonora S, Ceska M, Constantin G. Interleukin 10 (IL-10) inhibits the release of proinflammatory cytokines from human polymorphonuclear leukocytes. Evidence for an autocrine role of tumor necrosis factor and IL- 1 beta in mediating the production of IL- 8 triggered by lipopolysaccharide. J Exp Med 1993; 178: 2207.

48. de Waal Malefyt R, Abrams J, Bennett B, Figdor CG, de Vries JE. Interleukin I0(IL-10) inhibits cytokine synthesis by human monocytes: an autoregulatory role of IL-10 produced by monocytes. J Exp Med 1991; 174: 1209.

49. Wu J, Cunha FQ, Liew FY, Weiser WY. IL-10 inhibits the synthesis of migration inhibitory factor and migration inhibitory factor-mediated macrophage activation. J Immunol 1993; 151: 4325.

50. Willems F, Marchant A, Delville JP, et al. Interleukin-10 inhibits B7 and intercellular adhesion molecule-1 expression on human monocytes. Eur J Immunol 1994: 24: 1007

51. Le Moine O, Stordeur P, Schandene L, et al. Adenosine enhances IL-10 secretion by human monocytes. J Immunol 1996; 156: 4408.

52. Bouma MG, Stad RK, Van den Wildenberg FA, Buurman WA. Differential regulatory effects of adenosine on cytokine release by activated human monocytes. J Immunol 1994; 153:4159.

53. Weber NR, Henschler R, Schott E, et al. Interleukin-10 increases Bcl-2 expression and survival in primary human CD34+ hematopoietic progenitor cells. Blood 1996; 88: 2549.

54. Fiorentino DF, Zlotnik A, Vieira P, et al. IL-10 acts on the antigen-presenting cell to inhibit cytokine production by ThI cells. J Immunol 1991: 146: 3444 .

55. Jansen PM, van der Pouw Kraan TC, de Jong IW, et al. Release of interleukin-12 in experimental Escherichia coli septic shock in baboons: relation to plasma levels of interleukin- 10 and interferon-gamma. Blood 1996; 87: 5144 .

56. Tripp CS, Wolf SF, Unanue ER. Interleukin 12 and tumor necrosis factor alpha are costimulators of interferon gamma production by natural killer cells in severe combined immunodeficiency mice with listeriosis, and interleukin 10 is a physiologic antagonist. Proc Natl Acad Sci USA 1993; 90: 3725 .

57. Halloran PF, Wadgymar A. Autenried P. The regulation of expression of major histocompatibility complex products. Transplantation 1986:41: 413 .

58. Barth C, Von Menges A. Zanker B, Lammerding P. Stachowski J. Baldamus CA. Restricted T cell $V$ beta repertoire in renal allografts during acute and chronic rejection. Kidney Int 1996; 50: 2020. 
59. Almond PS, Bumgardner GL, Chen S, Matas AJ. Pretransplant sensitization with major histocompatibility complex class I+ class II- hepatocytes leads to accelerated skin graft rejection. $J$ Surg Res 1992; 53: 182.

60. Lane JS, Todd KE, Lewis MPN, et al. Interleukin-10 reduces the systemic inflammatory response in a murine model of intestinal ischemia/reperfusion. Surgery 1997; 122: 288.

61. Engles RE, Huber TS, Zander DS, et al. Exogenous human recombinant interleukin-10 attenuates hindlimb ischemia-reperfusion injury. J Surg Res 1997; 69: 425. 


\section{CHAPTER 3}

\section{Ischemia-reperfusion induced IGN- $\gamma$ up-regulation involvement of IL-12 and IL-18}

Marc A.R.C. Daemen, Cornelis van 't Veer, Tim G.A.M. Wolfs, Wim A. Buurman

The Journal of Immunology 2000,

American Association of Immunologists, reprinted with permission 


\section{ABSTRACT}

Tissue injury as a consequence of ischemia followed by reperfusion is characterized by early as well as late signs of inflammation. The latter, among others, involves IFN- $\gamma$ dependent up-regulation of MHC class I and II antigen expression. Employing a murine model of renal ischemia we show that renal IL-18 mRNA up-regulation coincides with caspase- 1 activation at day 1 following ischemia. IFN- $\gamma$ as well as IL-12 mRNA are subsequently up-regulated at day 6 following ischemia. Combined but not separate in vivo neutralization of the IFN- $\gamma$ inducing cytokines IL- 12 and IL- 18 reduces IFN- $\gamma$ dependent MHC class I and II up-regulation to a similar extent as IFN- $\gamma$ neutralization, suggesting the involvement of functional IL-12, IL-18 and IFN- $\gamma$ protein. These results reveal a novel relationship between tissue injury of non-microbial origin and the induction of IL12 as well as IL-18. The collaboration observed between endogenous IL-12 and IL-18 in the induction of IFN- $\gamma$ after renal ischemia-reperfusion, resembles the immune response to bacterial infections.

\section{INTRODUCTION}

The sequelae of events following renal ischemia and reperfusion $(\mathrm{I} / \mathrm{R})$ involves signs of not only an early ( 1 ) but also a late $(2,3)$ inflammatory response. The latter is characterized by enhanced expression of MHC class I and II antigens which are likely to predispose ischemically damaged kidneys to the development of graft rejection (3-5). Enhanced MHC expression after $\mathrm{I} / \mathrm{R}$ is a direct consequence of the potent MHC inducing capacities of IFN- $\gamma(6,7)$. However, the mechanisms by which IFN- $\gamma$ is induced after renal $\mathrm{I} / \mathrm{R}$ still remain to be resolved.

IFN- $\gamma$, commonly associated with resistance against pathogens, is produced largely by Th1-cells and large granular lymphocytes. In particular IL-12 (8), IL-18 (9) and, in an autocrine fashion, IFN- $\gamma(10)$ are involved in the intricate and tight regulation of IFN- $\gamma$ expression. Recently, Bohn et al. (11) reported that the LPS induced IL-12 production by peritoneal macrophages in vitro is inhibited by IL-18. They subsequently showed that this inhibitory effect is suppressed by IFN $-\gamma$. In addition, in vitro experiments indicated that IL-12 and IL-18 synergistically enhance production of IFN- $\gamma(12,13)$. This synergistic mechanism has been attributed to up-regulation of the IL-18 receptor by IL-12 (14). On the other hand, IFN- $\gamma$ production is limited by cytokines capable of suppressing Thl development such as IL-10 and IL-13 (15). In line with this, we recently demonstrated that endogenously produced IL-10 limits IFN- $\gamma$ induced renal MHC class I and II expression after I/R (4). IL-12 and IL-18 are commonly produced in response to pathogens and their products, however in this study we investigate the role of IL-12, IL18 and consequent IFN- $\gamma$ production triggered by tissue damage resulting from $\mathrm{I} / \mathrm{R}$. 
We demonstrate that up-regulation of MHC class I and II antigens following renal I/R can be prevented to a similar extent as in mice treated with anti- IFN- $\gamma$ antibodies by combined, but not separate, administration of antibodies directed against Il-12 and IL-18. This demonstrates for the first time that ischemic tissue damage initiates production of IL-12 as well as IL-18. Moreover, with respect to the in vivo kinetics of IL-12 and IL-18 we observe a resemblance between renal $\mathrm{I} / \mathrm{R}$ injury and in vivo immunoactivation by infectious agents.

\section{Materials and Methods}

\section{ANTIBODIES AND REAGENTS}

The following antibodies were used: anti-murine IFN $-\gamma \mathrm{mAb}$ F3, was kindly provided by HBT (Uden, The Netherlands); anti-murine IL-12 mAb C17.8, was kindly provided by Prof. Trinchieri (Wistar Institute, Philadelphia, PA)(16); mAb GL113, a control rat IgG1, was kindly provided by Dr. Savelkoul (Erasmus University, Rotterdam, The Netherlands); anti-murine $\mathrm{MHC}$ class $\mathrm{I} \mathrm{mAb} \mathrm{ml} / 42.3 .9 .8$ and $\mathrm{mAb} 5 \mathrm{D} 7$ producing hybridomas from the ATTC (Rockville, MD); anti-murine MHC class II mAb H82168.10 producing hybridoma was kindly provided by Dr. Pierres (CNRS INSERM, Marseille, France); anti-murine IL-18 pAb (purified rabbit IgG) was raised by immunizing rabbits with recombinant murine IL-18, kindly provided by Dr. Kurimoto (Fujisaki Institute, Okayama, Japan). Peroxidase conjugated goat anti-rat IgG was purchased from Jackson (West Grove, PA), Ac-YVAD-amc from the Peptide Institute (Osaka, Japan). All other reagents were purchased from Sigma (St. Louis, MO).

\section{Animal Model and Protocol}

All experiments were approved by the Institutional Animal Care Committee of the University of Maastricht. Renal ischemia was induced as follows: In brief, male Swiss mice (Charles River Breeding Laboratories, Heidelberg, FRG) were anesthetized and body temperature was maintained at $39^{\circ} \mathrm{C}$. After laparotomy ischemia was induced by clamping the left renal pedicle for 45 min during which the wound was covered. Subsequent to removal of the clamp, the contralateral kidney was removed and stored. After closing the abdomen, $0.25 \%$ bupivacaine was applied topically for postoperative pain management and mice were supplemented with prewarmed PBS to maintain fluid balance. At the time of sacrifice ( 1 and 6 days after ischemia), blood was collected and the left kidney was harvested.

Mice subjected to ischemia were treated 10 minutes prior to reperfusion with $0.5 \mathrm{ml}$ PBS i.p. containing either $300 \mu \mathrm{g}$ anti- IFN- $\gamma \mathrm{mAb}$ F3 ( $\mathrm{n}=20), 1 \mathrm{mg}$ anti-IL-12 mAb $\mathrm{C} 17.8(\mathrm{n}=20), 1 \mathrm{mg}$ anti-IL-18 pAb $(\mathrm{n}=20)$, a combination of $0.5 \mathrm{mg}$ anti-IL-12 mAb 
C17.8 and $0.5 \mathrm{mg}$ anti-IL-18 pAb $(\mathrm{n}=20)$ or PBS only $(\mathrm{n}=20)$. Two additional groups that received isotype-matched control $\mathrm{Ab}(5 \mathrm{D} 7 \mathrm{a}$ control rat IgG2a mAb; GL113 a control rat IgG1 $\mathrm{mAb} ; \mathrm{n}=6$ each) when compared to the ischemia/PBS group showed no significant differences (data not shown) indicating that aspecific IgG does not affect the evaluated parameters. Treatment of animals to be sacrificed at day 6 was repeated at day 4 after ischemia. A sham-group $(n=12)$ underwent the same surgical procedure as animals subjected to ischemia except for clamping of the renal pedicle. Sham operated animals were only treated with PBS. The capacity of the anti-IL-18 pAb to block biological activity was determined by measuring the ability of the anti-IL-18 pAb to neutralize IL-18 mediated enhancement of IFN- $\gamma$ production in vitro by stimulated T-cells $(1 \mathrm{mg} \mathrm{IgG/ml}$ inhibits the biological activity of $100 \mu \mathrm{g}$ of IL-18) (data not shown). Also, the in vivo neutralizing capacity of the anti-IL-18 pAb used, was confirmed by its effectiveness in combination with anti-IL-12 mAb as shown by the present results. Dosages of anti- IFN$\gamma$ and anti-IL-12 mAb are based on published results $(16,17)$.

\section{MEASUREMENTS OF RENAL IL-12, IL-18 AND IFN- $\gamma$ MRNA CONTENT}

Total RNA was extracted from kidneys and transcribed into cDNA of which the concentration was subsequently standardized based on the $\beta$-actin cDNA fraction. To determine renal IL-12 and IL-18 mRNA content, four 2-fold serial dilutions of cDNA were amplified with specific primers $(18,19)$. IFN- $\gamma$ mRNA expression was quantitatively measured by RT-PCR employing a multispecific control fragment as an internal standard (20). Relative amounts of IFN- $\gamma$ cDNA in specimens were estimated from concentrations of control fragment DNA added to achieve equal amplification compared to IFN- $\gamma$ cDNA employing IFN- $\gamma$ specific primers (20). After separation on $1.5 \%$ agarose gel, all PCR products were estimated by imaging the intensity of ethidium bromide luminescence with a CCD camera and image analysis with Sigma Gel software (SPSS, Chicago, IL).

\section{QUANTIFICATION OF RENAL CASPASE-1-LIKE ACTIVITY}

In order to quantify renal caspase-1 activity, samples were homogenized, snap frozen and stored at $-70^{\circ} \mathrm{C}$ in a buffer containing $200 \mathrm{mM} \mathrm{NaCl}, 10 \mathrm{mM}$ Tris $\mathrm{HCl}, \mathrm{pH} 7.0,5 \mathrm{mM}$ EDTA, $10 \%$ glycerol, $1 \mathrm{mM}$ PMSF, $0.1 \mu \mathrm{M}$ aprotinin, $1.0 \mu \mathrm{M}$ leupeptin, and $5 \mathrm{mM}$ oxidized glutathion. Renal lysates (containing $40 \mu \mathrm{g}$ total protein) were incubated with $50 \mu \mathrm{M}$ of the fluorogenic substrate Ac-YVAD-amc (caspase-1-like) in a cell-free system buffer containing $10 \mathrm{mM}$ Hepes, pH 7.4, $220 \mathrm{mM}$ mannitol, $68 \mathrm{mM}$ sucrose, $2 \mathrm{mM} \mathrm{NaCl}, 2.5 \mathrm{mM}$ $\mathrm{KH} 2 \mathrm{PO} 4,0.5 \mathrm{mM}$ EGTA, $2 \mathrm{mM} \mathrm{MgCl} 2,5 \mathrm{mM}$ pyruvate, $0.1 \mathrm{mM} \mathrm{PMSF}$, and $1 \mathrm{mM}$ dithiothreitol (21). The release of fluorescent 7-amino-4-methylcoumarin was measured for $1 \mathrm{~h}$ at $2 \mathrm{~min}$ intervals by spectrofluorometry. Data are expressed as the increase in fluorescence as a function of time, normalized against data obtained from the sham operated group. 
For the quantification of MHC class I and II antigens in the kidney, an enzyme immunoassay (EIA) was employed as previously described (4). In brief, renal tissue was homogenized in PBS $(20 \mathrm{mg} / \mathrm{ml})$ plus $8 \mathrm{nM}$ deoxyribonuclease I, $0.4 \mathrm{mM}$ PMSF, incubated with either $\mathrm{mAb} \mathrm{ml} / 42.3 .9 .8$ or $\mathrm{mAb} \mathrm{H} 82-168.10$, washed, incubated with peroxidase conjugated goat anti-rat IgG and washed again. Next, TMB substrate was added in a 96-well sample plate (Costar) to resuspended pellets and OD was determined at $450 \mathrm{~nm}$. All samples were measured in triplicate. MHC class I and II content were calculated per mg of renal tissue and standardized to a standard horseradish peroxidase titration curve. The obtained $\mathrm{MHC}$ class $\mathrm{I} / \mathrm{II}$ contents are presented relative to the amount of $\mathrm{MHC}$ class I/II in the contralateral control kidney.

For immunohistology of renal MHC class I and II, specimens of harvested kidneys were immediately frozen and stored at $-70^{\circ} \mathrm{C}$. Frozen sections $(5 \mu \mathrm{m})$ were stained for MHC class I with mAb ml/42.3.9.8 (22) and for MHC class II with mAb H82-168.10 using peroxidase-labeled goat anti-rat $\mathrm{IgG}$ as the secondary detection $\mathrm{mAb}$ and 3 -amino9-ethylcarbazole (AEC) as a chromogen followed by a hematoxylin counterstain. To block aspecific peroxidase activity sections were pretreated for $10 \mathrm{~min}$ with PBS containing $0.03 \% \mathrm{H} 2 \mathrm{O} 2$. No significant staining was detected in slides incubated with control mAb instead of the primary detecting $\mathrm{mAb}$ indicating the absence of significant background staining.

ASSAYS FOR RENAL MYELOPEROXIDASE (MPO) AND BLOOD UREA NITROGEN (BUN)

To quantify the extent of renal neutrophil accumulation, renal MPO content was determined (23). In brief, tissue samples were homogenized in $0.5 \%$ hexadecyltrimethylammonium bromide in $50 \mathrm{mM}$ PBS, $\mathrm{pH}=6.0,0.17 \mathrm{~g}$ tissue $/ \mathrm{ml}$. After heat incubation $(2 \mathrm{~h}$, $60^{\circ} \mathrm{C}$ ) and three freeze-thaw cycles, MPO content was measured in triplicate by incubating supernatants with tetramethylbenzidine (TMB) substrate in a 96-well sample plate (Costar, Cambridge, MA) followed by measurement of optical density (OD) at $450 \mathrm{~nm}$. MPO activity was calculated per mg renal tissue by comparing OD of samples with a standard titration curve of horseradish peroxidase. Data were standardized with respect to wet/dry ratios of the assayed renal tissue and are presented relative to the amount of MPO present in the contralateral kidney harvested immediately after ipsilateral reperfusion. Blood urea nitrogen (BUN) was measured in serum obtained at the time of sacrifice using a BUN unimate 5 kit in a Cobas Fara autoanalyzer (Roche, Basle, Switzerland). 


\section{STATISTICS}

Data are expressed the mean \pm SEM, and statistical analysis was performed by Student's T-test. $\mathrm{P}<0.05$ was taken to denote statistical significance.

\section{RESULtS}

RENAL I/R INDUCES ENDOGENOUS IL-18 FOLLOWED BY IL-12 WHICH BOTH MEDIATE IFN- $\gamma$ DEPENDANT MHC CLASS I AND II UP-REGULATION

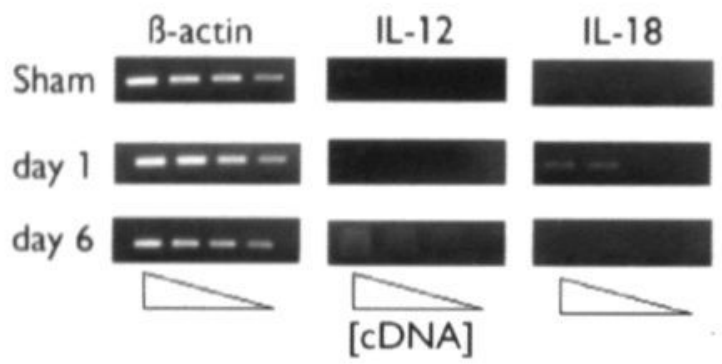

Figure 1. Renal IL-18 and IL-12 mRNA levels. Increased renal IL-18 mRNA and decreased IL-12 p40 mRNA expression at day I after I/R compared to kidneys obtained from sham operated controls. At day 6 renal IL-12 p40 mRNA levels increased compared to sham operated controls. Shown are representative samples of which cDNA was amplified in four 2 -fold serial dilutions and calibrated against identical levels of $\beta$-actin mRNA.

At day 1 after ischemia increased levels of kidney derived IL-18 mRNA were detected (Figure 1), while IFN- $\gamma$ mRNA expression remained constitutive (data not shown). Interestingly, at this timepoint constitutive IL-12 p40 mRNA levels slightly decreased (Figure 1). In animals sacrificed at 6 days after ischemia significant renal IL-18 mRNA levels were undetectable, whereas renal IL-12 p40 mRNA levels increased compared to constitutive levels (Figure 1). At this time, anti-IL-12 or anti-IL-18 Ab administration neither affected renal IFN- $\gamma$ mRNA levels (Figure 2) nor MHC class I and II expression (Figure 3) when compared to PBS treated controls. However, the combined administration of anti-IL-12 and anti-IL-18 Ab prevented the increase in renal IFN- $\gamma$ mRNA levels (Figure 2) as well as the up-regulation of renal MHC I and II (Figure 3,4) at day 6. In contrast to IL-12, the protein product of IL-18 mRNA translation requires further processing by activated caspase- 1 in order to become mature IL-18 $(9,18)$. The observed increase in renal caspase-1-like activity (Figure 5) indicates that the conditions for processing IL-18 protein are met for. Indeed, the effectiveness of combined anti-IL-12/18 as well as anti- IFN- $\gamma$ treatment indicate that IL-12, IL-18 and IFN- $\gamma$ protein are induced in the present model. 


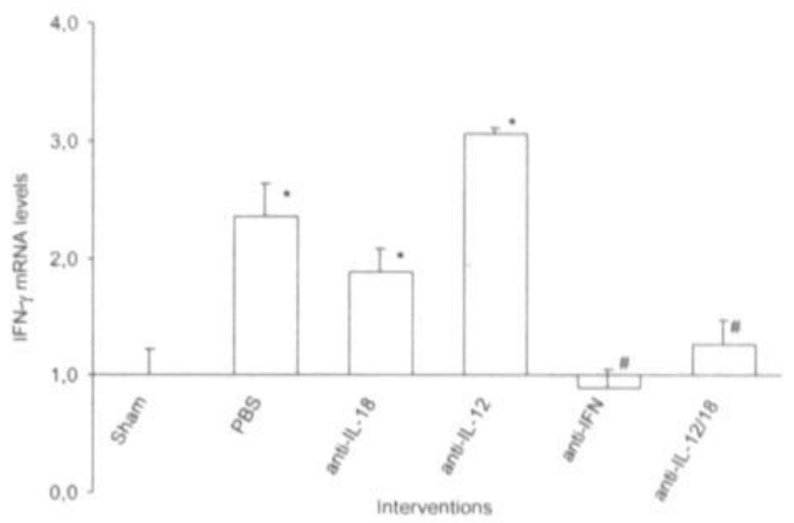

Figure 2. Renal IFN- $\gamma$ mRNA expression. Increased renal IFN- $\gamma$ mRNA expression at day 6 after ischemia compared to sham-operated animals $(n=6)$ as measured by quantitative RT-PCR is attenuated by anti- IFN- $\gamma \mathrm{Ab}(\mathrm{n}=10)$ or combined administration of anti-IL-18 and anti-IL$12 \mathrm{Ab}(\mathrm{n}=10)$. IFN- $\gamma \mathrm{mRNA}$ levels are expressed relative to $\beta$-actin mRNA levels and normalized to the sham group. Statistical significances compared to sham-operated animals (*) or compared to PBS treated animals (\#) are indicated. The columns are means \pm SEM, * and $\#=$ $\mathrm{P}<0.05$.

\section{DELAYED IFN- $\gamma$ DEPENDENT MHC CLASS I AND II UP-REGULATION AFTER RENAL I/R}

To explore the mechanisms by which I/R injury initiates IFN- $\gamma$ production and consequent enhanced MHC class I and II expression, we investigated renal IFN- $\gamma$ mRNA levels by means of RT-PCR as well as MHC class I and II expression by employing EIA and immunohistology. In line with previous reports $(6,24)$, the present findings reveal significantly increased levels of IFN- $\gamma$ mRNA (Figure 2) coinciding with significant MHC class I and II (Figure 3,4) up-regulation at 6 days following I/R when compared to sham operated controls. At day 6, tubular epithelium and arterial endothelium stained intensely positive for MHC class I (Figure 4), whereas MHC class II immunoreactivity was confined mainly to tubular epithelium (data not shown). The immunohistological data additionally showed that the contribution of infiltrating immune cells to $\mathrm{I} / \mathrm{R}$ induced $\mathrm{MHC}$ class I and II up-regulation was insignificant and that MHC class I and II immunostaining was most prominent in the outer stripe of the outer medulla. As previously reported $(8,30,31)$, the observed postischemic renal MHC class I and II up-regulation is an IFN$\gamma$ dependent process since the present results show a significant reduction in anti- IFN- $\gamma$ treated mice when compared to PBS treated controls (Figure 3). 

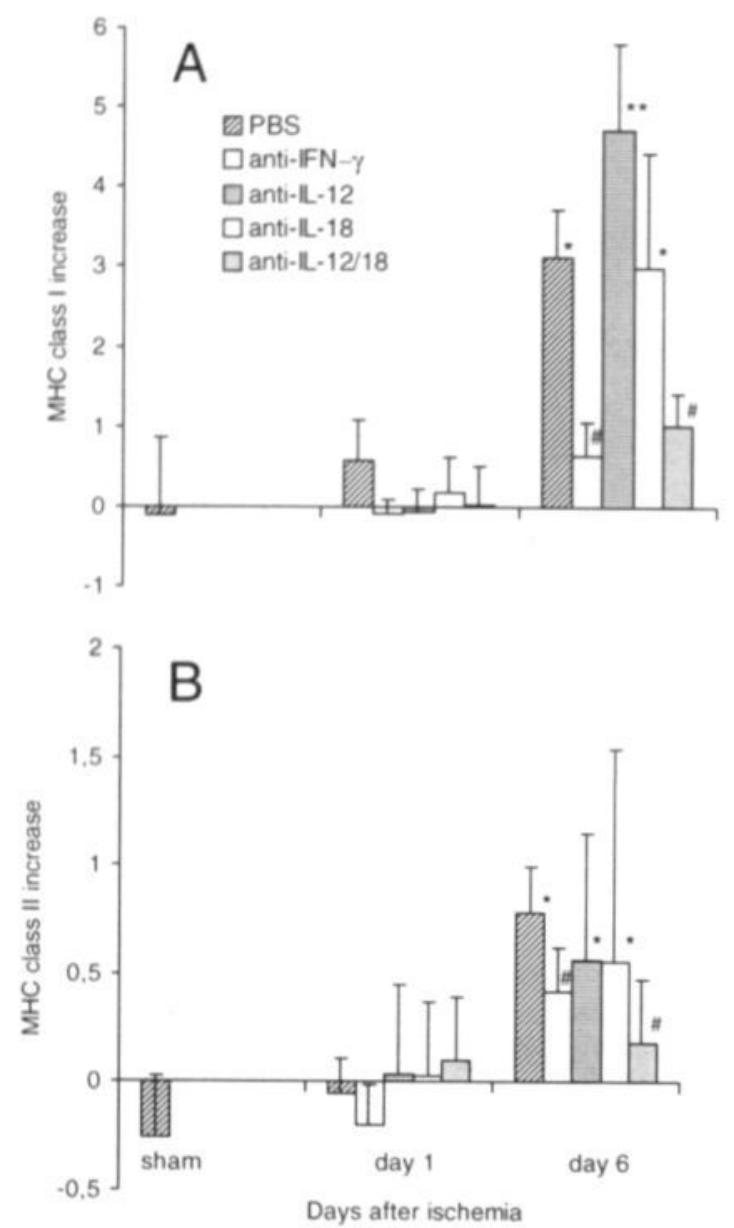

Figure 3. Renal MHC I and II antigen expression. Compared to sham-operated animals $(n=6)$, renal expression of MHC class I (A) and MHC class II (B) at day 6 after ischemia was enhanced as assessed by enzyme immuno-assay. This enhanced expression was equipotentialy prevented by anti-IFN- $\gamma(n=10)$ and combined anti-IL-12/18 $(n=10)$ treatment. Statistical significances compared to sham-operated animals $\left({ }^{*},{ }^{* *}\right)$ or compared to PBS treated animals $(\#)$ are indicated. The columns are means \pm SEM. $^{*}$ and $\#=\mathrm{P}<0.05 ;{ }^{* *}=\mathrm{P}<0.01$. 

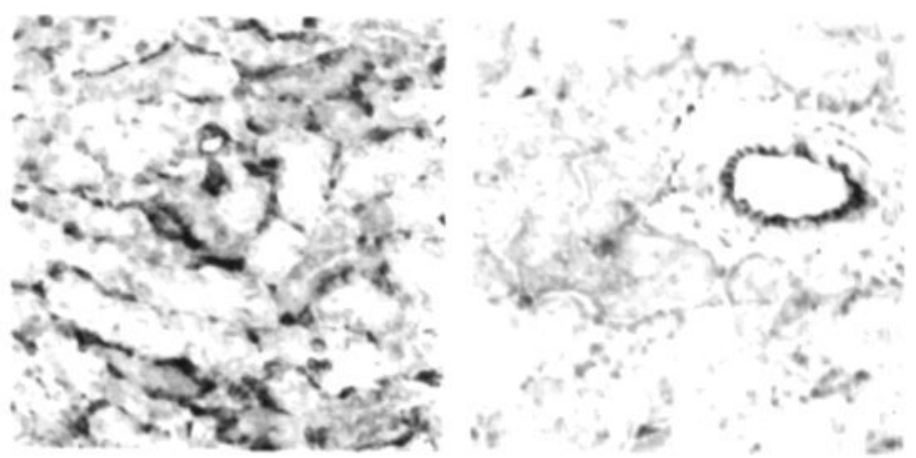

Figure 4. Immunohistology for renal MHC class I expression. MHC class I antigen expression as visualized by employing $\mathrm{mAb} \mathrm{ml/42.3.9.8} \mathrm{is} \mathrm{up-regulated} \mathrm{on} \mathrm{tubular} \mathrm{epithelium} \mathrm{at} \mathrm{day} 6$ after I/R in PBS treated animals (A). In contrast, at this timepoint only constitutive MHC class I expression was observed on arterial endothelium and tubular epithelium in animals treated with anti-IL-12/18 (B), anti- IFN- $\gamma$, in contralateral control kidneys or in kidneys obtained from sham-operated animals. (magnification 200x).

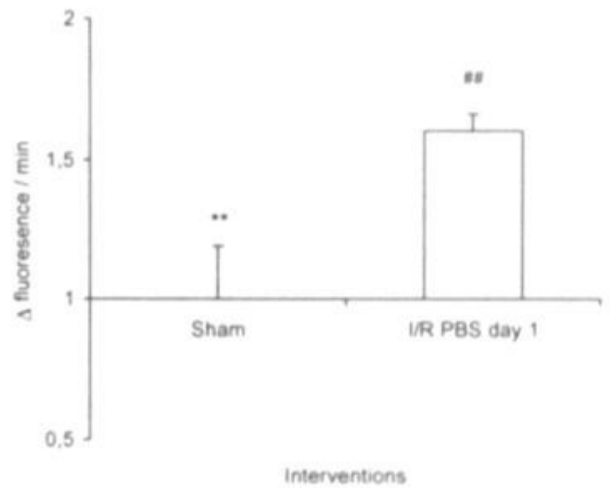

Figure 5. Renal caspase-1-like activity. Increased caspase-1-like activity as determined kinetically in kidneys obtained from PBS treated animals $(n=10)$ obtained after I day of reperfusion in a fluorogenic substrate assay in which Ac-YVAD-amc (caspase-I-like) served as a substrate. Data are expressed as the increase in fluorescence as a function of time, normalized against data obtained from the sham operated group $(n=6)$. Statistical significance compared to PBS treated animals was denoted at $\mathrm{P}<0.01\left({ }^{* *}\right)$ and compared to kidneys obtained from sham-operated animals at $\mathrm{P}<0.01$ (\#\#). The presented data are means \pm SEM.

\section{ENDOGENOUS IL-12 AND/OR IL-18 DO NOT MEDIATE THE EARLY INFLAMMATORY RESPONSE INDUCED BY RENAL I/R}

Compared to sham operated animals, $\mathrm{I} / \mathrm{R}$ increased kidney neutrophil accumulation and impaired kidney function (Figure 6) at day 1 after ischemia as measured by renal MPO and BUN content respectively. We investigated whether endogenous IL-12 and/or IL-18 
mediate these early consequences of ischemic tissue injury. The administration of antiIL-12 Ab, IL-18 Ab or a combination of both regimens failed to attenuate kidney neutrophil accumulation and deterioration of renal function (Figure 6) suggesting that these cytokines at this stage do not mediate reperfusion injury.

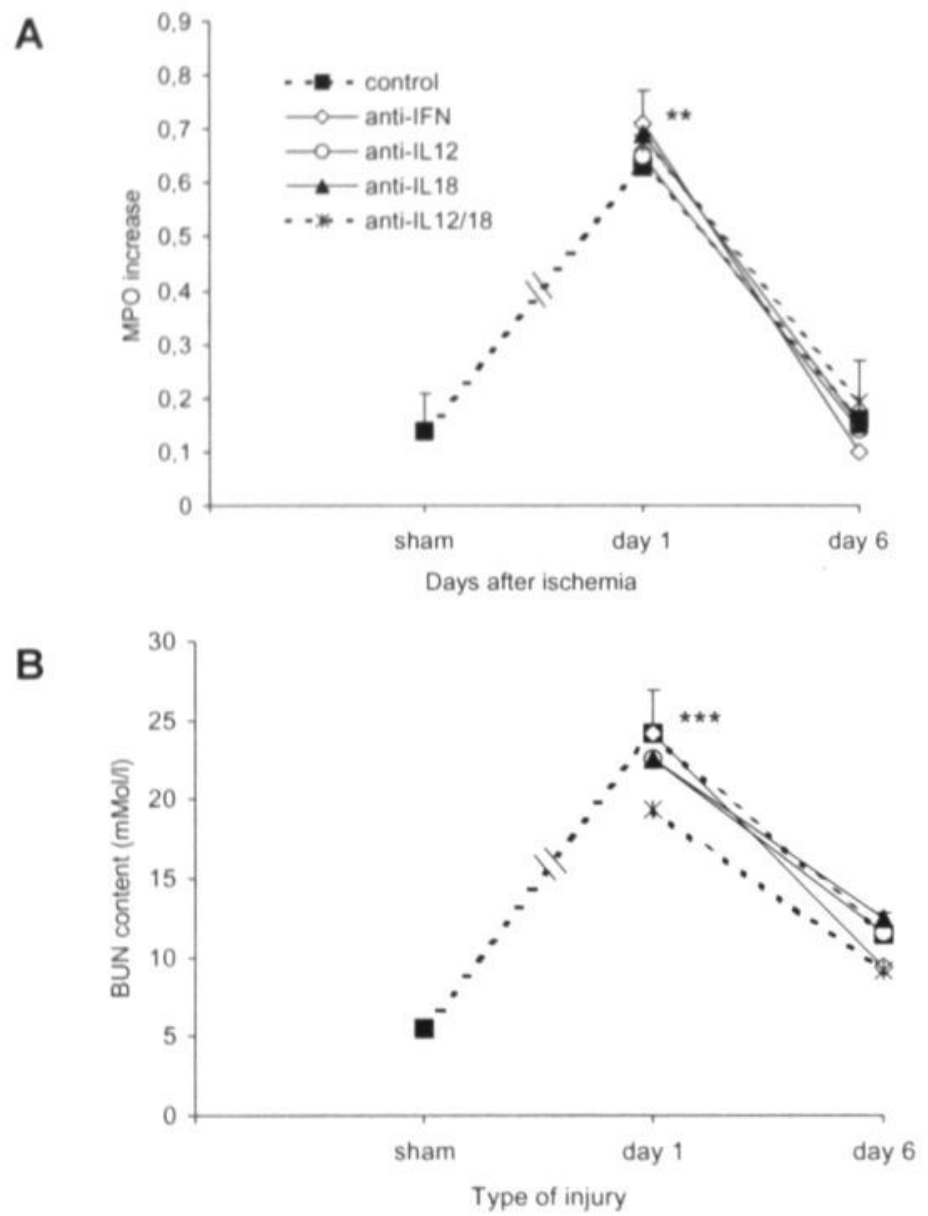

Figure 6. Renal neutrophil influx and function. Compared to sham-operated animals $(n=6)$, neutrophil influx (A) is up-regulated and renal function (B) impaired at day 1 after renal ischemia as measured by renal myeloperoxidase (MPO) increase and blood urea nitrogen (BUN) content, respectively. Note that all employed treatment regimens fail to attenuate this initial response ( $\mathrm{n}=10$ for each group). The statistical significant difference between PBS treated animals subjected to $\mathrm{I} / \mathrm{R}$ and sham-operated controls is indicated. The data shown are means. \pm SEM is included for the PBS treated group. ** 


\section{Discussion}

IFN- $\gamma$ is produced by T-cells and NK-cells following stimulation with IL-12 and/or IL18. The production of the heterodimeric cytokine IL-12 is tightly controlled by expression of the p40 subunit gene in macrophages, but also in tubular epithelial cells (25) when stimulated with, among others, bacteria or bacterial products (18). IL-18 on the other hand is an IFN- $\gamma$ inducing cytokine expressed by a far wider range of cell types and tissues than IL-12 (18). This may account for the observed renal IL-18 mRNA increase coinciding with the absence of significant IL-12 p40 mRNA induction after $1 / R$. Alternatively, based on experiments with Yersinia enterocolitica infected mice, Bohn et al. suggested that IL-18 downregulates local production of IL-12, which can be overruled by IFN- $\gamma(11)$. They showed that low amounts of IL-18 induced IFN- $\gamma$ in turn may activate macrophages to produce IL-12 which subsequently synergizes with IL-18 to produce high amounts of IFN- $\gamma$. Interestingly, in the present model such a mechanism may account for the observed downregulation of renal IL-12 p40 mRNA expression at day 1 and subsequent up-regulation at day 6 (Figure 1). Moreover, it may account for our finding that only anti- IFN- $\gamma$ and combined anti-IL-12/18 treatment prevented $\mathrm{I} / \mathrm{R}$ induced enhanced renaI IFN- $\gamma$ mRNA production (Figure 2) and subsequent MHC class I and II expression (Figures 3, 4).

Local tissue damage as a result of an infection may facilitate penetration of additional pathogens in an infected organ. It is tempting to speculate that IL-12/18 driven IFN- $\gamma$ and subsequent $\mathrm{MHC}$ up-regulation in response to tissue injury is a functionally important mechanism that primes injured tissue for enhanced immunosurveillance. If microbial induced cell death would lead to the observed late cytokine alterations and consequent induction of MHC antigens, this mechanism would target infected cells for recognition and elimination by T-cells $(26,27)$. Hence, MHC antigen up-regulation as a consequence of $\mathrm{I} / \mathrm{R}$ induced tissue damage may also facilitate the $\mathrm{T}$-cell response to invading pathogens. Besides ischemic damage, IFN- $\gamma$ production as well as $\mathrm{MHC}$ up-regulation are associated with poor allograft survival (28).

Many studies mainly focused on the potential involvement of IL-12 and/or IL-18 induced IFN- $\gamma$ production in host defense. The present findings for the first time indicate a relationship between tissue injury of non-pathogenic origin and the induction of both IL-12 and IL-18 collaborating in enhancing IFN- $\gamma$ production in vivo. The similarities observed between mechanisms of IFN- $\gamma$ induction during bacterial infections and nonmicrobial lesions such as renal $\mathrm{I} / \mathrm{R}$ injury raise the hypothesis that aspecific tissue damage contributes extensively to regulation of IFN- $\gamma$ production. However, to which extent these findings apply to other (non-) microbial stimuli remains to be elucidated. 


\section{REFERENCES}

1. Takada, M., K. C. Nadeau, G. D. Shaw, K. A. Marquette, and N. L. R. A. Tilney. The cytokine adhesion molecule cascade in ischemia/reperfusion injury of the rat kidney: inhibition by a soluble P selectin ligand. J Clin Invest 1997; 99:2682.

2. Takada, M., K. C. Nadeau, G. D. Shaw, and N. L. Tilney. Prevention of late renal changes after initial ischemia/reperfusion injury by blocking early selectin binding. Transplantation 1997; 64:1520.

3. Shoskes, D. A., N. A. Parfrey, and P. F. Halloran. Increased major histocompatibility complex antigen expression in unilateral ischemic acute tubular necrosis in the mouse. Transplantation 1990; 49:201.

4. Daemen, M. A. R. C., W. C. M. Van de Ven, E. Heineman, and W. A. Buurman. Pro- and antiinflammatory mechanisms in renal reperfusion injury in mice. Modulation by endogenous tumor necrosis factor alpha and interleukin-10. Transplantation 1999; 67:792.

5. Ferry, B., J. Halttunen, D. Leszczynski, H. Schellekens, P. H. Meide, and P. Hayry. Impact of class II major histocompatibility complex antigen expression on the immunogenic potential of isolated rat vascular endothelial cells. Transplantation 1987; 44:499.

6. Goes, N., J. Urmson, V. Ramassar, and P. F. Halloran. Ischemic acute tubular necrosis induces an extensive local cytokine response. Evidence for induction of interferon-gamma, transforming growth factor-beta I, granulocyte-macrophage colony- stimulating factor, interleukin-2, and interleukin-10. Transplantation 1995; 59:565.

7. Goes, N., J. Urmson, D. Vincent, V. Ramassar, and P. F. Halloran. Induction of major histocompatibility complex markers and inflammatory cytokines after ischemic injury to the kidney: lessons from interferon-gamma gene knockout mice. Transplant Proc 1995; 27:771.

8. Heinzel, F. P., R. M. Rerko, P. Ling, J. Hakimi, and D. S. Schoenhaut. Interleukin 12 is produced in vivo during endotoxemia and stimulates synthesis of gamma interferon. Infect Immun 1994; $62: 4244$.

9. Ghayur, T., S. Banerjee, M. Hugunin, D. Butler, L. Herzog, A. Carter, L. Quintal, L. Sekut, R. Talanian, M. Paskind, W. Wong, R. Kamen, D. Tracey, and H. Allen. Caspase-1 processes IFNgamma-inducing factor and regulates LPS- induced IFN-gamma production. Nature 1997; 386:619.

10. Halloran, P. F., P. Autenried, V. Ramassar, J. Urmson, and S. Cockfield. Local T cell responses induce widespread MHC expression. Evidence that IFN-gamma induces its own expression in remote sites. J Immunol 1992; 148:3837.

11. Bohn, E., A. Sing, R. Zumbihl, C. Bielfeldt, H. Okamura, M. Kurimoto, J. Heesemann, and I. B. Autenrieth. IL-18 (IFN-gamma-inducing factor) regulates early cytokine production in, and promotes resolution of, bacterial infection in mice. J Immunol 1998; 160:299.

12. Yoshimoto, T., H. Okamura, Y. I. Tagawa, Y. Iwakura, and K. Nakanishi. Interleukin 18 together with interleukin 12 inhibits $\operatorname{lgE}$ production by induction of interferon-gamma production from activated B cells. Proc Nat Acad Sci U.S.A. 1997; 94:3948.

13. Micallef, M. J., T. Ohtsuki, K. Kohno, F. Tanabe, S. Ushio, M. Namba, T. Tanimoto, K. Torigoe, M. Fuji, M. Ikeda, S. Fukuda, and M. Kurimoto. Interferon-gamma-inducing factor enhances T helper I cytokine production by stimulated human T cells - synergism with interleukin-12 for interferon-gamma production. Eur J Immunol 1996: 26:1647. 
14. Ahn, H. J., S. Maruo, M. Tomura, J. Mu, T. Hamaoka, K. Nakanishi, S. Clark, M. Kurimoto, H. Okamura, and H. Fujiwara. A mechanism underlying synergy between IL 12 and IFN gamma inducing factor in enhanced production of IFN gamma. $J$ Immunol 1997; 159:2125.

15. Muchamuel, T., S. Menon, P. Pisacane, M. C. Howard, and D. A. Cockayne. IL-13 protects mice from lipopolysaccharide-induced lethal endotoxemia: correlation with down-modulation of TNF-alpha, IFN-gamma, and IL-12 production. J Immunol 1997; 158:2898.

16. Wysocka, M., M. Kubin, L. Q. Vieira, L. Ozmen, G. Garotta, P. Scott, and G. Trinchieri. Interleukin-12 is required for interferon-gamma production and lethality in lipopolysaccharideinduced shock in mice. Eur $J$ Immunol 1995; 25:672.

17. Bemelmans, M. H., D. J. Gouma, and W. A. Buurman. LPS induced sTNF-receptor release in vivo in a murine model: investigation of the role of TNF, IL-1, LIF and IFN-gamma. $J$ Immunol 1993; 151:5554.

18. Tone, M., S. A. J. Thompson, Y. Tone, P. J. Fairchild, and H. Waldmann. Regulation of IL-18 (IFN-gamma Inducing Factor) gene expression. J Immunol 1998; 159:6156.

19. Stoll, S., G. Muller, M. Kurimoto, J. Saloga, T. Tanimoto, H. Yamauchi, H. Okamura, J. Knop, and A. H. Enk. Production of IL-18 (IFN-gamma-inducing factor) messenger RNA and functional protein by murine keratinocytes. J Immunol 1997; 159:298.

20. Platzer, C., G. Richter, K. Uberla, H. Hock, T. Diamantstein, and T. Blankenstein. Interleukin-4mediated tumor suppression in nude mice involves interferon-gamma. Eur $J$ Immunol 1992; 22:1729.

21. Vercammen, D., R. Beyaert, G. Denecker, V. Goossens, G. VanLoo, W. Declercq. J. Grooten, W. Fiers, and P. Vandenabeele. Inhibition of caspases increases the sensitivity of L929 cells to necrosis mediated by tumor necrosis factor. J Exp Med 1998; 187:1477.

22. Thor, G., H. Sepulveda, S. Chada, and R. W. Dutton. Monoclonal antibody that distinguishes between a phosphorylated, beta 2-microglobulin-associated, and a free, nonphosphorylated, chain of MHC class I. J Immunol 1993; 151:211.

23. Laight, D. W., N. Lad, B. Woodward, and J. F. Waterfall. Assessment of myeloperoxidase activity in renal tissue after ischemia/reperfusion. Eur J Pharmacol 1994; 292:81.

24. Shoskes, D. A. and P. F. Halloran. Ischemic injury induces altered MHC gene expression in kidney by an interferon-gamma-dependent pathway. Transplant Proc 1991; 23:599.

25. Fan, X., B. Oertli, and R. P. Wuthrich. Up-regulation of tubular epithelial interleukin-12 in autoimmune MRL-Fas(lpr) mice with renal injury. Kidney Int 1997; 51:79.

26. Lambert, M. E., Z. A. Ronai, I. B. Weinstein, and J. I. Garrels. Enhancement of major histocompatibility class I protein synthesis by DNA damage in cultured human fibroblasts and keratinocytes. Mol Cell Biol 1989; 9:847.

27. Reyburn, H. T., O. Mandelboim, G. M. Vales, D. M. Davis, L. Pazmany, and J. L. Strominger. The class I MHC homologue of human cytomegalovirus inhibits attack by natural killer cells. Nature 1997; 386:514.

28. Goes, N., M. Hobart, V. Ramassar, J. Urmson, and P. F. Halloran. Many forms of renal injury induce a stereotyped response with increased expression of MHC. IFN gamma, and adhesion molecules. Transplant Proc 1997; 29:1085. 
Chapter 3 


\section{CHAPTER 4}

Inhibition of apoptosis induced by ischemia-reperfusion prevents inflammation

Marc A.R.C. Daemen, Cornelis van 't Veer, Geertrui Denecker, Vincent H. Heemskerk, Tim G.A.M. Wolfs, Matthias Clauss, Peter Vandenabeele, and Wim A. Buurman

The Journal of Clinical Investigation 2000, reprinted with permission 


\section{ABSTRACT}

Ischemia followed by reperfusion leads to severe organ injury and dysfunction. Inflammation is considered to be the most important cause of tissue injury in organs subjected to ischemia. The mechanism that triggers inflammation and organ injury after ischemia remains to be elucidated, although different causes have been postulated. We investigated the role of apoptosis in the induction of inflammation and organ damage after renal ischemia. Using a murine model, we demonstrate a relation between apoptosis and subsequent inflammation. Administration at the time of reperfusion of the antiapoptotic agents insulin like growth factor-1 (IGF-1) and zVAD-fmk, a caspase inactivator, prevented the early onset of renal apoptosis but also inflammation and tissue injury. Conversely, when administered after onset of apoptosis, these protective effects were completely abrogated. The presence of apoptosis was directly correlated with post-translational processing of the chemoattractant endothelial monocyte-activating polypeptide II (EMAP-II), which may explain apoptosis-induced influx and sequestration of leukocytes in the reperfused kidney. These results strongly suggest that apoptosis is a crucial event that can initiate reperfusion induced inflammation and subsequent tissue injury. Described new pathophysiological insights provide important opportunities to effectively prevent clinical manifestations of reperfusion injury in the kidney, and potentially in other organs.

\section{INTRODUCTION}

Central organ systems including heart, brain, gut and kidney are particularly sensitive to ischemia followed by reperfusion ( $\mathrm{I} / \mathrm{R})$. Renal $\mathrm{I} / \mathrm{R}$ injury alone imposes a significant burden upon health-care by restricting function and availability of donor kidneys for transplantation and as a serious complication of circulatory shock.

Inflammation has been indicated as a major cause of $I / R$ induced tissue injury, since therapeutic strategies aimed to reduce inflammation often ameliorate $I / R$ injury (1). The local inflammatory reaction following reperfusion involves cytokines such as pro-inflammatory TNF- $\alpha$ as well as recruitment of neutrophils. In vitro studies imply roles for anoxia induced release of chemokines and neutrophil-endothelium interactions $(2,3)$ in the induction of inflammation after I/R. Nevertheless, little is known about the specific events that trigger this inflammatory response in vivo.

The present study investigates whether another early consequence of $I / R$, apoptotic cell death (4), contributes to the inflammatory response in a murine model of renal $I / R$. Our results challenge the paradigm stating that apoptosis represents a physiological mode of cell deletion allowing disposal of superfluous cells with minimal tissue reaction or even with active restraining of inflammation (5). We show that exogenous insulin-like growth factor I (IGF-1), a growth and survival factor, as well as the active caspase inhibitor Z- 
Val-Ala-Asp(OMe)-CH2F (zVAD-fmk) attenuate reperfusion induced inflammation, most likely as a consequence of their ability to inhibit apoptosis in vivo. These findings strongly suggest that apoptotic cell death, either directly or indirectly, significantly contributes to $\mathrm{I} / \mathrm{R}$ induced inflammation as well as to consequent tissue damage and may provide new therapeutic means to treat $\mathrm{I} / \mathrm{R}$ injury.

\section{MAterials AND Methods}

\section{ANTIBODIES AND REAGENTS}

Anti-murine neutrophil mAb Gr-1 from Pharmingen (San Diego, CA); peroxidase conjugated goat anti-rat and peroxidase conjugated goat anti-rabbit IgG from Jackson (West Grove, PA); peroxidase conjugated sheep anti-digoxigenin, digoxigenin 11-dUTP and TdT from Boehringer Mannheim (Mannheim, FRG); peroxidase conjugated rabbit antisheep IgG from DAKO (Copenhagen, Denmark); the rabbit antiserum SA 2846 was generated (Eurogentec, Seraing, Belgium) against human recombinant mature EMAP-II (23 $\mathrm{kDa}$ ) and recognized murine EMAP-II; Taq polymerase from Perkin Elmer (Norwalk, CT); LY294002 from Calbiochem (La Jolla, CA); recombinant human IGF-1 was kindly provided by Dr. H.P. Guler (Chiron Corporation, Emeryville, CA); zVAD-fmk and ZFA-fmk from Enzyme Systems (Livermore, CA); Ac-YVAD-amc and Ac-DEVD-amc from the Peptide Institute (Osaka, Japan). All other reagents were purchased from Sigma (St. Louis, MO).

\section{RENAL ISCHEMIA/REPERFUSION INJURY MODEL}

Male Swiss mice weighing 20-25 g were obtained from Charles River Breeding Laboratories (Heidelberg, FRG) and housed individuaily in standard laboratory cages with ad libitum access to food and water. The studies were approved by the Institutional Animal Care Committee of the University of Maastricht. At the start of the experiments, mice were anesthetized with sodium pentobarbital $(50 \mathrm{mg} / \mathrm{kg}$ i.p.). A rectal probe (ColePalmer, Vernon Hills, IL) to monitor body temperature was inserted and body temperature was maintained at $39^{\circ} \mathrm{C}$ by a heating lamp until animals recovered from anesthesia. Ischemia was induced by clamping the left renal pedicle for 45 min using a non-traumatic vascular clamp through a midline abdominal incision. After removal of the clamp the left kidney was inspected for restoration of blood flow. Next, the contralateral kidney was removed and stored for further analysis. The abdomen was closed in two layers and $0.25 \%$ bupivacaine was applied topically for postoperative pain management. Finally, to maintain fluid balance and volume status, mice were supplemented with $1 \mathrm{ml}$ prewarmed $\left(37^{\circ} \mathrm{C}\right)$ PBS s.c. The animals were sacrificed on different timepoints ranging from just before, through $24 \mathrm{~h}$ after reperfusion. At the time of sacrifice, blood was collected by 
orbital puncture and the left kidney was harvested for further analysis.

At the time of reperfusion mice were administered 100 ( $\mathrm{g}$ recombinant human IGF-1 s.c. $(\mathrm{n}=10), 30 \mu \mathrm{g}$ zVAD-fmk in $1 \%$ DMSO i.p. $(\mathrm{n}=10)$ or $20 \mu \mathrm{g}$ recombinant human EGF s.c. $(\mathrm{n}=10)$ dissolved in $0.3 \mathrm{ml}$ PBS. In separate groups $15 \mu \mathrm{g}$ LY294002 i.p. in 0.3 $\mathrm{ml}$ PBS containing $1 \%$ DMSO was administered with $(n=10)$ or without $(n=10)$ IGF-1 treatment. Also in separate groups, IGF-1 $(n=10)$ or zVAD-fmk $(n=10)$ were administered under similar conditions except after $2 \mathrm{~h}$ of reperfusion. Neither the solvent DMSO nor treatment with $30 \mu \mathrm{g}$ Z-Phe-ala-Ch2F (ZFA-fmk) in 1\% DMSO as a negative control for the caspase inhibiting properties of zVAD-fmk affected the outcome of performed experiments as compared to PBS treatment (data not shown). Therefore, the control group was treated with vehicle consisting of $0.3 \mathrm{ml}$ PBS s.c. $(n=12)$. A sham-group $(n=12)$ was subjected to the same surgical procedure without clamping of the renal pedicle, treated with PBS and sacrificed at corresponding timepoints. Dosages selected were based on pilot experiments with respect to zVAD-fmk and LY294002 (data not shown) and on studies in which IGF-1 or EGF were found to attenuate renal reperfusion injury (6).

\section{ASSAYS FOR MYELOPEROXIDASE (MPO) AND BLOOD UREA NITROGEN (BUN)}

To quantify the extent of renal neutrophil accumulation, renal MPO content was determined. Snap-frozen samples were thawed, homogenized for 30 seconds using a tissue homogenizer (T25B, IKA GmbH, Staufen, FRG) at 20,000 rotations $/ \mathrm{min}$ in $0.5 \%$ hexadecyltrimethylammonium bromide dissolved in $50 \mathrm{mM}$ PBS $\mathrm{pH}=6.0$ and made up to concentrations of $0.17 \mathrm{~g}$ renal tissue $/ \mathrm{ml}$. After heat incubation $\left(2 \mathrm{~h}, 60^{\circ} \mathrm{C}\right)$ in a water bath to verify myeloperoxidase heat resistance, samples were frozen and thawed in order to release cellular MPO. Next, samples were spun at 11,000 g for $5 \mathrm{~min}$ and supernatants were collected. Enzymatic detection of myeloperoxidase was performed in a 96-well plate (Costar, Cambridge, MA). Assay mixtures consisted of $40 \mu \mathrm{H} \mathrm{H}_{2} \mathrm{O}_{2}$ (final concentration $0.3 \mathrm{mM}$ ) in $80 \mathrm{mM}$ PBS pH=5.4 and $40 \mu \mathrm{l}$ in $0.5 \%$ hexadecyltrimethylammonium bromide, $50 \mathrm{mM}$ PBS $\mathrm{pH}=6.0$ containing diluted sample. The reaction was initiated by addition of $20 \mu \mathrm{l}$ tetramethylbenzidine (final concentration $1.6 \mathrm{mM}$ ) in dimethyl sulfoxide and stopped after $15 \mathrm{~min}$ by the addition of $50 \mu \mathrm{l} /$ well $1 \mathrm{M} \mathrm{H}_{2} \mathrm{SO}_{4}$. Subsequently, optical density (OD) was determined at $450 \mathrm{~nm}$. All samples were assayed in triplicate. MPO activity was calculated per mg renal tissue by comparing OD of sample wells with a titration curve of horseradish peroxidase. The obtained relative MPO activities were standardized with respect to wet/dry ratios of the assayed renal tissue and are presented relative to the amount of MPO present in the contralateral kidney harvested immediately after reperfusion and normalized with respect to the MPO increase at day 1 in PBS treated mice subjected to I/R. BUN content was measured in serum obtained by orbital punction at the time of sacrifice using a BUN unimate 5 kit in a Cobas Fara autoanalyzer (Roche, Basle, Switzerland). 


\section{APOPTOSIS ASSAYS}

Histological aspects of apoptosis were studied by standard terminal deoxynucleotidyl transferase (TdT)-mediated dUTP nick end labeling (TUNEL histology). To this end, 8 $\mu \mathrm{m}$ frozen sections were fixed for $30 \mathrm{~min}$ in $4 \%$ buffered formaldehyde, washed in PBS, pretreated for $10 \mathrm{~min}$ with PBS containing $0.6 \% \mathrm{H}_{2} \mathrm{O}_{2}$ and washed again. DNA fragments were elongated and labeled with TdT and digoxigenin 11-dUTP. Subsequently, sections were treated with sheep anti-digoxigenin $\mathrm{Ab}$ and washed. Finally, peroxidase-labeled rabbit anti-sheep $\mathrm{Ab}$, preincubated for $30 \mathrm{~min}$ in $10 \%$ murine serum, was applied and after washing developed with diaminobenzidine substrate. Sections pretreated with DNAse 1 in order to nick all DNA, served as positive controls.

In order to quantify renal caspase activity, fluorogenic substrates were employed with predominant caspase-1-like and caspase-3-like affinities. Samples were homogenized, snap frozen and stored at $-70^{\circ} \mathrm{C}$ in a buffer containing $200 \mathrm{mM} \mathrm{NaCl}, 10 \mathrm{mM}$ Tris $\mathrm{HCl}$, pH 7.0, $5 \mathrm{mM}$ EDTA, $10 \%$ glycerol, $1 \mathrm{mM}$ PMSF, $0.1 \mu \mathrm{M}$ aprotinin, $1.0 \mu \mathrm{M}$ leupeptin, and $5 \mathrm{mM}$ oxidized glutathion. Renal lysates (containing $40 \mu \mathrm{g}$ total protein) were incubated with $50 \mu \mathrm{M}$ of the fluorogenic substrates Ac-YVAD-amc (caspase-1-like) or AcDEVD-amc (caspase-3-like) in a cell-free system buffer containing $10 \mathrm{mM}$ Hepes, pH 7.4, $220 \mathrm{mM}$ mannitol, $68 \mathrm{mM}$ sucrose, $2 \mathrm{mM} \mathrm{NaCl}, 2.5 \mathrm{mM} \mathrm{KH}_{2} \mathrm{PO}_{4}, 0.5 \mathrm{mM}$ EGTA, $2 \mathrm{mM} \mathrm{MgCl}, 5 \mathrm{mM}$ pyruvate, $0.1 \mathrm{mM}$ PMSF, and $1 \mathrm{mM}$ dithiothreitol. The release of fluorescent 7-amino-4-methylcoumarin was measured for $1 \mathrm{~h}$ at $2 \mathrm{~min}$ intervals by spectrofluorometry (Cytofluor, PerSeptive Biosystems, Cambridge, MA). Data are expressed as the increase in fluorescence as a function of time, normalized against data obtained from the sham operated group.

The presence of internucleosomal DNA cleavage in kidneys was investigated with a commercially available ligase-mediated (LM)-PCR assay kit (Apoalert, Clontech, Palo Alto, CA) enabling semiquantitative measurement of the extent of apoptosis. In brief, DNA was isolated from tissue samples previously frozen at $-70^{\circ} \mathrm{C}$ employing a commercially available DNA purification kit (Wizard, Promega, Madison, WI) according to the manufacturers instructions. DNA purity and concentration were determined by electrophoresis through a $0.8 \%$ agarose gel containing ethidium bromide followed by visualization under ultraviolet illumination as well as by measuring absorbance at $260 / 280 \mathrm{~nm}$. Dephosphorylated adaptors were ligated to 5'-phosphorylated blunt ends with T4 DNA ligase (during $16 \mathrm{~h}$ at $16^{\circ} \mathrm{C}$ ) and served as primers in a LM-PCR under the following conditions: hotstart $\left(72^{\circ} \mathrm{C}\right.$ for $8 \mathrm{~min}$, Taq polymerase added after $\left.3 \mathrm{~min}\right), 25$ cycles $\left(94^{\circ} \mathrm{C}\right.$ for 15 seconds and $72^{\circ} \mathrm{C}$ for 180 seconds), post-cycling $\left(72^{\circ} \mathrm{C}\right.$ for $\left.15 \mathrm{~min}\right)$. To confirm that equal amounts of DNA were used for PCR, an internal control that consisted of DNA amplification with En-2 primer pairs was performed. Amplified DNA was subjected to gel electrophoresis on a $1.2 \%$ agarose gel containing ethidium bromide. 


\section{HISTOLOGY}

Histological aspects of apoptosis were studied to verify that $\mathrm{I} / \mathrm{R}$ also induced morphological characteristics of apoptosis. Kidneys were fixed in situ by perfusion with $2.5 \%$ glutaraldehyde in phosphate buffer through a left ventricular cardiac catheter in anesthetized mice after $3 \mathrm{~h}$ of reperfusion. After perfusion fixation renal specimens containing outer medulla segments were fixed in $2.5 \%$ glutaraldehyde overnight. Next, segments were postfixed in $1 \%$ osmium tetroxide, dehydrated in graded alcohols and embedded in Epon 812 plastic. Finally, sections $(1 \mu \mathrm{m})$ were stained with toluidine blue for lightmicroscopic examination.

From animals in the different treatment groups, specimens of harvested kidneys were immediately frozen and stored at $-70^{\circ} \mathrm{C}$. Sections $(5 \mu \mathrm{m})$ were stained for neutrophils with $\mathrm{mAb}$ Gr-1 using peroxidase-labeled goat anti-rat $\mathrm{IgG}$ as the secondary detection $\mathrm{mAb}$ and 3-amino-9-ethylcarbazole (AEC) as a chromogen followed by a hematoxylin counterstain. To block aspecific peroxidase activity sections were pretreated for $10 \mathrm{~min}$ with PBS containing $0.03 \% \mathrm{H}_{2} \mathrm{O}_{2}$. No significant staining was detected in slides incubated with control $\mathrm{mAb}$ instead of the primary detecting $\mathrm{mAb}$.

\section{WESTERN BLOT ANALYSIS}

Frozen samples of harvested kidneys were homogenized in a buffer containing $200 \mathrm{mM}$ $\mathrm{NaCl}, 10 \mathrm{mM}$ Tris $\mathrm{HCl}, \mathrm{pH} 7.0,5 \mathrm{mM}$ EDTA, $10 \%$ glycerol, $1 \mathrm{mM}$ PMSF and $0.1 \mu \mathrm{M}$ aprotinin. After centrifugation at $15000 \mathrm{~g}$, protein in the supernatants was quantified by the Bradford method, boiled in Leammli buffer and $35 \mu \mathrm{g}$ protein per lane was electrophoresed in $15 \%$ SDS/PAGE. Proteins were transferred to nitrocellulose membranes, which were subsequently blocked with $\mathrm{PBS} / 5 \%$ nonfat dry milk and incubated for $3 \mathrm{~h}$ with EMAP-II antiserum (SA 2846, diluted 1:2000 in PBS/0.1\% Tween 20). After washing, the membranes were incubated for $2 \mathrm{~h}$ with peroxidase-labeled goat anti-rabbit IgG (diluted 1:2000 in PBS/0.1\% Tween 20), washed and developed by enhanced chemiluminescence.

\section{STATISTICS}

Data are expressed as the mean \pm SEM and statistical analysis was performed by Student's T-test. $\mathrm{P}<0.05$ was taken to denote statistical significance. 


\section{RESULTS}

\section{RENAL I/R INDUCES APOPTOSIS AND SUBSEQUENT INFLAMMATION}

In order to determine the extent of apoptosis and exclude necrosis or mechanisms independent from apoptosis as main contributors to DNA fragmentation different techniques were employed. Kidneys were investigated by TUNEL histology in order to localize DNA fragmentation after reperfusion. Further, for morphological assessment of apoptosis toluidine blue histology was performed using plastic embedded tissues. Also, caspaselike activities and internucleosomal DNA cleavage were measured in homogenates of kidneys obtained after reperfusion.
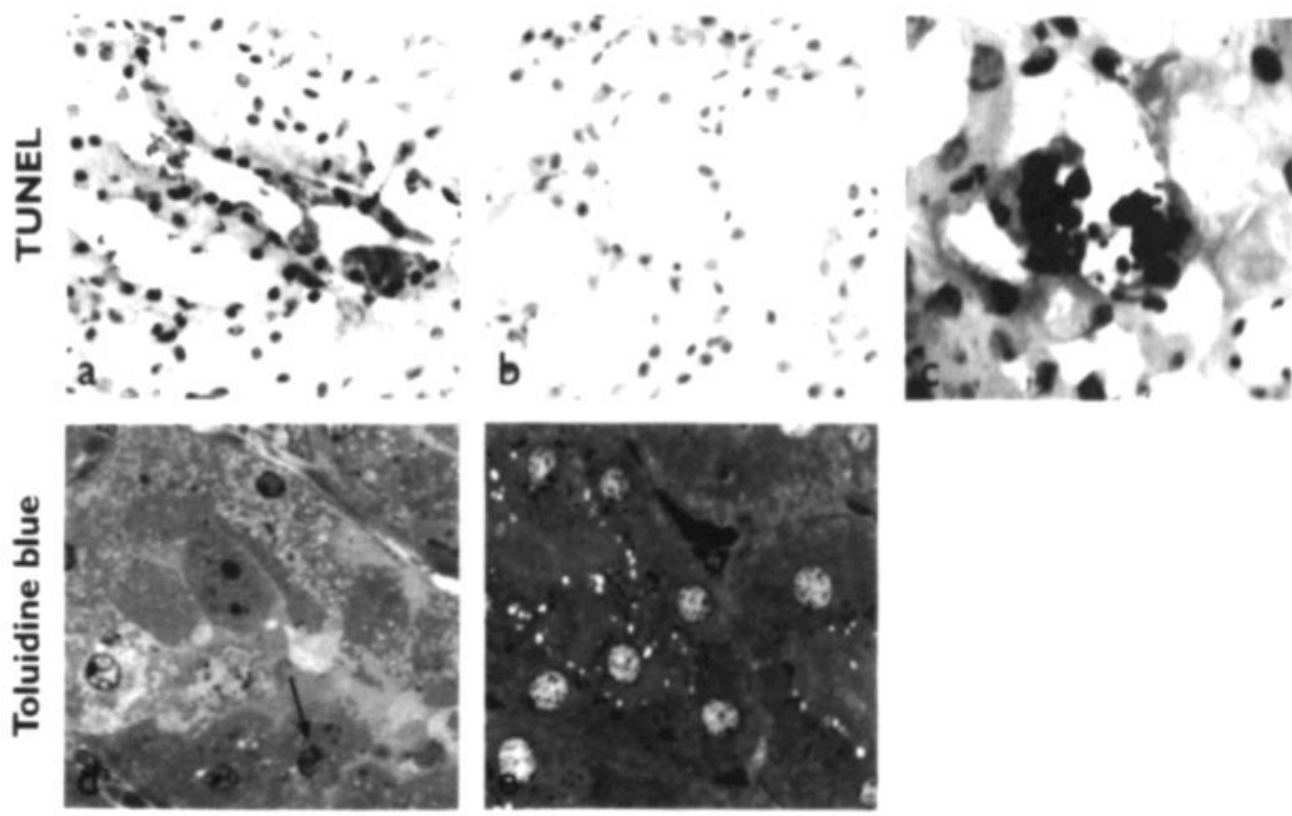

Figure 1. Representative light micrographs showing evident in situ detection of DNA nick ends by TUNEL histology (A,B,C). The tubular epithelial cells of the outer medulla of biopsies obtained after $2 \mathrm{~h}$ of reperfusion showed positive staining (A), in contrast to kidneys obtained from sham operated mice (B) (magnification $250 \mathrm{x}$ ). The presence of apoptotic bodies could be detected extracellularly and extruded into the tubular lumen after $2 \mathrm{~h}$ of reperfusion (C) (magnification $1000 \mathrm{x}$ ). Toluidine blue stains of $1 \mu \mathrm{m}$ sections, obtained from kidneys that were in situ fixed after $3 \mathrm{~h}$ of reperfusion and subsequently plastic embedded (D,E), revealed the presence of dense condensation of nuclear chromatin and nuclear fragmentation in apoptotic tubular epithelial cells (arrow) in the outer medulla (D), while morphological attributes of tubular epithelial cell apoptosis were generally absent in sham operated mice (E) (magnification $1000 \mathrm{x})$. 
TUNEL positive nuclei, restricted mainly to the tubular epithelial cells of the outer medulla, were identified in biopsies obtained after as early as $2 \mathrm{~h}$ of reperfusion (Figure la,b). At his timepoint, TUNEL histology revealed the extracellular presence of apoptotic bodies, which were often extruded into the tubular lumen (Figure 1c). In a separate group of mice sacrificed after $3 \mathrm{~h}$ of reperfusion, toluidine blue stained $1 \mu \mathrm{M}$ sections showed dense condensation of nuclear chromatin and nuclear fragmentation in apoptotic tubular epithelial cells (Fig, 1d,e). In addition, increased renal caspase-1-like and caspase-3-like activities (Figure 2) as well as apparent internucleosomal DNA cleavage (Figure 3 ) were observed after $2 \mathrm{~h}$ of reperfusion.
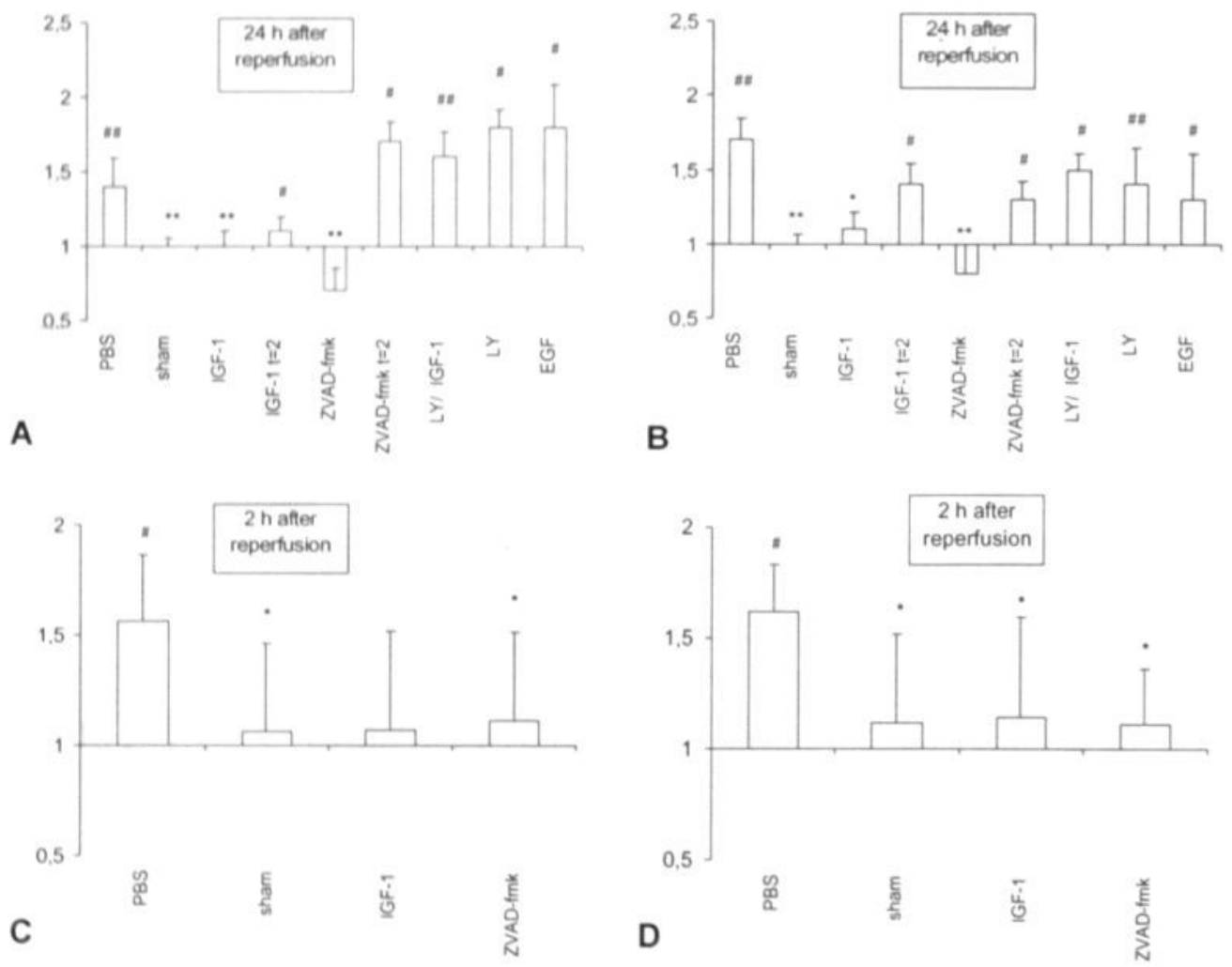

Figure 2. Renal caspase-like activities were determined kinetically in homogenates of tissue obtained after $24(\mathrm{~A}, \mathrm{~B})$ and $2 \mathrm{~h}(\mathrm{C}, \mathrm{D})$ of renal reperfusion in a fluorogenic substrate assay in which Ac-YVAD-amc (caspase-1-like) (A,C) or Ac-DEVD-amc (caspase-3-like) (B,D) served as substrates. Note that these data may represent a more generalized form of caspase activation as outlined in the main text. Data are expressed as the increase in fluorescence as a function of time, normalized against data obtained from the sham operated group. The groups that indicate $t=2$ on the $x$-axis received the indicated treatment after $2 \mathrm{~h}$ of reperfusion. All other groups were treated at the time of reperfusion. Statistical significance compared to control treated animals was denoted at $\mathrm{P}<0.05\left({ }^{*}\right)$ or $\mathrm{P}<0.01\left({ }^{* *}\right)$ and compared to contralateral control kidneys at $\mathrm{P}<0.05$ (\#) or $\mathrm{P}<0.01$ (\#\#). The presented data are means $\pm \mathrm{SEM}$. 
As previously documented (4), after 1 day of reperfusion the number of tubular epithelial cells containing TUNEL positive nuclei had increased and TUNEL positive nuclei of infiltrating immune cells were observed (data not shown). Also at this time, increased renal caspase-1 (Figure 2a) and caspase-3-like (Figure 2b) activities were detected. Together with the observed occurrence of internucleosomal DNA cleavage (Figure 3) these findings suggest the presence of ongoing renal apoptosis, starting as early as $2 \mathrm{~h}$ after reperfusion.

IGF-1 abrogates early apoptosis, impaired renal function and inflammation induced by $\mathrm{I} / \mathrm{R}$. We first investigated the relation between $\mathrm{I} / \mathrm{R}$ induced apoptosis and inflammation by employing IGF-1, because pilot experiments revealed that this agent prevented $I / R$ induced apoptosis in murine kidneys. Administration of IGF-1 at the time of reperfusion, as opposed to administration of PBS, prevented apoptosis as indicated by a decreased number of TUNEL-positive nuclei (data not shown), decreased caspase-like activities (Figure 2) and the absence of apparent internucleosomal DNA cleavage (Figure 3). These data reveal the anti-apoptotic potential of IGF-1 in an early phase after renal ischemia.

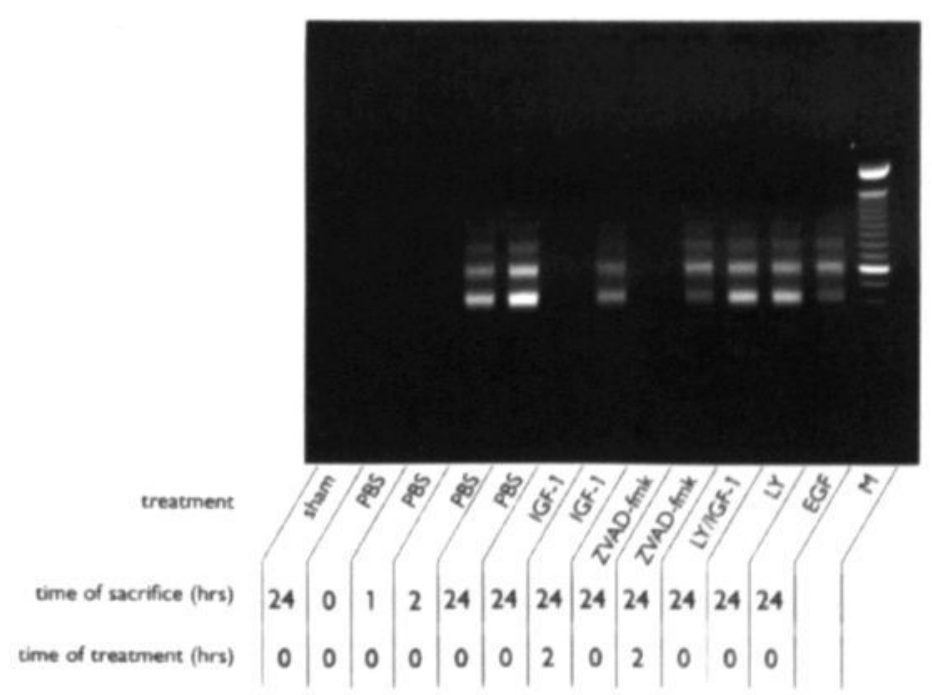

Figure 3. The extent of renal apoptosis in different treatment groups is also reflected by the presence of fragmented DNA (as a result of internucleosomal DNA cleavage) amplified by LM-PCR and visualized on ethidium-bromide-stained gel. M, molecular weight markers (range, 100 to 2000 base pairs).

Next, we studied whether abrogation of early apoptosis affects later consequences of renal I/R. IGF-1 administration at the time of reperfusion prevented the $I / R$ induced impairment of renal function as reflected by increased BUN content at day 1 (Figure 4). Moreover, IGF-1 treatment limited I/R induced inflammation at that timepoint by reduc- 
ing the renal influx of neutrophils as reflected by the presence of Gr-1 positive cells (Figure 5a,b) and the increased renal MPO activity (Figure 5c). Taken together, these findings indicate that exogenous IGF-1 prevents $I / R$ induced apoptosis, impairment of renal function and inflammation.

Protection from I/R induced apoptosis by IGF-1 is mediated by PI3 kinase. PI3 kinase, an important component of signal transduction by insulin family receptors, has been reported to mediate anti-apoptotic signaling by IGF-1 in vitro (7). In order to investigate more closely the mechanisms by which IGF-1 attenuates reperfusion induced apoptosis as well as inflammation, we treated mice with a combination of IGF-1 and LY294002, a selective PI3 kinase inhibitor (8). In contrast to IGF-1 treatment, combined administration of IGF-1 and LY294002 at the time of reperfusion failed to prevent apoptosis. Such treated animals exhibited an abrogation of IGF-1 induced inhibition of apoptosis, resulting in increased numbers of TUNEL-positive nuclei (data not shown), significant caspase-like activity (Figure 2) as well as apparent internucleosomal DNA cleavage (Figure 3 ) at 1 day after I/R. Moreover, at this timepoint they exhibited a decreased renal function (Figure 4) and an increased renal neutrophil influx (Figure 5c) when compared to IGF-1 treated animals. LY294002 compared to PBS treatment did not result in significant differences with respect to any of the parameters evaluated (Figure 2-5). These data demonstrate that in vivo anti-apoptotic signaling by IGF-1 is mediated by the PI3 kinase pathway.

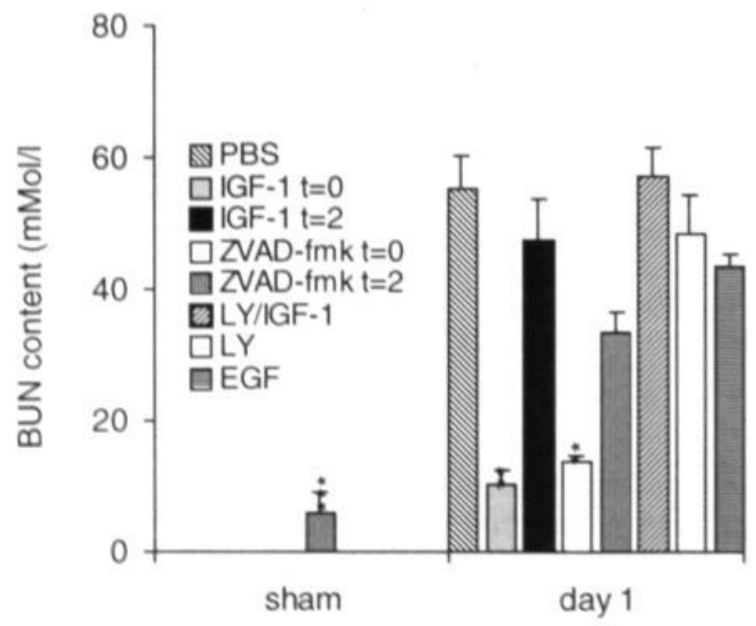

Figure 4. Renal function in the different experimental groups as reflected by blood urea nitrogen (BUN) content. Statistical significance compared to control treated animals was denoted at $\mathrm{P}<0.01\left(^{* *}\right)$ or $\mathrm{P}<0.001\left({ }^{* * *}\right)$. The data shown are means \pm SEM. 
Inflammation is dependent on antecedent apoptosis after renal $\mathrm{I} / \mathrm{R}$. Besides anti-apoptotic properties, IGF-1 has a well documented mitogenic potential that may contribute to the repair and recovery of ischemically injured renal tissue. To address the question whether the mitogenic effects of IGF-1 were responsible for the observed prevention of apoptosis and inflammation in our model, we treated mice with epidermal growth factor (EGF), a powerful mitogen for renal epithelial cells. EGF administered at the time of reperfusion failed to prevent reperfusion induced renal apoptosis as reflected by increased numbers of TUNEL-positive nuclei (data not shown), caspase-like activity (Figure 2) and apparent internucleosomal DNA cleavage (Figure 3) at day 1. Hence, the absence of any antiapoptotic effect excludes that EGF, as opposed to IGF-1, functions as a survival factor in the model employed. Moreover, as opposed to IGF-1, EGF prevented neither I/R induced impaired renal function (Figure 4) nor inflammation (Figure 5c) at day 1.
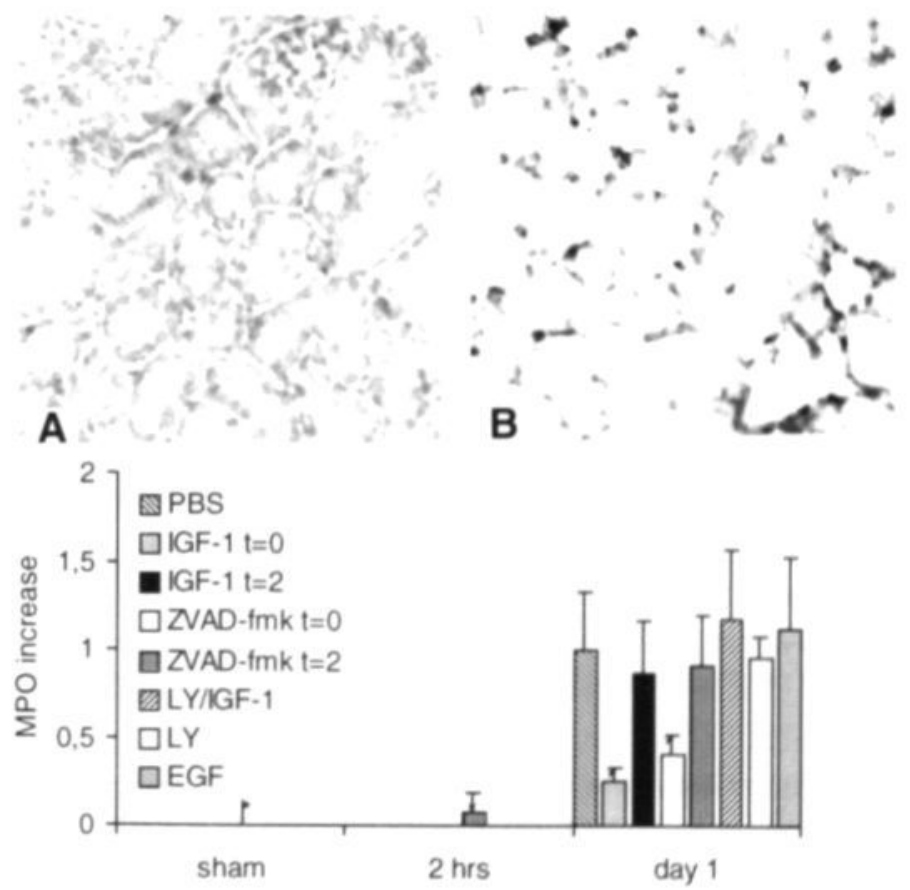

Figure 5. Representative light micrographs $(A, B)$ showing infiltrating neutrophils in areas with impaired renal morphological integrity in biopsies obtained from mice subjected to renal $\mathrm{I} / \mathrm{R}$ after 1 day of reperfusion (A). Neutrophils were stained with the anti-murine neutrophil $m A b$ Gr-1. Neither loss of morphological integrity, nor infiltrating neutrophils in kidneys obtained from sham operated mice (B) (magnification 200x). Neutrophil influx was assessed quantitatively by determination of MPO increase at $2 \mathrm{~h}$ and 1 day of reperfusion (C). Values are presented relative to the amount of MPO present in the contralateral kidney harvested immediately after reperfusion and normalized with respect to the MPO increase at day 1 in PBS treated mice subjected to $I / R$. Statistical significance as compared to control treated animals was denoted at $\mathrm{P}<0.05\left(^{*}\right)$. The presented data are means \pm SEM. 
To investigate whether in our model the anti-inflammatory effect of exogenous IGF-1 is a direct effect rather than a consequence of the absence of apoptosis, mice were treated with the tripeptide caspase inhibitor zVAD-fmk at the time of reperfusion as well as after $2 \mathrm{~h}$ of reperfusion. At the latter timepoint the presence of renal apoptosis is evident (Figure 1), while on the other hand, an inflammatory response as defined by the present parameters cannot yet be distinguished (Figure $5 \mathrm{c}$ ). In line with a recent report on cardiac I/R (9), we show that zVAD-fmk administered at the time of reperfusion completely abrogated renal apoptosis (Figure 2,3). In addition, zVAD-fmk administered at the time of reperfusion prevented the impairment of renal function (Figure 4) as well as the development of the inflammatory response (Figure $5 \mathrm{c}$ ) at day 1 . In contrast, zVAD-fmk administered after $2 \mathrm{~h}$ of reperfusion not only failed to attenuate the extent of the already initiated apoptotic response (Figure 2,3) but also failed to attenuate subsequent impairment of renal function (Figure 4) and the inflammatory response (Figure 5c). Similarly, at day 1 no reversement of renal apoptosis could be detected in mice that received IGF1 after $2 \mathrm{~h}$ of reperfusion (Figure 2,3) and animals exhibited signs of impaired renal function (Figure 4) and inflammation (Figure 5c) similar to PBS treated animals. These findings indicate that development of inflammation is dependent on antecedent apoptosis after I/R. Since abrogation of apoptosis by IGF-1 or zVAD-fmk limits I/R induced inflammation, apoptosis is a likely candidate for induction of inflammation in the model employed.

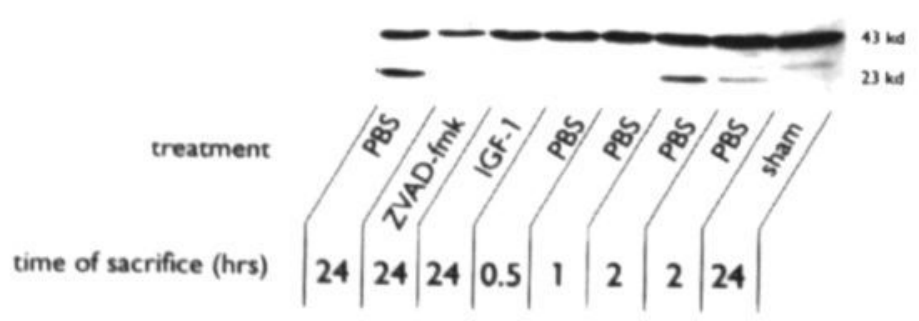

Figure 6. Post-translational processing of the EMAP-II protein is induced in parallel with apoptosis as early as after $2 \mathrm{~h}$ of reperfusion. Western blots were performed with protein isolated from kidneys from mice that were sacrificed after different periods of reperfusion. Incubation with the EMAP-II antiserum SA 2846 revealed constitutive expression of inactive pro-EMAPII, which resulted in a $43 \mathrm{kDa}$ band. After $2 \mathrm{~h}$ of reperfusion the presence of $23 \mathrm{kDa}$ mature EMAP-II was observed, which was even more apparent after $24 \mathrm{~h}$ of reperfusion. Anti-apoptotic treatment at the time of reperfusion with IGF-1 or zVAD-fmk evidently inhibited I/R induced EMAP-II maturation.

Post-translational processing of EMAP-II coincides with $\mathrm{I} / \mathrm{R}$ induced apoptosis and is inhibited by IGF-1 and zVAD-fmk. The precursor form of the chemokine EMAP-II can serve as a target substrate for activated caspases (10). We investigated the effect of $I / R$ on post-translational processing of EMAP-II by Western-blotting. Figure 6 shows that 
$\mathrm{I} / \mathrm{R}$ results in enhanced cleavage of the $43 \mathrm{kDa}$ EMAP-II precursor as early as after $2 \mathrm{~h}$ of reperfusion. The active $23 \mathrm{kDa}$ cleavage product remained detectable in kidneys subjected to $24 \mathrm{~h}$ of reperfusion. Hence, the formation of functional EMAP-II coincides with the manifestation of apoptosis after renal I/R. EMAP-II activation was clearly inhibited in kidneys obtained from sham-operated animals or from mice treated with zVAD-fmk at the time of reperfusion, after $2 \mathrm{~h}$ (data not shown) or $24 \mathrm{~h}$ (Figure 6) of reperfusion. At these timepoints, animals that were treated with IGF-1 at the time of reperfusion exhibited only low-intensity $23 \mathrm{kDa}$ bands (Figure 6). Digital image analysis of activated EMAP-II protein band intensities of the representative EMAP-II Western blot (Figure 6) reveals that the intensity of the $23 \mathrm{kDa}$ band after IGF-1 treatment is approximately $5 \%$ of the $23 \mathrm{kDa}$ band intensity $24 \mathrm{~h}$ after PBS treatment. These findings are in line with the other parameters measured in IGF-1 treated animals. As shown in Figure 6, the formation of $23 \mathrm{kDa}$ EMAP-II also resulted in formation of bands representing a molecular mass between 23 and $43 \mathrm{kDa}$, which has been suggested to be the result of intermediate cleavage product formation (10). These results demonstrate that renal $I / R$ induces EMAP-II activation. Both IGF-1 and the caspase inhibitor zVAD-fmk strongly reduce EMAP-II activation, which may explain the observed ability of these agents to inhibit the apoptosis-induced inflammatory response after renal $\mathrm{I} / \mathrm{R}$.

\section{Discussion}

We hypothesized that apoptosis following I/R constitutes a potential trigger of inflammation and studied this possibility by employing inhibitors of the apoptotic response in a murine model of renal $\mathrm{I} / \mathrm{R}$. Evidence for the early involvement of apoptosis is provided by the presence of DNA fragmentation, morphological features characteristic for apoptosis as well as increased caspase-1 and caspase-3-like activities in kidneys after 2 $\mathrm{h}$ of reperfusion. These findings are in line with various in vivo and in vitro reports showing that renal apoptosis after ischemia is induced by hypoxia (11) and ATP depletion (12). In addition, hydrolyzation of the plasma membrane component sphingosine and consequent liberation of ceramide has been reported to initiate apoptosis after as early as 30 min of renal reperfusion (13). Furthermore, during $\mathrm{I} / \mathrm{R}$ induced inflammation at day 1 , upregulated Fas (4) (capable of inducing apoptosis independent of ceramide-signaling), TNF- $\alpha(14)$ as well as p53 (15) have been associated with I/R induced apoptosis. In contrast, our in vivo findings clearly differ from data presented by Ueda et al. who reported that anoxia followed by reoxygenation of isolated rat proximal tubules in vitro may occur without morphological aspects of apoptosis (16).

The present findings show that mice treated with a single dose of IGF-1 at the time of reperfusion exhibited abrogation of apoptosis as demonstrated by decreased numbers of TUNEL-positive nuclei, decreased renal caspase-like activities and the absence of apparent internucleosomal DNA cleavage. These results confirm that IGF-1 is a potent 
inhibitor of reperfusion induced apoptosis. Also zVAD-fmk, a broad spectrum inhibitor of activated caspases, abrogated I/R induced apoptosis, while ZFA-fmk, a homologous peptide lacking the caspase inhibiting properties of zVAD-fmk failed to prevent apoptosis. Hence, inhibition of apoptosis prevented the loss of kidney function and the development of an inflammatory response. In contrast, administration of anti-apoptotic IGF-1 or zVAD-fmk after $2 \mathrm{~h}$ of reperfusion (after the onset of apoptosis) failed to prevent loss of kidney function and inflammation. Thusfar, few studies have addressed the potential of IGF-1 in ischemia induced apoptosis $(17,18)$. The latter report assumed a distinct "anti-neutrophil property" besides anti-apoptotic effects of IGF-1. In contrast, our findings clearly define apoptosis as an event arising proximal to the onset of $I / R$ induced inflammation.

We investigated whether mechanisms other than inhibition of apoptosis contributed to the anti-inflammatory and renal function improving effects of IGF-1 and zVAD-fmk. Caspase-1 as well as caspase-3-like activity during I/R induced apoptosis were significantly prevented by IGF-1 or zVAD-fmk administered at the time of reperfusion. While caspase-3 activation reflects many forms of apoptosis (19), a functional role of caspase1 during apoptosis appears to be restricted to cell death induced by specific agents such as FasL (20) and granzyme B (21). Caspase-1, also referred to as IL-1 converting enzyme (ICE), is involved in, but not essential to the maturation of IL-1 and IL-18 (22, 23). Therefore, activated caspase-1 induced release of IL-1 and/or IL-18 may contribute to the inflammatory response after I/R (23). However, in line with recent observations (24), inhibition of endogenous IL-1 (data not shown) and also IL-18 (25) only minimally decreased renal influx of neutrophils and loss of kidney function after 1 day of reperfusion when compared to administration of IGF-1 or zVAD-fmk (data not shown). Finally, it has to be taken into account that the measured renal caspase-like activities are likely to represent a more generalized form of caspase activation, since enzymatic activities of caspase- 1 and caspase-3 on Ac-YVAD-amc and Ac-DEVD-amc have been shown to be not fully specific (26).

The anabolic effect attributed to the growth factor IGF-1, putatively leading to enhanced tissue repair, may add to the therapeutic effect of IGF-1 (6). Moreover, IGF-1 induced renal NO can improve kidney function by directly enhancing renal circulation (27) as well as by contributing to limitation of apoptosis through inhibition of caspases (28). However, direct anti-inflammatory effects of IGF-1 have not been previously reported. The present findings show that neither treatment with EGF, a renotropic growth factor with anabolic effects similar to IGF-1 (29), nor treatment with IGF-1 or zVAD-fmk after $2 \mathrm{~h}$ of reperfusion, attenuated the loss of kidney function or inflammation.

Similar to in vitro observations $(7,30)$, we further showed by co-administrating the PI3 kinase inhibitor LY294002, that PI3 kinase constitutes an essential component of IGF-1 receptor mediated anti-apoptotic signaling in vivo. Taken together, these results demonstrate that the anti-inflammatory effects of IGF-1 and zVAD-fmk are distinctively medi- 
ated by anti-apoptotic signaling rather than by inhibition of IL-1 and/or IL-18 maturation, anabolic stimulation or NO induced enhanced kidney function. Nevertheless, despite the lack of an apparent functional role for activated caspase- 1 in our model, our findings do not definitely rule out the possibility that apoptosis and inflammation are two largely independent processes that share thus far unknown upstream molecular mechanisms.

The present findings demonstrate that inhibition of apoptosis after renal $\mathrm{I} / \mathrm{R}$ prevents subsequent inflammation. This apparently defines apoptosis to be critical for the induction of inflammation in the present model. Our results additionally demonstrate that $\mathrm{I} / \mathrm{R}$ induces activation of EMAP-II. Inactive pro-EMAP-II may serve as a target substrate for activated caspases (10), which we presently show to be upregulated as a consequence of I/R. The evident formation of mature EMAP-II coinciding with elaboration of $I / R$ induced apoptosis as well as the observed decrease in EMAP-II activation after IGF-1 or zVAD-fmk treatment are in line with a recent report of Knies et al. (10) who showed that release of mature EMAP-II is directly linked to apoptosis and can be abrogated in vitro by caspase inhibition. Mature EMAP-II is a potent chemokine that stimulates migration of PMNs and monocytes in vivo and induces tissue factor on endothelial cells (31) and TNF- $\alpha$ from monocytes (32). Its peptide sequence exhibits strong regional homology with other pro-inflammatory mediators such as human Von Willebrand factor antigen II (33) and IL-8 (34). Furthermore, it was recently demonstrated that mediators of apoptosis can cleave aminoacyl-tRNA synthetase, which subsequently leads to release of the pro-inflammatory cleavage products EMAP-II as well as the $\mathrm{NH}_{2}$-terminal catalytic domain of tyrosyl tRNA synthetase (35).

The present data suggest that EMAP-II maturation as a consequence of $\mathrm{I} / \mathrm{R}$ induced apoptosis contributes to recruitment of inflammatory cells to the reperfused kidney. However, more studies are needed to determine the functional role EMAP-II in I/R and to elucidate potential other mechanisms by which apoptosis induces an inflammatory response. Furthermore, the absence of sufficient phagocytosis of apoptotic cells has been associated with further degeneration and ultimately necrosis of apoptotic cells, a process termed "secondary necrosis" $(36,37)$. This secondary necrosis has been suggested to occur when the extent of necrosis overwhelms the phagocytic capacity of the tissue (38) and appears to be another important link between apoptosis and inflammation. It is tempting to speculate that phagocytosis cannot deal sufficiently with sudden widespread apoptosis within an organ subjected to prolonged ischemia, which ultimately leads to secondary necrosis and inflammation.

Many documented attempts to directly reduce the $I / R$ induced inflammatory response in various models have unmasked inflammation as a significant cause of subsequent tissue injury and dysfunction $(1,14)$. The present studies indicate that early apoptosis is a crucial event in the process that initiates inflammation and subsequent tissue injury because abrogation of early $\mathrm{I} / \mathrm{R}$ induced apoptosis prevents the development of inflammation and organ dysfunction. This concept of apoptosis induced inflammation follow- 
ing $\mathrm{I} / \mathrm{R}$ puts forth new important opportunities to effectively prevent clinical manifestations of reperfusion injury. The latter include among others prevention of complications arising from the use of ischemically damaged donor organs, cardiopulmonary bypass surgery, aortic cross-clamping and circulatory shock. Agents such as IGF-1 (which can be safely administered to humans), zVAD-fmk as well as new anti-apoptotic substances currently under investigation, may provide new therapeutic means to treat such conditions.

\section{REFERENCES}

1. Vedder, N.B., R.K. Winn, C.L. Rice, E.Y. Chi, K.E. Arfors, and J.M. Harlan. Inhibition of leukocyte adherence by anti-CD 18 monoclonal antibody attenuates reperfusion injury in the rabbit ear. Proc Natl Acad Sci U.S.A. 1990; 87:2643.

2. Shreeniwas, R., S. Koga, M. Karakurum, D. Pinsky, E. Kaiser, J. Brett, B.A. Wolitzky, C. Norton, J. Plocinski, and W. Benjamin. Hypoxia-mediated induction of endothelial cell interleukin-1 alpha. An autocrine mechanism promoting expression of leukocyte adhesion molecules on the vessel surface. J Clin Invest 1992; 90:2333.

3. Metinko, A.P., S.L. Kunkel, T.J. Standiford, and R.M. Strieter. Anoxia-hyperoxia induces monocyte-derived interleukin-8. J Clin Invest 1992; 90.79J.

4. Nogae, S., M. Miyazaki, N. Kobayashi, T. Saito, K. Abe, H. Saito, P.K. Nakane, Y. Nakanishi, and T. Koji. Induction of apoptosis in ischemia-reperfusion model of mouse kidney: Possible involvement of Fas. J Am Soc Nephrol 1998; 9:620.

5. Fadok, V.A., D.L. Bratton, A. Konowal, P.W. Freed, J.Y. Westcott, and P.M. Henson. Macrophages that have ingested apoptotic cells in vitro inhibit proinflammatory cytokine production through autocrine/paracrine mechanisms involving TGF-beta, PGE2, and PAF. J Clin Invest 1998; 101:890.

6. Goes, N., J. Urmson, D. Vincent, V. Ramassar, and P.F. Halloran. Effect of recombinant human insulin-like growth factor-1 on the inflammatory response to acute renal injury. $J \mathrm{Am} \mathrm{Soc}$ Nephrol 1996; 7:710.

7. Kulik, G., A. Klippel, and M.J. Weber. Antiapoptotic signalling by the insulin-like growth factor I receptor, phosphatidylinositol 3-kinase, and Akt. Mol Cell Biol 1997; 17:1595.

8. Vlahos, C.J., W.F. Matter, K.Y. Hui, and R.F. Brown. A specific inhibitor of phosphatidylinositol 3-kinase, 2-(4-morpholinyl)-8-phenyl-4H-1-benzopyran-4-one (LY294002). J Biol Chem $1994 ; 269: 5241$.

9. Yaoita, H., K. Ogawa, K. Maehara, and Y. Maruyama. Attenuation of ischemia/reperfusion injury in rats by a caspase inhibitor. Circulation 1998; 97:276.

10. Knies, U.E., H.A. Behrensdorf, C.A. Mitchell, U. Deutsch, W. Risau, H.C. Drexler, and M. Clauss. Regulation of endothelial monocyte-activating polypeptide II release by apoptosis. Proc Natl Acad Sci U.S.A. 1998; 95:12322.

11. Beeri, R., Z. Symon, M. Brezis, S.A. Ben Sasson, P.H. Baehr, S. Rosen, and R.A. Zager. Rapid DNA fragmentation from hypoxia along the thick ascending limb of rat kidneys. Kidney Int 1995: 47:1806.

12. Lieberthal, W., S.A. Menza, and J.S. Levine. Graded ATP depletion can cause necrosis or apoptosis of cultured mouse proximal tubular cells. Am. J Physiol 1998; 43:F315. 
13. Zager, R.A., M. Iwata, D.S. Conrad, K.M. Burkhart, and Y. Igarashi. Altered ceramide and sphingosine expression during the induction phase of ischemic acute renal failure. Kidney Int 1997; 52:60.

14. Daemen, M.A.R.C., W.C.M. Van de Ven, E. Heineman, and W.A. Buurman. 1999. Pro- and antiinflammatory mechanisms in renal reperfusion injury in mice. Modulation by endogenous tumor necrosis factor alpha and interleukin-10. Transplantation 1999; 67:792.

15. Raafat, A.M., M.T. Murray, T. McGuire, M. Defrain, A.P. Franko, R.S. Zafar, K. Palmer, L. Diebel, A. Dulioust, and S.A. Dulchavsky. Calcium blockade reduces renal apoptosis during ischemia reperfusion. Shock 1997; 8:186.

16. Ueda, N., P.D. Walker, S.M. Hsu, and S.V. Shah. Activation of a 15-kDa endonuclease in hypoxia/reoxygenation injury without morphologic features of apoptosis. Proc Natl Acad Sci U.S.A. 1995; 92:7202.

17. Hirschberg, R. and H. Ding. Mechanisms of insulin-like growth factor-l-induced accelerated recovery in experimental ischemic acute renal failure. Miner Electrolyte Metab 1998; 24:211.

18. Buerke, M., T. Murohara, C. Skurk, C. Nuss, K. Tomaselli, and A.M. Lefer. Cardioprotective effect of insulin-like growth factor I in myocardial ischemia followed by reperfusion. Proc Natl Acad Sci U.S.A. 1995; 92:8031.

19. Lazebnik, Y.A., S.H. Kaufmann, S. Desnoyers, G.G. Poirier, and W.C. Earnshaw. Cleavage of poly(ADP-ribose) polymerase by a proteinase with properties like ICE. Nature 1994; 371:346.

20. Los, M., Van-de Craen M., L.C. Penning, H. Schenk, M. Westendorp, P.A. Baeuerle, W. Droge, P.H. Krammer, W. Fiers, and O.K. Schulze. Requirement of an ICE/CED-3 protease for Fas/APO-1-mediated apoptosis. Nature 1995; 375:81.

21. Shi, L., G. Chen, G. MacDonald, L. Bergeron, H. Li, M. Miura, R.J. Rotello, D.K. Miller, P. Li, T. Seshadri, J. Yuan, and A.H. Greenberg. Activation of an interleukin I converting enzymedependent apoptosis pathway by granzyme B. Proc Natl Acad Sci U.S.A. 1996; 93:11002.

22. Ghayur, T., S. Banerjee, M. Hugunin, D. Butler, L. Herzog, A. Carter, L. Quintal, L. Sekut, R. Talanian, M. Paskind, W. Wong, R. Kamen, D. Tracey, and H. Allen. Caspase-1 processes IFNgamma-inducing factor and regulates LPS- induced IFN-gamma production. Nature 1997; 386:619.

23. Miwa, K., M. Asano, R. Horai, Y. Iwakura, S. Nagata, and T. Suda. Caspase 1-independant ILIbeta release and inflammation induced by the apoptosis inducer Fas ligand. Nature Med 1998; 4:1287.

24. Haq, M., J. Norman, S.R. Saba, G. Ramirez, and H. Rabb. Role of IL-1 in renal ischemic reperfusion injury. J Am Soc Nephrol 1998; 9:614.

25. Daemen, M.A.R.C., C. Van 't Veer, T.G.A.M. Wolfs, and W.A. Buurman. Ischemia-reperfusion induced IFN-gamma upregulation: Involvement of IL-12 and IL-18. J Immunol 1999; 162:5506.

26. Van de Craen, M., W. Declercq, I. Van den Brande, W. Fiers, and P. Vandenabeele. 1999. The proteolytic procaspase activation network: an in vitro analysis. Cell Death Differ 1999: 6:1117.

27. Noguchi, S., Y. Kashihara, Y. Ikegami, K. Morimoto, M. Miyamoto, and K. Nakao. Insulin-like growth factor-I ameliorates transient ischemia-induced acute renal failure in rats. J Pharmacol Exp Ther 1993; 267:919.

28. Li, J., T.R. Billiar, R.V. Talanian, and Y.M. Kim. Nitric oxide reversibly inhibits seven members of the caspase family via S-nitrosylation. Biochem Biophys Res Commun 1997; 240:419.

29. Norman, J., D.B. Badie, E.P. Nord, I. Kurtz, J. Schlosser, A. Chaudhari, and L.G. Fine. EGFinduced mitogenesis in proximal tubular cells: potentiation by angiotensin II. Am J Physiol 1987; 253:F299. 
30. Parrizas, M., A.R. Saltiel, and D. LeRoith. 1997. Insulin-like growth factor 1 inhibits apoptosis using the phosphatidylinositol 3'-kinase and mitogen-activated protein kinase pathways. J Biol Chem 1997; 272:154.

31. Kao, J., Y.G. Fan, I. Haehnel, J. Brett, S. Greenberg, et al. A peptide derived from the amino terminus of endothelial-monocyte-activating polypeptide II modulates mononuclear and polymorphonuclear leukocyte functions, defines an apparently novel cellular interaction site, and induces an acute inflammatory response. J Biol Chem 1994; 269:9774.

32. Kao, J., K. Houck, Y. Fan, I. Haehnel, S.K. Libutti, M.L. Kayton, T. Grikscheit, J. Chabot, R. Nowygrod, and S. Greenberg. Characterization of a novel tumor-derived cytokine. Endothelialmonocyte activating polypeptide II. J Biol Chem 1994; 269:25106.

33. Fay, P.J., Y. Kawai, D.D. Wagner, D. Ginsburg, et al. Propolypeptide of von Willebrand factor circulates in blood and is identical to von Willebrand antigen II. Science 1986; 232:995.

34. Clark, L.I., C. Schumacher, M. Baggiolini, and B. Moser. Structure-activity relationships of interleukin-8 determined using chemically synthesized analogs. Critical role of $\mathrm{NH}_{2}$-terminal residues and evidence for uncoupling of neutrophil chemotaxis, exocytosis, and receptor binding activities. J Biol Chem 1991; 266:23128.

35. Wkasugi, K., and P. Schimmel. Two distinct cytokines released from a human aminoacyl-tRNA synthetase. Science 1999; 284:147.

36. Lieberthal, W., V. Triaca, and J. Levine. Mechanisms of death induced by cisplatin in proximal tubular epithelial cells: apoptosis vs. necrosis. Am J Physiol 1996; 270:F700.

37. Lieberthal, W. and J.S. Levine. Mechanisms of apoptosis and its potential role in renal tubular epithelial cell injury. Am J Physiol 1996; 271:F477.

38. Schwartzman, R.A. and J.A. Cidlowski. Apoptosis: the biochemistry and molecular biology of programmed cell death. Endocr Rev 1993; 14:133. 


\title{
CHAPTER $\mathbf{5}$
}

\begin{abstract}
Functional protection by the acute phase proteins $\alpha 1$-acid glycoprotein (AGP) and $\alpha 1$-antitrypsin (AAT) against ischemiareperfusion injury by preventing apoptosis and inflammation
\end{abstract}

acute phase proteins in ischemia reperfusion

Marc A.R.C. Daemen, Vincent H. Heemskerk, Cornelis van 't Veer, Geertrui Denecker, Tim

G.A.M. Wolfs, Peter Vandenabeele, Wim A. Buurman 


\section{ABSTRACT}

Ischemia followed by reperfusion ( $\mathrm{I} / \mathrm{R})$ causes apoptosis, inflammation and tissue damage leading to organ malfunction. Ischemic preconditioning can protect against such injury. This study investigates the contribution of the acute phase proteins $\alpha 1$-acid glycoprotein (AGP) and $\alpha 1$-antitrypsin (AAT) to the protective effect of ischemic preconditioning in the kidney.

Exogenous AGP and AAT inhibited apoptosis and inflammation after $45 \mathrm{~min}$ of renal $\mathrm{I} / \mathrm{R}$ in a murine model. AGP and AAT administered upon reperfusion prevented apoptosis at $2 \mathrm{~h}$ and $24 \mathrm{~h}$ as evaluated by presence of internucleosomal DNA cleavage, TUNELhistology and determination of renal caspase-1 and 3-like activity. AGP and AAT exerted anti-inflammatory effects as reflected by reduced renal TNF- $\alpha$ expression and neutrophil influx after $24 \mathrm{~h}$. In general, these agents improved renal function. Similar effects were observed when AGP and AAT were administered $2 \mathrm{~h}$ upon reperfusion, however to a lesser extent and without functional improvement. Moreover, I/R elicted an acute phase response as reflected by elevated serum AGP and serum amyloid P (SAP) levels after 24 $h$, and increased hepatic acute phase protein $m R N A$ levels after 18 h of renal reperfusion.

We propose that the anti-apoptotic and anti-inflammatory effects of AGP and AAT contribute to the delayed type of protection associated with ischemic preconditioning and other insults. This mechanism is potentially involved in the course of many clinical conditions associated with $\mathrm{I} / \mathrm{R}$ injury. Moreover, exogenous administration of these proteins may provide new therapeutic means of treatment.

\section{INTRODUCTION}

Prolonged ischemia followed by reperfusion (I/R) induces apoptosis and inflammation, leading to organ dysfunction and tissue damage. We recently demonstrated that acute primary apoptosis during early reperfusion, is crucial to initiation of reperfusion-induced inflammation (1). Conversely, the central inflammatory mediator tumor necrosis factor$\alpha$ (TNF- $\alpha$ ) was shown to contribute to late apoptosis in the course of renal I/R (2).

TNF- $\alpha 1$ is also an inducer of the acute phase response (APR), a complex series of reactions executed by the host in the immediate aftermath of injury, trauma or infection (3). Protection against reperfusion injury can be induced by various means including antecedent administration of endotoxin (4-6), heat-shock (7) and single or multiple periods of brief antecedent ischemia (8). Besides such protection, the latter treatments are all expected to induce an APR $(3,9)$. During the APR, liver cells and various epithelial cells respond to increasing levels of among others TNF- $\alpha$ by producing acute phase proteins, including $\alpha 1$-acid glycoprotein (AGP) and $\alpha 1$-antitrypsin (AAT) (10). These two major acute phase proteins exhibit various anti-inflammatory effects (11-13) and have been shown to prevent hepatocyte apoptosis in a model of TNF- $\alpha /$ galactosamine toxicity (14). 
This study investigates whether AGP and AAT can reduce I/R-induced apoptosis and inflammation and whether renal $\mathrm{I} / \mathrm{R}$ induces an APR. The results show that physiological serum levels of exogenous AGP and AAT strongly reduce apoptosis and inflammation after $\mathrm{I} / \mathrm{R}$ and that renal $\mathrm{I} / \mathrm{R}$ induces an APR.

\section{METHODS}

\section{ANTIBODIES AND REAGENTS}

Anti-murine neutrophil mAb Gr-1 was obtained from Pharmingen (San Diego, CA); rabbit anti-murine AGP polyclonal Abs were kindly provided by Dr. P Heegaard (Danish Veterinary Laboratory, Copenhagen, Denmark); peroxidase conjugated goat anti-rat and peroxidase conjugated goat anti-rabbit IgG from Jackson (West Grove, PA); peroxidase as well as alkaline phosphatase conjugated sheep anti-digoxigenin and digoxigenin 11dUTP from Boehringer Mannheim (Mannheim, Germany); peroxidase conjugated rabbit anti-sheep IgG from DAKO (Copenhagen, Denmark); rabbit anti-murine serum amyloid P (SAP) and a SAP standard from Calbiochem-Novabiochem (San Diego, CA); AcYVAD-amc and Ac-DEVD-amc from the Peptide Institute (Osaka, Japan). All other reagents were purchased from Sigma (St. Louis, MO).

\section{EXPERIMENTAL PROTOCOL}

Male Swiss mice weighing 20-25 g from Charles River Breeding Laboratories (Heidelberg, Germany) were housed individually in standard cages with ad libitum access to food and water. The studies were approved by the Institutional Animal Care Committee of the University of Maastricht. 45 min unilateral ischemia of the left kidney was followed by contralateral nephrectomy as described in detail previously. 2 The animals were sacrificed at indicated timepoints. Upon sacrifice, blood was collected by orbital puncture and the left kidney was harvested.

Upon reperfusion mice were administered intraperitoneally (i.p.) $5 \mathrm{mg}$ bovine AGP $(\mathrm{n}=12)$ or $0.5 \mathrm{mg}$ human AAT $(\mathrm{n}=12)$ in $0.5 \mathrm{ml}$ sterile PBS, resulting in serum levels identical as observed during the APR. 10 In separate groups mice received AGP $(n=8)$ or AAT $(n=8)$ after $2 \mathrm{~h}$ of reperfusion. To further delineate the therapeutic efficacy of AGP treatment, mice received $1.7 \mathrm{mg}(\mathrm{n}=3), 0.5 \mathrm{mg}(\mathrm{n}=3)$ and $0.17 \mathrm{mg}(\mathrm{n}=3)$ of AGP in 0.5 $\mathrm{ml}$ PBS upon reperfusion, and were sacrificed after $2 \mathrm{~h}$. A control group received vehicle consisting of $0.5 \mathrm{ml}$ PBS i.p. $(n=10)$. A sham-group $(n=12)$ was subjected to the same surgical procedure without clamping of the renal pedicle, treated with PBS and sacrificed at corresponding timepoints.

In an experiment to investigate whether renal $\mathrm{I} / \mathrm{R}$ induced an $\mathrm{APR}$, mice were subjected to renal $\mathrm{I} / \mathrm{R}$ and blood was collected by orbital puncture at 8,16 and $24 \mathrm{~h}$ after 
ischemia $(\mathrm{n}=12)$. Additional animals received $30 \mu \mathrm{g}$ lipopolysacharide (LPS, Escherichia coli serotype O55:B5) i.p. $(n=3)$ or $0.5 \mathrm{ml}$ of PBS i.p. $(n=3)$ and served respectively as positive and negative controls for the development of an APR.

\section{APOPTOSIS ASSAYS}

Presence of internucleosomal DNA cleavage in kidneys was investigated with a commercial ligase-mediated (LM)-PCR assay kit (Apoalert, Clontech, Palo Alto, CA) according to the manufacturers instructions. Renal caspase-1 and caspase-3-like activities were measured as described (15) by measuring release of fluorescent 7-amino-4methylcoumarin for $1 \mathrm{~h}$ after incubating renal lysates with the fluorogenic substrates AcYVAD-amc (caspase-1-like) or Ac-DEVD-amc (caspase-3-like).

MYELOPEROXIDASE (MPO), BLOOD UREA NITROGEN (BUN) AND SERUM CREATININE

Renal neutrophil accumulation was quantified by measuring renal MPO content as described (2). MPO activity is expressed per mg tissue by comparing OD of samples with a horseradish peroxidase titration curve and standardized with respect to wet/dry ratios. BUN content and serum creatinine levels were measured in serum using a BUN unimate 5 kit and a CREA MPR3 kit (Boehringer Mannheim, Mannheim, Germany) in a Cobas Fara autoanalyzer (Roche, Basle, Switzerland).

\section{HiSTOLOGY}

Kidney specimens were immediately frozen and stored at $-70^{\circ} \mathrm{C}$ or fixed in buffered formaline and paraffin embedded. Frozen sections $(5 \mu \mathrm{m})$ were stained for neutrophils with $\mathrm{mAb}$ Gr-1 as described (1). Immunostaining for TNF- $\alpha$ with digoxigenin-labeled $\mathrm{mAb}$ 52B83 was performed on paraffin sections as described (2). Histological aspects of apoptosis were studied by standard terminal deoxynucleotidyl transferase (TdT)-mediated dUTP nick end labeling (TUNEL histology) as described (16 ).

SERUM AMYloid P (SAP) ELISA AND SINGLE RADIAL IMMUNODIFFUSION FOR SERUM AGP

Serum SAP was measured employing a sandwich ELISA. A 96-well immunomaxisorp plate (Nunc, Roskilde, Denmark) was coated with a rabbit anti-mouse SAP IgG. Aspecific binding was blocked with BSA and after washings, samples were diluted and a standard titration curve of a known quantity of murine SAP was obtained. Detection was performed using a biotinylated rabbit anti-mouse SAP IgG followed by incubation with substrate. Serum AGP levels were determined by single radial immunodiffusion (17) employing agar gels containing $5 \%$ anti-AGP serum. Since purified murine AGP 
was not readily available, the obtained results were calibrated against a dilution of murine plasma obtained $36 \mathrm{~h}$ after pretreatment with $30 \mu \mathrm{g}$ LPS, which also served as a positive control.

\section{MEASUREMENT OF HEPATIC ACUTE PHASE PROTEIN MRNA CONTENT}

Total RNA was extracted from livers and transcribed into cDNA of which the concentration was subsequently standardized based on the $\beta$-actin cDNA fraction. To determine hepatic AGP, AAT and SAP mRNA content, three 2 -fold serial dilutions of cDNA were amplified with specific primers. Murine AGP mRNA primers were designed based on sequence homology with an acute phase inducible gene in Mus caroli (18) sense primer 5'-GCGGCTGTCCTAAACCCT-3', antisense primer 5'-CAAGTCAAAGGCAAGCATG-3'; murine AAT mRNA specific were sense primer 5'-TCCCATGAGATCGCTACAAAC-3' and antisense primer 5'-TGATAATGGTTCTTGGCCTCT-3'; for murine SAP mRNA were used sense primer 5'-CTTCACCAGCCTTCTTTCAGA-3' and antisense primer 5'-ACGGACTGTGACTTTTGATTGT-3'; $\beta$-actin specific primers were sense primer 5'-TAAAACGCAGCTCAGTAACAGTCCG-3' and antisense primer 5'-TGCAATCCTGTGGCATCCATGAAAC-3'. After separation on a 1.5\% agarose gel, band proportions were estimated by measuring the intensity of ethidium bromide fluorescence with a digital camera (Imagemaster VDS, Pharmacia, Uppsala, Sweden) using commercial gel analysis software (Sigma Gel, SPSS, Chicago, IL).

\section{STATISTICS}

Data are expressed the mean \pm SEM, and statistical analysis was performed by Student's T-test. $\mathrm{P}<0.05$ was taken to denote statistical significance.

\section{RESULTS}

AGP AND AAT REDUCE EARLY AND DELAYED APOPTOSIS INDUCED BY RENAL I/R

Apoptosis contributes to $\mathrm{I} / \mathrm{R}$-induced organ dysfunction and may serve as a target for the protective effects of acute phase proteins. In kidneys obtained at $2 \mathrm{~h}$ of reperfusion from mice treated with either AGP or AAT, no apparent internucleosomal DNA cleavage was detected as compared to PBS treated animals (Figure 1). These early effects of AGP and AAT suggest direct inhibition of apoptosis, since early primary apoptosis precedes the first signs of inflammation in this model (2). In line, apoptosis was reduced after $24 \mathrm{~h}$ as indicated by the absence of apparent internucleosomal DNA cleavage (Figure 1), decreased numbers of TUNEL positive nuclei (Figure 2) and attenuated caspase-1 and 3like activities (Figure 3 ) as compared to PBS controls, possibly due to a combination of 
anti-apoptotic and anti-inflammatory effects. We previously demonstrated that inhibition of early apoptosis prevents the initiation of inflammation as well as secondary apoptosis caused by inflammation in our model (1). This study indicated that abrogation of inflammation did not occur when apoptosis inhibitors were administered after $2 \mathrm{~h}$ of reperfusion. Hence, apoptosis precedes the inflammatory response at $2 \mathrm{~h}$ of reperfusion. Administration of AGP or AAT at $2 \mathrm{~h}$ of reperfusion therefore enabled us to differentiate primary apoptosis from secondary apoptosis and to study the possible involvement of an anti-inflammatory effect of these acute phase proteins. AAT administered at $2 \mathrm{~h}$ of reperfusion decreased caspase-1 and 3-like activities after $24 \mathrm{~h}$ of reperfusion as compared to PBS treatment (Figure 3). However, AAT did not reduce internucleosomal DNA cleavage (Figure 1) whereas AGP reduced caspase-1 and 3-like activities (Figure 3) and prevented internucleosomal DNA cleavage after $24 \mathrm{~h}$ (Figure 1). These data suggest that reduced secondary apoptosis is a result of the anti-inflammatory effect of AGP and AAT, although we cannot exclude a contribution via direct inhibition of secondary apoptosis. To investigate therapeutic efficacy of AGP treatment, the effect of a dose range of AGP on internucleosomal DNA cleavage after $2 \mathrm{~h}$ of reperfusion was studied. A single dose of $1.7 \mathrm{mg}$ AGP upon reperfusion sufficed to reduce renal internucleosomal DNA cleavage (Figure 1). This therapeutic effect gradually declined when dosages of 0.5 of $0.17 \mathrm{mg}$ of AGP were employed (Figure 1). Rodent acute phase plasma has been reported to contain up to $3.5 \mathrm{mg} / \mathrm{ml} \mathrm{AGP}$ as compared to almost undetectable constitutive levels (10), indicating that systemic rises in endogenous AGP during an APR are potentially protective against I/R-induced apotosis.

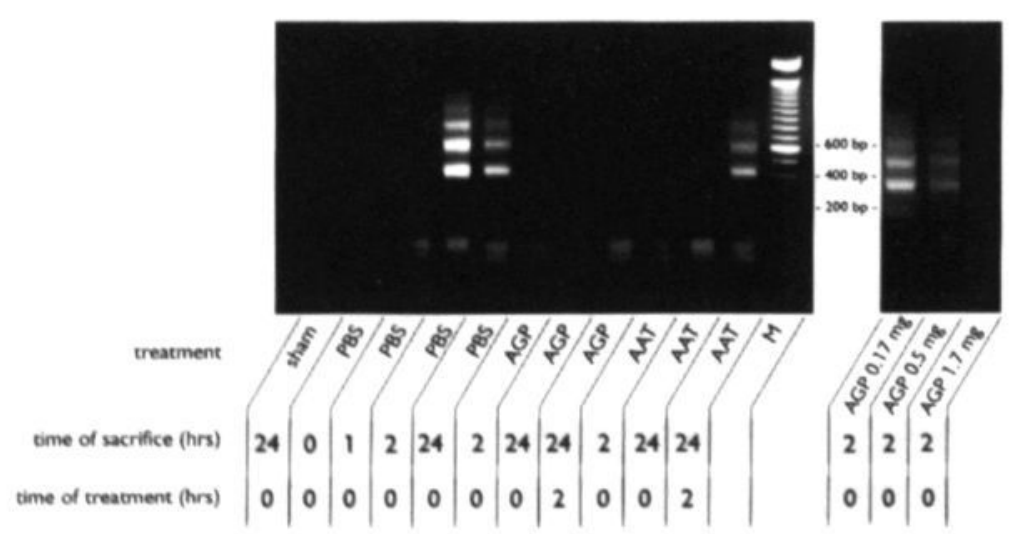

Figure 1. Renal apoptosis is reflected by fragmented DNA amplified by LM-PCR and visualized on ethidium-bromide-stained gel. In PBS treated animals internucleosomal DNA cleavage became apparent after $2 \mathrm{~h}$ of reperfusion. Treatment with AGP or AAT prevented internucleosomal DNA cleavage, except for AAT administered after $2 \mathrm{~h}$ of reperfusion. M, molecular weight markers (range, 100 to 2000 base pairs). 

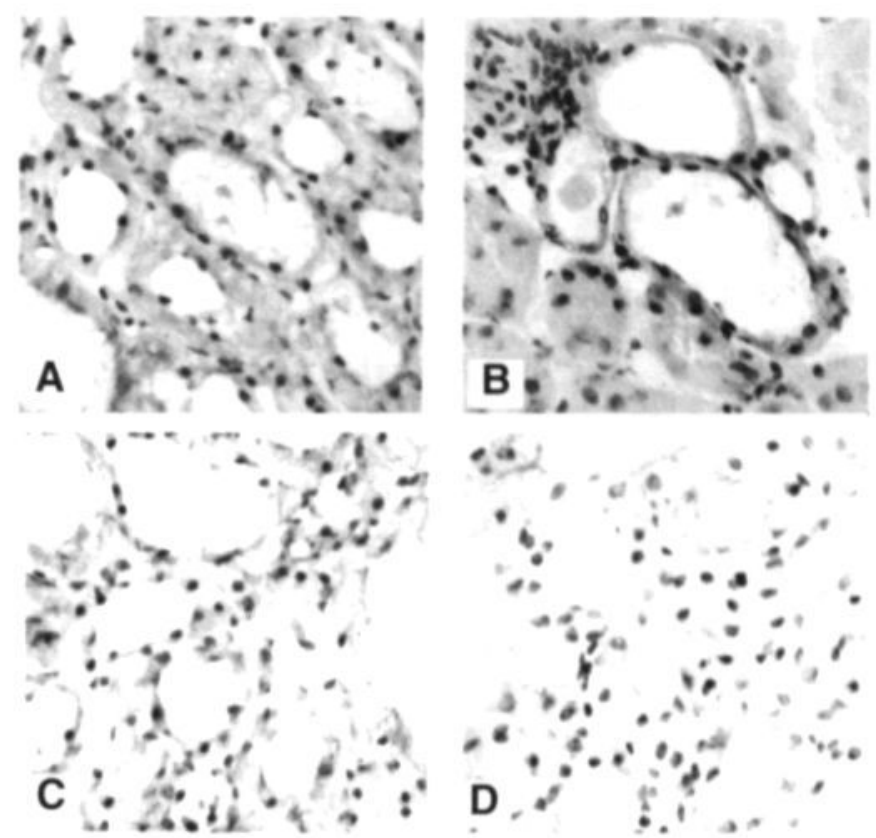

Figure 2. Representative light micrographs showing evident in situ detection of DNA nick ends by TUNEL histology (magnification 200x). In contrast to sham operated animals (A), tubular epithelial cells of the outer medulla of biopsies obtained from PBS treated mice after $24 \mathrm{~h}$ of reperfusion showed extensive apoptosis coinciding with influx of inflammatory cells as depicted in the upper left corner of the panel (B). Treatment with AGP upon reperfusion apparently decreased numbers of TUNEL-positive nuclei after $24 \mathrm{~h}(\mathrm{C})$ similar to mice treated with AAT upon reperfusion (D).

\section{AGP AND AAT REDUCE INFLAMMATION FOLLOWING I/R}

We studied the effects of AGP and AAT on I/R-induced inflammation by assessing renal TNF- $\alpha$ expression and neutrophil influx. At $24 \mathrm{~h}$ after I/R, AGP and AAT administered upon reperfusion limited TNF- $\alpha$ expression (Figure 5d,e) and neutrophil influx (Figure 4). These effects are most likely the result of direct inhibition of early primary apoptosis, implicated in the subsequent induction of inflammation. I Alternatively, also direct antiinflammatory effects may be involved. Nevertheless, these findings explain the observed inhibition of secondary apoptosis in mice treated upon reperfusion.

AGP and AAT given after $2 \mathrm{~h}$ of reperfusion attenuated inflammation at $24 \mathrm{~h}$ to a lesser extent than treatment upon reperfusion (Figure 4). However, treatments at both timepoints decreased inflammation as compared to PBS treated controls at $24 \mathrm{~h}$ of reperfusion (Figure 4). The latter controls showed significant renal inflammation as reflected by TNF- $\alpha$ expression in the outer stripe of the outer medulla, along damaged tubular epithelium (Figure 5b) and in infiltrating leukocytes (Figure 5c). Also, significant renal neutrophil accumulation was reflected by an enhanced MPO content (Figure 4) and evident 
accumulation of Gr-1 positive cells (Figure 6). AGP and AAT administered at $2 \mathrm{~h}$ prevented inflammation as reflected by these parameters, revealing a direct anti-inflammatory potential of AGP and AAT.

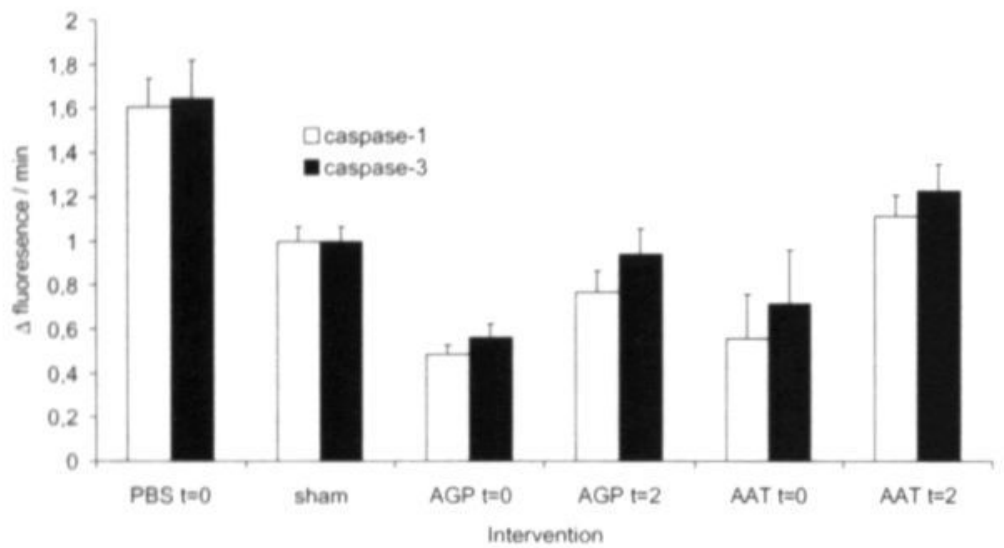

Figure 3. Renal caspase-like activities were determined kinetically in homogenates of tissue obtained after I day of reperfusion in a fluorogenic substrate assay in which Ac-YVAD-amc (caspase-1-like) or Ac-DEVD-amc (caspase-3-like) served as substrates. Data are expressed as the increase in fluorescence as a function of time, normalized against data obtained from the sham operated group. The groups that indicate $\mathrm{t}=2$ on the $\mathrm{x}$-axis received treatment after $2 \mathrm{~h}$ of reperfusion. All other groups were treated upon reperfusion. Compared to PBS treatment all groups showed significantly decreased caspase-like activities $(\mathrm{P}<0.05$; not indicated). Statistical significance compared to animals that received similar treatment upon reperfusion was denoted at $\mathrm{P}<0.05$ (\#). The presented data are means \pm SEM.

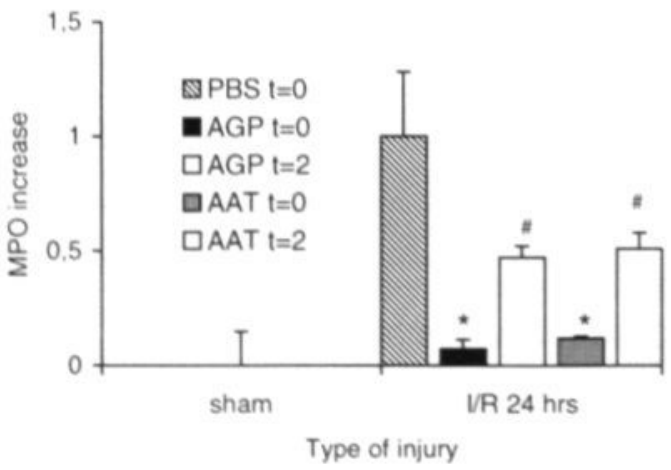

Figure 4. Neutrophil influx was assessed quantitatively by determination of MPO increase after $24 \mathrm{~h}$ of reperfusion. Values are presented relative to the amount of MPO present in the contralateral kidney harvested immediately after reperfusion and normalized with respect to the MPO increase after $24 \mathrm{~h}$ of reperfusion in PBS treated mice. The groups that indicate $\mathrm{t}=2$ received treatment after $2 \mathrm{~h}$ of reperfusion. Statistical significance as compared to control treated animals was denoted at $\mathrm{P}<0.05\left({ }^{*}\right)$ or $\mathrm{P}<0.01\left({ }^{* *}\right)$ and compared to animals that received similar treatment upon reperfusion at $\mathrm{P}<0.05(\#)$. The presented data are means $\pm \mathrm{SEM}$. 

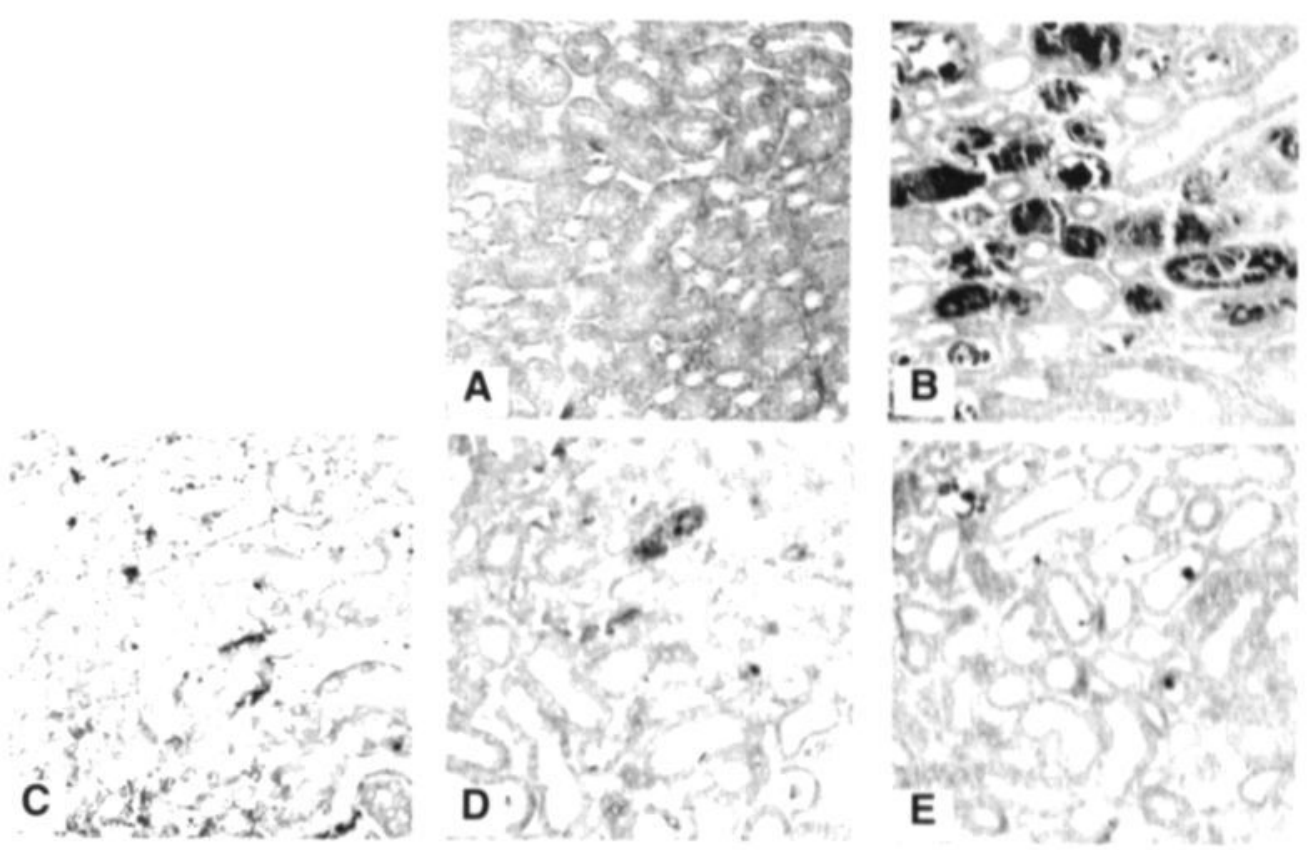

Figure 5. Representative light micrographs showing immunohistochemical staining of TNF- $\alpha$ by mAb 52B83 (magnification 100x). While absent in kidneys obtained from sham-operated controls (A), TNF- $\alpha$ was expressed in the outer stripe of the outer medulla, distributed in and along damaged tubular epithelium (B) as well as in infiltrating leukocytes (C) after $24 \mathrm{~h}$ of reperfusion. Treatment with AGP upon reperfusion decreased intrarenal TNF- $\alpha$ expression after $24 \mathrm{~h}$ (D) similar to mice treated with AAT upon reperfusion (E).

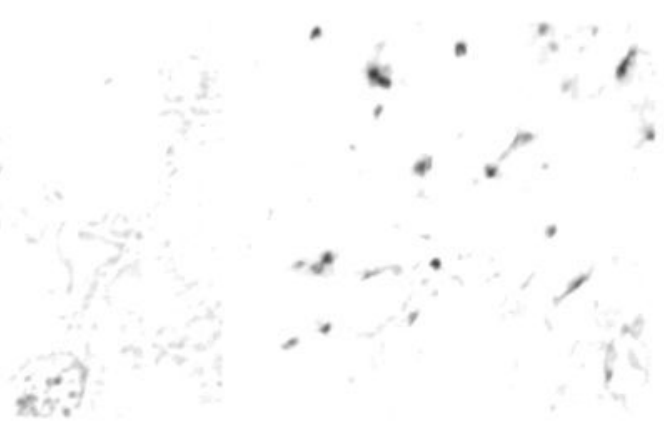

Figure 6. Representative light micrographs showing immunohistochemical staining by mAb Gr-1 of infiltrating neutrophils (magnification 100x). Neutrophils were scarcely present in kidneys obtained from sham-operated animals (left). In contrast, marked renal neutrophil accumulation (right) was observed after $24 \mathrm{~h}$ of reperfusion. 
Renal dysfunction was reflected by increased blood urea nitrogen (BUN) content, as well as serum creatinine levels after $24 \mathrm{~h}$ of reperfusion (Figure 7). Both AGP and AAT administered upon reperfusion lowered BUN content and serum creatinine levels as compared to PBS controls. However, AGP and AAT administered after $2 \mathrm{~h}$ of reperfusion failed to significantly decrease BUN or serum creatinine as compared to PBS treatment. These findings illustrate the necessity to prevent primary apoptosis-induced inflammation besides direct prevention of inflammation after $\mathrm{I} / \mathrm{R}$ for optimal therapeutic effects.

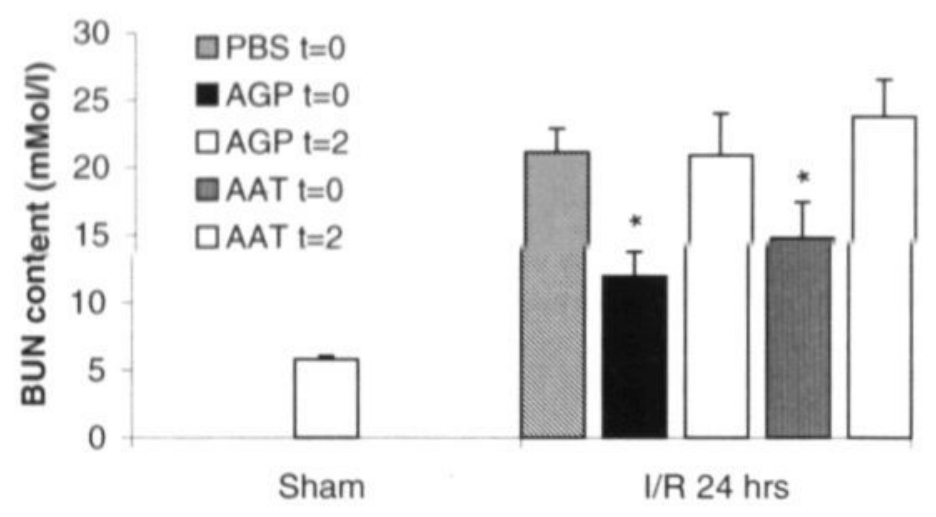

Figure 7a

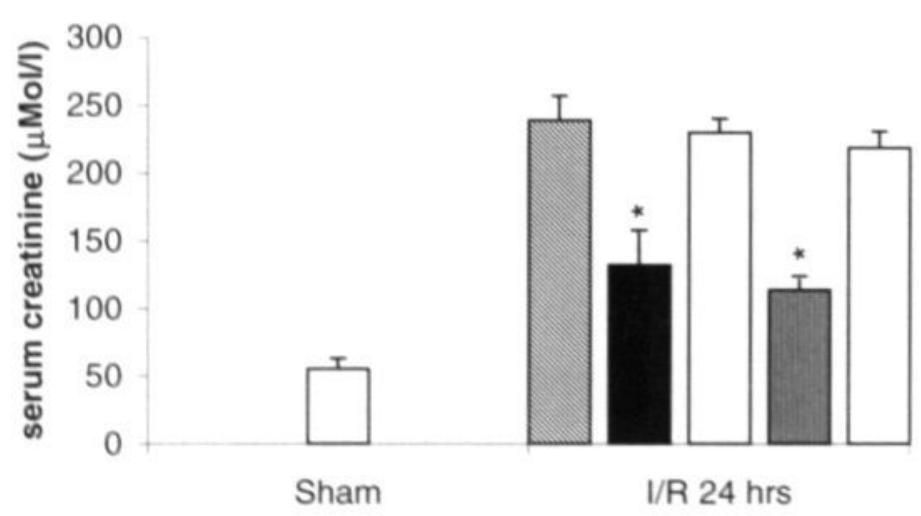

Figure 7. Renal function after $24 \mathrm{~h}$ in the different experimental groups as reflected by blood urea nitrogen $(B \cup N)$ content $(A)$ and serum creatinine $(B)$. The groups that indicate $t=2$ received treatment after $2 \mathrm{~h}$ of reperfusion. Statistical significance as compared to PBS treated animals was denoted at $\mathrm{P}<0.05(*)$. The data shown are means \pm SEM. 
To investigate whether renal $\mathrm{I} / \mathrm{R}$ induces an APR, serum SAP as well as AGP levels and hepatic acute phase protein mRNA content were measured. SAP was used as a marker for the APR since it is co-released with AGP and AAT during the APR. Renal I/R induced an elevation in plasma SAP levels at 16 and $24 \mathrm{~h}$ after ischemia (Table 1). LPS administration served as a positive control and increased SAP levels after $36 \mathrm{~h}$. Serum AGP levels increased to a similar extent (an approximate factor 10 as compared to constitutive levels) following $24 \mathrm{~h}$ of reperfusion and $36 \mathrm{~h}$ following LPS (data not shown). In contrast with previous reports $(9,10)$, our results show no apparent rise in hepatic AAT mRNA levels after renal I/R or LPS administration (Figure 8). Conversely, after $16 \mathrm{~h}$ of reperfusion hepatic AGP and SAP mRNA levels increased as compared to sham controls or mice that only received PBS (Figure 8 ). This rise in hepatic acute phase protein mRNA was similar to that observed in mice $16 \mathrm{~h}$ following $30 \mu \mathrm{g}$ LPS (Figure 8.). These data clearly demonstrate that renal $\mathrm{I} / \mathrm{R}$ induces an APR.

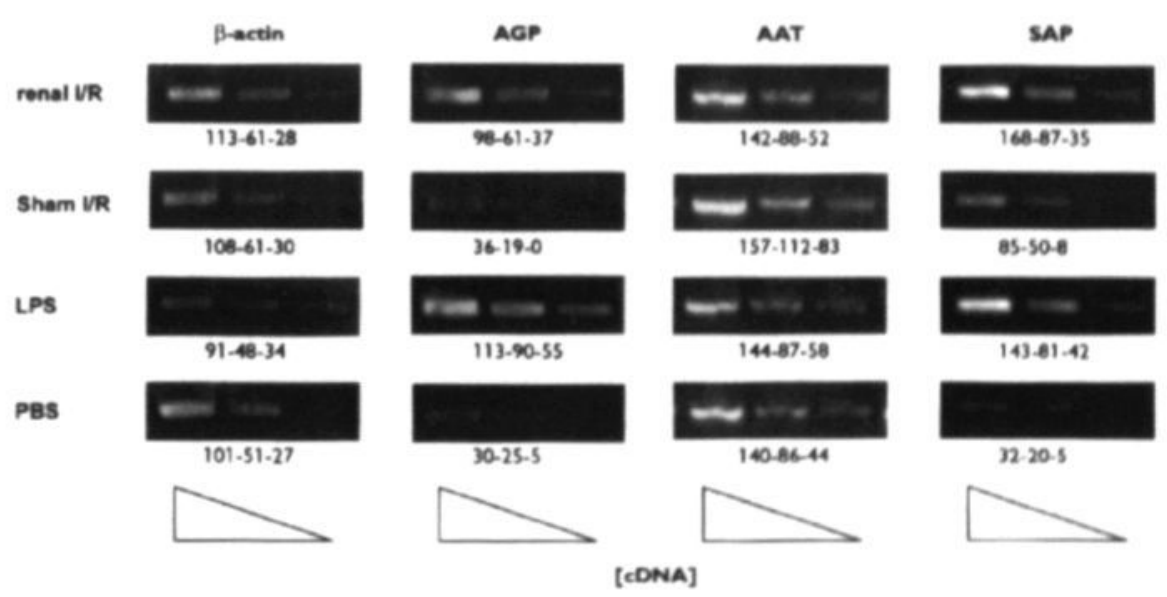

Figure 8. Hepatic acute phase protein mRNA expression at $16 \mathrm{~h}$ after either renal $\mathrm{I} / \mathrm{R}$, sham operation, administration of $30 \mu \mathrm{g}$ of LPS i.p. or PBS only. Shown are representative samples of which cDNA was amplified in three 2-fold serial dilutions and calibrated against identical levels of $\beta$-actin mRNA. Band proportions are indicated and expressed as pixel units, callibrated according to raw pixel values of the digital capture-image. Background (black) corresponds to a pixel value of 0 , amplified DNA (white) corresponds to a pixel value of 255 . 
Table 1. Effects of I/R on serum SAP levels

\begin{tabular}{llll} 
Intervention & $\begin{array}{l}\text { Time following } \\
\text { intervention (hrs) }\end{array}$ & $\begin{array}{l}\text { serum } \\
\text { SAP }(\mu \mathrm{g} / \mathrm{ml})\end{array}$ & $\mathrm{n}$ \\
\hline renal I/R & 8 & $25.8 \pm 8.1$ & 6 \\
$\mathrm{renal}$ I/R & 16 & $47.2 \pm 7.5$ & 6 \\
$\mathrm{renal}$ I/R & 24 & $127.4 \pm 26.4$ & 6 \\
sham I/R & 24 & $28.4 \pm 6.3$ & 3 \\
$30 \mu \mathrm{g} \mathrm{LPS} \mathrm{a}$ & 36 & $202.6 \pm 36.3$ & 3 \\
PBS control & - & $15.8 \pm 3.0$ & 3 \\
\hline
\end{tabular}

a In $0.5 \mathrm{ml}$ PBS i.p.

\section{Discussion}

The effects of the acute phase proteins AGP and AAT on early $(2 \mathrm{~h})$ and late $(24 \mathrm{~h})$ apoptosis and inflammation after renal I/R were investigated. Both AGP and AAT administered upon reperfusion, decrease early as well as late apoptosis as reflected by renal internucleosomal DNA cleavage, TUNEL-histology and caspase-like activities. In line, we previously demonstrated that abrogating acute early apoptosis with selective antiapoptotic agents prevents subsequent inflammation as well as secondary apoptosis caused by inflammation, whereas anti-apoptotic treatment initiated after onset of apoptosis does not reduce $\mathrm{I} / \mathrm{R}$-induced inflammation (1). In contrast, in the present study treatment after $2 \mathrm{~h}$ of reperfusion inhibited inflammation, which is supported by reports of anti-inflammatory effects mediated by AGP and AAT.12,13

Early primary $(19,20)$ as well as late secondary $(2,21)$ apoptosis following I/R have been reported to be caused by various means. The present results, showing that AGP and, to a lesser extent, AAT protect against TNF- $\alpha$ dependent late apoptosis (2), are in line with data from Van Molle et al (14). They showed that AGP protects against TNF- $\alpha$ induced liver apoptosis in both galactosamine and actinomycin D pretreated mice whereas AAT only conferred protection in the galactosamine model. Since inflammation is not involved in the process of primary apoptosis following $\mathrm{I} / \mathrm{R}$, our results show that the antiapoptotic potential of AGP and AAT is not limited to TNF- $\alpha$-induced apoptosis.

AGP has been reported to exhibit anti-inflammatory properties such as inhibition of PMN activation and induction of macrophage derived IL-1 receptor antagonist release. 11 AGP also binds to bacterial endotoxin and protects mice from endotoxin-induced septic and hypovolemic shock $(22,23)$. Currently, no clear anti-apoptotic property can be deduced from the AGP molecule. AAT can inhibit neutrophil superoxide production (24), induce macrophage derived IL- 1 receptor antagonist release 11 and reduce TNF- $\alpha$ - 
induced lethality (25). AAT additionally inhibits elastase 26 and as a consequence elastase-dependent synthesis and release of platelet-activating factor (26), a mediator of $\mathrm{I} / \mathrm{R}$ induced inflammation (27). Elastase has been reported to cleave tyrosyl-tRNA synthetase during apoptosis to fragments with IL-8-like chemotactic properties (28), a process potentially involved in primary I/R-induced apoptosis (1). AGP or AAT may interact with the proteolytic cascade of enzymes involved in apoptosis. However, both acute phase proteins lack inhibitory effects on caspases in vitro (personal communication, Dr. C. Libert, University of Ghent). Further studies are needed to establish the molecular mechanisms by which AGP and AAT prevent I/R-induced apoptosis and inflammation.

Antecedent ischemia can induce protection from $\mathrm{L} / \mathrm{R}$-induced injury in a biphasic pattern. 8 Such protection lasts for $30 \mathrm{~min}$ to $2 \mathrm{~h}$ and is followed by a second window of protection appearing 12-24 h later. This so called ischemic preconditioning has been attributed to local protective mechanisms including induction of heat-shock proteins (29) and adenosine formation (30). However, brief ischemia in remote organs $(31,32)$ or endotoxin pretreatment (4-6) have been shown to confer similar protection, suggesting involvement of other than local mechanisms. Indeed, the observed I/R-induced SAP and AGP increase and elevated hepatic acute phase protein mRNA content show that renal $I / R$ induces an APR. Our data also indicate that the serum AGP increase during the APR is of potentially sufficient extent to protect against I/R-induced apoptosis. Thus, an APR likely confers systemic protection against $I / R$ injury, which could contribute to the second window of protection associated with ischemic preconditioning.

The physiological mode of protection outlined above may determine the natural history of clinical conditions associated with $\mathrm{I} / \mathrm{R}$ as observed during severe trauma or septic shock. For instance, sepsis mortality is highest during the initial disease stages and the chances of survival increase with disease duration (33). This increased survival may well be a consequence of protection against shock-like complications since systemic levels of acute phase proteins increase as the disease progresses (34). Moreover, protective acute phase proteins such as AGP and AAT may provide new means to treat clinical conditions associated with $\mathrm{I} / \mathrm{R}$ injury.

We conclude that the APR may be part of a physiological protection mechanism against $\mathrm{I} / \mathrm{R}$ injury and show that protection conferred by acute phase proteins such as AGP and AAT is mediated by distinct anti-apoptotic as well as anti-inflammatory effects. We additionally demonstrate that $\mathrm{I} / \mathrm{R}$ itself induces an APR, which may explain the second window of protection induced by ischemic preconditioning. 


\section{REFERENCES}

1. Daemen MARC, Van 't Veer C, Denecker G, Heemskerk VH, Wolfs TGAM, Vandenabeele P, Buurman WA. Inhibition of apoptosis induced by ischemia-reperfusion prevents inflammation. J Clin Invest 1999;104:541-549.

2. Daemen MARC, Van de Ven WCM, Heineman E, Buurman WA. Pro- and anti-inflammatory mechanisms in renal reperfusion injury in mice. Modulation by endogenous tumor necrosis factor alpha and interleukin-10. Transplantation 1999;67:792-800.

3. Baumann H, Gauldie J. The acute phase response. Immunol Today 1994;15:74-80.

4. Meng X, Ao L, Brown JM, Meldrum DR, Sheridan BC, Cain BS, Banerjee A, Harken AH. LPS induces late cardiac functional protection against ischemia independent of cardiac and circulating TNF-alpha. Am J Physiol 1997;273:H1894-H1902.

5. Berg JT, Allison RC, Taylor AE. Endotoxin extends survival of adult mice in hyperoxia. Proc Soc Exp Biol Med 1990;193:167-170.

6. Heemann U, Szabo A, Hamar P, Müller V, Witzke O, Lutz J, Philipp T. Lipopolysaccharide pretreatment protects from renal ischemia/reperfusion injury. Am J Pathol 2000; 156: 287-293.

7. Yamashita N, Hoshida S, Taniguchi N, Kuzuya T, Hori M. Whole-body hyperthermia provides biphasic cardioprotection against ischemia/reperfusion injury in the rat. Circulation 1998;98:1414-1421.

8. Meldrum DR, Cleveland JJ, Rowland RT, Banerjee A, Harken AH, Meng X. Early and delayed preconditioning: differential mechanisms and additive protection. Am J Physiol 1997;273:H725H733.

9. Yiangou M, Paraskeva E, Hsieh CC, Markou E, Victoratos P, Scouras Z, Papaconstantinou J. Induction of a subgroup of acute phase protein genes in mouse liver by hyperthermia. Biochim Biophys Acta 1998;1396:191-206.

10. Schreiber G, Tsykin A, Aldred AR, Thomas T, Fung WP, Dickson PW, Cole T, Birch H, De Milland JF. The acute phase response in the rodent. Ann N Y Acad Sci 1989;557:61-85.

11. Tilg H, Vannier E, Vachino G, Dinarello CA, Mier JW. Anti-inflammatory properties of hepatic acute phase proteins: preferential induction of interleukin 1 (IL-1) receptor antagonist over IL-1 beta synthesis by human peripheral blood mononuclear cells. J Exp Med 1993;178:1629-1636.

12. Williams JP, Weiser MR, Pechet TT, Kobzik L, Moore FJ, Hechtman HB. Alpha 1-acid glycoprotein reduces local and remote injuries after intestinal ischemia in the rat. Am J Physiol 1997:273:G1031-G1035.

13. Libert C, Vanmolle W, Brouckaert P, Fiers W. Alpha(1)-antitrypsin inhibits the lethal response to TNF in mice. $J$ Immunol 1996;157:5126-5129.

14. Van Molle W, Libert C, Fiers W, Brouckaert P. Alpha(1)-acid glycoprotein and alpha(1)-antitrypsin inhibit TNF-induced but not anti-FAS-induced apoptosis of hepatocytes in mice. $J$ Immunol 1997:159:3555-3564.

15. Vercammen D, Beyaert R, Denecker G, Goossens V, VanLoo G, Declercq W, Grooten J, Fiers W, Vandenabeele P. Inhibition of caspases increases the sensitivity of L929 cells to necrosis mediated by tumor necrosis factor. J Exp Med 998;187:1477-1485.

16. Gavrieli Y, Sherman Y, Ben SS. Identification of programmed cell death in situ via specific labeling of nuclear DNA fragmentation. J Cell Biol 1992:119:493-501.

17. Mancini G, Carbonara AO, Heremans JF: Immunochemical quantitation of antigens by single radial immunodiffusion. Immunochem 1965:2:235-254. 
18. Prowse KR, Baumann H. Molecular characterization and acute phase expression of the multiple Mus caroli alpha 1-acid glycoprotein (AGP) genes. Differences in glucocorticoid stimulation and regulatory elements between the rat and mouse AGP genes. J Biol Chem 1990;265:10201-10209.

19. Lieberthal W, Menza SA, Levine JS. Graded ATP depletion can cause necrosis or apoptosis of cultured mouse proximal tubular cells. Am J Physiol 1998;43:F315-F327.

20. Zager RA, Iwata M, Conrad DS, Burkhart KM, Igarashi Y. Altered ceramide and sphingosine expression during the induction phase of ischemic acute renal failure. Kidney Int 1997;52:60-70.

21. Nogae S, Miyazaki M, Kobayashi N, Saito T, Abe K, Saito H, Nakane PK, Nakanishi Y, Koji T. Induction of apoptosis in ischemia-reperfusion model of mouse kidney: Possible involvement of Fas. J Am Soc Nephrol 1998;9:620-631.

22. Moore DF, Rosenfeld MR, Gribbon PM, Winlove CP, Tsai CM. Alpha-1-acid (AAG, orosomucoid) glycoprotein: interaction with bacterial lipopolysaccharide and protection from sepsis. Inflammation 1997;21:69-82.

23. Muchitsch EM, Auer W, Pichler L: Effects of alpha 1-acid glycoprotein in different rodent models of shock. Fundam Clin Pharmacol 1998;12:173-181.

24. Bucurenci N, Blake DR, Chidwick K, Winyard PG. Inhibition of neutrophil superoxide production by human plasma alpha 1-antitrypsin. Febs Lett 1992;300:21-24.

25. Libert C, Brouckaert P, Fiers W. Protection by alpha 1-acid glycoprotein against tumor necrosis factor-induced lethality. J Exp Med 1994;180:1571-1575.

26. Camussi G, Tetta C, Bussolino F, Baglioni C. Synthesis and release of platelet-activating factor is inhibited by plasma alpha 1-proteinase inhibitor or alpha 1-antichymotrypsin and is stimulated by proteinases. J Exp Med 1988;168:1293-1306.

27. Torras J, Bordalba JR, Seron D, Moliner R, Carrera M, Valles J, Martinez Castelao A, Alsina J, Grino JM. Protective effect of the PAF antagonist BN 52021 in an experimental renal warm ischemia model. Transpl Int 1993;6:236-238.

28. Wkasugi K, Schimmel P. Two distinct cytokines released from a human aminoacyl-tRNA synthetase. Science 1999;284:147-150.

29. Kume M, Yamamoto Y, Saad S, Gomi T, Kimoto S, Shimabukuro T, Yagi T, Nakagami M, Takada Y, Morimoto T, Yamaoka Y. Ischemic preconditioning of the liver in rats: implications of heat shock protein induction to increase tolerance of ischemia-reperfusion injury. J Lab Clin Med 1996; 128:251-258.

30. Baxter GF, Marber MS, Patel VC, Yellon DM. Adenosine receptor involvement in a delayed phase of myocardial protection 24 hours after ischemic preconditioning. Circulation 1994:90:2993-3000.

31. Verdouw PD, Gho BC, Koning MM, Schoemaker RG, Duncker DJ. Cardioprotection by ischemic and nonischemic myocardial stress and ischemia in remote organs. Implications for the concept of ischemic preconditioning. Ann N Y Acad Sci 1996;793:27-42.

32. Gho BC, Schoemaker RG, Van den Doel DM. Duncker DJ. Verdouw PD. Myocardial protection by brief ischemia in noncardiac tissue. Circulation 1996;94:2193-2200.

33. Rangel FM, Pittet D. Hwang T, Woolson RF. Wenzel RP. The dynamics of disease progression in sepsis: Markov modeling describing the natural history and the likely impact of effective antisepsis agents. Clin Infect Dis 1998:27:185-190.

34. Dominioni L, Dionigi R, Zanello M. Monico R, Cremaschi R, Ballabio A, Massa M, Comelli M, Dal RP. Sepsis score and acute-phase protein response as predictors of outcome in septic surgical patients. Arch Surg 1987;122:141-146. 


\title{
CHAPTER 6
}

Activated caspase-1 is not a central mediator of inflammation after renal ischemia-reperfusion

\author{
Role of caspase-1 in renal ischemia
}

Marc A.R.C. Daemen, Geertrui Denecker, Cornelis van 't Veer, Tim G.A.M. Wolfs,

Peter Vandenabeele, and Wim A. Buurman

Transplantation 2001, reprinted with permission 


\section{ABSTRACT}

Recent observations suggest that caspase activation during early apoptosis plays a functional role in the induction of the deleterious inflammatory response to reperfusion in a kidney subjected to ischemia and reperfusion. Release of the pro-inflammatory cytokines IL-1 and IL-18 may occur as a part of the apoptotic response through activation of caspase-1/ICE. We hypothesized that caspase-1 activation is a key event in the process of apoptosis/caspase-dependent inflammation as observed during development of renal reperfusion injury. As compared to controls, caspase-1 deficient knockout mice subjected to $45 \mathrm{~min}$ of renal ischemia followed by $24 \mathrm{~h}$ of reperfusion showed no improvement of renal function as reflected by serum ureum and creatinine. These mice showed a slightly attenuated renal inflammatory response as indicated by a decreased renal neutrophil influx, but failed to show significantly altered intrarenal TNF- $\alpha$ production. Moreover, caspase-1 deficient mice exhibited a clear reperfusion-induced apoptotic reaction as reflected by renal TUNEL histology, caspase-3-like activation and internucleosomal DNA cleavage. Consistently, treatment with agents capable of neutralizing the proinflammatory activation products of caspase-1 (IL-1 receptor antagonist, anti IL-1 receptor antibody, anti IL-18 antibody) also minimally reduced renal functional deterioration, inflammation and apoptosis after $24 \mathrm{~h}$ of reperfusion. These findings suggest that activated caspase-1 and its inflammatory cleavage products are involved in, but not crucial to the induction of inflammation after I/R. Hence, beside caspase-1, other (combinations of) activated caspases are likely to play a more prominent role in ischemia-reperfusioninduced inflammation.

\section{INTRODUCTION}

Ischemia-reperfusion ( $\mathrm{I} / \mathrm{R})$ injury to kidneys can complicate various clinical conditions such as hemorragic or septic shock, intra-abdominal aneurysm repair, cardiopulmonary bypass and renal transplantation. Acute renal failure, which is the result of $I / R$ injury in $50 \%$ of cases (1), is reflected by an array of morphological alterations as well as loss of renal function. Despite progression in disease control, acute renal failure is associated with unacceptabe high mortality and morbidity (2).

During reperfusion, a destructive inflammatory reaction develops which is reflected by cytokine production, induction of adhesion molecules and consequent influx of neutrophils. It is well established that the extent of acute renal failure in response to I/R can be limited by treatment with anti-inflammatory agents $(3,4)$. Besides inflammation, induction of apoptosis has been reported to occur during the reperfusion phase (5) and even during ischemia (6). We recently showed that inhibition of apoptosis by the broad spectrum caspase inhibitor ZVAD-fmk prevented inflammation and tissue damage in a murine model of renal I/R (7). Conversely, we demonstrated in this model that endoge- 
nous TNF- $\alpha$ contributes to the development of late inflammation related apoptosis (5). Thus, inflammation and apoptosis amplify and maintain each other in the course of renal $\mathrm{I} / \mathrm{R}$ injury by a mechanism which remains to be resolved.

In a recent report, Miwa et al. demonstrated that release of IL-1, a proximal mediator of neutrophil chemotaxis and adhesion molecule expression, may occur as a part of the apoptotic response (8). IL-1 (9), as well as the IFN- $\gamma$ inducing cytokine IL-18 (10) are processed into an active form by IL-1 $\beta$ converting enzyme (ICE/caspase-1), an enzyme among others associated with apoptosis. Interestingly, both IL-1 (11) and IL-18 (12) have been associated with inflammation induced by renal $I / R$.

The present study investigates the functional contribution of caspase-1 activation to renal I/R injury. We show that cytokine production as a result of caspase-1 activation is not a crucial event leading to inflammation after I/R. Hence, apoptosis has to contribute to $\mathrm{I} / \mathrm{R}$-induced inflammation largely by other caspase-dependent mechanisms.

\section{Materials AND Methods}

\section{ANTIBODIES AND REAGENTS}

Anti-murine neutrophil monoclonal antibody (mAb) Gr-1 from Pharmingen (San Diego, $\mathrm{CA}$ ); peroxidase conjugated goat anti-rat and peroxidase conjugated goat anti-rabbit IgG from Jackson (West Grove, PA); peroxidase conjugated sheep anti-digoxigenin, digoxigenin 11-dUTP and TdT from Boehringer Mannheim (Mannheim, Germany); peroxidase conjugated rabbit anti-sheep IgG from DAKO (Copenhagen, Denmark); the rat anti murine IL-1 receptor-1 mAb 1F3 was kindly provided by Dr. W. Falk (University of Regensburg, Germany); IL-1 receptor antagonist (IL-1RA) was kindly provided by Dr. J Vannice (Synergen, Boulder, CO); anti-murine IL-18 polyclonal antibody (pAb) was purified rabbit IgG, raised by immunizing rabbits with recombinant murine IL-18, kindly provided by Dr. M. Kurimoto (Fujisaki Institute, Okayama, Japan); Ac-DEVD-amc from the Peptide Institute (Osaka, Japan). All other reagents were purchased from Sigma (St. Louis, MO).

\section{ANIMALS}

Male caspase-1-/- (13) mice (strain C57BL/6), which were littermates, as well as wild type control mice, which were also littermates, were homozygotes used at the age of 8 15 weeks and were a kind gift of Dr. Seshadri (BASF Bioresearch Corporation, Worcester, MA). The suspected deletion of the employed batch of animals was confirmed by evaluation of serum IL-1 $\beta$ levels and lethality in response to LPS challenge (14). Male Swiss mice at the age of 6-10 weeks were obtained from Charles River Breeding Laboratories (Heidelberg, Germany). During the experiment, mice were housed individ- 
ually in standard laboratory cages with ad libitum access to food and water. The studies were approved by the Institutional Animal Care Committees of the University of Maastricht, the Netherlands and Ghent, Belgium in accord with the U.S. National Institutes of Health guide for care and use of laboratory animals.

\section{EXPERIMENTAL PROTOCOL}

At the start of the experiments, mice were anesthetized with sodium pentobarbital ( 50 $\mathrm{mg} / \mathrm{kg}$ i.p.). A rectal probe (Cole-Palmer, Vernon Hills, IL) to monitor body temperature was inserted and body temperature was maintained at $39^{\circ} \mathrm{C}$ by a heating pad until recovery from anesthesia. The left renal pedicle was clamped for 45 min using a non-traumatic vascular clamp through a midline abdominal incision. After removal of the clamp the kidney was inspected for restoration of blood flow. Next, the contralateral kidney was removed and stored for further analysis. The abdomen was closed in two layers and $0.25 \%$ bupivacaine was applied topically for postoperative pain management. Finally, to maintain fluid balance and volume status, mice were supplemented with $1 \mathrm{ml}$ prewarmed $\left(37^{\circ} \mathrm{C}\right)$ PBS s.c. The animals were sacrificed after $24 \mathrm{~h}$ of reperfusion. As previously shown in this model, the signs of renal apoptosis, inflammation and functional deterioration are ubiquitous after $24 \mathrm{~h}$ of reperfusion (5) and their manifestation is dependent on early I/R-induced caspase activation (12), which accounts for the focus on this timepoint after ischemia. At the time of sacrifice, blood was collected by orbital puncture and the postischemic kidney was harvested.

In an experiment performed to delineate the role of caspase-1 in renal I/R and to eliminate the possibility of a dosing or delivery problem with employed neutralizing agents, caspase-1-/- mice were subjected to renal $I / R(n=8)$ or to the same surgical procedure without clamping of the renal pedicle ( Swiss mice were subjected to renal $\mathrm{I} / \mathrm{R}$ and administered intraperitoneally $0.5 \mathrm{mg}$ anti ILIR mAb $(n=8), 1 \mathrm{mg} \mathrm{IL-1RA}(\mathrm{n}=8)$, or $1 \mathrm{mg}$ anti-IL-1 $8 \mathrm{pAb}(\mathrm{n}=8)$ dissolved in $0.5 \mathrm{ml}$ sterile PBS at the time of reperfusion. Additional Swiss mice were subjected to the $I / R$ $(\mathrm{n}=10)$ or sham $(\mathrm{n}=12)$ procedure, administered vehicle consisting of $0.5 \mathrm{ml}$ PBS i.p. and sacrificed $24 \mathrm{~h}$ after surgery. As extra controls for caspase-1-/- mice we used wild type caspase-1+/+ mice of similar background. These mice showed no differences with respect to any of the evaluated parameters (data not shown), except for a slight reduction in TNF- $\alpha$ staining intensity as compared to similarly treated Swiss mice.

\section{APOPTOSIS ASSAYS}

Genomic DNA was extracted from kidneys employing a commercially available DNA purification kit (Wizard, Promega, Madison, WI) according to the manufacturers instructions. The presence of internucleosomal DNA cleavage in kidneys was investigated with 
a commercially available ligase-mediated (LM)-PCR assay kit (Apoalert, Clontech, Palo Alto, CA) on equal amounts of DNA according to the manufacturers instructions. This technique allows semiquantitative measurement of apoptosis based on the number of PCR cycles necessary for apparent amplification (15). All DNA samples were amplified under the following PCR-protocol: hotstart $\left(72^{\circ} \mathrm{C}\right.$ for $\left.8 \mathrm{~min}\right), 25$ cycles $\left(94^{\circ} \mathrm{C}\right.$ for $60 \mathrm{sec}-$ onds and $72^{\circ} \mathrm{C}$ for 180 seconds $)$ and post-cycling $\left(72^{\circ} \mathrm{C}\right.$ for $\left.15 \mathrm{~min}\right)$. Amplified DNA was subjected to gel electrophoresis on a $1.2 \%$ agarose gel containing ethidium bromide. Band proportions were estimated for the 600,400 and 200 bp DNA fragments by measuring the intensity of ethidium bromide fluorescence with a digital camera (Imagemaster VDS, Pharmacia, Uppsala, Sweden) using commercially available gel analysis software (Sigma Gel, SPSS, Chicago, IL).

Renal caspase-3-like activities were measured as described previously (16). In brief, renal lysates (containing $40 \mu \mathrm{g}$ total protein) were incubated with $50 \mu \mathrm{M}$ of the fluorogenic substrate Ac-DEVD-amc (caspase-3-like) and the release of fluorescent 7-amino4-methylcoumarin was measured for $1 \mathrm{~h}$ at $2 \mathrm{~min}$ intervals by spectrofluorometry (Cytofluor, PerSeptive Biosystems, Cambridge, MA).

\section{RENAL MYELOPEROXIDASE}

To quantify the extent of renal neutrophil accumulation, renal myeloperoxidase (MPO) content was determined as described previously $(5,17)$. In brief, equal quantities of homogenized renal tissue were heat incubated and supernatants were collected. After addition of $\mathrm{H}_{2} \mathrm{O}_{2}$, supernatants were incubated with tetramethylbenzidine and the reaction was stopped by the addition of $\mathrm{H}_{2} \mathrm{SO}_{4}$ in a 96-well plate (Costar, Cambridge, MA). Optical density (OD) was measured and MPO activity was calculated per mg renal tissue by comparing the OD of sample wells with a titration curve of horseradish peroxidase and standardized with respect to wet/dry ratios.

\section{HistologY}

Paraffin sections $(5 \mu \mathrm{m})$ were stained with periodic acid Schiff (PAS). Immunostaining for TNF- $\alpha$ with digoxigenin-labeled mAb 52B83 (5) was also performed on paraffin sections using alkaline phosphatase conjugated sheep anti-digoxigenin as the secondary detection mAb and NBT/BCIP as a chromogen followed by methyl green counterstaining. Histological aspects of apoptosis were studied on paraffin sections by standard terminal deoxynucleotidyl transferase (TdT)-mediated dUTP nick end labeling (TUNEL histology) (18). Sections pretreated with DNAse 1 in order to nick all DNA, served as positive controls.

Frozen sections $(5 \mu \mathrm{m})$ were stained for neutrophils with $\mathrm{mAb}$ Gr-1 (19) using peroxidase-labeled goat anti-rat IgG as the secondary detection $\mathrm{mAb}$ and 3-amino-9-ethylcar- 
bazole (AEC) as a chromogen followed by a hematoxylin counterstain. To block aspecific peroxidase activity sections were pretreated for $10 \mathrm{~min}$ with PBS containing $0.03 \%$ $\mathrm{H}_{2} \mathrm{O}_{2}$. No significant staining was detected in slides incubated with a control $\mathrm{mAb}$.

\section{RENAL FUNCTION}

Renal function was determined in serum obtained by orbital punction at the time of sacrifice. Blood urea nitrogen (BUN) and serum creatinine were kinetically measured with a Cobas Fara autoanalyzer (Roche, Basle, Switzerland).

\section{STATISTICS}

Prior to experimentation, required numbers of animals per group were determined by analysis of power using data obtained from pilot-studies. All data are expressed as the mean \pm SEM, and statistical analysis was performed by Student's T-test. $\mathrm{P}<0.05$ was taken to denote statistical significance.

\section{RESULtS}

\section{ROLE OF CASPASE-1 ACTIVATION IN THE DEVELOPMENT OF RENAL I/R INJURY}

The role of caspase- 1 in renal I/R injury was studied by subjecting caspase- 1 deficient mice to renal ischemia as described before (5). Overall assessment of renal functional damage as measured by determination of BUN and serum creatinine, showed that the lack of caspase-1 did slightly, but not significantly reduce the extent of renal functional impairment as compared to controls (Figure 1A and B). In line, no apparent reduction in the extent of tissue damage was histologically discernable in kidneys from caspase-1-/mice after I/R as compared to controls (Figure 2, data not shown). Neutrophil influx as reflected by renal MPO content was minimally but significantly decreased after $I / R$ in caspase-1-/- mice when compared to PBS treated controls, however as compared to sham operated controls renal MPO content was significantly increased (Figure 3). Also, the observed decrease in I/R-induced MPO content in caspase-1-/- mice did not result in an additional improvement in renal function (Figures $1 \mathrm{~A}$ and $1 \mathrm{~B}$ ). As compared to wild type controls, caspase-1-/- mice did not show an apparent decrease in renal inflammation after $\mathrm{I} / \mathrm{R}$ as reflected by immunohistology for neutrophils (Figure 4) and TNF- $\alpha$ (Figure 5). We observed that both the caspase-1-/- and caspase-1+/+ mice with similar phenotypic background, as compared to the Swiss mice showed a slightly lower TNF- $\alpha$ specific staining intensity. However, no differences between caspase-1-/- and caspase- $1+/+$ mice were observed. Evaluation of the degree of apoptosis after $24 \mathrm{~h}$ of reperfusion as reflect- 
ed by renal TUNEL-histology (Figure 6), caspase-3-like activation (Figure 7) and internucleosomal DNA cleavage (Figure 8 ) showed no significant differences between caspase-1-/- and caspase-1+/+ mice. The observed large variability in caspase-3-like activity (Figure 7) may be a consequence of the multispecificity of Ac-DEVD-amc as a substrate as well as of the fact that kidney homogenates (containing different cell types and extracellular material) were used. Considering this, one could speculate that the non-significant tendency of caspase-3-like activity to decrease in kidneys from caspase-1-/- mice (Figure 7) reflects reduced proteolytic activation of caspase-3 and other caspases that can be activated by caspase-1 and exhibit affinity for the DEVD-motif $(20,21)$. Although slightly attenuated inflammation and apoptosis were observed in caspase-1-/- mice, the present findings indicate that renal $\mathrm{I} / \mathrm{R}$-induced apoptosis, inflammation and tissue damage occur largely independent from caspase-1 activation.

A

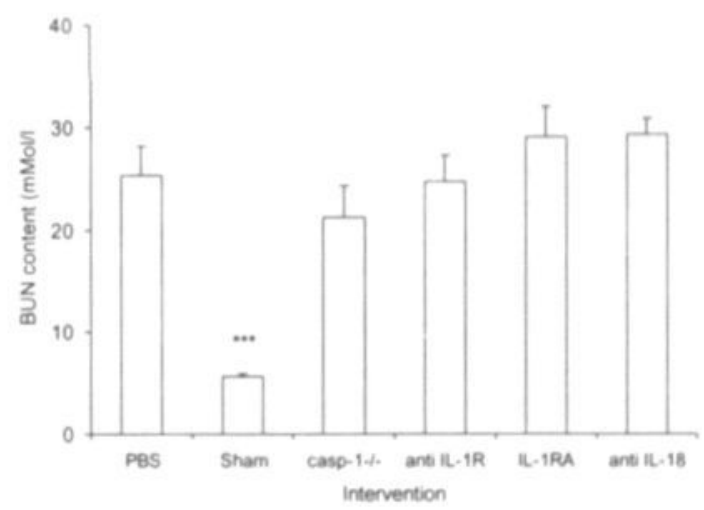

B

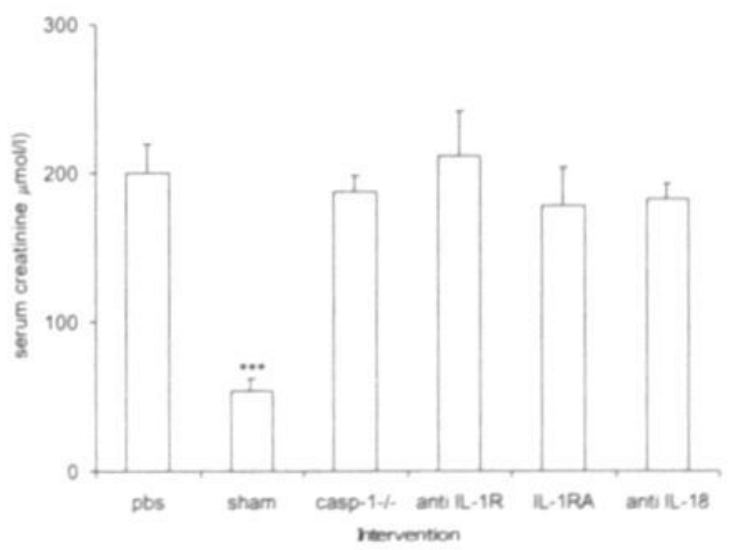

Figure 1. Renal function after $24 \mathrm{~h}$ in the different experimental groups as reflected by blood urea nitrogen (BUN) (A) and creatinine (B) content. Statistical significance as compared to PBS treated animals was denoted at $\mathrm{P}<0.05\left(^{*}\right)$. As compared to sham controls, all groups showed significantly $(\mathrm{P}<0.001)$ increased $\mathrm{BUN}$ and serum creatinine levels (not indicated). The data shown are means \pm SEM. 
EFFECT OF IL-1 OR IL-18 NEUTRALIZATION ON RENAL FUNCTION AND TISSUE DAMAGE AFTER I/R

Interventions with IL-1RA, anti IL-1R and anti IL-18 in the employed model failed to significantly decrease BUN content (Figure 1A) or serum creatinine (Figure 1B) as compared to PBS controls after $24 \mathrm{~h}$ of reperfusion. IL-1RA, anti IL-1R and anti IL-18 also could not prevent the loss of histological integrity in animals subjected to renal I/R (Figure 2, data not shown). Similar to PBS controls, kidney damage was histologically evident in these mice after $24 \mathrm{~h}$ of reperfusion. PAS staining revealed dilatation of proximal convoluted tubuli, intraluminal tubular debris, loss of tubular brush border membrane integrity, patchy necrosis and detachment of tubular cells from supporting basement membranes. These findings suggest a lack of functional involvement of activated caspase- 1 and its proinflammatory activation products in the injurious response to renal $\mathrm{I} / \mathrm{R}$.
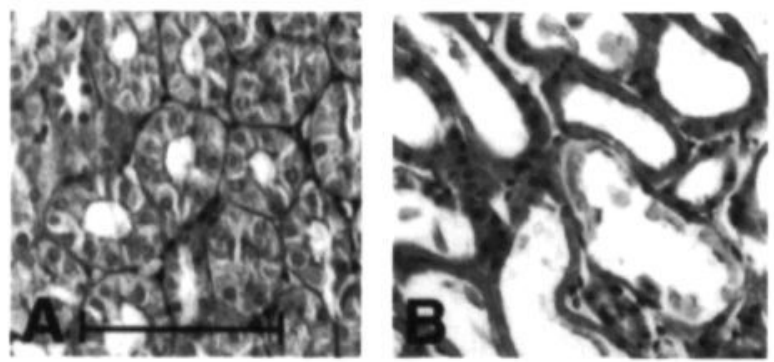

Figure 2. PAS-stains of renal biopsies $24 \mathrm{~h}$ after surgery (magnification 200x, bar represents $200 \mu \mathrm{m}$ ). As compared to Swiss mice subjected to the sham-procedure (A), renal I/R in Swiss mice treated with PBS leads to extensive histological damage, characterized by tubular dilatation, luminal debris, tubular vacuolization, damaged brush border membranes and tubular necrosis at $24 \mathrm{~h}$ (B). Neither the absence of caspase-1 nor the different treatment regimens attenuated the extent of histological damage (data not shown).

EFFECT OF IL-1 OR IL-18 NEUTRALIZATION ON ACUTE INFLAMMATION AFTER RENAL I/R

Administration IL-1RA did not significantly attenuate I/R-induced renal influx of neutrophils as reflected by unaltered renal MPO activity (Figure 3) and Gr-1 immunohistology (Figure 4) as compared to PBS-treated controls. Anti IL-1R treatment significantly attenuated renal MPO content as compared to PBS treated controls, but in kidneys from such treated mice, formation of a neutrophil infiltrate as reflected by Gr-1 immunohistology was clearly observed (data not shown). 


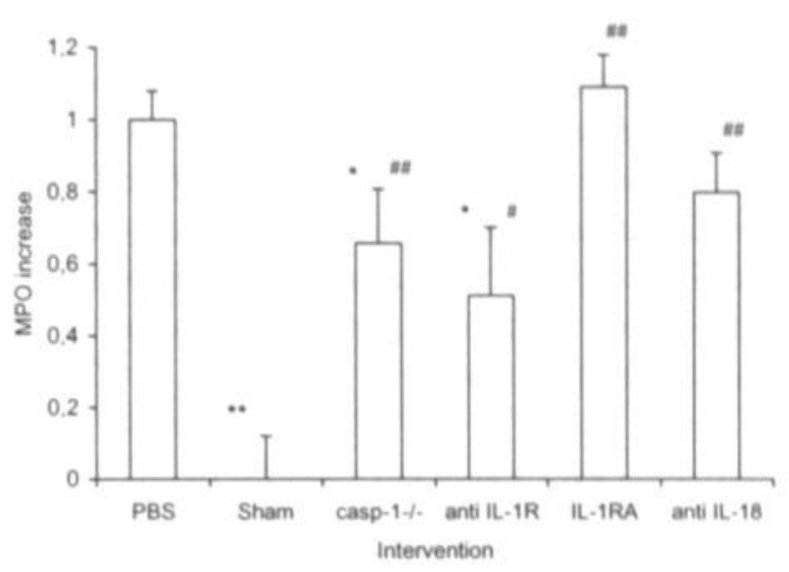

Figure 3. Neutrophil influx was assessed quantitatively by determination of MPO increase after $24 \mathrm{~h}$ of reperfusion. Values are presented relative to the amount of MPO present in the contralateral kidney harvested immediately after reperfusion and normalized with respect to the MPO increase after $24 \mathrm{~h}$ of reperfusion in PBS treated mice. Statistical significance as compared to PBS treated animals was denoted at $\mathrm{P}<0.05(*)$ and $\mathrm{P}<0.01(* *)$. Statistical significance as compared to sham controls was denoted at $\mathrm{P}<0.05$ (\#) and $\mathrm{P}<0.01$ (\#\#). The presented data are means \pm SEM.
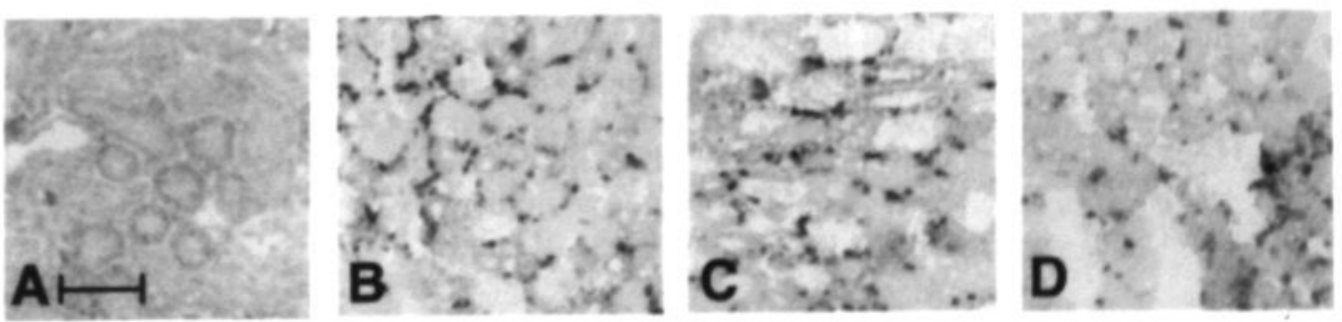

Figure 4. Immunohistochemical staining by mAb Gr-1 of infiltrating neutrophils (magnification 100x, bar represents $200(\mathrm{~m})$. Neutrophils were scarcely present in kidneys obtained from sham-operated Swiss mice (A). In contrast, marked renal neutrophil accumulations were observed in PBS treated Swiss mice after $24 \mathrm{~h}$ of reperfusion (B). After $24 \mathrm{~h}$ of reperfusion caspase-1-/- mice (C) or Swiss mice treated with ILIRA (D), anti IL-IR or anti IL-18 (data not shown) showed similar I/R-induced renal neutrophil infiltrates.

Our data do not reveal whether the latter is a result of dissimilar assay sensitivity or is due to pharmacokinetic differences between $17 \mathrm{kDa}$ IL-1RA and $150 \mathrm{kDa}$ anti IL-1R. As compared to PBS controls, IL-1RA (Figure 5) and anti IL-IR (data not shown) failed to apparently attenuate enhanced renal TNF- $\alpha$ production most prominently distributed in and along damaged tubular epithelium and infiltrating leukocytes in the outer stripe of the outer medulla. IL-1 neutralization did not significantly decrease the extent of I/Rinduced renal apoptosis as reflected by TUNEL histology (Figure 6, data not shown), up- 
regulation of caspase-3-like activity (Figure 7) and apparent internucleosomal DNA cleavage (Figure 8). However, consistent with the observations in caspase-1-/- mice that were subjected to renal I/R, a moderate effect of IL-1 and IL-18 inhibition on caspase-3 activity was observed (Figure 7). The present findings also confirm that IL-18 does not extensively contribute to acute I/R-induced inflammation (Figure 3) or apoptosis (Figures 7 and $8)$. Similarly, these data indicate that neither caspase-1 dependent nor caspase- 1 independent production of IL-1 as a result of apoptosis is crucial to the induction of acute inflammation after renal $\mathrm{I} / \mathrm{R}$ (Figure 3 and 4 ).
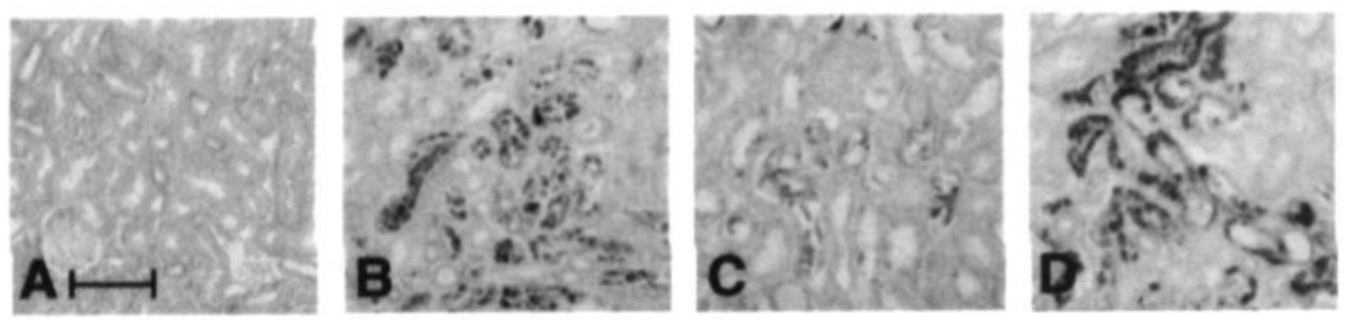

Figure 5. Immunohistochemical staining of TNF- $\alpha$ by mAb $52 \mathrm{~B} 83$ (magnification 100x, bar represents $200 \mu \mathrm{m})$. While absent in kidneys obtained from sham-operated Swiss mice (A), TNF- $\alpha$ was expressed in the outer stripe of the outer medulla, distributed in and along damaged tubular epithelium and in infiltrating leukocytes in Swiss mice after $24 \mathrm{~h}$ of reperfusion (B). ILIRA (C), anti IL-IR and anti IL-18 treated Swiss mice (data not shown) showed similar renal TNF- $\alpha$ expression after $24 \mathrm{~h}$ of reperfusion. The caspase-1-/- (D) and caspase-1+/+ (data not shown) mice as compared to the Swiss mice showed a minimal decrease in TNF- $\alpha$ specific staining intensity. However, in this respect no differences between caspase-1-/- and caspase$1+1+$ mice were observed.
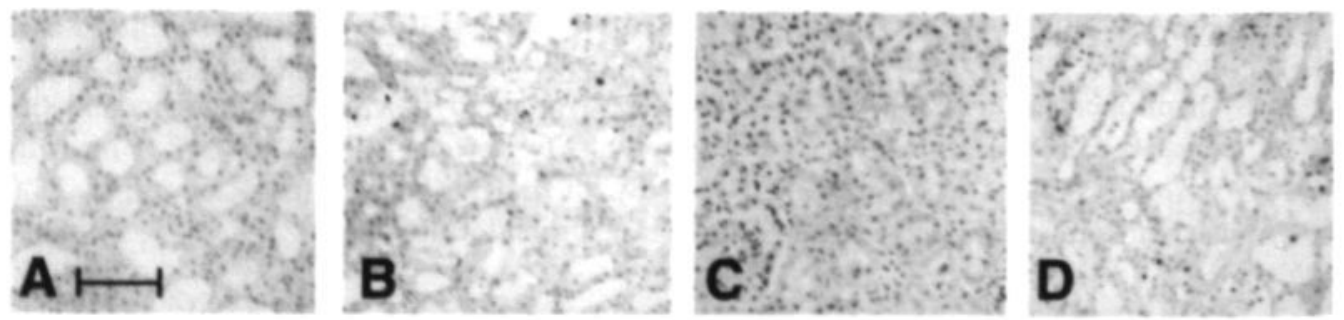

Figure 6. Representative light micrographs showing in situ detection of DNA nick ends by TUNEL histology (magnification 100x, bar represents $200 \mu \mathrm{m}$ ). Nuclei of apoptotic cells exhibit brown staining as a result of internucleosomal DNA cleavage. Nuclei lacking fragmented DNA stain blue. In contrast to sham operated Swiss mice (A), tubular epithelial cells of the outer medulla of biopsies obtained from either PBS treated Swiss mice (B) or caspase1-/- mice (C) after 24 h of reperfusion showed extensive apoptosis. Treatment with IL-IRA (D), anti IL-IR or anti IL-18 (data not shown) did not result in attenuation of apoptosis after 24 $\mathrm{h}$ as reflected by TUNEL-histology. 


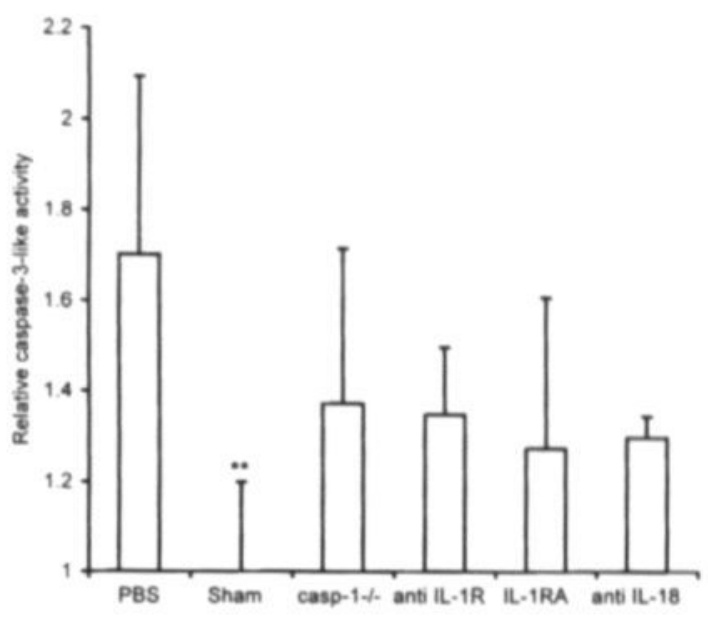

Figure 7. Renal caspase-3-like activities were determined kinetically in homogenates of tissue obtained after $24 \mathrm{~h}$ of reperfusion in a fluorogenic substrate assay in which Ac-DEVD-amc served as a substrate. As discussed in the main text, the large variabilities may be a consequence of the multispecificity of Ac-DEVD-amc as a substrate or a consequence of employing tissue homogenates. Data are expressed as the increase in fluorescence as a function of time, normalized against data obtained from the sham operated group. Statistical significance as compared to PBS treated animals was denoted at $\mathrm{P}<0.01(* *)$. Except for PBS treated mice, no groups showed significantly altered caspase-3-like activities after I/R as compared to sham controls (not indicated). The data shown are means \pm SEM.

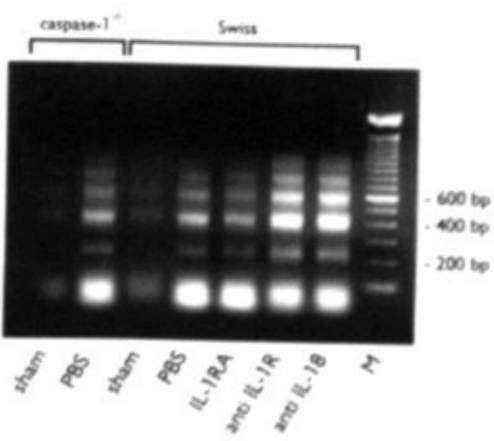

Figure 8. The extent of renal apoptosis after $24 \mathrm{~h}$ of reperfusion is reflected by the presence of fragmented DNA amplified by LM-PCR and detected on ethidium-bromide-stained gel. Neither the absence of caspase-1 nor the different treatment regimens prevented renal internucleosomal DNA cleavage. M, molecular weight markers (range, 100 to 2000 base pairs). 


\section{DISCUSSION}

It was previously demonstrated that upregulated caspase-1-like activity after renal I/R $(12,22)$ can be prevented by treatment with the broad-spectrum caspase inhibitor zVADfmk. We recently demonstrated that the latter treatment abrogates I/R-induced apoptosis and inflammation (7), suggesting a functional role for activated caspase-1 after renal $\mathrm{I} / \mathrm{R}$. In order to elucidate the putative involvement of caspase-1, we subjected caspase-1-/mice to renal I/R. The present findings show that the absence of caspase- 1 does not lead to significant attenuation of apoptosis or inflammation in our model after $24 \mathrm{~h}$ of reperfusion. Hence, these findings suggest that $\mathrm{I} / \mathrm{R}$-induced apoptosis, inflammation and consequent tissue damage can occur independent from caspase-1 activation.

Release of biologically active IL-1 is largely dependent on activation of intracellular caspase-1. However, recent observations show that inflammation mediated by the proinflammatory cytokine IL-1 can be induced by apoptotic cells in vivo independent from active caspase-1 (8). Active caspase- 1 also mediates release of the IFN- $\gamma$ inducing cytokine IL-18 (23). Like IL-1 (24), this pro-inflammatory cytokine has been shown to be up-regulated early after renal reperfusion and, in conjunction with IL-12 to contribute to delayed I/R-induced inflammation characterized by IFN- $\gamma$ dependent renal MHC upregulation $(12,25)$. Similar to wildtype controls, caspase-1 deficient knockout mice showed marked increases in renal MHC class I and II expression after 7 days of renal reperfusion (personal unpublished observation). We hypothesized that activated caspase1 constitutes an intermediate between apoptosis and inflammation. Such a mechanism may explain why apoptosis extensively contributes to the development of subsequent inflammation in the course of renal I/R (7). However, the present findings indicate that neutralization of endogenous IL-1 only marginally decreased I/R-induced acute inflammation and organ damage. Neutralization of endogenous IL-18 also did not reduce the extent of inflammation and organ damage, which is in line with previous results from our laboratory (12). In the model employed, caspase-activation is essential for the development of subsequent inflammation and organ damage (7). The present results indicate a limited functional role for activated caspase- 1 and its activation products in the events leading to inflammation after renal I/R. Hence, beside caspase-1, other caspases or combinations thereof, are likely to be more prominently involved.

In the heart, Yaoita et al. showed that zVAD-fmk treatment reduced I/R-induced infarct volume and apoptosis (26), but the contribution of caspase-1 inhibition to this therapeutic effect remains to be established. In the brain, Hara et al. showed that intraventricular administration of $80 \mathrm{ng} z V A D$-fmk to mice and rats subjected to $2 \mathrm{~h}$ filamentous middle cerebral artery occlusion followed by reperfusion, significantly decreased infarct volume and neurological deficit (27). Administration of $400 \mathrm{ng}$ of the caspase-1 selective inhibitor YVAD-CMK mimicked these results (27). In line, transgenic mice overexpressing a caspase-1-blocking mutant form of caspase-1 exhibited decreased brain infarct 
volume, reduced internucleosomal DNA cleavage and attenuated local IL-1 expression following brain $\mathrm{I} / \mathrm{R}(28,29)$. The discrepancy between the results obtained in models of $\mathrm{I} / \mathrm{R}$-induced brain damage and the present data obtained in a model of renal $\mathrm{I} / \mathrm{R}$, may reflect pathophysiological differences at the organ level. Although comparison between organ systems is difficult, the latter notion is supported by the observed lack of therapeutic efficacy of IL-1 neutralization in the treatment of $\mathrm{I} / \mathrm{R}$-induced renal injury (reference 11 and present results) as compared to the efficacy of IL-1 inhibition to reduce I/Rinduced brain injury (30-32).

We previously demonstrated that zVAD-fmk treatment abrogated renal $\mathrm{I} / \mathrm{R}$ injury (7), potentially as a result of caspase- 1 inhibition. In line, recent evidence suggests functional involvement of caspase-1 in hypoxic injury to proximal tubules in an in vitro model (33). However, tubular damage in this in vitro model is characterized by the presence of hypoxia-induced necrosis rather than apoptosis (34). In contrast, the moderate period of ischemia applied in the present in vivo model in caspase-1-/- mice is followed by a strong reperfusion-induced apoptotic reaction. The present results do not exclude a contribution of caspase-1 in hypoxia-induced necrotic lesions, but rather establish a limited overall role for caspase-1 activation in the development of renal $\mathrm{I} / \mathrm{R}$ injury in vivo.

The link between caspase activation and onset of inflammation remains largely unknown. Insufficient local phagocytotic capacity to resolve sudden widespread apoptosis may lead to secondary necrosis and inflammation in kidneys subjected to $I / R(35,36)$. Furthermore, activation of other pro-inflammatory mediators by apoptosis has been reported, including cleavage products of aminoacyl-tRNA synthetases (37) and activation and release of the chemokine endothelial monocyte-activating polypeptide II (EMAP-II). Recently, the latter has been demonstrated after renal I/R (7) and may be selectively triggered by caspase activation (38). However, more studies are required to elucidate the functional role of caspase activation in the induction of an inflammatory response after $\mathrm{I} / \mathrm{R}$.

The observation that abrogation of early I/R-induced renal caspase activation prevents the development of inflammation indicates that key features of the apoptotic process are crucial to the initiation of inflammation and subsequent tissue injury. Although renal caspase-1-like activity is clearly up-regulated after $I / R$, our present results indicate that neither activated caspase-1 nor its inflammatory cleavage products are central mediators of apoptosis-induced inflammation after renal $\mathrm{I} / \mathrm{R}$. Thus, other activated caspases besides caspase-1, or combinations of activated caspases with affinity for peptide caspase inhibitors like zVAD-fmk are essential for the development of the injurious response following renal $\mathrm{L} / \mathrm{R}$. More insight in the role of these caspases in the induction of inflammation may provide a basis to more effectively treat the clinical aspects of renal $\mathrm{L} / \mathrm{R}$ injury. 


\section{REFERENCES}

1. Thadhani R, Pascual M, Bonventre JV: Acute renal failure. N Engl J Med 1996; 334: 1448-1460.

2. Lieberthal W, Levinsky NG: Treatment of acute tubular necrosis. Semin Nephrol 1990; 10: 571583.

3. Rabb H, Mendiola CC, Saba SR, Dietz JR, Smith CW, Bonventre JV, Ramirez G: Antibodies to ICAM-1 protect kidneys in severe ischemic reperfusion injury. Biochem Biophys Res Comm 1995; $211: 67-73$.

4. Takada M, Nadeau KC, Shaw GD, Marquette KA, Tilney NL: The cytokine adhesion molecule cascade in ischemia/reperfusion injury of the rat kidney: Inhibition by a soluble P selectin ligand. J Clin Invest 1997; 99: 2682-2690.

5. Daemen MARC, Van de Ven M, Heineman E, Buurman WA: Involvement of endogenous interleukin-10 and tumor necrosis factor-alpha in renal ischemia-reperfusion injury. Transplantation 1999; 67: 792-800.

6. Rasper DM, Vaillancourt JP, Hadano S, Houtzager VM, Seiden I, Keen SC, Tawa P, Xanthoudakis S, Nasir J, Martindale D, Koop BF, Peterson EP, Thornberry NA, Huang JQ, MacPherson DP, Black SC, Hornung F, Lenardo MJ, Hayden MR, Roy S, Nicholson DW: Cell death attenuation by 'Usurpin', a mammalian DED-caspase homologue that precludes caspase8 recruitment and activation by the CD-95 (Fas, APO-1) receptor complex. Cell Death Differ 1998; 5: 271-288.

7. Daemen MARC, Van 't Veer C, Denecker G, Heemskerk VH, Wolfs TGAM, Clauss M, Vandenabeele P, Buurman WA: Inhibition of apoptosis induced by ischemia-reperfusion prevents inflammation. J Clin Invest 1999; 104, 541-549.

8. Miwa K, Asano M, Horai R, Iwakura Y, Nagata S, Suda T: Caspase-1-independant IL-1 $\beta$ release and inflammation induced by the apoptosis inducer Fas ligand. Nature Med 1998; 4: 1287-1292.

9. Cerretti DP, Kozlosky CJ, Mosley B, Nelson N, Van Ness NK, Greenstreet TA, March CJ, Kronheim SR, Druck T, Cannizzaro LA: Molecular cloning of the interleukin-1 $\beta$ converting enzyme. Science 1992; 256: 97-100.

10. Ushio S, Namba M, Okura T, Hattori K, Nukada Y, Akita K, Tanabe F, Konishi K, Micallef M, Fujii M, Torigoe K, Tanimoto T, Fukuda S, Ikeda M, Okamura H, Kurimoto M: Cloning of the cDNA for human IFN-gamma-Inducing factor, expression in escherichia coli, and studies on the biologic activities of the protein. J Immunol 1996; 156: 4274-4279.

11. Haq M, Norman J, Saba SR, Ramirez G, Rabb H: Role of IL-1 in renal ischemic reperfusion injury. J Am Soc Nephrol 1998; 9: 614-619.

12. Daemen MARC, Van 't Veer C, Wolfs TGAM, Buurman WA: Ischemia-reperfusion induced IFN-gamma up-regulation: Involvement of IL-12 and IL-18. J Immunol 1999; 162: 5506-5510.

13. Li P, Allen H, Banerjee S, Franklin S, Herzog L, Johnston C, McDowell J, Paskind M, Rodman $\mathrm{L}$, Salfeld J: Mice deficient in IL-1 beta-converting enzyme are defective in production of mature IL-I beta and resistant to endotoxic shock. Cell 1995; 80: 401-4II.

14. Van Molle MW, Brouckaert P, Libert C: Caspase-1 is not involved in experimental hepatitis in mouse. Febs Lett 1999; 445: 115-118.

15. Staley K, Blaschke AJ, Chun J: Apoptotic DNA fragmentation is detected by a semiquantitative ligation-mediated PCR of blunt DNA ends. Cell Death Differ 1997: 4:66-75. 
16. Vercammen D, Beyaert R, Denecker G, Goossens V, VanLoo G, Declercq W, Grooten J, Fiers W, Vandenabeele P: Inhibition of caspases increases the sensitivity of L929 cells to necrosis mediated by tumor necrosis factor. J Exp Med 1998; 187: 1477-1485.

17. Laight DW, Lad N, Woodward B, Waterfall JF: Assessment of myeloperoxidase activity in renal tissue after ischemia/reperfusion. Eur J Pharmacol 1994; 292: 81-88.

18. Gavrieli Y, Sherman Y, Ben SS: Identification of programmed cell death in situ via specific labeling of nuclear DNA fragmentation. J Cell Biol 1992; 119: 493-501.

19. Fleming TJ, Fleming ML, Malek TR: Selective expression of Ly-6G on myeloid lineage cells in mouse bone marrow. RB6-8C5 mAb to granulocyte-differentiation antigen (Gr-1) detects members of the Ly-6 family. J Immunol 1993; 151: 2399-2408.

20. Garcia CM, Peterson EP, Rasper DM, Vaillancourt JP, Zamboni R, Nicholson DW, Thomberry NA: Purification and catalytic properties of human caspase family members. Cell Death Differ 1999; 6: 362-369.

21. Van de Craen M, Declercq W, Van den Brande I, Fiers W, Vandenabeele P: The proteolytic procaspase activation network: An in vitro analysis. Cell Death Differ (in press)

22. Kaushal GP, Singh AB, Shah SV: Identification of gene family of caspases in rat kidney and altered expression in ischemia-reperfusion injury. Am J Physiol 1998; 274: F587-F595.

23. Ghayur T, Banerjee S, Hugunin M, Butler D, Herzog L, Carter A, Quintal L, Sekut L, Talanian $\mathrm{R}$, Paskind M, Wong W, Kamen R, Tracey D, Allen H: Caspase-1 processes IFN-gamma-inducing factor and regulates LPS-induced IFN-gamma production. Nature 1997; 386: 619-623.

24. Kelly KJ, Williams WW, Colvin RB, Meehan SM, Springer TA, Gutierrezramos JC, Bonventre $\mathrm{JV}$ : Intercellular adhesion molecule-1-deficient mice are protected against ischemic renal injury. J Clin Invest 1996; 97:1056-1063.

25. Shoskes DA, Parfrey NA, Halloran PF: Increased major histocompatibility complex antigen expression in unilateral ischemic acute tubular necrosis in the mouse. Transplantation 1990; 49: 201-207.

26. Yaoita H, Ogawa K, Maehara K, Maruyama Y: Attenuation of ischemia/reperfusion injury in rats by a caspase inhibitor. Circulation 1998; 97: 276-281.

27. Hara H, Friedlander RM, Gagliardini V, Ayata C, Fink K, Huang Z, Shimizu SM, Yuan J, Moskowitz MA: Inhibition of interleukin-1 beta converting enzyme family proteases reduces ischemic and excitotoxic neuronal damage. Proc Natl Acad Sci USA 1997; 94: 2007-2012.

28. Friedlander RM, Gagliardini V, Hara H, Fink KB, Li W, MacDonald G, Fishman MC, Greenberg $\mathrm{AH}$, Moskowitz MA, Yuan J: Expression of a dominant negative mutant of interleukin-I beta converting enzyme in transgenic mice prevents neuronal cell death induced by trophic factor withdrawal and ischemic brain injury. J Exp Med 1997; 185: 933-940.

29. Schielke GP, Yang GY, Shivers BD, Betz AL: Reduced ischemic brain injury in interleukin-1 beta converting enzyme-deficient mice. J Cereb Blood Flow Metab 1998; 18: 180-185.

30. Betz AL, Schielke GP, Yang GY: Interleukin-1 in cerebral ischemia. Keio J Med 1996; 45: 230237.

31. Garcia JH, Liu KF, Relton JK: Interleukin-1 receptor antagonist decreases the number of necrotic neurons in rats with middle cerebral artery occlusion. Am J Pathol 1995; 147: 1477-1486.

32. Yamasaki Y, Matsuura N, Shozuhara H, Onodera H, Itoyama Y, Kogure K: Interleukin-I as a pathogenetic mediator of ischemic brain damage in rats. Stroke 1995; 26: 676-680.

33. Edelstein CL, Shi Y, Schrier RW: Role of caspases in hypoxia-induced necrosis of rat renal proximal tubules. J Am Soc Nephrol 1999; 10: 1940-1949. 
Chapter 6

34. Ueda N, Walker PD, Hsu SM, Shah SV: Activation of a 15-kDa endonuclease in hypoxia/reoxygenation injury without morphologic features of apoptosis. Proc Natl Acad Sci USA 1995; 92: 7202-7206.

35. Schwartzman RA, Cidlowski JA: Apoptosis: the biochemistry and molecular biology of programmed cell death. Endocr Rev 1993; 14: 133-151.

36. Lieberthal W, Koh JS, Levine JS: Necrosis and apoptosis in acute renal failure. Semin Nephrol 1998; 18: 505-518.

37. Wkasugi K, Schimmel P: Two distinct cytokines released from a human aminoacyl-tRNA synthetase. Science 1999; 284: 147-150.

38. Knies UE, Behrensdorf HA, Mitchell CA, Deutsch U, Risau W, Drexler HC, Clauss M: Regulation of endothelial monocyte-activating polypeptide II release by apoptosis. Proc Natl Acad Sci USA 1998; 95: 12322-12327. 


\section{CHAPTER 7}

Chemokines are intermediates between apoptosis and inflammation after renal ischemia-reperfusion

Marc A.R.C. Daemen, Bart de Vries, Cornelis van 't Veer, Tim G.A.M. Wolfs, and Wim A. Buurman 


\section{AbSTRaCt}

Ischemia followed by reperfusion ( $\mathrm{L} / \mathrm{R})$ of a kidney initiates a destructive inflammatory reaction that is largely responsible for subsequent organ dysfunction. As a consequence, transplantation of ischemically damaged donor kidneys has been limited. One of the earliest prerequisites for the development of $\mathrm{I} / \mathrm{R}$-induced inflammation is locally increased chemokine expression. We recently demonstrated that also apoptosis, characterized by intracellular caspase-activation, contributes to the development of inflammation following $\mathrm{I} / \mathrm{R}$.

Renal I/R was investigated employing a murine model of 45 min unilateral ischemia and contralateral nephrectomy. The contribution of renal apoptosis, reflected by the extent of internucleosomal DNA fragmentation, was functionally investigated using interventions with the pan-caspase inhibitor zVAD-fmk. Renal expression of the chemokines MIP-2 and KC were investigated using RT-PCR and immunohistology and EMAP-II activation using Western blotting. Neutrophil influx in the postischemic kidney and kidney dysfunction were reflected by renal myeloperoxidase activity and serum ureum and creatinine levels, respectively.

We demonstrate renal up-regulation of the CXC chemokines KC and MIP-2 at the mRNA and protein level after 1 to $16 \mathrm{~h}$ of reperfusion, coinciding with intrarenal activation of the chemokine EMAP-II. Treatment with the caspase inhibitor ZVAD-fmk upon reperfusion effectively prevented I/R-induced renal apoptosis, KC and MIP-2 up-regulation and EMAP-II activation after $2 \mathrm{~h}$ of reperfusion as well as neutrophil influx and functional impairment after $24 \mathrm{~h}$ of reperfusion.

These data for the first time show that chemokine induction following $\mathrm{I} / \mathrm{R}$ is dependent on caspase activation.

\section{INTRODUCTION}

Renal ischemia reperfusion (I/R) induces a destructive inflammatory reaction, as reflected by cytokine production and neutrophil influx in reperfused tissue. Anti-inflammatory treatment limits tissue damage induced by renal $I / R$, indicating that inflammation causes $\mathrm{I} / \mathrm{R}$ induced organ injury $(1,2)$. We demonstrated in a murine model of renal $\mathrm{I} / \mathrm{R}$ that caspase inhibition during $\mathrm{I} / \mathrm{R}$-induced apoptosis prevents inflammation and tissue damage (3). This suggests that apoptosis functionally contributes to renal I/R injury. However, the underlying mechanism of this contribution remains to be resolved.

The hallmark of $\mathrm{V} / \mathrm{R}$-induced inflammation is neutrophil influx in postischemic tissue (4). This requires antecedent local expression of neutrophil chemotactic factors. Indeed, mRNA up-regulation of the CXC chemokine $\mathrm{KC}$ has been reported after renal $\mathrm{I} / \mathrm{R}(5,6)$ and $\mathrm{KC}$ and macrophage inflammatory protein-2 (MIP-2) mRNA production were demonstrated following hepatic I/R (7). Moreover, chemokines such as endothelial 
monocyte-activating polypeptide-II (EMAP-II) have been implicated during early renal reperfusion (3). The latter chemokine shares neutrophil chemotactic activity with CXC chemokines (8) and is activated in, and released by apoptotic cells (9).

This study investigates the interplay between caspase activation, chemokine induction and inflammation in a murine model of renal $\mathrm{I} / \mathrm{R}$. Evidence is provided that renal $\mathrm{KC}$ and MIP-2 production as well as EMAP-II activation are dependent on reperfusion-induced caspase activation.

\section{Materials And Methods}

\section{ANTIBODIES AND REAGENTS}

Rabbit anti-murine MIP-2 polyclonal $\mathrm{Ab}$ and rabbit anti-murine $\mathrm{KC}$ polyclonal $\mathrm{Ab}$ were a kind gift from Dr. D. Remick (University of Michigan, Ann Arbor, MI); peroxidase conjugated goat anti-rabbit IgG from Jackson (West Grove, PA); the rabbit antiserum SA 2846 was generated (Eurogentec, Seraing, Belgium) against recombinant mature human EMAP-II ( $23 \mathrm{kDa})$, crossreactive with murine EMAP-II; zVAD-fmk and zFA-fmk were from Enzyme Systems (Livermore, CA); All other reagents were purchased from Sigma (St. Louis, MO).

\section{EXPERIMENTAL PROTOCOL}

All experiments were approved by the Institutional Animal Care Committee of the University of Maastricht. Renal ischemia was induced as described in detail previously (11). In brief, male Swiss mice (Charles River Breeding Laboratories, Heidelberg, Germany) were subjected to renal ischemia by clamping the left renal pedicle for $45 \mathrm{~min}$. Subsequent to removal of the clamp, the contralateral kidney was removed and stored. After 1, 2, 4, 6, 16 and $24 \mathrm{~h}$ of reperfusion blood was collected, the left kidney was harvested and mice were killed.

Upon reperfusion mice were administered intraperitoneally (i.p.) with $30 \mu \mathrm{g} \mathrm{Z}$-ValAla-Asp(OMe)-CH2F (zVAD-fmk) $(\mathrm{n}=20)$ dissolved in $0.3 \mathrm{ml}$ sterile PBS/1\% DMSO. A control group was treated with vehicle consisting of $0.3 \mathrm{ml}$ PBS s.c. $(n=20)$ and a sham-group $(n=12)$ was subjected to the same surgical procedure without clamping of the renal pedicle, treated with PBS and sacrificed at corresponding timepoints. Neither the solvent DMSO nor $30 \mu \mathrm{g}$ Z-Phe-Ala-Ch2F (zFA-fmk) in $1 \%$ DMSO as a negative control for the caspase inhibiting properties of $\mathrm{zVAD}$-fmk affected the outcome of performed experiments as compared to PBS treatment (data not shown). 


\section{ASSAY FOR RENAL INTERNUCLEOSOMAL DNA CLEAVAGE}

Genomic DNA was extracted from kidneys employing a commercial DNA purification kit (Wizard, Promega, Madison, WI) according to the manufacturers instructions. Internucleosomal DNA cleavage in kidneys was investigated on equal amounts of DNA as previously described (12) with a commercial ligase-mediated (LM)-PCR assay kit (Apoalert, Clontech, Palo Alto, CA) enabling semiquantitative measurement of apoptosis.

\section{RT-PCR FOR MURINE MIP-2 AND KC}

Total renal RNA was extracted and transcribed into cDNA of which the concentration was standardized based on the B-actin fraction. To determine renal MIP- 2 and KC mRNA content, four 2-fold serial dilutions of cDNA were amplified with specific primers (synthesized by Eurogentec, Seraing, Belgium), which were as follows: MIP-2 sense $5^{\prime}$-TGCCGGCTCCTCAGTGCTG-3' and MIP-2 antisense 5'-AAACTTTTTGACCGCCCTTGA-3'; KC sense 5'-CGCTCGCTTCTCTGTGCA-3' and KC antisense 5'-ATTTTCTGAACCAAGGGAGCT-3'. After separation on $1.2 \%$ agarose gel, PCR products were estimated by imaging ethidium bromide luminescence with a CCD camera.

RENAL MYELOPEROXIDASE (MPO), BLOOD UREA NITROGEN (BUN) AND SERUM CREATININE

To quantify the extent of renal neutrophil accumulation, renal MPO content was determined as described previously (11). BUN content and serum creatinine were measured in serum obtained by orbital puncture at the time of sacrifice using a BUN unimate 5 kit and a CREA MPR3 kit (Boehringer Mannheim, Mannheim, Germany) in a Cobas Fara autoanalyzer (Roche, Basle, Switzerland).

\section{MIP-2 AND KC IMMUNOHISTOLOGY}

Specimens of harvested kidneys were immediately fixed in buffered formaline and paraffin embedded. Sections $(5 \mu \mathrm{m})$ were pretreated for $10 \mathrm{~min}$ with PBS containing $0.03 \%$ $\mathrm{H} 2 \mathrm{O} 2$ and staining for MIP-2 and KC was performed with the appropriate polyclonal $\mathrm{Ab}$. Peroxidase-labeled goat anti-rabbit IgG was used as a secondary detection mAb and 3amino-9-ethylcarbazole (AEC) as a substrate, followed by a hematoxylin counterstain. No significant staining was detected in slides incubated with control rabbit serum instead of the primary detecting $\mathrm{Ab}$. 
WESTERN BLOT ANALYSIS OF EMAP-II ACTIVATION

Frozen samples of harvested kidneys were homogenized and prepared as described previously (3). $35 \mu \mathrm{g}$ protein per lane was electrophoresed in 15\% SDS/PAGE, proteins were transferred to nitrocellulose membranes, which were blocked with PBS/5\% nonfat dry milk and incubated for $3 \mathrm{~h}$ with EMAP-II antiserum (diluted 1:2000 in PBS/0.1\% Tween 20). After washings, membranes were incubated for $2 \mathrm{~h}$ with peroxidase-labeled goat anti-rabbit IgG, washed and developed by enhanced chemiluminescence.

\section{STATISTICS}

Data are expressed the mean \pm SEM, and statistical analysis was performed by Student's T-test. $\mathrm{p}<0.05$ was taken to denote statistical significance.

\section{RESULTS AND DISCUSSION}

Various cell types that are present in the kidney are able to produce $\mathrm{CXC}$ chemokines like KC and MIP-2, including tubular cells (13), monocytes (14) and mesangial cells (15). To study the involvement of chemokines produced by these cells during $I / R$, we evaluated renal KC and MIP-2 production at the transcriptional, and at the protein level. As compared to sham controls, renal $\mathrm{KC}$ mRNA levels increased after $\mathrm{I}$ and $2 \mathrm{~h}$ of reperfusion (Figure $1)$, which is in line with previous observations $(5,6)$. In addition, coinciding with $\mathrm{KC}$ mRNA up-regulation, increased levels of renal MIP-2 mRNA were detected (Figure 1). Similar to sham controls, renal KC and MIP-2 protein were not discernable by immunohistology at these timepoints (data not shown). Starting from $4 \mathrm{~h}$ of reperfusion, $\mathrm{KC}$ and MIP-2 mRNA additionally increased, reaching peak levels at $6 \mathrm{~h}$ (Figure 1). At that time, immunohistology revealed the presence of extracellular KC (Figure 2B) and MIP-2 (Figure $2 \mathrm{C}$ ) in the proximity of tubular epithelial cells of the outer stripe of the outer medulla, which was absent in sham controls (Figure 2A). After $16 \mathrm{~h}$ of reperfusion, KC and MIP- 2 mRNA was still increased as compared to sham controls, however to a lesser extent as compared to kidneys obtained after $6 \mathrm{~h}$ (Figure 1). These findings for the first time reveal the timecourse of KC and MIP-2 induction in the development of inflammation following renal I/R.

Next, we investigated the effect of I/R on proteolytic EMAP-II activation by Westernblotting. It has been shown that active EMAP-II can induce the CXC chemokine IL- 8 in vitro (8). After $1 \mathrm{~h}$ of reperfusion, no apparent EMAP-II activation was found (Figure 3). However after $2 \mathrm{~h}$, enhanced cleavage of the $43 \mathrm{kDa}$ EMAP-II precursor was observed (Figure 3), resulting in appearance of the active $23 \mathrm{kDa}$ cleavage product, which remained detectable until $24 \mathrm{~h}$ of reperfusion, confirming previous results (3). The present findings show additional chemokine induction between 2 and $6 \mathrm{~h}$ of renal reperfusion. This sequence of events suggests that EMAP-II activation, a caspase-dependent process 
observed after as early as $2 \mathrm{~h}$ of reperfusion, is functionally involved in $\mathrm{L} / \mathrm{R}$-induced CXC chemokine induction. Such involvement could explain the therapeutic efficacy of caspase inhibition in preventing I/R-induced inflammation as reported previously (3).

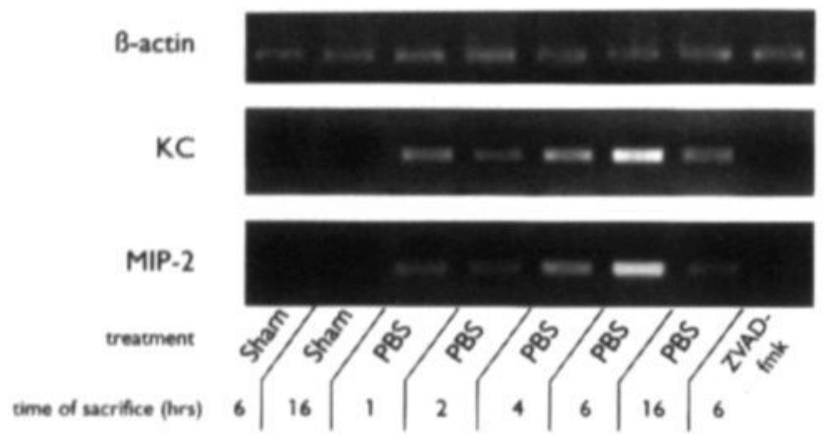

Figure 1. Renal KC and MIP-2 mRNA levels. Increased renal mRNA for both chemokines was detected after $\mathrm{I}$ and $2 \mathrm{~h}$ of reperfusion. From $2 \mathrm{~h}$ of reperfusion KC and MIP-2 mRNA levels additionally increased, reaching peak levels at $6 \mathrm{~h}$ and decreased again after $16 \mathrm{~h}$. Significant chemokine mRNA expression was neither detected in mice treated with ZVAD-fmk upon reperfusion nor in sham controls. Shown are representative samples of samples calibrated against equal amounts of $\beta$-actin mRNA.

Pro-EMAP-II has been shown to be a substrate for activated caspases $(9,10)$. We therefore studied the mechanisms by which caspase activation contributes to I/R injury. The present findings reveal abrogation of EMAP-II activation after $2 \mathrm{~h}$ of reperfusion in mice that were administered zVAD-fmk upon reperfusion (Figure 3 ). The involvement of EMAP-II in CXC chemokine induction after $\mathrm{I} / \mathrm{R}$, is supported by the present observation that zVAD-fmk abrogated also I/R-induced KC and MIP-2 mRNA up-regulation after 2 (data not shown) and $6 \mathrm{~h}$ (Figure 1) of reperfusion. Consistently, no renal KC and MIP2 protein was detected by immunohistology in ZVAD-fmk treated mice after $6 \mathrm{~h}$ of reperfusion (Figures 2D and E).

To confirm the efficacy of caspase inhibition on $\mathrm{L} / \mathrm{R}$-induced apoptosis, subsequent inflammation and organ dysfunction, we investigated the effects of zVAD-fmk on I/Rinduced renal internucleosomal DNA cleavage (a feature of apoptosis downstream of caspase activation), neutrophil influx and renal function. We observed a clear reduction in internucleosomal DNA cleavage (Figure 4) and neutrophil influx as reflected by a reduced renal MPO content (Figure 5) as well as significant renal functional improvement as reflected by decreased BUN content (Figure 6A) and serum creatinine levels (Figure $6 \mathrm{~B}$ ) in zVAD-fmk treated mice after $24 \mathrm{~h}$ of reperfusion. These results confirm our earlier data and show that the caspase inhibitor ZVAD-fmk interferes with a crucial mechanism in the development of $\mathrm{I} / \mathrm{R}$-induced tissue damage. The functional involvement of KC and MIP-2 was previously demonstrated in the development of inflammation and tissue injury after hepatic I/R (7). Hence, in our renal I/R model, the observed 
therapeutic effect of zVAD-fmk is a likely consequence of the abrogation of chemokine induction. Interestingly, a recent report indicates that caspase inhibition induced by ZAsp-cmk pretreatment fully prevents the development of hepatic I/R injury in rats (16). In line, EMAP-II can induce chemokines as well as $\mathrm{P}$ - and E-selectin in vitro (8) and we demonstrate its activation to be a caspase-dependent process that preceeds and coincides with chemokine induction during the development of inflammation following $\mathrm{I} / \mathrm{R}$. Therefore, it is tempting to hypothesize that activated EMAP-II plays an intermediate role between $\mathrm{I} / \mathrm{R}$-induced caspase activation and inflammation.
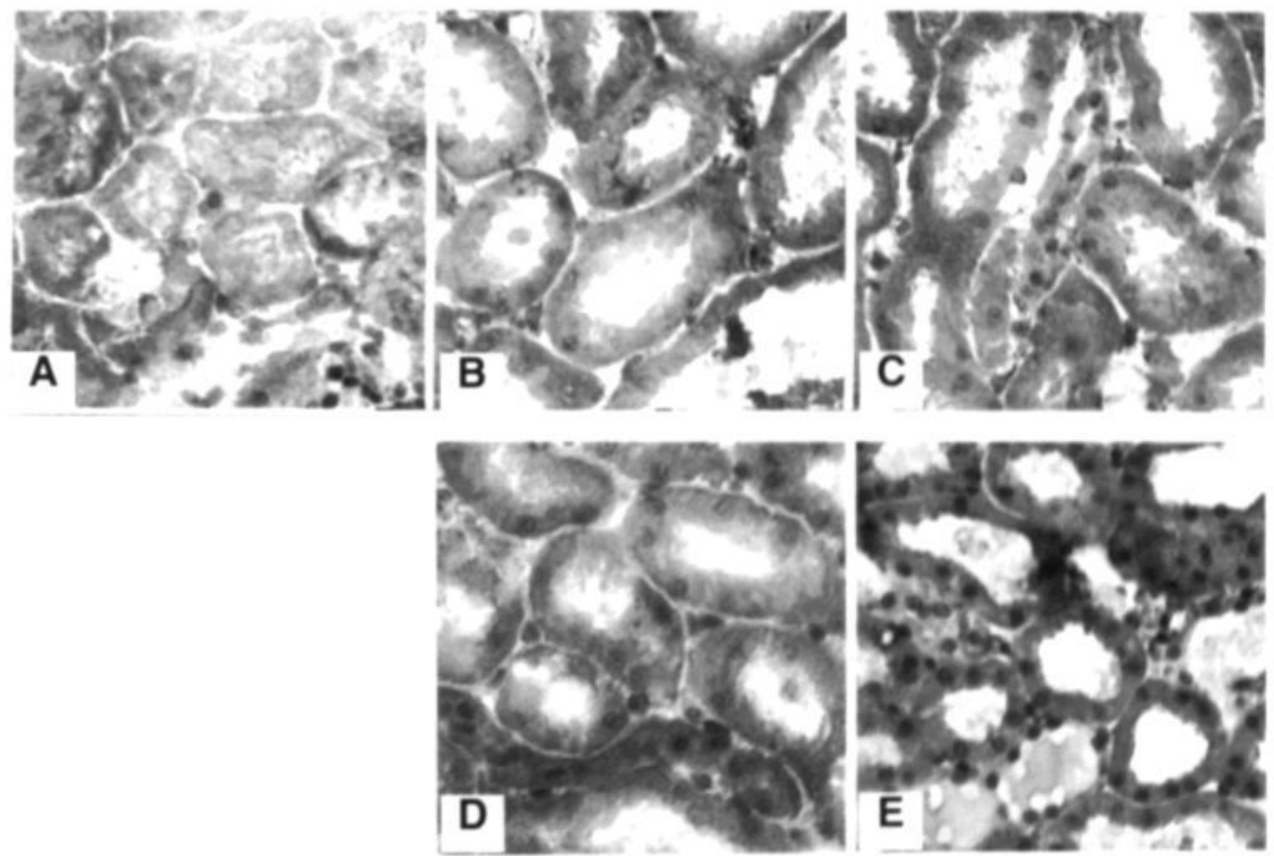

Figure 2. Representative immunohistology for renal KC and MIP-2 protein. While absent in sham controls (A), KC (B) as well as MIP-2 (C) could be clearly detected extracellularly in the proximity of tubular epithelial cells of the outer stripe of the outer medulla. Mice treated with zVAD-fmk upon reperfusion failed to show significant renal KC (D) or MIP-2 (E) expression. (magnification was $\times 250$ ).

Several hypothesis may explain apoptosis induced inflammation during I/R. Caspase-1 mediated IL-1 $\beta$ (17) and IL-18 (18) release may occur during apoptosis in vivo. However, neither neutralization of IL-1 (19) nor IL-18 (20) significantly attenuated inflammation after renal $\mathrm{I} / \mathrm{R}$. Alternatively, insufficient local phagocytotic capacity to clear apoptotic cells has been associated with subsequent necrosis, a process termed "secondary necrosis" (21). Since discrimination between apoptosis and necrosis in vivo, seldom yields conclusive results $(22,23)$, it is difficult to estimate the contribution of secondary necrosis to I/R-induced inflammation in the employed model. 
Our findings suggest that chemokines are important intermediates between apoptosis and initiation as well as perpetuation of inflammation after I/R. The chemokine EMAP-II is processed and released upon the induction of apoptosis in vivo and in vitro (9). In line, pro-EMAP-II is activated by caspase-7 (10), a prominent apoptotic effector caspase (24) and the peptide sequence of active EMAP-II exhibits strong homology with other proinflammatory mediators (25). Moreover, it was shown that pro-apoptotic mediators can cleave aminoacyl-tRNA synthetase, leading to release of the pro-inflammatory $\mathrm{NH}_{2}$-terminal catalytic domain of tyrosyl tRNA synthetase (mini-TyRS)(26), demonstrating the existence of different pro-inflammatory aspects of apoptosis that potentially contribute to I/R injury.

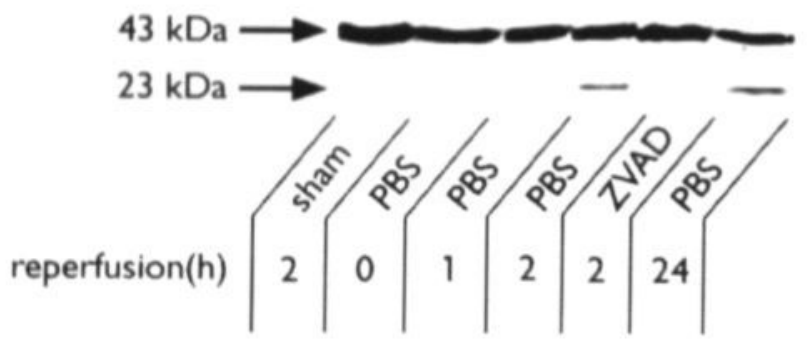

Figure 3. Representative Western blots showing intrarenal EMAP-II activation. 43 kDa proEMAP-II was constitutively present in all samples. After 2 as well as $24 \mathrm{~h}$ of reperfusion 23 kDa active EMAP-II was detected in PBS treated mice subjected to renal I/R. Conversely, active EMAP-II was neither detected in mice treated with zVAD-fmk upon reperfusion nor in sham controls after $2 \mathrm{~h}$ of reperfusion.

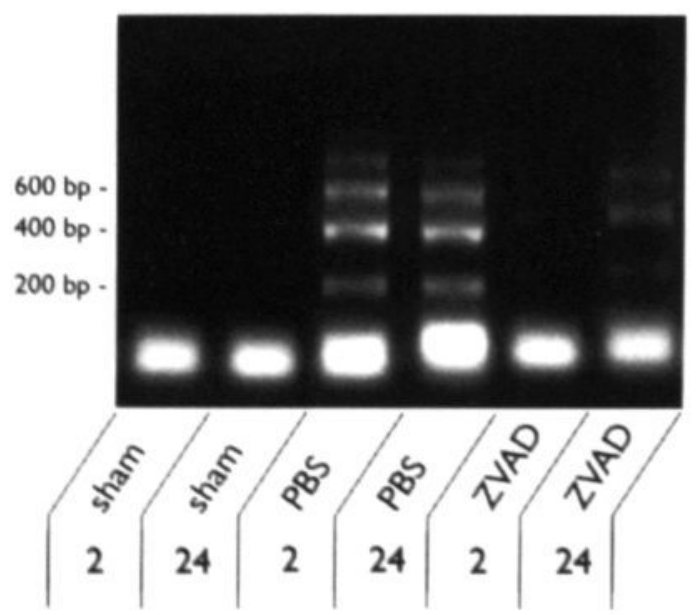

Figure 4. The extent of renal apoptosis in different treatment groups is also reflected by the presence of fragmented DNA (as a result of internucleosomal DNA cleavage) amplified by LM-PCR and visualized on ethidium-bromide stained gel. Base pairs (bp) are indicated. 


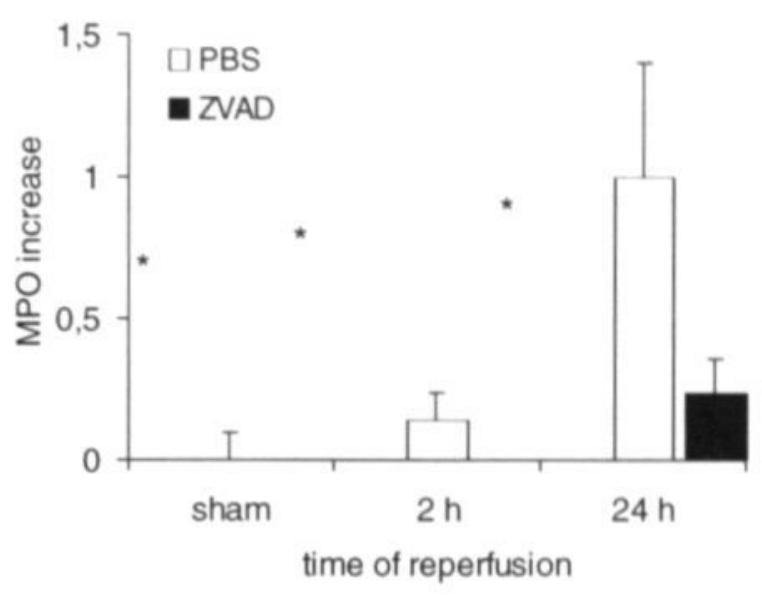

Figure 5. Neutrophil influx was assessed quantitatively by determination of MPO increase at 2 and $24 \mathrm{~h}$ of reperfusion. Values are presented relative to the amount of MPO present in the contralateral kidney harvested immediately after reperfusion and normalized with respect to the MPO increase at $24 \mathrm{~h}$ in PBS treated mice subjected to I/R. Statistical significance as compared to PBS controls was denoted at $\mathrm{p}<0.05\left({ }^{*}\right)$. The presented data are means \pm SEM

In summary, our findings associate apoptosis with liberation of pro-inflammatory mediators and for the first time show that chemokine-induction during $\mathrm{I} / \mathrm{R}$ is dependent on caspase activation. Caspase inhibitors such as zVAD-fmk, Z-Asp-cmk (16) and insulinlike growth factor-I (3) may provide novel means to treat conditions complicated by $\mathrm{I} / \mathrm{R}$ injury (27). Elucidation of the full contribution to I/R pathogenesis of EMAP-II, miniTyRS, and other pro-inflammatory mediators that are liberated during apoptosis awaits the development of specific neutralizing agents directed against these factors. This could then yield a better mechanistic insight, which is necessary to effectively and specifically prevent clinical manifestations of $\mathrm{L} / \mathrm{R}$ injury, including complications arising from the use of ischemically damaged donor organs, cardiopulmonary bypass surgery, aortic crossclamping and circulatory shock. 

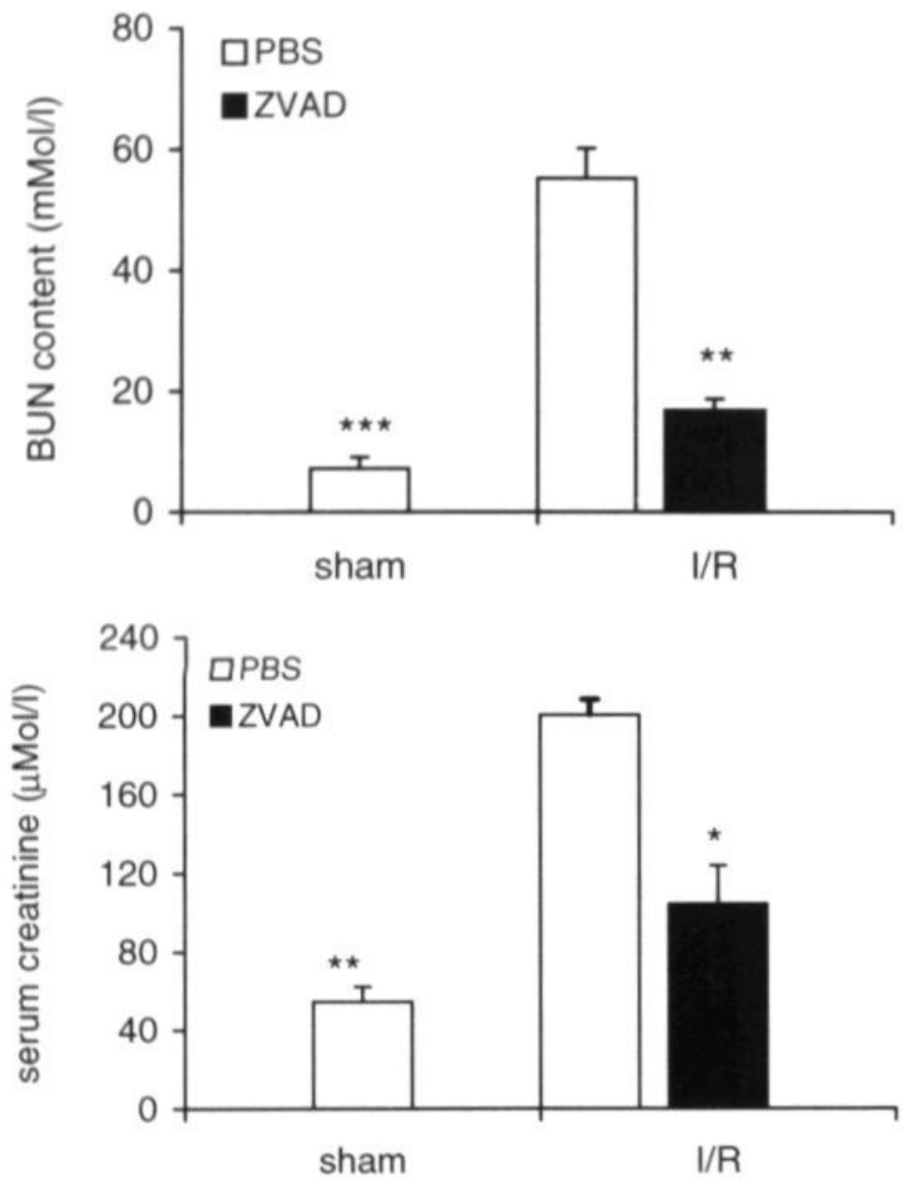

Figure 6. Renal function after $24 \mathrm{~h}$ in the different experimental groups as reflected by blood urea nitrogen (BUN) (A) and creatinine (B) content. Statistical significance as compared to PBS treated animals was denoted at $\mathrm{p}<0.05\left({ }^{*}\right)$. The data shown are means \pm SEM.

\section{REFERENCES}

1. Takada M, Nadeau KC, Shaw GD, Marquette KA, Tilney NL. The cytokine adhesion molecule cascade in ischemia/reperfusion injury of the rat kidney: Inhibition by a soluble P selectin ligand. J Clin Invest 1997; 99: 2682.

2. Linas SL, Whittenburg D, Parsons PE. Repine JE. Mild renal ischemia activates primed neutrophils to cause acute renal failure. Kidney Int 1992; 42: 610 .

3. Daemen MARC, Van ' $t$ Veer C, Denecker G. Heemskerk VH, Wolfs TGAM, Clauss M. Vandenabeele P. Buurman WA. Inhibition of apoptosis induced by ischemia-reperfusion prevents inflammation. J Clin Invest 1999; 104: 541. 
4. Klausner JM, Paterson IS, Goldman G, Kobzik L, Rodzen C, Lawrence R, Valeri CR, Shepro D, Hechtman HB. Postischemic renal injury is mediated by neutrophils and leukotrienes. Am J Physiol 1989; 256: F794.

5. Chiao H, Foster S, Thomas R, Lipton J, Star RA. Alpha-melanocyte-stimulating hormone reduces endotoxin-induced liver inflammation. J Clin Invest 1996; 97: 2038.

6. Safirstein R, Megyesi J, Saggi SJ, Price PM, Poon M, Rollins BJ, Taubman MB. Expression of cytokine-like genes JE and $\mathrm{KC}$ is increased during renal ischemia. Am J Physiol 1991; 261: F1095.

7. Lentsch AB, Yoshidome H, Cheadle WG, Miller FN, Edwards MJ. Chemokine involvement in hepatic ischemia/reperfusion injury in mice: roles for macrophage inflammatory protein-2 and KC. Hepatology 1998; 27: 1172.

8. Kao J, Houck K, Fan Y, Haehnel I, Libutti SK, Kayton ML, Grikscheit T, Chabot J, Nowygrod R, Greenberg S. Characterization of a novel tumor-derived cytokine. Endothelial-monocyte activating polypeptide II. J Biol Chem 1994; 269: 25106.

9. Knies UE, Behrensdorf HA, Mitchell CA, Deutsch U, Risau W, Drexler HC, Clauss M. Regulation of endothelial monocyte-activating polypeptide II release by apoptosis. Proc Natl Acad Sci USA 1998; 95: 12322.

10. Behrensdorf HA, Van de Craen M, Knies UE, Vandenabeele P, Clauss M. The endothelial monocyte-activating polypeptide II (EMAP II) is a substrate for caspase-7. FEBS Lett 2000; 466: 143.

11. Daemen MARC, Van de Ven WCM, Heineman E, Buurman WA. Involvement of endogenous interleukin-10 and tumor necrosis factor-alpha in renal ischemia-reperfusion injury. Transplantation 1999; 67: 792 .

12. Staley K, Blaschke AJ, Chun J. Apoptotic DNA fragmentation is detected by a semiquantitative ligation-mediated PCR of blunt DNA ends. Cell Death Differ 1997; 4: 66.

13. Von Asmuth AE, Dentener MA, Ceska M, Buurman WA. IL-6, IL-8 and TNF production by cytokine and lipopolysaccharide-stimulated human renal cortical epithelial cells in vitro. Eur Cytokine Netw 1994; 5: 301.

14. Kopydlowski KM, Salkowski CA. Cody MJ, Van Rooijen N, Major J, Hamilton TA, Vogel SN. Regulation of macrophage chemokine expression by lipopolysaccharide in vitro and in vivo. $J$ Immunol 1999; 163: 1537.

15. Luo Y, Lloyd C, Gutierrez RJ, Dorf ME. Chemokine amplification in mesangial cells. J Immunol 1999; 163: 3985

16. Cursio R. Gugenheim J. Ricci JE. Crenesse D, Rostagno P, Maulon L, Saint PM, Ferrua B. Auberger AP. A caspase inhibitor fully protects rats against lethal normothermic liver ischemia by inhibition of liver apoptosis. FASEB J 1999: 13: 253.

17. Miwa K. Asano M. Horai R. Iwakura Y. Nagata S, Suda T. Caspase I-independant IL- I $\beta$ release and inflammation induced by the apoptosis inducer Fas ligand. Nature Med 1998; 4: 1287.

18. Saha N, Moldovan F, Tardif G. Pelletier JP. Cloutier JM. Martel PJ. Interleukin-1 $\beta$-converting enzyme/caspase- 1 in human osteoarthritic tissues: localization and role in the maturation of interleukin-1 $\beta$ and interleukin-18. Arthritis Rheum 1999; 42: 1577.

19. Haq M. Norman J, Saba SR. Ramirez G, Rabb H. Role of IL-I in renal ischemic reperfusion injury. J Am Soc Nephrol 1998: 9: 614.

20. Daemen MARC, Van 't Veer C. Wolfs TGAM. Buurman WA. Ischemia-reperfusion induced IFN-gamma upregulation: Involvement of IL-12 and IL-18. J Immunol 1999; 162: 5506.

21. Lieberthal W. Levine JS. Mechanisms of apoptosis and its potential role in renal tubular epithelial cell injury. Am J Physiol 1996: 271: F477. 
22. Farber E. Programmed cell death: necrosis versus apoptosis. Mod Pathol 1994; 7: 605.

23. Columbano A. Cell death: current difficulties in discriminating apoptosis from necrosis in tie context of pathological processes in vivo. J Cell Biochem 1995; $58: 181$.

24. Stennicke HR, Salvesen GS. Biochemical characteristics of caspases-3, -6, -7, and -8. J Bil Chem 1997: 272: 25719.

25. Clark LI, Schumacher C, Baggiolini M, Moser B. Structure-activity relationships of interleuki8 determined using chemically synthesized analogs. Critical role of $\mathrm{NH} 2$-terminal residues ard evidence for uncoupling of neutrophil chemotaxis, exocytosis, and receptor binding activities $J$ Biol Chem 1991; 266: 23128.

26. Wkasugi K. Schimmel P. Two distinct cytokines released from a human aminoacyl-tRNA sylthetase. Science 1999; 284: 147.

27. Deigner HP, Kinscherf R. Modulating apoptosis: current applications and prospects for futue drug development. Curr Med Chem 1999; 6: 399. 


\section{CHAPTER $\mathbf{8}$}

Release of heart fatty-acid binding protein from damaged renal cells of the rat: potential as an early marker for mild ischemia-reperfusion injury

Jur K. Kievit, Marc A.R.C. Daemen, Maurice M.A.L. Pelsers, Gauke Kootstra, Jan F.C. Glatz, and Wim A. Buurman 


\section{ABSTRACT}

Heart-type fatty acid-binding protein (H-FABP) is a small $(15 \mathrm{kDa})$ cytoplasmatic protein present in cardiomyocytes, but also in renal tubular cells. Plasma H-FABP is used as a sensitive marker for early detection of myocardial infarction. The aim of this study was to evaluate $\mathrm{H}-\mathrm{FABP}$ in a rat model as a marker for renal ischemia/reperfusion (I/R) injury, in comparison to the marker proteins total Glutathione S-Transferase (GST) and LDH.

Female Lewis rats $(250-300 \mathrm{~g})$ were anaesthetized and canulated in the right femoral artery. Subsequently, a laparotomy was performed and warm ischemia was induced to the left kidney by cross-clamping the renal vessels for 0 (sham), 20, 40 or $60 \mathrm{~min}$, followed by reperfusion. Each group consisted of 6 rats. Blood samples $(0.5 \mathrm{ml})$ were drawn after $0,15,30,60$ and $120 \mathrm{~min}$ of reperfusion. H-FABP was analyzed with a rapid, one step sandwich ELISA and LDH and GST were analyzed enzymatically. After sacrifice, rat kidneys were harvested for histological analysis.

Immunohistochemical staining of rat kidney showed H-FABP presence in distal tubular cells. From 15 min onwards after reperfusion, mean H-FABP plasma levels were significantly increased in the 20,40 and $60 \mathrm{~min}$ WIT groups compared to the sham group $(\mathrm{p}<0.05)$. GST and LDH levels were only significantly raised in the $60 \mathrm{~min}$ WIT group, starting 15 and $60 \mathrm{~min}$ after reperfusion, respectively.

The results indicate that plasma LDH and GST reliably detect severe renal I/R injury in respectively the late and early reperfusion phase, but fail to detect mild $I / R$ injury. Plasma H-FABP reliably detects mild as well as severe $\mathrm{I} / \mathrm{R}$ injury in the early reperfusion phase. The data suggest the usefulness of plasma H-FABP as a viability test during machine perfusion of NHB donor kidneys.

\section{INTRODUCTION}

Implementation of a non-heart-beating (NHB) donor program is often considered the most promising approach towards solving the problem of donor kidney shortage (1). However, kidneys from NHB donors inevitably suffer warm ischemic injury starting immediately after cessation of cardiac action, lasting until (in situ) cooling with a cold perfusate is applied (2). As a result of the relatively long warm ischemic period NHB donor kidneys are more susceptible to ischemia-reperfusion (I/R) injury after transplantation than kidneys from heartbeating donors. This difference has been reported to be a result of, among others, free oxygen radical formation, apoptosis and inflammation (3-6).

Insight into the extent of ischemic injury inflicted on a donor kidney before transplantation is of crucial importance. However, in the clinical situation the duration of the ischemic episode is often unclear. Additionally, prolonged hypotension or hypoxia of unknown duration can inflict substantial but difficult to estimate damage during reperfusion. 
Heart-type fatty acid-binding protein (H-FABP) is a small $(15 \mathrm{kDa})$ cytoplasmatic protein involved in subcellular transport of long-chain fatty acids $(7,8)$. H-FABP shows a tissue specific distribution and is present not only in heart and skeletal muscles, but also in kidney, both in human and rat $(9,10)$. Due to its small size H-FABP has proven to be a sensitive marker in the early detection of acute myocardial infarction, with a better performance of H-FABP over myoglobin and CK-MB(11). The aim of this study was to investigate whether H-FABP release from ischemically damaged rat kidneys can be employed as a reliable plasma marker of ischemia-reperfusion damage. To this end, $\mathrm{H}$ FABP plasma levels were compared with standard markers of renal cell injury in a rat model.

\section{MATERIALS AND METHOdS}

\section{EXPERIMENTAL PROTOCOL}

Female inbred Lewis rats with an average weight of $300 \mathrm{~g}$, housed and fed under standard laboratory conditions were used. All experiments performed were approved by the institutional Experimental Animal Care Committee of the University of Maastricht. Rats were anaesthetized with pentobarbital $(6 \mathrm{mg} / 100 \mathrm{~g}$ bodyweight in saline i.p.). After shaving the abdomen, right groin and neck, rats were placed on a heating pad. Body temperature was monitored continuously with a rectal thermometer and maintained at $37^{\circ} \mathrm{C}$ throughout the procedure. Subsequently, the right femoral artery was cannulated with a polyethylene (PE10) catheter, which was tunneled subcutaneously to the neck and filled with heparanized saline. After closure of the incision in the right groin, a median laparotomy was performed and the left renal artery and vein were cross-clamped atraumatically for 0 ( sham, group I, n=6), 20 (group II, n=6), 40 (group III, n=6) or 60 (group IV, n=6) min, followed by removal of the clamp to initiate reperfusion. Quality of ischemia was checked 5 min after cross-clamping by assessing the aspect of the ischemic kidney. Similarly, quality of reperfusion was checked $5 \mathrm{~min}$ after removal of the clamp. After closure of the laparotomy wound, the rats were allowed to recover from anesthesia. Blood samples $(0.5 \mathrm{ml})$ were collected in citrate tubes from the arterial catheter immediately before reperfusion (T0), and at 15, 30,60 and $120 \mathrm{~min}$ after reperfusion (Figure 1). Preliminary results showed a marked a-specific increase off each of the markers after more than 120 min of reperfusion, also in the sham group (results not shown). All samples were replaced immediately with an equal volume of heparanized saline $(10 \mathrm{IU} / \mathrm{ml})$. Rats were supplemented with pre-warmed saline to maintain fluid balance and had free access to water and food. Eight hours after reperfusion rats were sacrificed and both left and right kidney were immediately removed for histological analysis. 


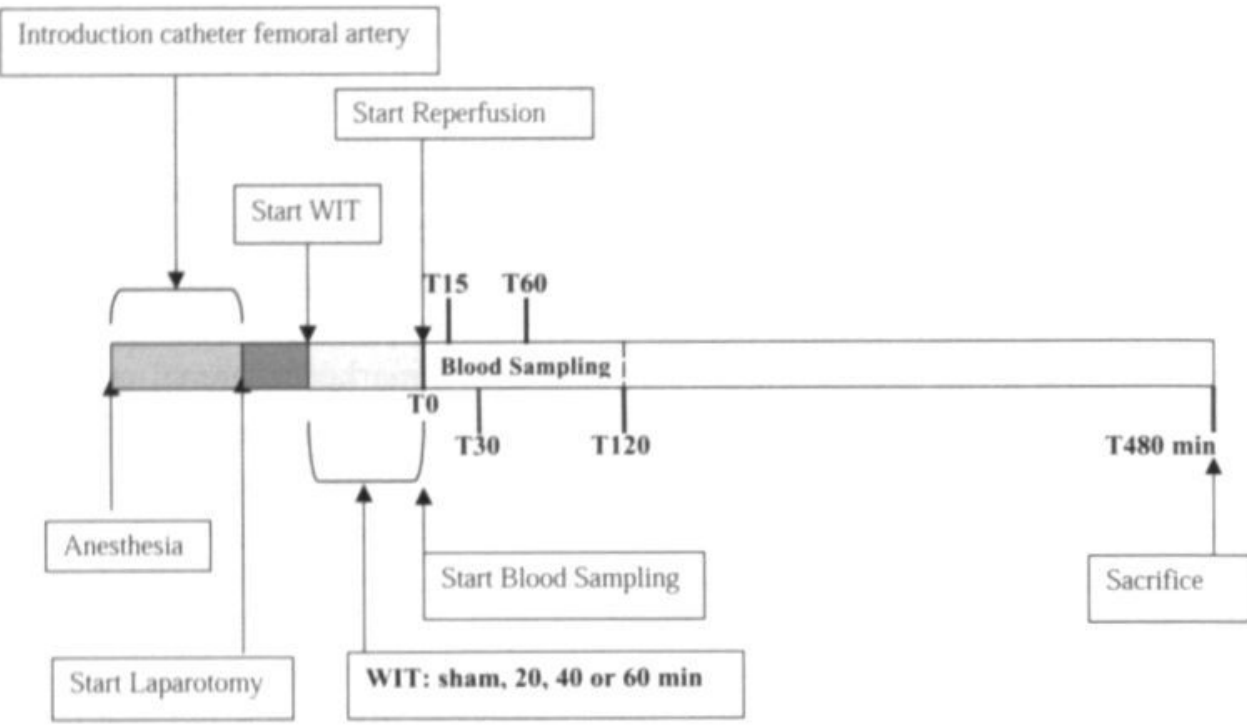

Figure 1. Schematic representation of the study design.

\section{HISTOLOGY}

Specimens of harvested kidneys were immediately fixed in buffered formaline and paraffin embedded. Sections $(5 \mu \mathrm{m})$ were stained for H-FABP with mAb 67D3 (a mouse antirat IgG, kindly provided by Hycult biotechnology b.v., Uden, the Netherlands) using peroxidase-labeled goat anti-rat IgG (Jackson, West Grove, PA) as the secondary detection $\mathrm{mAb}$ and 3-amino-9-ethylcarbazole (AEC) (Sigma, St. Louis, MO) as a chromogen. To block aspecific peroxidase activity sections were pretreated for $10 \mathrm{~min}$ with PBS containing $0.03 \% \mathrm{H} 2 \mathrm{O} 2$. No significant staining was detected in slides incubated with control $\mathrm{mAb}$ instead of the primary detecting $\mathrm{mAb}$.

\section{ANALYSIS OF EXPERIMENTAL PARAMETERS}

LDH was determined using a standard colorimetric assay (Boehringer Mannheim, Almere, The Netherlands). Plasma GST was measured by assessing the ability of GST to catalyze the conversion of chlorodinitrobenzene (CDNB) (Sigma) and glutathion (GSH) (Sigma) into GS-dinitrobenzene and $\mathrm{HCl}$. GS-dinitrobenzene formation represents GST activity and was kinetically analyzed spectrophotometrically $(340 \mathrm{~nm})$ on a Cobas Bio system (F. Hoffmann La-Roche, Basel, Switzerland).

For H-FABP detection a commercially available ELISA kit (kindly provided by Hycult biotechnology b.v., Uden, the Netherlands) was used according to the manufacturers 
instructions. The assay employs high-affinity monoclonal antibodies to human H-FABP which cross-react with rat H-FABP. Rat H-FABP was used as calibrator.

\section{STATISTICS}

Statistical significance for differences between groups was calculated with a non-parametric Mann-Whitney $U$ test and $\mathrm{p}<0.05$ was considered significant.

\section{RESULTS}

\section{H-FABP IS PRESENT IN TUBULAR EPITHELIAL CELLS}

H-FABP was reported earlier to be localized in tubular epithelial cells of the rat kidney $(9,10)$. In order to confirm the presence of H-FABP in the rat kidney, paraffin embedded sections of normal rat kidney were studied by immunohistology. Positive immunostaining for $\mathrm{H}-\mathrm{FABP}$ was present in the cytosol of proximal tubular cells, however less prominent compared to distal tubular epithelial cells (Figure 2A). H-FABP was not detected in glomeruli or vascular endothelial cells. No significant staining was detected in slides incubated with control mAb instead of the primary detecting mAb (Figure 2B). These results indicate that an increase in H-FABP blood levels due to renal damage caused by ischemia and reperfusion, if any, may be reflected by release of H-FABP from damaged renal tubular cells. In order to confirm substantial damage to renal rat tissue inflicted by $\mathrm{I} / \mathrm{R}$ in the experimental groups, sections of paraffin embedded rat kidney exposed to 60 min of warm ischemia followed by 8 hours of reperfusion were PAS stained. In concordance with other experimental models of renal I/R injury (6), cross-sections showed an overall dilatation of proximal convoluted tubuli, intraluminal tubular debris, loss of tubular brush border membrane integrity, patchy necrosis and detachment of proximal as well as distal tubular cells from supporting basement membranes (Figure 2C). Sections of kidneys not exposed to warm ischemia showed no histological damage (Figure 2D).

\section{LDH AND GST DETECT SEVERE I/R INJURY ONLY}

The extent of $\mathrm{I} / \mathrm{R}$ damage was first assessed by measuring plasma LDH and GST levels. LDH plasma levels showed a considerable overlap for the 4 groups of rats up to $60 \mathrm{~min}$ after reperfusion (Figures 3A, 4A). Only in case of severe ischemic damage (60 min WIT) LDH was significantly enhanced in contrast to the sham, 20 and $40 \mathrm{~min}$ WIT groups, but not earlier than after $60 \mathrm{~min}$ of reperfusion $(\mathrm{p}=0.002)$ (Table 1). The high baseline level of $\mathrm{LDH}$, also found in the sham group, limited the sensitivity of this parameter. Similarly, GST levels showed a high baseline level, and a modest increase during the $120 \mathrm{~min}$ reperfusion phase (Figures 3B, 4B). Only for the longest WIT of $60 \mathrm{~min}$ a 
significant increase of GST was seen from 15 min after reperfusion ( $\mathrm{p}=0.026)$ onwars (Table 1). These findings indicate that plasma LDH and GST detect severe I/R injury n the late and early reperfusion phase respectively, but each fail to detect mild $\mathrm{I} / \mathrm{R}$ injury
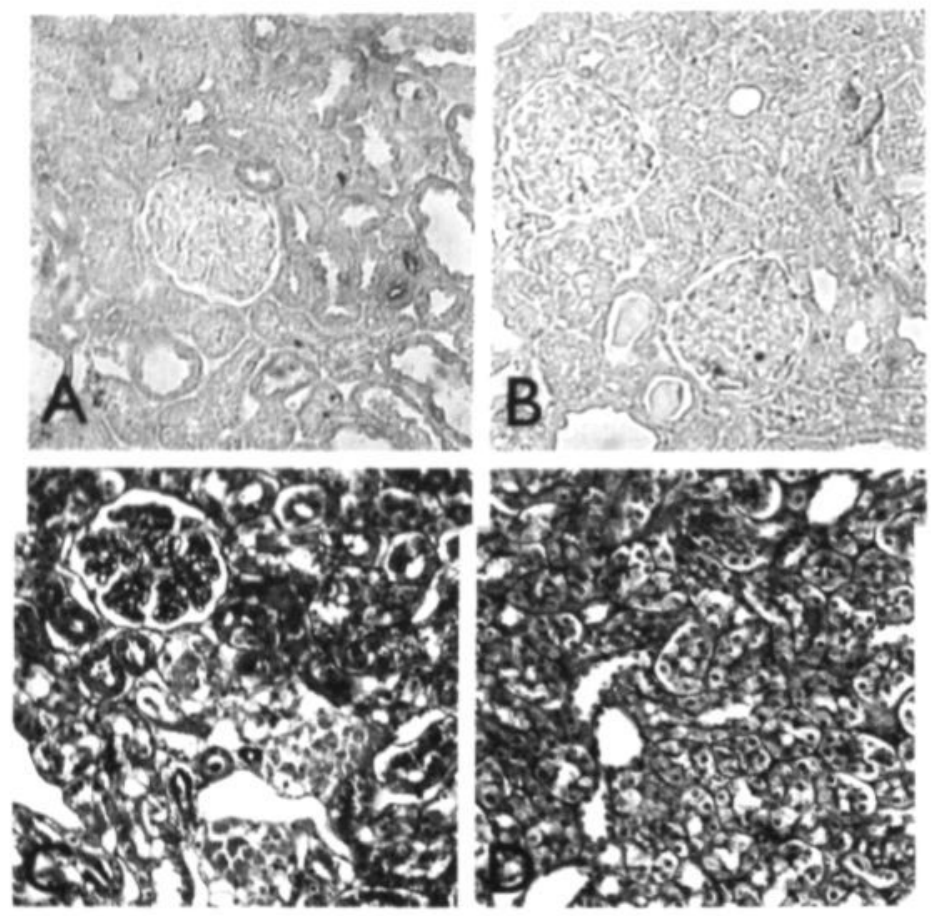

Figure 2. Sections of harvested rat kidneys fixed in buffered formaline were stained for H-FABP. Positive immunostaining for H-FABP was present in the cytosol of proximal tubular cells, however less prominent compared to distal tubular epithelial cells. H-FABP was not detected in glomeruli or vascular endothelial cells $(\mathbf{A})$. No significant staining was detected in slides incubated with control $\mathrm{mAb}$ instead of the primary detecting $\mathrm{mAb}(\mathbf{B})$. Sections of paraffin embedded rat kidney exposed to $60 \mathrm{~min}$ of warm ischemia followed by 8 hours of reperfusion were PAS stained. Cross-sections showed an overall dilatation of proximal convoluted tubuli, intraluminal tubular debris, loss of tubular brush border membrane integrity, patchy necrosis and detachment of proximal as well as distal tubular cells from supporting basement membranes (C). Sections of kidneys not exposed to warm ischemia showed no histological damage (D).

\section{EARLY DETECTION OF MILD I/R INJURY BY H-FABP}

In order to determine the usefulness of the low molecular-weight cytoplasmatic protein $\mathrm{H}-\mathrm{FABP}$ to detect renal $\mathrm{I} / \mathrm{R}$ damage, we measured plasma H-FABP levels in the various groups. H-FABP levels in all 4 groups start at a relatively low base-line level with a very narrow distribution (mean $25^{\text {th }}$ and $75^{\text {th }}$ percentile 2.9 and $5.5 \mu \mathrm{g} / \mathrm{L}$ respectively)(Figures 
3C, 4C). After unclamping of the renal vessels, all 3 ischemic groups, show a significant increase in H-FABP level as early as after $15 \mathrm{~min}$ of reperfusion $(\mathrm{p}=0.016,0.004$ and 0.004 for WIT of 20,40 and 60 min respectively) (Table 1). At successive sample times, H-FABP levels in the 20, 40 and 60 min WIT groups were significantly increased compared to the sham group. Mutual comparison of the 3 experimental groups showed no significant difference in H-FABP between the 20 and 40 min WIT groups $(p=0.15)$, but clearly between the 20 and $60 \mathrm{~min}$ WIT $(p=0.006)$ and the 40 and $60 \mathrm{~min}$ WIT $(p=0.01)$ groups. These results show that $\mathrm{H}-\mathrm{FABP}$ is a sensitive early marker of renal damage as a consequence of $\mathrm{I} / \mathrm{R}$ with little overlap between the experimental groups.

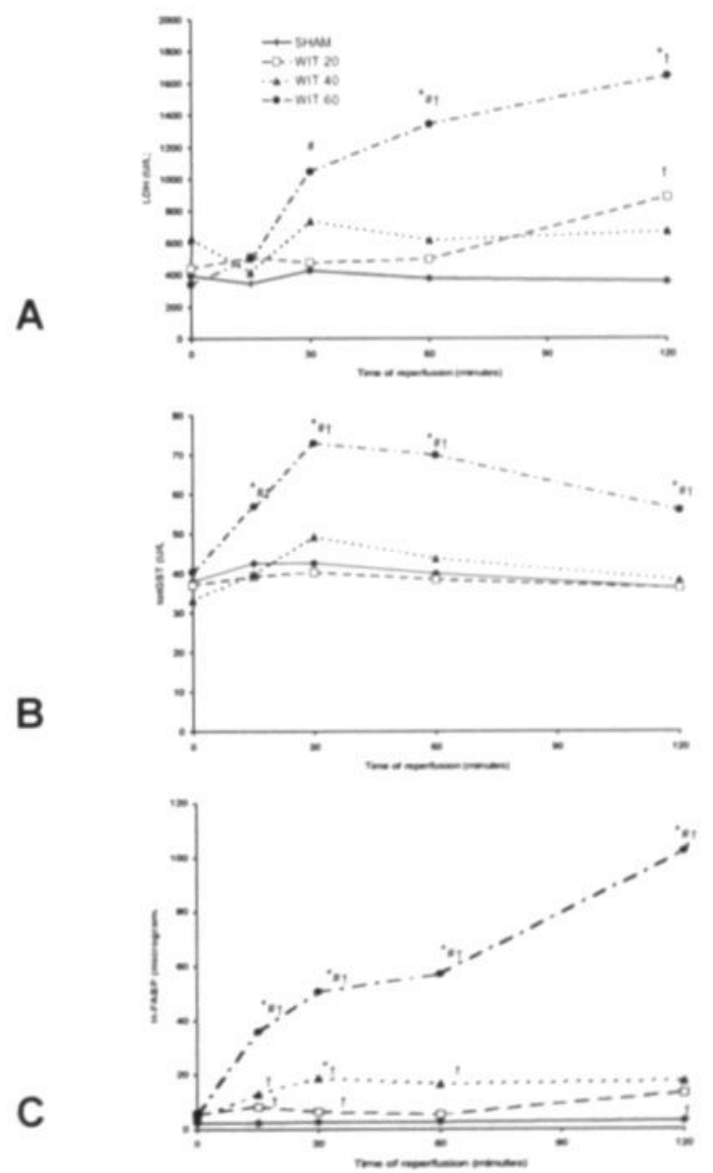

Figure 3. Mean LDH levels of all 4 WIT groups immediately before and at 4 successive sample times during reperfusion (A). Mean GST levels of all 4 WIT groups immediately before and at 4 successive sample times during reperfusion (B). Mean H-FABP levels of all 4 WIT groups immediately before and at 4 successive sample times during reperfusion (C). Significant differences in comparison with the sham, $20 \mathrm{~min}$ WIT and $40 \mathrm{~min}$ WIT groups is indicated with $*$, \# and + respectively. 

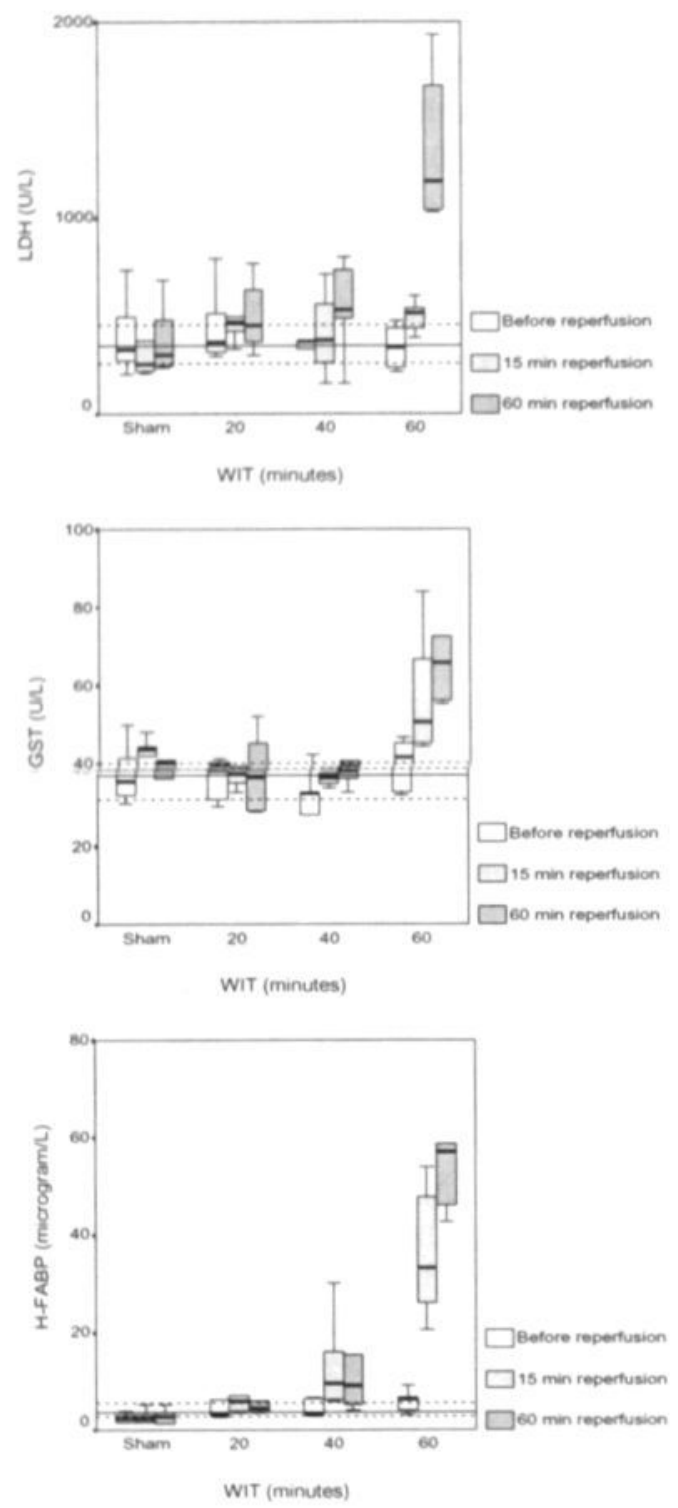

Figure 4. Boxplot of LDH values after 0, 15 and $60 \mathrm{~min}$ of reperfusion (A). Boxplot of GST values after 0,15 and $60 \mathrm{~min}$ of reperfusion (B). Boxplot of $\mathrm{H}-\mathrm{FABP}$ values after 0,15 and 60 min of reperfusion $(\mathbf{C})$. Every box holds the median levels and $25^{\text {th }}$ and $75^{\text {th }}$ percentiles (lower and upper line of each box respectively). Outer lines indicate 1.5 times the interquartile distance from the median. Baseline levels are indicated by the area between the lower and upper dashed (- horizontal lines, representing mean 25 th and 75 th percentiles respectively of all groups immediately before reperfusion. The middle (continuous) horizontal line represents average median levels of all groups immediately before reperfusion. 
Table 1. Summary of statistical analysis of LDH, GST and H-FABP plasma levels after 15, 30 , 60 and 120 minutes of reperfusion

\begin{tabular}{|c|c|c|c|c|}
\hline $\mathrm{WIT}^{1}(\mathrm{~min})$ & 15 & 30 & 60 & 120 \\
\hline 20 versus sham & $\begin{array}{l}\mathrm{H}-\mathrm{FABP}^{2} \\
-\end{array}$ & $\begin{array}{l}\mathrm{H}-\mathrm{FABP} \\
-\end{array}$ & - & $\begin{array}{l}\text { H-FABP } \\
\text { LDH }\end{array}$ \\
\hline 40 versus sham & $\begin{array}{l}\mathrm{H}-\mathrm{FABP} \\
-\end{array}$ & H-FABP & $\begin{array}{l}\mathrm{H}-\mathrm{FABP} \\
-\end{array}$ & - \\
\hline 60 versus sham & $\begin{array}{l}\text { H-FABP } \\
\text { GST }^{3} \\
\text { LDH }^{2} \quad \text { LDH }\end{array}$ & $\begin{array}{l}\text { H-FABP } \\
\text { GST }\end{array}$ & $\begin{array}{l}\text { H-FABP } \\
\text { GST }\end{array}$ & $\begin{array}{l}\text { H-FABP } \\
\text { GST }\end{array}$ \\
\hline 40 versus 20 & $\begin{array}{l}- \\
- \\
-\end{array}$ & $\begin{array}{l}\mathrm{H}-\mathrm{FABP} \\
-\end{array}$ & - & - \\
\hline 60 versus 20 & $\begin{array}{l}\text { H-FABP } \\
\text { GST }\end{array}$ & $\begin{array}{l}\text { H-FABP } \\
\text { GST } \\
\text { LDH }\end{array}$ & $\begin{array}{l}\text { H-FABP } \\
\text { GST } \\
\text { LDH }\end{array}$ & $\begin{array}{l}\text { H-FABP } \\
\text { GST }\end{array}$ \\
\hline 60 versus 40 & $\begin{array}{l}\text { H-FABP } \\
\text { GST }\end{array}$ & $\begin{array}{l}\text { H-FABP } \\
\text { GST }\end{array}$ & $\begin{array}{l}\text { H-FABP } \\
\text { GST } \\
\text { LDH }\end{array}$ & $\begin{array}{l}\text { H-FABP } \\
\text { GST } \\
\text { LDH }\end{array}$ \\
\hline
\end{tabular}

I WIT, warm ischemic time; ${ }^{2}$ H-FABP, heart fatty-acid binding protein; ${ }^{3}$ GST, Glutathione STransferase. Only significant differences $(p<0.05)$ are mentioned.

\section{DISCUSSION}

The results of this study indicate that plasma LDH and GST reliably detect severe renal $I / R$ injury in respectively the late and early reperfusion phase, but fail to detect mild $I / R$ injury. H-FABP permits detection of both mild and severe $\mathrm{I} / \mathrm{R}$ injury in the early reperfusion phase.

Many attempts towards quantification of cellular damage due to ischemia or I/R have been made. Much effort has been put into measuring the "energy charge" of renal tissue and the effect of ischemia on this system. The energy charge can either be investigated using HPLC techniques, in which the ratio of Total Adenine Nucleotides (TAN) over its Degradation Products (DP) is measured (12), or using 31P-Magnetic Resonance Spectroscopy (MRS) in which an analysis is made of the ratio of Phosphorus Mono-Esthers (PME) over inorganic Phosphorus ( $\mathrm{Pi}$ ) concentrations in renal tissue corresponding to the concentrations of AMP and free phosphorus (13). However, clinically these techniques appear to be too cumbersome. Another approach for estimating renal damage is to use 
the $\mathrm{Na}^{+} / \mathrm{K}^{+}$ratio. In vitro experiments on sections of both human and rat kidneys, analysing the release of intra-cellular $\mathrm{K} \cdot$ into the interstitium correlates with increasing cell damage, however failed to provide sufficient specific data (14). Analysis of mitochondrial function after experimental ischemic damage using a tetrazolium reduction test has been reported to be successful (15), however was not implemented as a clinical test. Also assessment of cell viability ratio using two dyes staining specifically viable or nonviable cells proved to be aspecific (16).

Machine preservation is regaining new interest as the modality of choice in order to assess renal damage prior to transplantation(17). In the past mainly the change in intrarenal vascular resistance (IRR)(18) during machine preservation and release of LDH into the perfusate (19) were analyzed. In case of unnoticed leakage of perfusate from the system connected to the renal artery or due to a poorly flushed kidney with a considerable residual amount of donor blood these tests proved less reliable. Recently measurement of release of the enzyme $\alpha$-Glutathione S-Transferase ( $\alpha$-GST) (molecular mass $45 \mathrm{kDa}$ ) proved superior over IRR and LDH release. It appeared to be the only marker that permits discrimination between kidneys with delayed onset of function (DF) and kidneys that never started to function $(\mathrm{PNF})(20,21)$. Enzymatic analyses of "total GST" in perfusate, consisting of $\alpha$-GST, $\pi$-GST, $\mu$-GST and $\sigma$-GST, provided similar results as $\alpha$-GST analysis, since almost all GST released from a kidney due to ischemic damage consists of $\alpha$-GST (22). However due to a substantial overlap in GST levels between the DF and PNF groups it is not possible to define a cut-off point for discarding or accepting a kidney for transplantation with sufficient sensitivity and specificity. Hence, over-cautious selection of supposedly suitable kidneys for transplantation may result in discarding a vast number of viable donor kidneys.

H-FABP belongs to a family of at least 9 cytoplasmatic FABP proteins with known genomic structure, each with a tissue specific distribution in human and various other species (7). Cytoplasmatic FABP's have a size of approximately $14 \mathrm{kDa}$ and function in intracellular long-chain fatty acid transport (8). In addition FABP's seem to play a role in signal transduction pathways (23) and in cell growth and differentiation (24). Release of cytoplasmatic FABP's from damaged cells was proven to be a powerful diagnostic tool for several applications. For instance in the field of cardiology analysis of H-FABP levels in plasma has proven a superior diagnostic tool in the early detection of myocardial infarction compared to other soluble proteins, such as myoglobin (18 kDa), LDH (135 $\mathrm{kDa})$ and Creatine Kinase MB $(\mathrm{CK}-\mathrm{MB}, 80 \mathrm{kDa})(11,25,26)$. This can be explained by the smaller size of $\mathrm{H}-\mathrm{FABP}(14 \mathrm{kDa})$ resulting in a more rapid extravasation and, consequently, early peak level of H-FABP compared to LDH and CK-MB (27), and by a relatively low baseline concentration of H-FABP in plasma. Likewise, intestinal FABP (I$\mathrm{FABP}$ ) has been suggested to serve as a diagnostic marker for early small-intestinal mucosal injury (28). 
In concordance with the early detection of ischemic damage to myocardial cells in rat and human, assessment of H-FABP in the present study allowed detection of mild renal $\mathrm{I} / \mathrm{R}$ injury in a very early phase, whereas GST and LDH could only detect severe ischemic damage. The small size of H-FABP compared to LDH and GST seems an important advantage and the low baseline level of H-FABP appears to be a conclusive property of this marker protein.

The present study confirmed the presence of $\mathrm{H}-\mathrm{FABP}$ in rat kidney, mainly localized in distal tubular cells. Several studies have reported a similar distribution of H-FABP in rat and human kidney $(9,10)$. Given this similarity in combination with the results of the present study, H-FABP can be potentially considered a suitable marker of early renal ischemic or I/R damage in clinical medicine. A prerequisite for successful clinical implication of a new test is a relatively rapid measurement procedure. Since the ELISA used to measure H-FABP levels requires approximately 1 hour in total (29), clinical implementation of $\mathrm{H}-\mathrm{FABP}$ as a marker protein for early renal damage due to mild ischemic or $\mathrm{I} / \mathrm{R}$ phenomena is feasible. Recently an on-line flow displacement immunoassay for H-FABP has been developed, permitting detection of both physiological and pathological plasma concentrations up to $2000 \mu \mathrm{g} / \mathrm{L}$ (30). Application of this biosensor technique has been successfully described to analyze H-FABP plasma levels within $10 \mathrm{~min}$.

The next step will be to investigate the suitability of H-FABP implementation as a sensitive marker of renal ischemic or $\mathrm{I} / \mathrm{R}$ damage in the clinical situation. Based on the present findings, we expect H-FABP release from human kidneys during hypothermic machine preservation, after ischemic injury to occur earlier and more abundantly than LDH and GST release. This could render H-FABP a marker of viability of NHB donor kidneys. Definition of a safe cut-off H-FABP level, with sufficient sensitivity and specificity for accepting or discarding a damaged kidney for transplantation should be the ultimate goal. Currently, studies to investigate H-FABP as a marker of ischemic damage to human kidneys have been initiated.

In summary, in a rodent model LDH and GST reliably detect severe renal I/R injury in the late and early reperfusion phase respectively, but fail to detect mild I/R injury. H-FABP reliably detects mild and severe $I / R$ injury in the early reperfusion phase. The small size of H-FABP, low baseline level and strong increase in level after even mild $I / R$ damage makes H-FABP a powerful marker of renal $\mathrm{I} / \mathrm{R}$ injury in the rat. Strong similarities in $\mathrm{H}$ FABP distribution between human and rat kidney have initiated studies investigating the release of $\mathrm{H}-\mathrm{FABP}$ from ischemic damaged machine preserved human kidneys, in order to assess the suitability of H-FABP as a viability test for NHB donor kidneys. 


\section{REFERENCES}

1. Cho YW, Terasaki PI, Cecka JM, Gjertson DW. Transplantation of kidneys from donors whose hearts have stopped beating. $N$ Engl J Med 1998; 338: 221.

2. Kootstra G, Kievit JK, Heineman E. The non heart-beating donor. Br Med Bull 1997; 53: 844.

3. Tilney NL, Guttman RD. Effects of ischemia/reperfusion injury on the transplanted kidney. Transplantation 1997; 64: 945.

4. Lieberthal W, Koh JS, Levine JS. Necrosis and apoptosis in acute renal failure. Semin Nephrol 1998: 18: 505 .

5. Weinberg JM. The cell biology of ischemic renal injury. Kidney Int 1991; 39: 476.

6. Daemen MARC, van de Ven MW, Heineman E, Buurman WA. Involvement of endogenous interleukin-10 and tumor necrosis factor- alpha in renal ischemia-reperfusion injury. Transplantation 1999; 67: 792.

7. Glatz JFC, van der Vusse GJ. Cellular fatty acid-binding proteins: their function and physiological significance. Prog Lipid Res 1996; 35: 243.

8. Schaap FG, Binas B, Danneberg H, van der Vusse GJ, Glatz JF. Impaired long-chain fatty acid utilization by cardiac myocytes isolated from mice lacking the heart-type fatty acid binding protein gene. Circ Res 1999; 85: 329.

9. Kimura H, Odani S, Nishi S, Sato H, Arakawa M, Ono T. Primary structure and cellular distribution of two fatty acid-binding proteins in adult rat kidneys. J Biol Chem 1991; 266: 5963.

10. Maatman RGHJ, van de Westerlo EM, van Kuppevelt THMSM, Veerkamp JH. Molecular identification of the liver- and the heart-type fatty acid-binding proteins in human and rat kidney. Use of the reverse transcriptase polymerase chain reaction. Biochem J 1992; 288: 285.

11. Glatz JFC, van der Vusse GJ, Simoons ML, Kragten JA, van Dieijen-Visser MP, Hermens WT. Fatty acid-binding protein and the early detection of acute myocardial infarction. Clin Chim Acta 1998: 272: 87 .

12. Maessen JG, van der Vusse GJ, Vork M, Coumans WA, Kootstra G. Determination of warm ischemia time at donor nephrectomy. Transplantation 1988; $45: 147$.

13. Bretan PJ, Baldwin N, Novick AC, et al. Pretransplant assessment of renal viability by phosphorus-31 magnetic resonance spectroscopy. Clinical experience in 40 recipient patients. Transplantation 1989; 48: 48 .

14. Sells RA, Bore PJ, McLaughlin GA, Johnson JN, Tyrrell I. A predictive test for renal viability. Transplant Proc 1977; 9: 1557.

15. Terasaki PI, Martin DC, Smith RB. A rapid metabolism test to screen cadaver kidneys for transplantation. Transplantation 1967; 5: 76.

16. Savioz D, Bolle JF, Graf JD, et al. Kinetics of cellular viability in warm versus cold ischemia conditions of kidney preservation. A biometric study. Transplantation 1996; 62: 414.

17. Daemen JH, de Vries B, Oomen AP, DeMeester J, Kootstra G. Effect of machine perfusion preservation on delayed graft function in non-heart-beating donor kidneys - early results. Transpl Int 1997; 10: 317.

18. Tesi RJ, Elkhammas EA, Davies EA, Henry ML. Ferguson RM. Pulsatile kidney perfusion for evaluation of high-risk kidney donors safely expands the donor pool. Clin Transplant 1994; 8: 134.

19. Codd JE, Garvin PJ, Morgan R, Jellinek M, Newton WT. Allograft viability determined by enzyme analysis. Transplantation 1979; $28: 447$. 
20. Daemen JW, Oomen AP, Janssen MA, et al. Glutathione S-transferase as predictor of functional outcome in transplantation of machine-preserved non-heart-beating donor kidneys. Transplantation 1997; 63: 89.

21. Kievit JK, Oomen AP, Janssen MA, van Kreel BK, Heineman E, Kootstra G. Viability assessment of non-heart-beating donor kidneys by alpha glutathione S-transferase in the machine perfusate. Transplant Proc 1997; 29: 1381.

22. Kievit JK, Janssen MA, Nederstigt AP, Kreel van BK, Kootstra G. Viability assessment of machine perfused NHB donor kidneys by the enzyme Total Glutathione S-Transferase in machine perfusate. Book of Abstracts XVII World Congress of The Transplantation Society, 1217 July 1998: 78.

23. Glatz JFC, Börchers T, Spener F, van der Vusse GJ. Fatty acids in cell signalling: modulation by lipid binding proteins. Prostaglandins Leukot Essent Fatty Acids 1995; 52: 121.

24. Börchers T, Hohoff C, Bühlmann C, Spener F. Heart-type fatty acid binding protein - involvement in growth inhibition and differentiation. Prostaglandins Leukot Essent Fatty Acids 1997; 57: 77 .

25. Glatz JFC, Kleine AH, van Nieuwenhoven FA, Hermens WT, van Dieijen Visser MP, van der Vusse GJ. Fatty-acid-binding protein as a plasma marker for the estimation of myocardial infarct size in humans. Br Heart $J$ 1994; 71: 135.

26. Van Nieuwenhoven FA, Kleine $\mathrm{AH}$, Wodzig $\mathrm{KWH}$, et al. Discrimination between myocardial and skeletal muscle injury by assessment of the plasma ratio of myoglobin over fatty acid-binding protein. Circulation 1995; 92 : 2848.

27. Hermens WT. Mechanisms of protein release from injured heart muscle. In: Kaski JC, Holt DW, eds. Dev Cardiovasc Med, vol 205. Boston: Kluwer Academic Publishers, 1998: 85.

28. Lieberman JM, Sacchettini J, Marks C, Marks WH. Human intestinal fatty acid binding protein: report of an assay with studies in normal volunteers and intestinal ischemia. Surgery 1997; 121: 335.

29. Wodzig KWH, Pelsers MMAL, van der Vusse GJ, Roos W, Glatz JFC. One-step enzyme-linked immunosorbent assay (ELISA) for plasma fatty acid-binding protein. Ann Clin Biochem 1997; 34: 263.

30. Kaptein WA, Korf J, Cheng S, Yang M, Glatz JF, Renneberg R. On-line flow displacement immunoassay for fatty acid-binding protein. $J$ Immunol Methods 1998; 217: 103. 


\section{CHAPTER 9}

Caspase-7 activation and cFLIP depletion during renal ischemia": correlation with the extent of reperfusion injury

Marc A.R.C. Daemen, Jur K. Kievit, Bart de Vries, Cornelis van 't Veer,

Tim G.A.M. Wolfs, Peter Vandenabeele, and Wim A. Buurman 


\section{ABSTRACT}

A critical role for apoptosis in the development of renal ischemia-reperfusion $(\mathrm{I} / \mathrm{R})$ injury has been established in the past. The initial apoptogenic events during ischemia and early reperfusion remain to be resolved. Using a murine model, the involvement of pro-apoptotic caspase-7 and anti-apoptotic cFLIP during renal I/R was investigated. Extended ischemic times up to $45 \mathrm{~min}$, with or without $2 \mathrm{~h}$ of reperfusion, induced formation of 19 $\mathrm{kDa}$ active caspase- 7 and reduced intrarenal cFLIP content. Treatment with the caspase inhibitor zVAD-fmk upon reperfusion failed to prevent caspase-7 activation but effectively reduced cFLIP depletion. The length of renal ischemia paralleled with the extent of renal apoptosis and tubular damage after $2 \mathrm{~h}$ of reperfusion as measured by quantification of intranucleosomal DNA cleavage and serum H-FABP levels, respectively. After $24 \mathrm{~h}$ of reperfusion, the length of ischemia correlated with the extent of renal inflammation and kidney dysfunction as reflected by renal neutrophil accumulation and serum ureum and creatinine levels. These findings are the first to show apoptogenic processes during ischemia that correlate with the extent of apoptosis, inflammation, tissue damage and dysfunction upon reperfusion. Caspase-7 activation and cFLIP depletion during ischemia may be employed to predict the amount of damage to grafts subjected to prolonged ischemia prior to transplantation. These results also attest to the potential of antiapoptotic therapy in the prevention of clinical reperfusion injury.

\section{INTRODUCTION}

Apoptosis is a feature of tissue damage caused by external stimuli such as radiation $(1,2)$, physical forces (3), intoxication (4) and ischemia (5). Passive as well as active processes have been implicated in the development of apoptosis after such stimuli. For instance, DNA damage is implicated in radiation-induced tissue damage and also a prominent attribute of ischemia-reperfusion $(\mathrm{I} / \mathrm{R})$ injury where it has been suggested to be mediated by reactive oxygen free radicals. Under these conditions, sub lethal DNA damage may activate the tumor suppressor gene p53 to initiate apoptosis, thereby preventing transmission of mutations $(2,6)$. The functional contribution of these and other apoptogenic mechanisms to the development of tissue damage during reperfusion largely remains to be resolved.

In various $\mathrm{I} / \mathrm{R}$ models it has been established that conversion to the apoptotic phenotype occurs within several hours of reperfusion (7-9). Apoptosis in the course of reperfusion is a very ingenious solution for quick removal of irreparably damaged and expended cells without the need for an inflammatory response. However, recent evidence shows that caspase activation, essential for the initiation and execution of apoptosis, plays a crucial role in development of tissue damage and dysfunction during reperfusion $(9,10)$. Thus, it is of critical importance to investigate which mechanisms lead to caspase acti- 
vation and apoptosis after $\mathrm{I} / \mathrm{R}$. Insight in the way by which early biochemical events lead to later development of tissue damage and the timeframe in which these events take place, could yield new therapeutic as well as diagnostic means to face the clinical problem of reperfusion injury. Especially to the management of acute renal failure, which is the result of I/R injury in $50 \%$ of cases (11), such new clinical tools would be of great benefit.

Apoptosis is an active process and several crucial aspects of the apoptotic response require ATP (12), which is depleted during ischemia (13). Consequently, completion of apoptosis essentially requires reperfusion. However, it is likey that during ischemia, cells conform to biochemical criteria that facilitate execution of apoptosis upon reperfusion. Therefore, in the present study we chose to investigate several hallmarks of the caspaseactivation cascade not only after reperfusion, but also during the ischemic phase. Using a murine model of renal I/R, the putative involvement of caspase-7 activation and cellular FLICE/caspase-8 inhibitory protein (cFLIP) depletion during ischemia as well as reperfusion and its consequences for the development of $\mathrm{I} / \mathrm{R}$ injury are investigated. First we studied caspase-7, an intracellular effector enzyme of the apoptotic cascade that is enzymatically redundant with caspase-3 (14). Moreover, caspase-7 is the main proteolytic activator of EMAP-II (15), a chemokine that becomes locally activated during reperfusion (9), suggesting a functional role for caspase-7 in the development of $I / R$ injury. We also investigated the involvement of cFLIP, a constitutively expressed antiapoptotic agent (16). The $55 \mathrm{kDa}$ full-size form of cFLIP has been demonstrated to become depleted in the reperfused heart (17). cFLIP is a constitutive inhibitor of deathreceptor mediated apoptosis $(16,18)$, a prominent form of apoptosis in the course of $\mathrm{I} / \mathrm{R}$ $(19,20)$.

\section{Materials AND Methods}

\section{EXPERIMENTAL PROTOCOL}

All experiments were approved by the Institutional Animal Care Committee of the University of Maastricht and were conducted in accord with the NIH Guide for the Care and Use of Laboratory Animals. Renal ischemia was induced as reported previously (20). In brief, male Swiss mice weighing 20-25 g (Charles River Breeding Laboratories, Heidelberg, Germany) were anesthetized with sodium pentobarbital ( $50 \mathrm{mg} / \mathrm{kg}$ i.p.) and body temperature was maintained at $39^{\circ} \mathrm{C}$. After laparotomy, the left renal pedicle was clamped for 15, 30 or $45 \mathrm{~min}$, during which the wound was covered with sterile gauze. Mice were sacrificed without renal reperfusion and the right and left kidney were harvested, immediately frozen in liquid nitrogen and stored at $-80^{\circ} \mathrm{C}$. Control animals were subjected to a sham procedure, which was similar except for clamping of the renal pedicle. 
In separate groups of mice, renal ischemia was followed by release of the clamps in order to initiate reperfusion. Subsequently the right kidney was removed and stored, the abdomen was closed, $0.25 \%$ bupivacaine was applied topically for postoperative pain management and mice were supplemented with $1 \mathrm{ml}$ prewarmed PBS to maintain fluid balance. Since the early apoptotic response that contributes to subsequent inflammation is discernable as early as after $2 \mathrm{~h}$ of reperfusion (9), mice were subjected to 15,30 or 45 min of ischemia and $2 \mathrm{~h}$ of reperfusion. As previously shown, in this model the signs of renal inflammation and functional deterioration are ubiquitous after $24 \mathrm{~h}$ of reperfusion (9), which accounts for the focus on this timepoint after ischemia. Additional animals were treated with $30 \mu \mathrm{g} \mathrm{zVAD}$-fmk in $1 \%$ DMSO i.p. $(n=6)$ at the time of reperfusion and sacrificed after $2 \mathrm{~h}$ of reperfusion. $\mathrm{zVAD}-\mathrm{fmk}$ is a caspase inhibitor which previously has been shown to effectively inhibit I/R-induced apoptosis and inflammation (9). At the time of sacrifice, blood was collected by orbital puncture and the left kidney was harvested. Control animals were subjected to a sham procedure, which was similar except for clamping of the renal pedicle, and sacrificed at 2 or $24 \mathrm{~h}$ after surgery.

\section{WESTERN BLOTTING FOR RENAL CASPASE-7 AND CFLIP}

Frozen samples of harvested kidneys were homogenized in a buffer containing $200 \mathrm{mM}$ $\mathrm{NaCl}, 10 \mathrm{mM}$ Tris $\mathrm{HCl}, \mathrm{pH} 7.0,5 \mathrm{mM}$ EDTA, $10 \%$ glycerol, $1 \mathrm{mM}$ PMSF and $0.1 \mu \mathrm{M}$ aprotinin. Whole homogenates as well as cytosolic, mitochondrial and microsomal centrifugation fractions were prepared according to a procedure described previously (21). After centrifugations, the protein in the supernatants was quantified by the Bradford method, heated for $5 \mathrm{~min}$ at $95^{\circ} \mathrm{C}$ in Leammli buffer and $50 \mu \mathrm{g}$ (caspase-7) or $150 \mu \mathrm{g}$ (cFLIP) total protein per lane was electrophoresed on a $15 \%$ polyacrylamide/SDS gel. Proteins were transferred to nitrocellulose membranes, which were subsequently blocked with PBS $/ 5 \%$ nonfat dry milk $/ 0.1 \%$ Tween 20 and incubated for $1 \mathrm{~h}$ with rabbit antimurine caspase-7 (generated by immunizing rabbits with the recombinant protein (22)) or rabbit anti-human cFLIP cross-reactive with murine cFLIP (a kind gift from Dr. D. Nicholson, Merck Frosst Inc, Pointe Claire, Canada) diluted 1:2000 in PBS/0.1\% Tween 20. After washings, the membranes were incubated for $2 \mathrm{~h}$ with peroxidase-labeled goat anti-rabbit IgG (Jackson Inc, West Grove, PA) diluted 1:2000 in PBS/0.1\% Tween 20, washed and developed by enhanced chemiluminescence.

\section{ASSAY FOR INTERNUCLEOSOMAL DNA-CLEAVAGE}

Genomic DNA was extracted from kidneys employing a commercially available DNA purification kit (Wizard, Promega, Madison, WI) according to the manufacturers instructions. The presence of internucleosomal DNA cleavage in kidneys was investigated with a commercially available ligase-mediated (LM)-PCR assay kit (Apoalert, Clontech, Palo 
Alto, CA) on equal amounts of DNA according to the manufacturers instructions. This technique allows semiquantitative measurement of apoptosis (23). All DNA samples were amplified under the following PCR-protocol: hotstart $\left(72^{\circ} \mathrm{C}\right.$ for $\left.8 \mathrm{~min}\right), 25$ cycles $\left(94^{\circ} \mathrm{C}\right.$ for 60 seconds and $72^{\circ} \mathrm{C}$ for 180 seconds) and post-cycling $\left(72^{\circ} \mathrm{C}\right.$ for $\left.15 \mathrm{~min}\right)$. Amplified DNA was subjected to gel electrophoresis on a $1.2 \%$ agarose gel containing ethidium bromide. Band proportions were estimated for the 600, 400 and 200 bp DNA fragments by measuring the intensity of ethidium bromide fluorescence with a digital camera (Imagemaster VDS, Pharmacia, Uppsala, Sweden) using commercially available gel analysis software (Sigma Gel, SPSS, Chicago, IL).

\section{MURINE HEART FATTY ACID-BINDING PROTEIN (H-FABP) ELISA}

Tubular epithelial cells have been shown to contain cytoplasmatic H-FABP to a similar extent as cardiomyocytes $(24,25)$. To evaluate I/R-induced tubular epithelial damage, serum $\mathrm{H}-\mathrm{FABP}$, reflecting release of this protein from damaged tubular epithelium was measured. To this end, a commercially available ELISA kit (kindly provided by Hycult Biotechnology b.v., Uden, the Netherlands) was used according to the manufacturers instructions. This assay employs high-affinity monoclonal antibodies to human H-FABP, cross-reacting with murine H-FABP. The supplied murine H-FABP was used as a calibrator.

\section{RENAL MYELOPEROXIDASE ASSAY}

To quantify the extent of renal neutrophil accumulation, renal MPO content was determined $(20,26)$. In brief, tissue samples were homogenized in $0.5 \%$ hexadecyltrimethylammonium bromide in $50 \mathrm{mM}$ PBS, $\mathrm{pH}=6.0,0.17 \mathrm{~g}$ tissue $/ \mathrm{ml}$. After heat incubation ( 2 $\mathrm{h}, 60^{\circ} \mathrm{C}$ ) and three freeze-thaw cycles, MPO content was measured in triplicate by incubating supernatants with tetramethylbenzidine (TMB) substrate in a 96-well sample plate (Costar, Cambridge, MA) followed by measurement of optical density (OD) at $450 \mathrm{~nm}$. MPO activity was calculated per mg renal tissue by comparing OD of samples with a standard titration curve of horseradish peroxidase. Data were standardized with respect to wet/dry ratios of the assayed renal tissue and are presented relative to the amount of MPO present in the contralateral kidney harvested immediately after ipsilateral reperfusion.

\section{EVALUATION OF BLOOD UREA NITROGEN (BUN) AND SERUM CREATININE}

Blood urea nitrogen (BUN) and serum creatinine were measured in serum obtained the time of sacrifice using a BUN unimate 5 kit in a Cobas Fara autoanalyzer (Roche, Basle, Switzerland). 


\section{STATISTICS}

Data are expressed the mean \pm SEM, and statistical analysis was performed by Student's T-test. $\mathrm{P}<0.05$ was taken to denote statistical significance.

\section{RESULTS}

\section{RENAL ISCHEMIA INDUCES CASPASE-7 ACTIVATION AND CFLIP DEPLETION}

In order to investigate whether apoptogenic processes emerge during ischemia, we evaluated the effect of 15, 30 and $45 \mathrm{~min}$ of ischemia on renal caspase- 7 activation by Western blotting. A period of renal ischemia as short as $15 \mathrm{~min}$ induced marked caspase7 activation as reflected by cleavage of the $35-\mathrm{kDa}$ inactive caspase-7 precursor to 19 $\mathrm{kDa}$ active caspase-7 (Figure 1). Prolongation of ischemia to 30 and $45 \mathrm{~min}$ lead to additional formation of activated caspase- 7 as compared to the $15 \mathrm{~min}$ ischemia group or sham-operated controls (Figure 1). Fractional centrifugation of $45 \mathrm{~min}$ ischemic kidney homogenates revealed that active caspase- 7 was predominantly present in the cytosol and not in mitochondria or microsomes (Figure 2). No constitutive renal caspase-7 activation was detected in sham-operated mice (Figure 1).

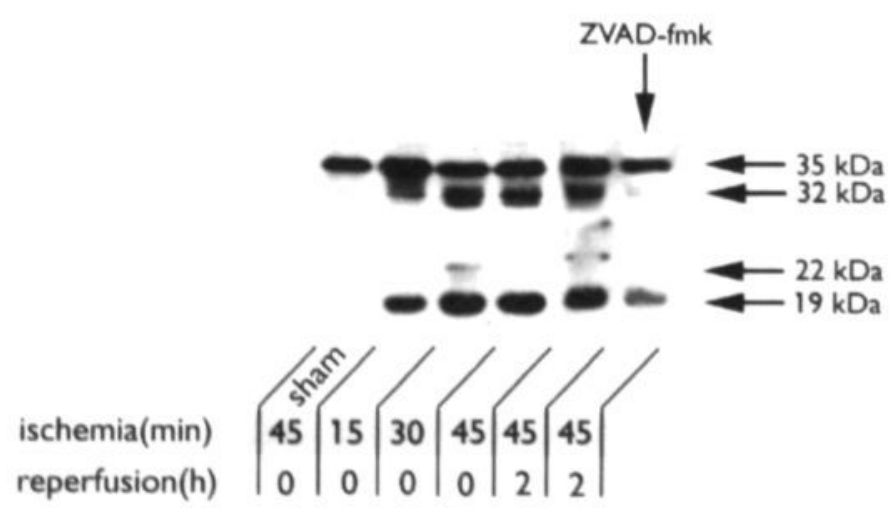

Figure 1. Effects of ischemia with or without subsequent reperfusion on intrarenal caspase-7 activation. Western blot analysis revealed constitutive expression of inactive $35 / 32 \mathrm{kDa}$ procaspase-7 in sham controls. Ischemia lasting from 15 to 45 min lead to formation of $22 / 19 \mathrm{kDa}$ activated caspase-7 as compared to sham-operated controls. Activated caspase-7 was also detectable in kidneys rendered ischemic for $45 \mathrm{~min}$ after $2 \mathrm{~h}$ reperfusion. The caspase blocker zVAD-fmk, administered upon reperfusion, slightly reduced caspase-7 activation after $2 \mathrm{~h}$ of reperfusion. 
Similarly, we employed Western blotting to evaluate the effects of renal ischemia on the extent of cFLIP depletion. An ischemic period of $15 \mathrm{~min}$ induced no apparent depletion of renal 55-kDa cFLIP as compared to constitutive cFLIP levels in kidneys from shamoperated controls (Fig. 3). Extended ischemic times of 30 and 45 min were associated with a reduction in renal cFLIP content as compared to sham-operated controls (Figure 3 ). Taken together, these data show that during ischemia apoptogenic processes emerge, which may facilitate apoptosis upon reperfusion.

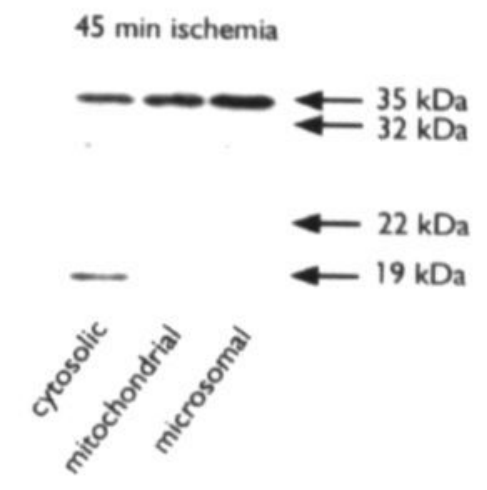

Figure 2. Subcellular distrubution of caspase-7 in kidneys rendered ischemic for $45 \mathrm{~min}$. While $35 / 32 \mathrm{kDa}$ pro-caspase- 7 was generaly present, $22 / 19 \mathrm{kDa}$ activated caspase- 7 was only present in the cytosol and not in mitochondria or microsomes as demonstrated by Western blot analysis employing representative fractions of kidney homogenates.

ZVAD-FMK DOES NOT INHIBIT CASPASE-7 ACTIVATION AND PREVENTS CFLIP DEPLETION UPON RENAL REPERFUSION

Next, we investigated the effects of renal ischemia followed by reperfusion on intrarenal caspase-7 activation and cFLIP depletion. Activated caspase-7 was clearly present in kidneys subjected to $45 \mathrm{~min}$ of ischemia and $2 \mathrm{~h}$ of reperfusion (Figure 1). We previously showed that zVAD-fmk administration upon reperfusion prevented caspase-1 and caspase- 3 activation and additionally conferred protection against reperfusion injury (9). The present results indicate that $\mathrm{zVAD}$-fmk treatment minimally reduced up-regulation of $19 \mathrm{kDa}$ caspase- 7 after $2 \mathrm{~h}$ of reperfusion (Figure 1), suggesting caspase independent processing of caspase- 7 in the course of renal I/R. Although zVAD-fmk treated mice upregulate the $19 \mathrm{kDa}$ form of caspase- 7 after $2 \mathrm{~h}$, it has to be taken into account that caspase-7 activity most likely is blocked in these animals. Hence, these results do not rule out functional involvement of activated caspase- 7 in the cascade leading to tissue injury subsequent to renal $\mathrm{I} / \mathrm{R}$.

In a model of cardiac $I / R$, reperfusion has previously been demonstrated to reduce endogenous cFLIP levels (17). In line, kidneys subjected to $45 \mathrm{~min}$ of ischemia and $2 \mathrm{~h}$ 
of reperfusion exhibited a strongly decreased cFLIP content as compared to sham controls or kidneys subjected to ischemia alone (Figure 3). Interestingly, zVAD-fmk treatment effectively prevented reperfusion-induced cFLIP depletion after $2 \mathrm{~h}$ of reperfusion (Figure 3). These findings suggest that during early reperfusion, activated caspases are involved in downregulation of cFLIP. Whether ischemia additionally decreases cFLIP transcription or translation cannot be concluded from the present data.

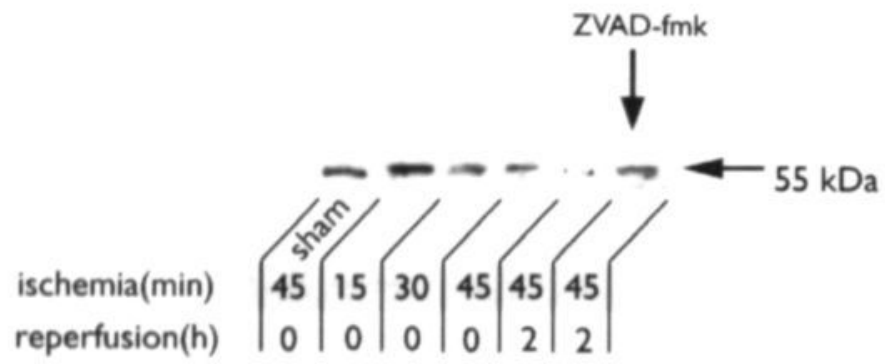

Figure 3. Effects of ischemia with or without subsequent reperfusion on intrarenal cFLIP content. Western blot analysis revealed constitutive expression of cFLIP in sham controls. Ischemia lasting from 30 to $45 \mathrm{~min}$ lead to cFLIP depletion as compared to sham controls and kidneys rendered ischemic for $15 \mathrm{~min}$. Renal cFLIP was clearly depleted in kidneys rendered ischemic for $45 \mathrm{~min}$ after $2 \mathrm{~h}$ reperfusion. However, the caspase blocker zVAD-fmk, administered upon reperfusion, prevented reperfusion-induced cFLIP depletion.

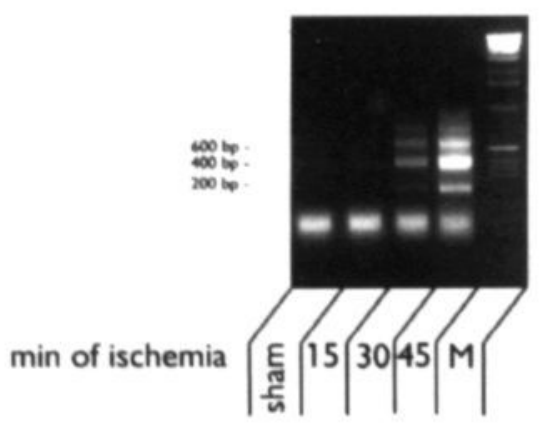

Figure 4. The extent of renal apoptosis in kidneys subjected to 15, 30 and $45 \mathrm{~min}$ of ischemia and $2 \mathrm{~h}$ of reperfusion as reflected by the presence of fragmented DNA (as a result of internucleosomal DNA cleavage) amplified by LM-PCR and visualized on ethidium-bromide-stained gel. M, molecular weight markers (range, 100 to 2000 base pairs). 


\section{EARLY APOPTOSIS AFTER EXTENDED ISCHEMIC PERIODS FOLLOWED BY REPERFUSION}

We questioned whether the observed apoptogenic processes that increased in parallel with the length of ischemia, correlated with the extent of apoptosis upon reperfusion. In this model of $\mathrm{I} / \mathrm{R}$ injury, apoptosis is discernable after $2 \mathrm{~h}$ of reperfusion. This apoptotic response contributes extensively to the ensuing inflammatory response, which can be effectively prevented by zVAD-fmk treatment upon reperfusion (9). We investigated the effects of increasing ischemic times on the extent of early apoptosis, as reflected semi quantitatively by the amount of renal internucleosomal DNA cleavage. Extended periods of ischemia of 15 to $45 \mathrm{~min}$ followed by $2 \mathrm{~h}$ of reperfusion, concomitantly lead to an increased extent of apoptosis as revealed by increased internucleosomal DNA fragmentation (Figure 4). No apparent internucleosomal DNA fragmentation was observed in kidneys from sham controls sacrificed $2 \mathrm{~h}$ after surgery (Figure 4 ). We previously showed that apoptosis in this model is associated with increased numbers of TUNEL-positive nuclei, caspase activation and morphological alterations indicative for renal apoptosis after $2 \mathrm{~h}$ of reperfusion (9). The current data show that extended periods of ischemia tip a balance in favour of apoptosis upon reperfusion.

ISCHEMIA IS REFLECTED BY H-FABP RELEASE FROM DAMAGED TUBULI DURING REPERFUSION

$\mathrm{I} / \mathrm{R}$ has been reported to directly damage cells resulting in spillage of intracellular contents. Murine H-FABP $(14 \mathrm{kDa})$ is constitutively present in the cytosol of tubular epithelium $(24,25)$ and was measured to test whether increasing ischemic periods cause tubular damage upon reperfusion. Moderate but significant increases in serum H-FABP were demonstrated in mice subjected to 15 and $30 \mathrm{~min}$ of renal ischemia (Figure 5) and, as expected, $45 \mathrm{~min}$ of renal ischemia resulted in even higher serum H-FABP levels after 2 $\mathrm{h}$ of reperfusion as compared to sham controls. Mice sacrificed after $24 \mathrm{~h}$ of reperfusion failed to show significantly elevated serum H-FABP levels (data not shown), which demonstrates that this low-molecular marker reflects early rather than late renal damage. Thus, extended periods of ischemia induce increasing amounts of direct tubular damage.

We have previously shown that treatment with the caspase inhibitor zVAD-fmk at the time of reperfusion effectively prevented renal reperfusion-induced apoptosis, inflammation and functional deterioration in the model that is also employed in this study. In order to investigate the effect of caspase-inhibition on early tubular damage, mice were treated with zVAD-fmk, subjected to $45 \mathrm{~min}$ of renal ischemia and $2 \mathrm{~h}$ of reperfusion. These mice showed a slight but non-significant reduction in serum H-FABP levels as compared to PBS controls (Figure 5), indicating that tubular epithelial damage during early reperfusion occurs independent from I/R-induced renal caspase activation. 


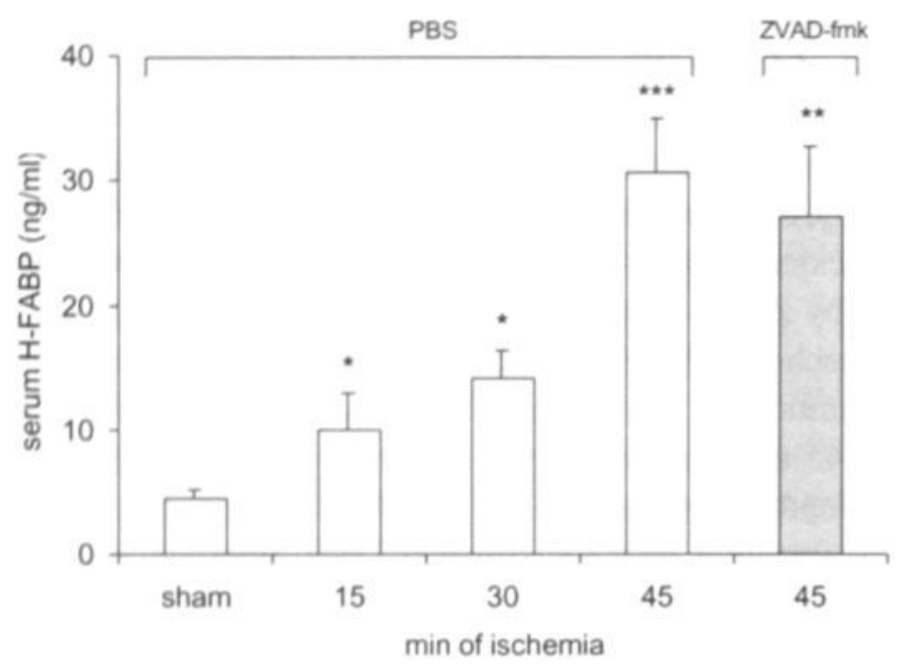

Figure 5. The effect of 15, 30 and $45 \mathrm{~min}$ of renal ischemia followed by $2 \mathrm{~h}$ of reperfusion on serum levels of the tubular damage marker H-FABP. Longer periods of ischemia lead to increased serum levels of H-FABP after reperfusion. The caspase blocker zVAD-fmk, administered upon reperfusion, did not significantly alter serum H-FABP levels after 45 min of ischemia and $2 \mathrm{~h}$ of reperfusion. Statistical significance as compared to sham controls was denoted at $\mathrm{P}<0.05\left({ }^{*}\right), \mathrm{P}<0.01\left({ }^{* *}\right)$ and $\mathrm{P}<0.001\left({ }^{* * *}\right)$. The presented data are means $\pm \mathrm{SEM}$.

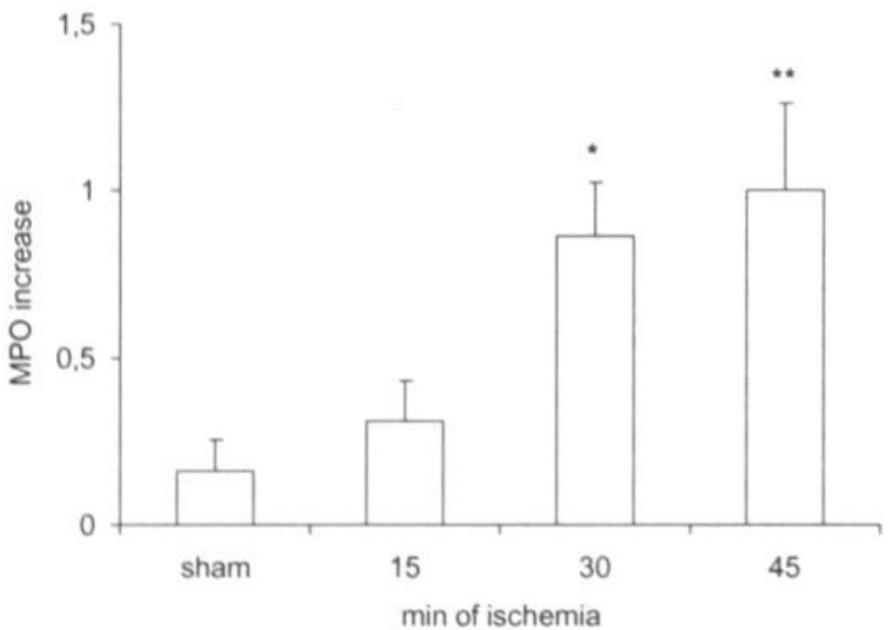

Figure 6. Neutrophil influx was assessed quantitatively by determination of MPO increase after $24 \mathrm{~h}$ of reperfusion. Values are presented relative to the amount of MPO present in the contralateral kidney harvested immediately after reperfusion and normalized with respect to the MPO increase at $24 \mathrm{~h}$ in PBS treated mice subjected to $45 \mathrm{~min}$ of ischemia. Statistical significance as compared to control treated animals was denoted at $\mathrm{P}<0.05\left({ }^{*}\right)$ and $\mathrm{P}<0.01\left({ }^{* *}\right)$. The presented data are means \pm SEM. 
RENAL INFLAMMATION AND FUNCTIONAL IMPAIRMENT AFTER EXTENDED ISCHEMIA FOLLOWED BY REPERFUSION

We questioned whether the length of ischemia corresponds with the extent of inflammation during reperfusion. Renal MPO content, reflecting the amount of infiltrated neutrophils, was significantly increased in mice subjected to 30 or $45 \mathrm{~min}$ of ischemia followed by $24 \mathrm{~h}$ of reperfusion as compared to sham-operated controls (Figure 6). However, the observed increased renal MPO in mice subjected to $15 \mathrm{~min}$ of ischemia and $24 \mathrm{~h}$ of reperfusion did not reach significance as compared to sham controls (Figure 6). The length of the ischemic period also affected renal function as measured by BUN and serum creatinine content after $24 \mathrm{~h}$ of reperfusion. BUN as well as serum creatinine were significantly increased in mice subjected to 15,30 or $45 \mathrm{~min}$ of ischemia followed by 24 $\mathrm{h}$ of reperfusion as compared to sham controls (Figure 7).
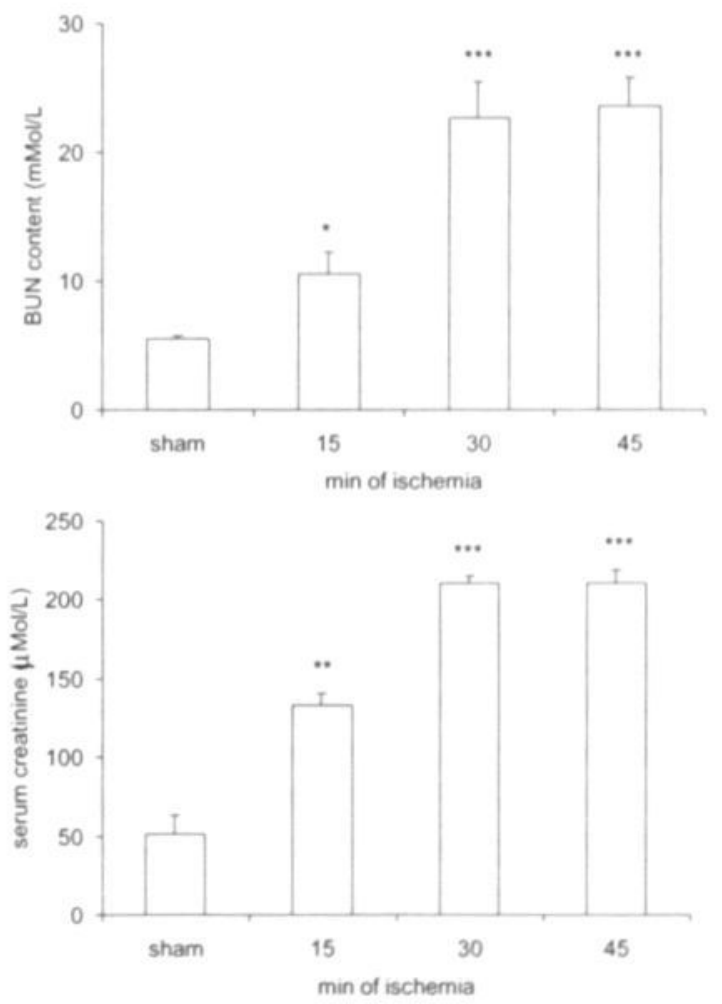

Figure 7. Renal function after 15,30 and $45 \mathrm{~min}$ of ischemia and $24 \mathrm{~h}$ of reperfusion as reflected by blood urea nitrogen (BUN) content $(\mathbf{A})$ and serum creatinine (B). Statistical significance as compared to sham controls was denoted at $\mathrm{P}<0.05$ (*), $\mathrm{P}<0.01$ (**) and $\mathrm{P}<0.001$ (***). The presented data are means \pm SEM. 


\section{DISCUSSION}

We investigated the association between renal caspase-7 and cFLIP modulation with different lengths of ischemia as well as reperfusion. The relation between renal caspase-7 and cFLIP modulation by I/R and subsequent development of renal injury were studied. We show that caspase-7 activation and cFLIP depletion not only occur in the reperfusion phase, but are also modulated by ischemia alone. Evaluation of the kinetics of caspase-7 processing during ischemia reveals a strong correlation with ischemic time, renal apoptosis, injury, inflammation and dysfunction following reperfusion (Figure 8). A similar correlation exists between the latter parameters and cFLIP depletion during ischemia (Figure 8). Thus, caspase-7 activation and potentially cFLIP depletion are measures that can be assayed during ischemia in order to predict the amount of injury induced by subsequent reperfusion.

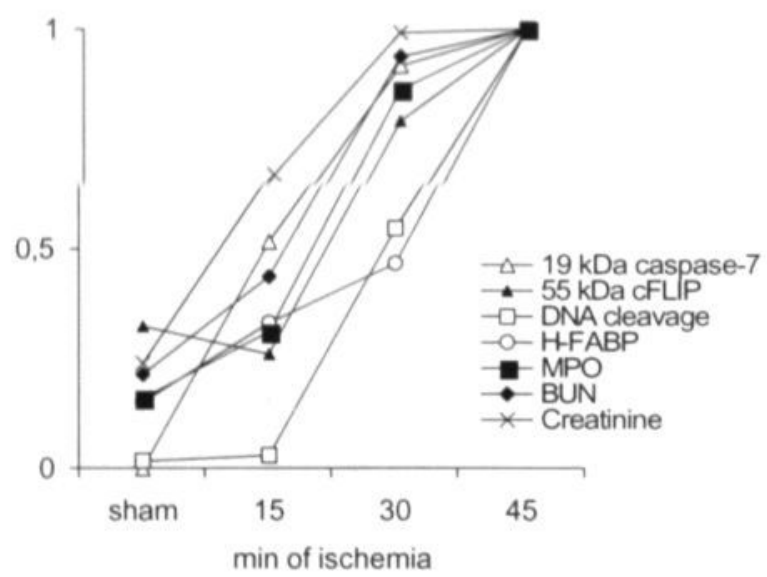

Figure 8. Kinetics of parameters evaluated during different periods of ischemia alone (renal formation of $19 \mathrm{kDa}$ caspase-7 and $55 \mathrm{kDa}$ cFLIP depletion) and parameters evaluated after 2 $\mathrm{h}$ (serum H-FABP and internucleosomal DNA cleavage) or $24 \mathrm{~h}$ (MPO increase, BUN and creatinine) of reperfusion. Data are normalized compared to the $45 \mathrm{~min}$ ischemia group and cFLIP depletion is expressed as 1/cFLIP content. Caspase-7, cFLIP and apoptosis were estimated employing digital band intensity analysis.

Caspase-7 activation, similar to activation of caspase-3, is an abundant effector mechanism in many forms of apoptosis. The present results show that during renal ischemia, caspase- 7 is activated in the kidney and is predominantly present in the cytosolic compartment. The latter finding contrasts with the results of Chandler et al. who report that in the liver, active caspase-7 is mainly microsome associated (21). We show that extension of the period of ischemia, concomitantly lead to additional intrarenal formation of activated caspase-7. This indicates that mechanisms initiated in the ischemic phase con- 
tribute to caspase activation in a time dependent fashion. After $2 \mathrm{~h}$ of reperfusion, renal caspase-7 was abundantly present in its activated form. This is in line with the observation that kidneys subjected to $2 \mathrm{~h}$ of reperfusion exhibited internucleosomal DNA-cleavage of which the magnitude also increased in parallel to the length of ischemia.

Apoptosis is an active process requiring ATP, which is rapidly depleted during ischemia (13). The latter consideration as well as the present results imply that during ischemia alone, cells may accumulate mediators that facilitate the ATP-dependent execution of apoptosis that can only be initiated by reperfusion. For instance, internucleosomal DNAcleavage in the course of apoptosis is an ATP-dependent process, since it is considered that the apoptotic signal has to be transmitted from the cytosol to the nucleus, which requires ATP hydrolysis $(27,28)$. Caspase- 7 activation (initiated prior to reperfusion in our model of renal $I / R$ ) by itself is insufficient to induce the apoptotic phenotype (29). In line, we previously demonstrated absence of internucleosomal DNA-cleavage before reperfusion (9). Hence, nuclear recruitment of caspase-7 upon ATP repletion in the course of early reperfusion likely contributes to initiation of apoptosis.

Caspase-7 is not only an intracellular effector enzyme of the apoptotic cascade, it is also the main proteolytic activator of the chemokine EMAP-II (15). Interestingly, we recently showed that I/R leads to EMAP-II activation after $2 \mathrm{~h}$ of reperfusion, but not after 0.5 or $1 \mathrm{~h}$ of reperfusion (9), while caspase- 7 is already activated during ischemia. This time-lap may reflect slow proteolytic processing of EMAP-II by activated caspase7 similar as observed under in vitro conditions (15). Alternatively, compartimentalized subcellular distribution of active caspase-7 (21) and EMAP-II precursor may prevent early EMAP-II activation. However, fractional centrifugation (21) of homogenates of kidneys subjected to I/R, followed by detection of EMAP-II precursor and active caspase-7 by Western blotting of microsomal, mitochondrial and cytosolic fractions, revealed presence of both $43 \mathrm{kDa}$ EMAP-II precursor (data not shown) and activated caspase-7 (Figure 2) in the cytosol.

Inhibition of activated caspases by zVAD-fmk can prevent the development of $\mathrm{I} / \mathrm{R}$ induced tissue damage in various organ systems $(9,10,30)$. In the course of renal $I / R$, zVAD-fmk administration prevents activation of caspase-1 and caspase-3 (9). In the latter study we also demonstrated that zFA-fmk, a peptide homologous to, but lacking the caspase inhibiting properties of zVAD-fmk, failed to prevent apoptosis and I/R-induced renal injury. Thus, it is unlikely that aspecific attributes of zVAD-fmk account for the observed effects. The present findings show that zVAD-fmk treatment upon reperfusion only slightly attenuated caspase- 7 activation as determined after $2 \mathrm{~h}$ of reperfusion. This minimal reduction in caspase- 7 activity implies reduced caspase-mediated processing of caspase-7 in the presence of zVAD-fmk. Alternatively, caspase-independent caspase-7 activation by granzymes (31) or calpains (32) is involved during reperfusion. The latter is a tempting hypothesis since calpain activation inhibitors effectively prevent $\mathrm{I} / \mathrm{R}$ induced tissue injury in the heart (33), brain (34), liver (35) and kidney (36) as well as 
hypoxia-induced caspase-dependent necrosis in cultured renal tubular cells (37).

Besides caspase- 7 activation, activation of caspase- 8 is a likely feature of $I / R$ injury. Caspase-8, among others, is activated in the course of death-receptor mediated apoptosis (38) and death-ligands like TNF- $\alpha$ and FasL have been shown to extensively contribute to $\mathrm{I} / \mathrm{R}$ injury $(20,39)$. Also, caspase- 8 activation has been reported following hypoxiareoxygenation of cultured renal cells (40). We now show that extended periods of ischemia-induced reductions in renal cFLIP content, which may facilitate caspase- 8 dependent apoptosis upon reperfusion. In line, in addition to data from Rasper et al. (17) who showed significant cFLIP depletion in the reperfused heart, the present findings indicate a loss of renal cFLIP during extended ischemic periods as well as after subsequent reperfusion. cFLIP constitutively prevents death-receptor mediated apoptosis by precluding recruitment of the caspase- 8 zymogen to the death-signalling complex $(16,17)$. It is not known whether low cFLIP levels alone are sufficient to initiate an apoptotic response, however decreased cFLIP/caspase- 8 ratios were shown to sensitize cells to death-receptor mediated apoptosis (41). Moreover, cFLIP overexpression renders tumor cells refractory to Fas-dependent T-cell induced apoptosis (42). Hence, low cFLIP levels in reperfused tissue potentially enhance I/R-induced apoptosis and/or prevent resistance against apoptosis.

Recent data show caspase-dependent processing of caspase inhibitors including cFLIP $(43,44)$. In line, the present results show that administration of the caspase-inhibitor zVAD-fmk upon reperfusion almost completely prevented reperfusion-induced cFLIP depletion. This finding suggests that during early reperfusion, cFLIP is processed by activated caspases. Thus, the observed therapeutic effects of zVAD-fmk may be partially attributed to maintaining high levels of intracellular cFLIP.

We recently demonstrated that serum $\mathrm{H}$-FABP is a sensitive and specific diagnostic marker for reperfusion-induced desintegration of renal tubular cells (Kievit et al, in press). The present data indicate that, in parallel to extended periods of ischemia, serum $\mathrm{H}-\mathrm{FABP}$ levels increased after $2 \mathrm{~h}$ of reperfusion. This serum H-FABP increase likely reflects cellular spillage as a consequence of acute reperfusion-induced necrosis because at this timepoint no signs of inflammation are present (9). zVAD-fmk treatment could not prevent early cellular damage as reflected by unaltered serum H-FABP levels after $2 \mathrm{~h}$ of reperfusion. Conversely, we previously showed that zVAD-fmk administered upon reperfusion effectively prevented $\mathrm{I} / \mathrm{R}$-induced inflammation, tissue damage and dysfunction (9). This shows that in the course of $I / R$, caspase activation rather than release of noxious content from damaged cells, instigates inflammation and subsequent tissue damage. The latter does not relate a specific mode of cell death to subsequent development of inflammation and tissue injury since caspase activation is associated with apoptosis as well as necrosis $(37,45)$. Rather, we propose a model involving irreversible acute cellular damage initiated by reperfusion, possibly as a result of liberation of oxygen free radicals and mechanical trauma. In our study this acute damage is reflected by H-FABP release. 
Besides, following this initial acute response, subacute reversible cell damage by means of apoptosis and secondary necrosis develops. These instigate among others the destructive inflammatory response leading to more significant organ damage and dysfunction. Taken together, these data show that the extent of ischemia corresponds with apoptogenic changes during ischemia and also with apoptosis, inflammation and impairment of renal function that develop in the course of reperfusion. This may be employed to predict the amount of reperfusion damage upon clinical transplantation of kidneys subjected to prolonged periods of ischemia, so-called non-heart-beating (NHB) donors (46). NHB donation is associated with a high incidence of delayed graft function, rendering implementation of a NHB donor program still controversial (47). Methods that can establish whether ischemically damaged donor organs are suitable to be used for transplantation will minimize complications from the use of NHB grafts. Reliable viability tests that estimate the extent of ischemic damage and predict post-transplant function will justify wider implementation of NHB donation. In addition, caspase-7 activation and cFLIP depletion potentially initiate and/or amplify ischemia-induced apoptosis upon reperfusion, which is essential to consequent development of inflammation and organ damage. Hence, antiapoptotic therapies aimed at preventing caspase-7 activation and cFLIP depletion in the course of $\mathrm{I} / \mathrm{R}$ may be clinically effective.

\section{REFERENCES}

1. Caricchio R, Reap EA, Cohen PL: Fas/Fas ligand interactions are involved in ultraviolet-Binduced human lymphocyte apoptosis. J Immunol 1998; 161:241-251.

2. Lowe SW, Schmitt EM, Smith SW, Osborne BA, Jacks T: P53 is required for radiation-induced apoptosis in mouse thymocytes. Nature 1993; 362:847-849.

3. Leri A, Claudio PP, Li Q, Wang X, Reiss K, Wang S, Malhotra A, Kajstura J, Anversa P: Stretchmediated release of angiotensin II induces myocyte apoptosis by activating p 53 that enhances the local renin-angiotensin system and decreases the Bcl-2-to-Bax protein ratio in the cell. J Clin Invest 1998; 101:1326-1342.

4. Tanimoto A, Hamada T, Koide $\mathrm{O}$ : Cell death and regeneration of renal proximal tubular cells in rats with subchronic cadmium intoxication. Toxicol Pathol 1993; 21:341-352.

5. Schumer M, Colombel MC, Sawczuk IS, Gobe G, Connor J, O'Toole KM, Olsson CA, Wise GJ, Buttyan R: Morphologic, biochemical, and molecular evidence of apoptosis during the reperfusion phase after brief periods of renal ischemia. Am J Pathol 1992; 140:831-838.

6. Raafat AM, Murray MT, McGuire T, Defrain M, Franko AP, Zafar RS, Palmer K. Diebel I. Dulioust A, Dulchavsky SA: Calcium blockade reduces renal apoptosis during ischemia reperfusion. Shock 1997; 8:186-192.

7. Beeri R, Symon Z, Brezis M, Ben Sasson SA. Baehr PH, Rosen S, Zager RA: Rapid DNA fragmentation from hypoxia along the thick ascending limb of rat kidneys. Kidney Int 1995; 47:18061810 .

8. Lieberthal W, Menza SA. Levine JS: Graded ATP depletion can cause necrosis or apoptosis of cultured mouse proximal tubular cells. Am J Physiol 1998: 43:F315-F327. 
9. Daemen MARC, Van 't Veer C, Denecker G, Heemskerk VH, Wolfs TGAM, Vandenabeele P. Buurman WA: Inhibition of apoptosis induced by ischemia-reperfusion prevents inflammation. J Clin Invest 1999; 104:541-549.

10. Cursio R, Gugenheim J, Ricci JE, Crenesse D, Rostagno P, Maulon L, Saint PM, Ferrua B, Auberger AP: A caspase inhibitor fully protects rats against lethal normothermic liver ischemia; by inhibition of liver apoptosis. FASEB J 1999:13:253-261.

11. Thadhani R, Pascual M, Bonventre JV: Acute renal failure. N Engl J Med 334:1448-1460, 1996

12. Eguchi Y, Shimizu S, Tsujimoto Y: Intracellular ATP levels determine cell death fate by apoptosis or necrosis. Cancer Res 1997; 57:1835-1840.

13. Maessen JG: Evaluation of ischemic injury in donor kidneys: an experimental study. Thesis, University of Maastricht, 1988

14. Duan H, Chinnaiyan AM, Hudson PL, Wing JP, He WW, Dixit VM: ICE-LAP3, a novel mammalian homologue of the Caenorhabditis elegans cell death protein Ced-3 is activated during Fas- and tumor necrosis factor-induced apoptosis. J Biol Chem 1996; 271:1621-1625.

15. Behrensdorf HA, Van de Craen M, Knies UE, Vandenabeele P, Clauss M: The endothelial monocyte-activating polypeptide II (EMAP II) is a substrate for caspase-7. Febs Lett 2000; 466:143-147.

16. Tschopp J, Irmler M, Thome M: Inhibition of fas death signals by FLIPs. Curr Opin Immunol 1998; 10:552-558.

17. Rasper DM, Vaillancourt JP, Hadano S, Houtzager VM, Seiden I, Keen SC, Tawa P, Xanthoudakis S, Nasir J, Martindale D, Koop BF, Peterson EP, Thornberry NA, Huang JQ. MacPherson DP. Black SC. Hornuge F. Lenardo. MI. Hasden. MR. BguS. Nisbolson DW.Call death attenuation by 'Usurpin', a mammalian DED-caspase homologue that precludes caspase8 recruitment and activation by the CD-95 (Fas, APO-1) receptor complex. Cell Death Differ $1998 ; 5: 271-288$.

18. Hu SM, Vincenz C, Ni J, Gentz R, Dixit VM: I-FLICE, a novel inhibitor of tumor necrosis factor receptor-1- and CD-95-induced apoptosis. J Biol Chem 1997; 272:17255-17257.

19. Nogae S, Miyazaki M, Kobayashi N, Saito T, Abe K, Saito H, Nakane PK, Nakanishi Y, Koji T: Induction of apoptosis in ischemia-reperfusion model of mouse kidney: Possible involvement of Fas. J Am Soc Nephrol 1998; 9:620-631.

20. Daemen MARC, Van de Ven WCM, Heineman E, Buurman WA: Pro- and anti-inflammatory mechanisms in renal reperfusion injury in mice. Modulation by endogenous tumor necrosis factor alpha and interleukin-10. Transplantation 1999; 67:792-800.

21. Chandler JM, Cohen GM, MacFarlane M: Different subcellular distribution of caspase-3 and caspase-7 following Fas-induced apoptosis in mouse liver. J Biol Chem 1998; 273:10815-10818.

22. Van de Craen M, Declercq W, Van den Brande I, Fiers W, Vandenabeele P: The proteolytic procaspase activation network: an in vitro analysis. Cell Death Differ 1999; 6:1117-1124.

23. Staley K, Blaschke AJ, Chun J: Apoptotic DNA fragmentation is detected by a semiquantitative ligation-mediated PCR of blunt DNA ends. Cell Death Differ 1997; 4:66-75.

24. Maatman RG, Van de Westerloo EM, Van Kuppevelt TH, Veerkamp JH: Molecular identification of the liver- and the heart-type fatty acid-binding proteins in human and rat kidney. Use of the reverse transcriptase polymerase chain reaction. Biochem $J$ 1992; 288:285-290.

25. Kimura H, Odani S, Nishi S, Sato H, Arakawa M, Ono T: Primary structure and cellular distribution of two fatty acid-binding proteins in adult rat kidneys. J Biol Chem 1991; 266:5963-5972.

26. Laight DW, Lad N, Woodward B, Waterfall JF: Assessment of myeloperoxidase activity in renal tissue after ischemia/reperfusion. Eur J Pharmacol 1994: 292:81-88. 
27. Melchior F, Gerace L: Mechanisms of nuclear protein import. Curr Opin Cell Biol 1995; 7:310318.

28. Yasuhara N, Eguchi Y, Tachibana T, Imamoto N, Yoneda Y, Tsujimoto Y: Essential role of active nuclear transport in apoptosis. Genes Cells 1997; 2:55-64.

29. Orth K, O'Rourke K, Salvesen GS, Dixit VM: Molecular ordering of apoptotic mammalian CED-3/ICE-like proteases. J Biol Chem 1996; 271:20977-20980.

30. Yaoita H, Ogawa K, Maehara K, Maruyama Y: Attenuation of ischemia/reperfusion injury in rats by a caspase inhibitor. Circulation 1998; 97:276-281.

31. Van de Craen M, Van den Brande I, Declercq W, Irmler M, Beyaert R, Tschopp J, Fiers W, Vandenabeele P: Cleavage of caspase family members by granzyme B: a comparative study in vitro. Eur J Immunol 1997; 27:1296-1299.

32. Ruiz-Vela A, Gonzalez D, De Buitrago G, Martinez AC: Implication of calpain in caspase activation during $\mathrm{B}$ cell clonal deletion. EMBO J 1999; 18:4988-4998.

33. Yoshida K, Inui M, Harada K, Saido TC, Sorimachi Y, Ishihara T, Kawashima S, Sobue K: Reperfusion of rat heart after brief ischemia induces proteolysis of calspectin (nonerythroid spectrin or fodrin) by calpain. Circ Res 1995; 77:603-610.

34. Harada K, Maekawa T, Abu SK, Yamashima T, Yoshida K: Translocation and down-regulation of protein kinase $\mathrm{C}$-alpha, -beta, and -gamma isoforms during ischemia-reperfusion in rat brain. $J$ Neurochem 1999; 72:2556-2564.

35. Kohli V, Madden JF, Bentley RC, Clavien PA: Calpain mediates ischemic injury of the liver through modulation of apoptosis and necrosis. Gastroenterology 1999; 116:168-178.

36. Shi Y, Melnikov V, Schrier RW, Edelstein CL: Downregulation of the calpain inhibitor protein calpastatin by caspases during renal ischemia-reperfusion. Am J Physiol 2000; 279:F509-F5I7.

37. Edelstein CL, Shi Y, Schrier RW: Role of caspases in hypoxia-induced necrosis of rat renal proximal tubules. J Am Soc Nephrol 1999; 10:1940-1949.

38. Tran TB, Miller RJ: Apoptosis: death and transfiguration. Science Med 1999; 6:18-27.

39. Nogae S, Miyazaki M, Kobayashi N, Saito T, Abe K, Saito H, Nakane PK, Nakanishi Y, Koji T: Induction of apoptosis in ischemia-reperfusion model of mouse kidney: Possible involvement of Fas. J Am Soc Nephrol 1998; 9:620-631.

40. Feldenberg LR, Thevananther S, Del Rio M, De Leon M, Devarajan P: Partial ATP depletion induces Fas- and caspase-mediated apoptosis in MDCK cells. Am J Physiol 1999; 276:F837. F846.

41. Tepper CG, Seldin MF: Modulation of caspase-8 and FLICE-inhibitory protein expression as a potential mechanism of Epstein-Barr virus tumorigenesis in Burkitt's lymphoma. Blood 1999; 94:1727-1737.

42. Medema JP, De Jong J, Van Hal T, Melief CJ, Offringa R: Immune escape of tumors in vivo by expression of cellular FLICE-inhibitory protein. J Exp Med 1999; 190:1033-1038.

43. Scaffidi C, Schmitz I, Krammer PH, Peter ME: The role of cFLIP in modulation of CD95induced apoptosis. J Biol Chem 1999; 274:1541-1548.

44. Johnson DE, Gastman BR. Wieckowski E, Wang GQ. Amoscato A, Delach SM, Rabinowich H: Inhibitor of apoptosis protein hILP undergoes caspase-mediated cleavage during $\mathrm{T}$ lymphocyte apoptosis. Cancer Res 2000; 60:1818-1823.

45. Suzuki A: Amyloid beta-protein induces necrotic cell death mediated by ICE cascade in PCI2 cells. Exp Cell Res 1997: 234:507-511.

46. Wijnen RM, Booster MH. Stubenitsky BM. De Boer J. Heineman E, Kootstra G: Outcome of transplantation of non-heart-beating donor kidneys. Lancet 1995: 345:1067-1070. 


\section{Chapter 9}

47. McLaren AJ, Jassem W, Gray DW, Fuggle SV, Welsh KI, Morris PJ: Delayed graft function: risk factors and the relative effects of early function and acute rejection on long-term survival in cadaveric renal transplantation. Clin Transplant 1999; 13:266-272. 


\section{Summary/Samenvatting}




\section{SUMMARY}

In CHAPTER 1 the clinical relevance of $\mathrm{I} / \mathrm{R}$-injury is outlined. Clinical as well as experimental studies have contributed to the elucidation of crucial mechanistic aspects of I/Rpathophysiology. The specific contributions of apoptosis and inflammation to the development of tissue damage as a consequence of $I / R$ are discussed. The first section deals with some of the more general morphological and biochemical aspects of apoptosis and necrosis. While apoptosis paradigmatically is a directed and energy dependent process that is not followed by an inflammatory response, necrosis is believed to mainly represent gross injury to the cell followed by inflammation. Several arguments are put forth suggesting that apoptosis and necrosis, in practice as well as from a functional point of view, may be indistinguishable forms of cell death.

In the second section the general principles of induction and execution of apoptosis are described. Apoptosis can be induced by death-receptor dependent (extrinsic) or deathreceptor independent (intrinsic) stimuli. Subsequently, caspases are enzymes that mediate the intracellular execution of apoptosis, which will ultimately result in the apoptotic phenotype. The third section outlines the important role of inflammation in the development of $\mathrm{I} / \mathrm{R}$-induced organ injury. Aspecific tissue damage is inflicted by oxygen free radicals produced as a result of compromised energy metabolism or neutrophil oxidative burst activity. I/R-induced acute inflammation is characterized by influx of neutrophils to the postischemic tissue where they contribute to tissue injury. Also, delayed I/R-induced inflammation that enhances tissue immunogenicity is discussed.

The fourth section of the introduction addresses the interplay between apoptosis and inflammation in the course of $\mathrm{I} / \mathrm{R}$. Besides apoptosis, activated caspases can mediate the proteolytic activation of pro-inflammatory cytokines such as IL-1 and EMAP-II in the course of $\mathrm{I} / \mathrm{R}$. These and other caspase substrates are potentially involved in I/R-injury pathogenesis. Moreover, natural endogenous protection mechanisms such as cFLIP accumulation (which prevents activation of caspase- 8 and therefore activation of the extrinsic apoptotic pathway) or the acute phase response can inhibit apoptosis and inflammation following $\mathrm{I} / \mathrm{R}$ and may determine the outcome.

At the end of the introduction, clinical perspectives of perceiving apoptosis as a functional contributor to I/R-injury are evaluated. Pharmacological modulation of apoptosis by means of specific inhibition of apoptotic pathways may be applied to treat a variety of clinical conditions including renal I/R-injury. Besides, diagnostic means to predict the extent of reperfusion injury in ischemically injured transplant grafts could be based upon the important role of apoptosis in I/R pathophysiology. It is concluded that an overall balance between factors favoring either necrosis, apoptosis or cell survival will ultimately determine the amount of reperfusion injury. 
In CHAPTER 2 the interplay between $\mathrm{I} / \mathrm{R}$-induced renal inflammation and apoptosis was investigated. To this end, the roles of the pro-inflammatory mediator TNF- $\alpha$ and the antiinflammatory mediator IL-10 in inflammation and apoptosis following renal I/R were studied. Mice were subjected to $45 \mathrm{~min}$ of ischemia followed by reperfusion and subsequently administered neutralizing antibodies against either TNF- $\alpha$ (TN3), IL-10 (JES5$2 \mathrm{~A} 5$ ) or control. After 1 day of reperfusion anti- TNF- $\alpha$ treatment reduced while anti-IL10 treatment exacerbated postischemic renal injury, inflammation and, to a lesser extent, apoptosis as measured by changes in blood urea nitrogen content, immunohistologically detectable renal TNF- $\alpha$ protein and neutrophils, histological integrity of renal parenchyma and DNA-ladder formation. Furthermore, anti-IL-10 treatment enhanced MHC class I and II expression at day 7 as measured by enzyme immuno assay and immunohistology. These data indicate that the extent of reperfusion induced apoptosis is modulated by the inflammatory response during which locally produced TNF- $\alpha$ plays a significant role in the development of tissue injury. Subsequently, this pro-inflammatory reaction is accompanied by endogenous production of the anti-inflammatory cytokine IL-10 which serves as a physiological counterbalance to the effects of TNF- $\alpha$.

In CHAPTER 3 delayed I/R-induced inflammation, involving IFN- $\gamma$ dependent upregulation of MHC class I and II antigen expression, is addressed. Employing a murine model of renal ischemia we show that renal IL-18 mRNA upregulation coincides with caspase1 activation at day 1 following ischemia. IFN- $\gamma$ as well as IL- 12 mRNA are subsequently upregulated at day 6 following ischemia. Combined but not separate in vivo neutralization of the IFN- $\gamma$ inducing cytokines IL- 12 and IL- 18 reduces IFN- $\gamma$ dependent MHC class I and II upregulation to a similar extent as IFN- $\gamma$ neutralization, suggesting the involvement of functional IL-12, IL-18 and IFN- $\gamma$ protein. These results reveal a novel relationship between tissue injury of non-microbial origin and the induction of IL-12 as well as IL-18. The collaboration observed between endogenous IL-12 and IL-18 in the induction of IFN- $\gamma$ after renal I/R, resembles the immune response to bacterial infections.

In CHAPTER 4 the functional role of apoptosis in the induction of inflammation and organ damage after renal ischemia was investigated. Using a murine model, we demonstrate a relation between apoptosis and subsequent inflammation. Administration at the time of reperfusion of the anti-apoptotic agents insulin like growth factor-1 (IGF-1) and zVADfmk, a caspase inactivator, prevented the early onset of renal apoptosis but also inflammation and tissue injury. Conversely, when administered after onset of apoptosis, these protective effects were completely abrogated. The presence of apoptosis was directly correlated with post-translational processing of the chemoattractant endothelial monocyte-activating polypeptide II (EMAP-II), which may explain apoptosis-induced influx and sequestration of leukocytes in the reperfused kidney. These results strongly suggest that apoptosis is a crucial event, underlying reperfusion induced inflammation and subsequent tissue injury. 
In CHAPTER 5, employing the same experimental model of renal I/R injury, we tested the hypothesis that $\mathrm{I} / \mathrm{R}$ of a kidney induces an acute phase response and that mediators of this response attenuate $\mathrm{I} / \mathrm{R}$ induced apoptosis and inflammation. These mediators, including $\alpha .1$-acid glycoprotein (AGP) and $\alpha 1$-antitrypsin (AAT) significantly decreased postischemic apoptosis as reflected by internucleosomal DNA cleavage, TUNEL histology and caspase-1- and -3-like activation. I/R-induced inflammation, investigated by TNF- $\alpha$ histology and determination of renal neutrophil influx was also decreased. Moreover, $I / R$ induced an acute phase response with potential protective properties. It is speculated that the acute phase response is functionally involved in the development of $I / R$ injury. Similar to I/R-induced up-regulation of MHC class I and II, an I/R-induced (local or hepatic) acute phase response is likely to encompass strong physiological protection against tissue injury ( $\mathrm{I} / \mathrm{R})$ and the consequences of tissue injury (for instance secondary infection).

In CHAPTER 6 we hypothesize that caspase-1 activation is a key event in the process of apoptosis/caspase-dependent inflammation as observed during development of renal reperfusion injury. Such involvement of caspase-1 is likely since this enzyme has been reported to participate not only in the apoptotic process, but also in inflammation by means of activating the pro-inflammatory cytokines IL-1 and IL-18. As compared to controls, caspase-1 deficient knockout mice subjected to $45 \mathrm{~min}$ of renal ischemia followed by $24 \mathrm{~h}$ of reperfusion showed no improvement of renal function as reflected by serum ureum and creatinine. These mice showed a slightly attenuated renal inflammatory response as indicated by a decreased renal neutrophil influx, but failed to show significantly altered intrarenal TNF- $\alpha$ production. Moreover, caspase- 1 deficient mice exhibited a clear reperfusion-induced apoptotic reaction as reflected by renal TUNEL histology and internucleosomal DNA cleavage. Consistently, treatment with agents capable of neutralizing the pro-inflammatory activation products of caspase-1 (IL-1 receptor antagonist, anti IL-1 receptor antibody, anti IL-18 antibody) also minimally reduced renal functional deterioration, inflammation and apoptosis after $24 \mathrm{~h}$ of reperfusion. These findings suggest that activated caspase-1 and its inflammatory cleavage products are involved in, but not crucial to the induction of inflammation after I/R. Hence, beside caspase-1, other (combinations of) activated caspases are likely to play a more prominent role in ischemia-reperfusion-induced inflammation.

In CHAPTER 7 we investigate the relation between apoptosis and early chemokine induction in the course of renal I/R. Chemokine induction is an early prerequisite for the development of a local inflammatory response, as observed following I/R. Employing a murine model of renal I/R-injury we demonstrate renal up-regulation of the CXC chemokines KC and MIP-2 at the mRNA and protein level after 1 to $16 \mathrm{~h}$ of reperfusion, coinciding with intrarenal activation of the chemokine EMAP-II. Treatment with the cas- 
pase inhibitor zVAD-fmk upon reperfusion effectively prevented I/R-induced renal apoptosis, KC and MIP-2 up-regulation and EMAP-II activation after $2 \mathrm{~h}$ of reperfusion as well as neutrophil influx and functional impairment after $24 \mathrm{~h}$ of reperfusion. These data for the first time show that chemokine induction following $\mathrm{I} / \mathrm{R}$ is dependent on caspase activation.

In CHAPTER 8 the potential of Heart Fatty Acid-Binding Protein (H-FABP) as a marker for renal I/R-injury was evaluated in a rat model. H-FABP is a low molecular intra-cytoplasmatic protein that is among others involved in intracellular fatty-acid transport and is present in renal as well as cardiac cells. H-FABP has been proven to be a powerful tool for diagnosing tissue injury since it is released from damaged cells. After cross-clamping the renal vessels for different times and subsequent reperfusion, blood samples and renal biopsies were obtained for further analysis. Serum H-FABP was analyzed by ELISA and compared with serum Glutathione S-Transferase (GST) and LDH levels. Immunohistochemical staining of rat kidney showed H-FABP presence in distal tubular cells. From 15 min onwards after reperfusion, mean H-FABP plasma levels were significantly increased in the 20,40 and $60 \mathrm{~min}$ ischemia groups compared to the sham group. GST and LDH levels were only significantly raised in the $60 \mathrm{~min}$ ischemia group, starting at 15 and $60 \mathrm{~min}$ after reperfusion, respectively. This shows that plasma LDH and GST reliably detect severe renal I/R injury in respectively the late and early reperfusion phase, but fail to detect mild I/R injury. Plasma H-FABP reliably detects mild as well as severe I/R injury in the early reperfusion phase. Plasma H-FABP levels may be successfuly used as a viability test during machine perfusion of NHB donor kidneys.

In CHAPTER 9 the early involvement of pro-apoptotic caspase-7 and anti-apoptotic cFLIP during renal $\mathrm{I} / \mathrm{R}$ was investigated. Insight in the early and critical role of apoptosis in the development of I/R-injury and the way by which early biochemical events lead to later development of tissue damage, could yield new therapeutic as well as diagnostic means to face the clinical problem of reperfusion injury. Extended ischemic times up to $45 \mathrm{~min}$, with or without $2 \mathrm{~h}$ of reperfusion, induced formation of $19 \mathrm{kDa}$ active caspase- 7 and reduced intrarenal cFLIP content. Treatment with the caspase inhibitor zVAD-fmk upon reperfusion failed to prevent caspase-7 activation but effectively reduced cFLIP depletion. The length of renal ischemia paralleled with the exent of renal apoptosis and tubular damage after $2 \mathrm{~h}$ of reperfusion as measured by quantification of intranucleosomal DNA cleavage and serum H-FABP levels, respectively. At $24 \mathrm{~h}$ of reperfusion, the length of ischemia correlated with the extent of renal inflammation and kidney dysfunction as reflected by renal neutrophil accumulation and serum ureum and creatinine levels. These findings are the first to show apoptogenic processes during ischemia that correlate with the extent of apoptosis, inflammation, tissue damage and dysfunction upon reperfusion. Caspase-7 activation and cFLIP depletion during ischemia may even be successfuly 
Summary

employed to predict the amount of damage to grafts subjected to prolonged ischemia prior to transplantation. These results also attest to the potential of anti-apoptotic therapy in the prevention of clinical reperfusion injury. 


\section{SAMENVATting}

In HoOfdSTUK 1 wordt de klinisiche relevantie van I/R-schade besproken. Zowel klinisch als experimenteel onderzoek heeft bijgedragen aan het in kaart brengen van belangrijke pathofysiologische eigenschappen van I/R-schade. De specifieke bijdrage van apoptose en ontsteking aan het ontstaan van weefselschade ten gevolge van I/R komt aan de orde. Het eerste gedeelte behandelt algemene morfologische en biochemische aspecten van apoptose en necrose. Apoptose wordt paradigmatisch gezien als een gericht en actief proces dat geen aanleiding vormt tot het ontstaan van een ontstekingsreaktie. Necrose daarentegen wordt verondersteld het resultaat te zijn van uitgebreide beschadiging van een cel en vormt de aanleiding tot een ontstekingsreaktie. Meerdere argumenten worden gegeven vóór een voorstelling van zaken waarbij apoptose en necrose, in praktijk en functioneel beschouwd, twee niet te onderscheiden vormen van celdood zijn.

In het tweede gedeelte worden de algemene beginselen van inductie en executie van apoptose beschreven. Apoptose kan worden geïnduceerd door celdood-receptor afhankelijke (extrinsieke) alsook door celdood-receptor onafhankelijke (intrinsieke) stimuli. Vervolgens zijn de caspasen enzymen die verantwoordelijk zijn voor de intracellulaire executie van apoptose, hetgeen uiteindelijk leidt tot het manifest worden van het apoptotische fenotype. Het derde gedeelte beschrijft de rol van de ontstekingsreaktie in het ontstaan van I/R-schade. Aspecifieke weefselschade wordt veroorzaakt door vrije zuurstof radicalen die vrijkomen tengevolge van een belast energie metabolisme of door uitstort van de inhoud van geactiveerde neutrofielen. De acute ontstekingsreaktie wordt gekenmerkt door lokale influx van deze neutrofielen in het gereperfundeerde weefsel alwaar zij een bijdrage leveren aan het ontstaan van weefselschade. Daarnaast wordt de sub-acute ontstekingsreactie die tengevolge van $\mathrm{I} / \mathrm{R}$ ontstaat en de immunogeniciteit van het weefsel verhoogt, besproken.

Het vierde gedeelte van de introductie behandelt de interactie tussen apoptose en ontsteking in het verloop van I/R. Naast apoptose, kunnen geactiveerde caspasen tijdens I/R de proteolytische activatie van ontstekingsbevorderende cytokinen als EMAP-II en IL-1 mediëren. Deze en andere substraten voor caspasen zijn mogelijk betrokken bij de pathogenese van I/R-schade. Bovendien spelen endogene natuurlijke protectieve mechanismen een rol bij het beperken van apoptose en ontsteking tengevolge van I/R. Tot deze processen behoren cFLIP accumulatie (waardoor caspase-8 niet meer kan worden geactiveerd en activatie van extrinsieke apoptose voorkomen wordt) en de acute fase respons.

Het einde van de introductie gaat in op de klinische implicaties van het concept van functionele betrokkenheid van apoptose bij het ontstaan van I/R-schade. Farmacologische modulatie van apoptose via specifieke inhibitie van apoptotische cascades kan mogelijk aangewend worden ter behandeling van uiteenlopende klinische aandoeningen waaronder nier I/R-schade. Bovendien is het mogelijk om op basis van de pathofysiologische betrokkenheid van apoptose diagnostische technieken te ontwikkelen 
die de mate van reperfusieschade kunnen voorspellen nog voordat een ischemisch beschadigd donororgaan wordt getransplanteerd. Er wordt geconcludeerd dat een algemene balans tussen processen die necrose of apoptose danwel overleving van de cel bevorderen, de uiteindelijke hoeveelheid reperfusieschade bepalen.

In HoOFDSTUK 2 wordt onderzoek beschreven naar de interactie tussen I/R-geïnduceerde nier apoptose en ontsteking. Hiervoor werd de rol van de ontstekingsbevorderende mediator TNF- $\alpha$ en de ontstekingsremmende mediator IL-10 bestudeerd. Er werd gebruik gemaakt van een experimenteel muizen model waarin een nier werd blootgesteld aan 45 minuten ischemie gevolgd door reperfusie en dieren werden behandeld met neutraliserende antistoffen gericht tegen TNF- $\alpha$ (TN3), IL-10 (JES5-2A5) of controle. Anti-TNF$\alpha$ behandeling verminderde de postischemische nierschade (histologie), ontsteking (renale TNF- $\alpha$ synthese en neutrofiel influx) en apoptose (formatie van DNA ladders), terwijl anti-IL-10 behandeling deze parameters juist bevorderde na 1 dag reperfusie. Anti-IL-10 behandeling verhoogde bovendien de renale expressie van MHC klasse I en II, gemeten na 7 dagen reperfusie door middel van een enzym immuno assay en immunohistologie. Deze resultaten tonen aan dat de mate van I/R-geïnduceerde apoptose wordt beinvloed door de acute ontstekingsreaktie in het kader waarvan lokaal geproduceerd TNF- $\alpha$ een prominente rol speelt. Deze ontstekingsreactie gaat tevens gepaard met endogene productie van het ontstekingsremmende cytokine IL-10, hetgeen een fysiologisch tegenwicht biedt ter compensatie van de effecten van TNF- $\alpha$.

In Hoofdstuk 3 komt de sub-acute I/R-geïnduiceerde ontsteking aan de orde waarbij er sprake is van IFN- $\gamma$ afhankelijke, verhoogde MHC klasse I en II produktie. Door gebruik te maken van een muizen model voor nier I/R-schade wordt aangetoond dat verhoogde renale IL-18 mRNA produktie gelijktijdig plaatsvindt met caspase-1 activatie op dag 1 na ischemie. Vervolgens, op dag 6 na ischemie, is er sprake van verhoogde renale IFN$\gamma$ mRNA en IL-12 mRNA produktie. Enkel gecombineerde, maar niet separate in vivo neutralisatie van de IFN- $\gamma$ inducerende cytokinen IL-12 en IL-18 verminderden de IFN$\gamma$ afhankelijke renale MHC klasse I en II produktie in dezelfde mate als IFN- $\gamma$ neutralisatie. Dit laatste wijst op functionele betrokkenheid van IL-12, IL-18 alsook IFN- $\gamma$ eiwit. Deze resultaten leggen een nieuwe relatie bloot tussen weefselschade van niet-microbiële oorsprong en de inductie van zowel IL-12 als IL-18. De wijze waarop endogeen IL-12 en IL-18 samenwerken om IFN- $\gamma$ te induceren in het verloop van nier $I / R$, vertoont sterke overeenkomst met de lokale immuunrespons op bacteriële infecties.

In Hoofdstuk 4 wordt onderzoek beschreven naar de functionele rol van apoptose in het ontstaan van ontsteking en weefselschade na nier I/R. Door gebruik te maken van een muizen model wordt een oorzakelijk verband aangetoond tussen apoptose en de hierop volgende ontstekingsreaktie. Het op het moment van reperfusie toedienen van de anti- 
apoptotische groeifactor IGF-1 of de caspase inactivator zVAD-fmk voorkwam vroege I/R-geïnduceerde nier apoptose, ontsteking en orgaanschade. Omgekeerd, wanneer deze anti-apoptotische farmaca werden aangewendt ná het ontstaan van apoptose, traden de beschermende effecten niet op. De aanwezigheid van apoptose correleerde met de posttranslationele activatie van het chemokine EMAP-II, hetgeen potentieel een verklaring vormt voor de waargenomen apoptose-afhankelijke influx van neutrofielen in de gereperfundeerde nier. Deze resultaten suggereren sterk dat apoptose een cruciale voorwaarde is voor het ontstaan van I/R-geïnduceerde ontsteking en weefselschade.

In Hoofdstuk 5, gebruik makend van hetzelfde muizen nier I/R-model, wordt de hypothese onderzocht dat nier $I / R$ een acute fase respons induceert en dat acute fase eiwitten I/R-geïnduceerde apoptose en ontsteking verminderen. De acute fase eiwitten $\alpha 1$-acid glycoproteine (AGP) en $\alpha 1$-antitrypsine (AAT) verminderden significant postischemische nier apoptose gemeten door bepaling van intranucleosomale DNA klieving, TUNEL histologie alsmede caspase-1 en caspase- 3 type activatie. Daarnaast was de I/Rgeïnduceerde ontsteking, onderzocht middels TNF- $\alpha$ immunohistologie en nier neutrofiel influx, eveneens duidelijk afgenomen. Bovendien vormde $\mathrm{I} / \mathrm{R}$ de aanleiding voor het ontstaan van een acute fase respons met potentieel beschermende eigenschappen. Er kan hierom worden gespeculeerd dat de acute fase respons functioneel betrokken is bij de ontwikkeling van I/R-geïnduceerde orgaanschade. Overeenkomstig I/R-geïnduceerde verhoogde produktie van MHC klasse I en II, is de acute fase respons (lokaal of hepatisch) die optreedt na $I / R$ eveneens deel van een fysiologisch systeem dat bescherming biedt tegen een overmaat aan weefselschade (I/R) en de gevolgen van weefselschade (bijvoorbeeld secundaire infectie).

In Hoofdstuk 6 wordt gehypothetiseerd dat caspase-1 activatie een essentiële gebeurtenis is in het proces van apoptose/caspase-afhankelijke ontsteking zoals waargenomen na nier I/R. Zulke betrokkenheid van caspase-1 is plausibel omdat van dit enzym is aangetoond dat het naast apoptose ook ontsteking kan mediëren middels activatie van de ontstekingsbevorderende cytokinen IL-1 en IL-18. Vergeleken met controles vertoonden caspase-1 deficiente knockout muizen blootgesteld aan 45 minuten nierischemie gevolgd door 24 uur reperfusie geen verbetering van nierfunktie gemeten door bepaling van serum ureum en creatinine spiegels. Wel vertoonden deze muizen een licht afgenomen renale ontstekingsreaktie gemeten aan de hand van kwantificatie van neutrofiel influx. Van een evidente afname in intrarenale TNF- $\alpha$ productie was bij deze muizen geen sprake. Caspase-1 deficiënte muizen vertoonden een duidelijke reperfusie-geïnduceerde apoptotische reaktie in de nier zoals weerspiegeld door TUNEL histologie en internucleosomale DNA klieving. Overeenkomstig bleken behandelingen met neutraliserende agentia gericht tegen de ontstekingsbevorderende activatie producten van caspase-1 (IL-1 receptor antagonist, anti-IL-1 receptor en anti-IL-18 antilichamen) slechts minimaal in staat 
nierfunctie, ontsteking en apoptose te kunnen verbeteren na 24 uur reperfusie. Deze bevindingen suggereren dat geactiveerd caspase-1 en haar ontstekingsbevorderende klievingsproducten betrokken zijn bij, maar niet van cruciaal belang zijn voor het ontstaan van ontsteking na $I / R$. Het is daarom waarschijnlijk dat er naast caspase-1, andere (combinaties van) geactiveerde caspasen een belangrijke rol spelen bij het ontstaan van I/R-geïnduceerde ontsteking.

In HoOfdSTuk 7 wordt de relatie onderzocht tussen apoptose en vroege chemokine inductie na $\mathrm{I} / \mathrm{R}$. Vroege produktie van chemokines is een voorwaarde voor de ontwikkeling van een lokale ontstekingsreaktie, zoals gezien na nier $\mathrm{I} / \mathrm{R}$. In een muizen model voor nier $\mathrm{I} / \mathrm{R}$ wordt aangetoond dat verhoogde renale produktie op eiwit en mRNA niveau van de CXC chemokinen KC en MIP-2, samenvalt met intrarenale activatie van het chemokine EMAP-II. Behandeling met de caspase inactivator zVAD-fmk ten tijde van reperfusie voorkwam het ontstaan van nier apoptose, inductie van KC en MIP-2 alsook activatie van EMAP-II na 2 uur reperfusie. Daarnaast voorkwam zVAD-fmk nier neutrofiel influx en verslechtering van nierfunktie na 24 uur reperfusie. Deze gegevens tonen voor het eerst aan dat chemokine inductie ten gevolge van $\mathrm{I} / \mathrm{R}$ afhankelijk is van caspase activatie.

In HoOfDSTUK 8 wordt het potentieel van $\mathrm{H}$-FABP als marker voor nier $\mathrm{I} / \mathrm{R}$-schade in een ratten model geëvalueerd. H-FABP is een laag-moleculair intra-cytoplasmatisch eiwit dat onder andere betrokken is bij het intracellulaire vetzuur transport en zich zowel in hartals in niercellen bevindt. Plasma H-FABP bepaling heeft zich zeer bruikbaar getoond ter diagnostisering van cardiale weefselschade omdat het vrijkomt uit beschadigde hartcellen. Na verschillende periodes ischemie, gevolgd door reperfusie werden bloedmonsters en nierbiopten ter analyse afgenomen. Serum H-FABP spiegels werden bepaald met behulp van een ELISA en vergeleken met serum Glutathion S-Transferase (GST) en LDH spiegels. Immunohistologie voor ratten H-FABP toonde evident aanwezigheid van dit eiwit in distaal tubulus epitheel aan. Vergeleken met de sham groep stegen vanaf 15 minuten reperfusie de plasma $\mathrm{H}-\mathrm{FABP}$ spiegels significant in ratten blootgesteld aan ischemie gedurende 20, 40 en 60 minuten. Plasma GST en LDH spiegels waren slechts significant verhoogd in ratten blootgesteld aan 60 minuten nierischemie, respectievelijk beginnend vanaf 15 en 60 minuten na ischemie. Dit laat zien dat plasma LDH en GST spiegels betrouwbaar ernstige, maar niet matige I/R-schade in respectievelijk de late en vroege reperfusiefase kunnen detecteren. Met plasma H-FABP spiegels daarentegen is het mogelijk zowel milde als ernstige $\mathrm{I} / \mathrm{R}$-schade te detecteren in de vroege reperfusiefase. Mogelijk kan bepaling van plasma H-FABP worden aangewend als succesvolle "viability test" gedurende machineperfusie van NHB donor nieren. 
In HoOFDSTUK 9 wordt tenslotte de vroege betrokkenheid van pro-apoptotisch caspase-7 en anti-apoptotisch cFLIP bij nier I/R geanalyseerd. Inzichten in de vroege en kritieke rol die apoptose speelt bij het ontstaan van I/R-schade en de wijze waarop vroege biochemische veranderingen leiden tot latere ontwikkeling van weefselschade, voorzien in nieuwe therapeutische en diagnostische mogelijkheden ter detectie en behandeling van klinische I/R-schade. Ischemische periodes oplopend tot 45 minuten, al dan niet gevolgd door 2 uur reperfusie, induceerden formatie van $19 \mathrm{kDa}$ actief caspase- 7 en reduceerden de intrarenale hoeveelheid cFLIP. Behandeling met de caspase-inactivator zVAD-fmk ten tijde van reperfusie bleek niet in staat renale caspase-7 activatie te voorkomen, maar voorkwam wel cFLIP depletie in de nier. De duur van ischemie kwam zowel overeen met de mate van apoptose (internucleosomale DNA klieving) als met de mate van tubulaire schade (plasma H-FABP spiegels) 2 uur na ischemie. Na 24 uur reperfusie kwam de lengte van ischemie overeen met de mate van nier ontsteking en dysfunktie weerspiegeld door accumulatie van neutrofielen in de nier en serum ureum en creatinine spiegels. Deze resultaten tonen voor het eerst aan dat apoptotische processen gedurende de ischemische fase correleren met de mate van apoptose, ontsteking en orgaanschade zoals waargenomen ten tijde van reperfusie. Caspase-7 activatie en cFLIP depletie gedurende ischemie kunnen mogelijk worden aangewend om de hoeveelheid orgaanschade te voorspellen waaraan ischemisch beschadigde donor organen na transplantatie zullen worden blootgesteld. Tevens vormen deze resultaten een argument voor de effectiviteit van antiapoptotische therapie ter behandeling van klinische reperfusieschade. 
Dankwoord 


\section{Dankwoord}

Mijn promotor, Professor Wim Buurman. Beste Wim, zoveel superlatieven zijn al op schrift gesteld over je creatieve geest, de veelomvattende relevanties die je zo luchtig kan koppelen aan stoffige wetenschappelijkheden en de onvermoeibare gedrevenheid waarmee je door de jaren heen ons labje in de wereldtop heb weten te houden. Je was een goeie baas en het is een ongeloofelijke eer jouw eerste promovendus te mogen zijn.

Ik wil iedereen bedanken met wie ik de afgelopen jaren goed heb samengewerkt. In het bijzonder dank ik Professor Gauke Kootstra vanwege de mogelijkheid om onder zijn beroemde vlag het onderwerp nier ischemie-reperfusie schade te kunnen onderzoeken. Ook ben ik Professor Peter Vandenabeele en Dr. Trui Denecker van de Universiteit van Gent zeer erkentelijk voor hun gastvrijheid tijdens mijn verblijf in Gent en voor hun erg succesvolle moleculaire bijdragen aan dit proefschrift. Zonder uw inbreng op het gebied caspase-biologie had ons werk nooit zo competitief kunnen zijn. I sincerely thank Professor Mathias Clauss of the Max Planck Instituut in Bad Nauheim for his contributions on the subject of EMAP-II. Mijn hartelijke dank gaat tevens uit naar de beoordelingscommissie van dit proefschrift onder voorzitterschap van Professor Donckerwolcke.

Zonder een aantal goede collegae was dit boekje er ook niet geweest. Beste Tim, jouw kennis van moleculair biologische technieken heeft dit proefschrift tot iets bijzonders gemaakt. Je weet dat je nog lang niet aan je taks zit en je hebt inmiddels bewezen dat je ook op wetenschappelijk gebied een zwaargewicht bent. Beste Kees, altijd onverdroten, menig massa-experiment is ons ten deel gevallen en ook onze gemeenschappelijke voorliefde voor de derde helft was een goede basis tot samenwerking. Jouw komst naar Maastricht was zowel wetenschappelijk (het aantal bloedstollende momenten op het lab nam aanzienlijk toe) maar ook sociaal gezien een welkome vernieuwingsimpuls. Mijn goede vriend en collega Vincent (vincentheerstnogsteedsinmaastricht) Heemskerk. Samen met jou en Mart-Jan vormde ik het standvastige mannelijke heelkunde onderzoeks front in de goede ouwe tijd op Wim's lab. Jullie opereerden de biggen en ik de muizen. Onze survival-tochten in Yosemite National Park waren memorabel, evenals schieten met 44 magnums en housen tot het licht werd. Ik hoop dat je na zoveel inspanningen de mogelijkheid krijgt om je heelkundige ambities waar te maken.

Voor veel collegae heb ik de afgelopen jaren een bijzondere waardering gekregen. Hartelijk dank aan mijn kamergenoten, Nicole, Trudi, Mieke, Maarten, Danielle, Marloes, Erik, Mohammed, Kiyoko en Misha. Het was wat krap maar wel de moeite waard. Bedankt Anita (dat JCI praatgroepje moest er dan toch maar eens van komen), Jur (onze korte samenwerking was een genoegen en daarnaast zeer productief), Bart (met een gerust hart draag ik de fakkel aan je over), Isabel, Annemarie, Monique (het was jammer genoeg heel kort, maar wel erg krachtig), Jessica, Judith, Patricia, Mehmet, Juanita, Mark en Gaby. Niet te vergeten zijn de secretaresses die menige dasknoop voor mij hebben gestrikt en die mij met de nodige ondersteunende handelingen/gesprekken terzijde 
hebben gestaan, bedankt Mickey en Brigitte. En alle studenten Isa, Brigitte, Isabelle, Nicole, Isolde, neef Pieter, Erik, Rudi, Ingrid, Peter, Paul, Jenni, Sjoerd, Robert, Harald en natuurlijk Femke.

Iemand wie ik bijzonder erkentelijk ben is Dr. Harrie Kurvers. Beste Harrie, het is inmiddels al wat jaren geleden en ondanks het feit dat je me altijd hebt verteld dat ik het langzaamste jongetje van de klas was, heb je me wel geleerd hoe ik mijn veters moest strikken. Bedankt nog daarvoor. Veel leerlingen van jouw "klasje", zijn inmiddels voortrekkers op het gebied van klinisch en basaal onderzoek waaronder Francois (Fransje) van Dielen, Pieter Bullens, Dr. Esther Lutgens (CL!), Roland Beuk, Xander Wehrens, Trifon Vainas, Ewald Dumont, Ruben Dammers en last but not least Ellen Rouwet (met wie ik altijd, met veel genoegen, de prijzenpot moest delen minus de provisie voor jouw inspanningen). Onze tijd op het Lab Microcirculatie was zeer de moeite waard.

Ik wil ook de medewerkers van het CPV hartelijk bedanken voor het verzorgen van de proefdieren op de momenten dat ik er niet was. Met name Harry, Brigitte, Peter, Frans en in het bijzonder Dr. Ton van den Bogaard voor het bieden van een inspirerend ethisch tegenwicht. Daarnaast wil ik Dr. Peter Frederik en Paul Bomans bedanken voor hun bijdrage aan die prachtige JCI september '99 cover die er niet was geweest zonder hun betrokkenheid. Ook wil ik Geert-Jan en Jo van de AV-dienst van het AZM bedanken voor hun zeer professionele inspanningen. Gerrit Kranenburg wil ik bedanken voor zijn geduldige hulp bij het gebruik van de CORBAS-robot. Ik ben Lei Beucken en Karin Scheele voorts erkentelijk voor de lay-out van dit proefschrift.

Er was er buiten het lab ook nog een leven dat best de moeite waard was. Het voordeel van de combinatie studeren-promoveren is dan ook dat de studententijd wat wordt opgerekt. Bedankt EHD Mezekouw voor vriendschap behalve in rethorische zin, SV Circumflex, de SUF-band (jullie waren onvergetelijk....Denis, Arjan, Bram, Kathy, Martijn, Bas en David) en Het Bestuur (Mark, Henno, Ritse \& Linda, Ellen en Marja). $\mathrm{Na}$ lang dralen komt er dan toch een eind aan dat studentenleven, maar ik had het zelfs voor dit proefschrift niet willen missen.

Mijn paranimfen Dr. Ferdinand le Noble en Rob van den Langenberg. Beste Ferdi, farmacoloog, fysioloog, embryoloog, DJ, muzikant, zoogdiervorser, structuurman, wetenschapssocioloog en vader. Vanaf de eerste dag dat we elkaar op het lab tegen het lijf liepen waren we goede vrienden. Er was geen illegale houseparty of jij zat in de organisatie en er was geen hoogexperimentele nieuwe Limburgse popband of jij was er de basgitarist van. Je bent een raswetenschapper waarop onze universiteit zuinig moet zijn. En beste Rob, jij was altijd mijn voornaamste externe adviseur, zowel wetenschappelijk (als editor van The Medical Journal of Medicine) alsook op andere expertisevlakken. Onze vakanties (samen met David en Jeroen) waren geweldig. Tof dat jullie beiden me terzijde willen staan. 
Ik wil mijn goede vriend Harry van Hout bedanken voor al onze diepe gesprekken nu en vroeger. Het waren wilde maar goede tijden. Meer dan wie dan ook wens ik jou wijsheid en vrede toe op de weg die je gaat. Welke tong je ook verkiest om in te spreken, ik zal proberen je te blijven verstaan. Aan jou draag ik, met veel bewondering, dit werk op.

Tenslotte wil ik mijn familie bedanken. In het bijzonder mijn tante Ineke (de microscoop die ik van je kreeg toen ik 7 werd, is nog goed van pas gekomen). Bedankt voor je voortdurende belangstelling. Broer Alex, Adriënne, Demi en Bas bedankt voor jullie steun en aanwezigheid. Pap en mam, jullie stonden altijd voor mij en mijn broer klaar, ook als de tijden minder waren. Als professionals in de gezondheidszorg waren en zijn jullie nog steeds een voorbeeld voor mij. Wat een geluk heb ik met zulke ouders.

Hartelijk dank iedereen.

Marc 
Curriculum Vitae 


\section{Curriculum Vitae}

Marc Daemen was born on queensday April $30^{\text {th }}$ in Geleen, the Netherlands. He attended high school at the Albert Schweitzer Atheneum in Geleen (Atheneum- $\beta$ ) from 1985 to 1991. From 1991 until 1996 he attended Medical School at the University of Maastricht. During his medical training he worked as a student researcher on the subject of neuropathic pain and reflex sympathetic dystrophy at the Department of General Surgery of the University of Maastricht (head Prof. Dr. G. Kootstra) under the guidance of Dr. H. Kurvers and Prof. Dr. P. Kitslaar. His studies were interrupted in 1993-1994 to focus on the latter and to be daily secretary of the oldest traditional student society of Maastricht (S.V. Circumflex). From June 1996 to December 1999 he was a research fellow at the Laboratory of Experimental Surgery of the University of Maastricht (head Prof. Dr. W. Buurman). During this period the work that is contained in this thesis was accomplished under the guidance of Prof. Dr. W. Buurman. In Januari 2000 he started his clinical rotations in anticipation on acquiring his Medical Degree in Januari of the year 2002. 


\section{Publications}




\section{AWARDS}

Student Research Prize 1994-1995 Stichting Wetenschappelijk Onderzoek Limburg of the Faculty of Medicine, University of Maastricht, the Netherlands:Autonomic dysfunction in an animal model of neuropathic pain: sympathetic denervation or hyperactivity?

Dutch Hippokrates Award 1995 of the Leidsch Medisch Genootschap Hippokrates, University of Leiden, the Netherlands:The role of the autonomic nervous system in an animal model of reflex sympathetic dystrophy (Sudeck's disease).

National Institutes of Health Travel Grant 1999 of the National Institute of Health, Bethesda, MD, United States:Delayed inflammation after renal ischemia-reperfusion: involvement of $I F N-g, I L-12$ and $I L-18$.

\section{Publications}

Daemen MARC, Kurvers HAJM, Kitslaar PJEHM, Van den Wildenberg FAJM, Beuk RJ, Rouwet EV, Jacobs MJHM, Reneman RS: Microcirculatoire aspecten van een neuropathisch pijnsyndroom: de rol van het sympathische zenuwstelsel. Nederlands Tijdschrift voor Vaatdiagnostiek 8 (3), 9-13, 1995.

Kurvers HAJM, Stassen F, Jacobs MJHM, Daemen MARC, Rouwet EV, Van den Wildenberg FAJM, Kitslaar PJEHM, Slaaf DW, Reneman RS, De Mey JGR: Microcirculatory abnormalities in Reflex Sympathetic Dystrophy and an animal model of neuropathic pain; hyper-sensitivity to catecholamines consequent to autonomic denervation? NVBP-pijnbulletin 2, 2-4, 1994.

Kurvers HAJM, Hofstra L, Jacobs MJHM, Daemen MARC, Van den Wildenberg FAJM, Kitslaar PJEHM, Slaaf DW, Reneman RS: Reflex Sympathetic Dystrophy; does sympathetic dysfunction originate from peripheral neuropathy? Surgery 119, 288-296, 1996.

Rouwet EV, Spincemaille GH, Barendse G, Van Kleef M, Adang EMM, Kurvers HAJM, Daemen MARC, Van den Wildenberg FAJM: Spinal cord stimulation bij de behandeling van reflex sympathische dystrofie. NVBP-pijnbulletin 16, 8-11, 1996.

Luijckx GJ, Boiten J, Van Kroonenburgh M, Kitslaar PJEHM, Kurvers HAJM, Daemen MARC, Leunissen K, Beintema M, Lodder J: Systemic small-vessel disease is not exclusively related to lacunar stroke. A pilot study. Journal of Stroke and Cerebrovascular Disease 7, 52-57, 1998. 
Daemen MARC, Kurvers HAJM, Kitslaar PJEHM, Slaaf DW, Bullens PHJ, Van den Wildenberg FAJM: Neurogenic inflammation in an animal model of neuropathic pain. Neurological Research 20, 41-45, 1998.

Daemen MARC, Kurvers HAJM, Bullens PHJ, Slaaf DW, Freling G, Kitslaar PJEHM, Van den Wildenberg FAJM: Motor denervation induces altered muscle fibre type densities and atrophy in a rat model of neuropathic pain. Neuroscience \& Letters 247, 204-208, 1998.

Kurvers HAJM, Daemen MARC, Slaaf DW, Stassen F, Van den Wildenberg FAJM, Kitslaar PJEHM, De Mey JGR: Partial peripheral neuropathy and denervation induced adrenoceptor supersensitivity. Functional studies in an experimental model. Acta Orthopaedica Belgica 64, 64-70, 1998.

Bullens PHJ, Daemen MARC, Freling G, Kitslaar PJEHM, Van den Wildenberg FAJM, Kurvers HAJM: Motor dysfunction and reflex sympathetic dystrophy: bilateral motor denervation in an experimental model. Acta Orthopaedica Beligica 64, 218-223, 1998.

Daemen MARC, Kurvers HAJM, Bullens PH, Barendse G, Van Kleef M, Van den Wildenberg FAJM: Neurogenic inflammation and reflex sympathetic dystrophy: in vivo and in vitro assessment in an experimental model. Acta Orthopaedica Beligica 64, 441 447, 1998.

Lemson MS, Zwiers I, Kurvers HAJM, Daemen MARC, Beuk RJ, Tordoir JHM: Prosthetic arteriovenous fistulas for hemodialysis impair the macro- and microcirculation of the hand more than Brescia/Cimino AV fistulas. Journal of Vascular Technology 21 , 187-191, 1997.

Daemen MARC, Van de Ven WCM, Heineman E, Buurman WA: Involvement of endogenous IL-10 and TNF-a in renal ischemia-reperfusion injury. Transplantation 67, $792-800,1999$.

Daemen MARC, Van 't Veer C, Wolfs TGAM, Buurman WA: Ischemia-reperfusion induced IFN- $\gamma$ upregulation: involvement of IL-12 and IL-18. Journal of Immunology $162,5506-5510,1999$.

Heemskerk VH, Daemen MARC, Buurman WA: Insulin-like growth factor-1 (IGF-1) and growth hormone $(\mathrm{GH})$ in immunity and inflammation. Cytokine and Growth Factor Reviews 10, 5-14, 1999. 
Piersma FA, Daemen MARC, Van den Bogaard AEJM, Buurman WA: Interference of pain control employing opioids in in vivo immunological experiments: Pain control in immunological research. Laboratory Animals 33, 328-333, 1999.

Daemen MARC, Van 't Veer C, Denecker G, Heemskerk VH, Wolfs TGAM, Clauss M, Vandenabeele P, Buurman WA: Inhibition of apoptosis induced by ischemia-reperfusion prevents inflammation. Journal of Clinical Investigation 104, 541-549, 1999.

Daemen MARC, Heemskerk VH, Van 't Veer C, DeneckerG, Wolfs TGAM Vandenabeele P, Buurman WA. Functional protection by acute phase proteins alpha(1)acid glycoprotein and alpha(1)-antitrypsin against ischemia/reperfusion injury by preventing apoptosis and inflammation. Circulation 102, 1420-1426, 2000.

Daemen MARC, Vandenabeele P, Buurman WA. How cells die counts. American Journal of Kidney Diseases 36, 662 - 668, 2000.

Daemen MARC, Denecker G, Van 't Veer C, Wolfs TGAM, Vandenabeele P, Buurman WA. Activated caspase-1 is not a central mediator of inflammation in the course of schemia-reperfusion. Transplantation, In Press.

Daemen MARC, De Vries B, Van 't Veer C, Wolfs TGAM, Buurman WA: Apoptosis and chemokine-induction following renal ischemia-reperfusion. Transplantation, In Press.

Kievit JK, Daemen MARC, Pelsers MMAL, Kootstra G, Glatz JFC, Buurman WA: Release of heart fatty-acid binding protein from damaged renal cells of the rat: Potential as an early marker for mild ischemia-reperfusion injury. Transplant International, In Press.

De Vries B, Daemen MARC, Buurman WA: Apoptosis in renal ischemia-reperfusion injury. In: Mechanisms of organ dysfunction in critical illness. Update in intensive care and emergency medicine. Springer Verlag. In Press.

Daemen MARC, Kievit JK, De Vries B, Van 't Veer C, Wolfs TGAM, Vandenabeele P, Buurman WA: Caspase-7 activation and cFLIP depletion in the course of renal ischemia and reperfusion: correlation with the extent of reperfusion injury. Submitted.

Daemen MARC, Buurman WA. Apoptosis and inflammation in renal ischemia-reperfusion. A review. Submitted. 
De Vries B, Daemen MARC, Wolfs TGAM, Van Schadewijk A, Van 't Veer C, Buurman WA: Local production of acute phase proteins in renal ischemia-reperfusion injury. Submitted.

Wolfs TGAM, Van 't Veer C, Van Schadewijk A, Daemen MARC, Hiemstra PS, Buurman WA: In vivo expression of Toll-like receptor 2 and 4 by renal epithelial cells: IFN-g and TNF-a mediated up-regulation during inflammation. Submitted. 


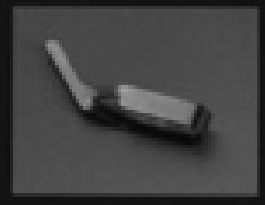

